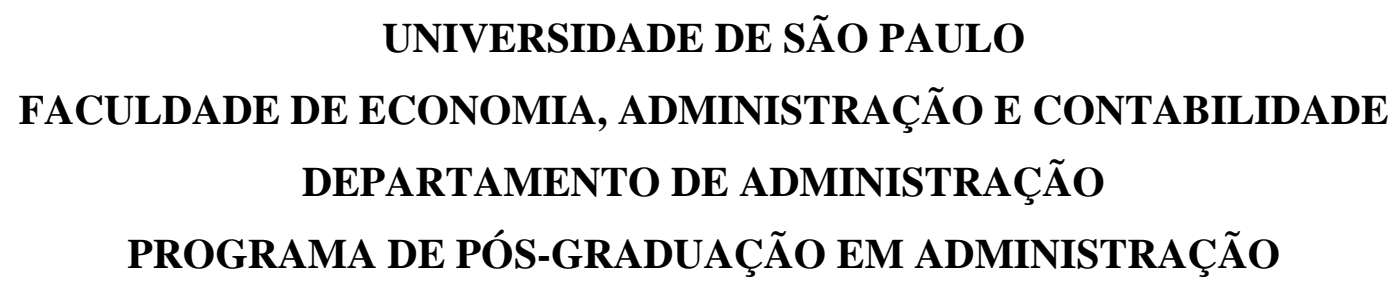

ADOÇÃO DE INOVAÇÕES: O USO DO E-LEARNING POR COLABORADORES DE UMA EMPRESA DE TELECOMUNICAÇÕES

Liliana Vasconcellos

Orientadora: Profa. Dra. Maria Tereza Leme Fleury

SÃo PAULO

2008 
Profa. Dra. Suely Vilela

Reitora da Universidade de São Paulo

Prof. Dr. Carlos Roberto Azzoni

Diretor da Faculdade de Economia, Administração e Contabilidade

Prof. Dr. Isak Kruglianskas

Chefe do Departamento de Administração

Prof. Dr. Lindolfo Galvão de Albuquerque Coordenador do Programa de Pós-Graduação em Administração 


\section{ADOÇÃO DE INOVAÇÕES: O USO DO E-LEARNING POR COLABORADORES DE UMA EMPRESA DE TELECOMUNICAÇÕES}

Tese apresentada ao Departamento de Administração da Faculdade de Economia, Administração e Contabilidade da Universidade de São Paulo como requisito para obtenção do título de Doutor em Administração.

Orientadora: Profa. Dra. Maria Tereza Leme Fleury 
Vasconcellos, Liliana

Adoção de inovações : o uso do e-learning por colaboradores de uma empresa de telecomunicações / Liliana Vasconcellos. -São Paulo, 2008.

$243 \mathrm{p}$.

Tese (Doutorado) - Universidade de São Paulo, 2008 Bibliografia

1.Inovações tecnológicas (Administração) 2. Educação à distância 3. Educação corporativa 4. Tecnologia da informação I. Universidade de São Paulo. Faculdade de Economia, Administração e Contabilidade. II. Título.

CDD - 658.514 
Ao Luís, meu amor, fonte de paixão, amizade e felicidade infinitas. 


\section{AGRADECIMENTOS}

Após quatro anos de dedicação a este projeto, é com enorme satisfação que agradeço àqueles que, de diferentes maneiras, tornaram esta experiência extremamente rica e única na minha vida. Foram muitas as contribuições, recebidas de diversas formas.

Ao meu pai, Eduardo Vasconcellos, meu mentor e modelo desde sempre, agradeço pelos conselhos sempre oportunos e revestidos de amor, pelas oportunidades de trabalho conjunto, pelas discussões muito estimulantes e pelas palavras de incentivo nos momentos difíceis.

À minha orientadora, professora Maria Tereza Leme Fleury: não me vem outra palavra à cabeça que não gratidão. Seja pela precisa e sempre extremamente gentil orientação, pelas palavras de apoio, pela disponibilidade e pelo exemplo que, em muitos sentidos, me fez manter o foco e prosseguir com tenacidade.

Ao professor Scott D. Johnson, da University of Illinois at Urbana-Champaign, por ter viabilizado o período enriquecedor que passei como Visiting Scholar do Department of Human Resource Education e ao professor Wenhao David Huang pela relevante troca de experiências. Ao professor Edgard Cornachione e Andrea Presotto pelas discussões estimulantes e por todo apoio e hospitalidade durante minha estadia em Urbana-Champaign.

Aos professores André Luiz Fischer e Isak Kruglianskas pelas valiosas contribuições por ocasião do exame de qualificação. Aos professores Marisa Éboli e Nicolau Reinhard pela disponibilidade em participar da entrevista e pela excelente contribuição para reflexão sobre o modelo conceitual do trabalho. Ao professor Cesar Alexandre de Souza pelas discussões sobre o Modelo TAM, participação no pré-teste do questionário e orientações estatísticas. Aos demais professores com os quais tive oportunidade de cursar disciplinas e que trouxeram reflexões importantes para o estudo.

Por questões de confidencialidade, não posso identificar nominalmente as valorosas pessoas da empresa que cordialmente colaborou com essa pesquisa. Mesmo assim, sou-lhes grata pela acolhida calorosa, pela prontidão no compartilhamento das informações e pela franqueza nas discussões, sinais da qualidade dos profissionais que trabalham nessa empresa que, sob muitos aspectos, é um modelo no setor no qual atua. $\mathrm{O}$ apoio recebido foi valioso e essencial para a realização do trabalho.

À FIA - Fundação Instituto de Administração, que disponibilizou o software para realização aplicação do questionário, viabilizou a participação e apresentação de artigo no Congresso Internacional de Educação a Distância (em 2005, 2006 e 2007) e no BALAS - The Business Association of Latin American Studies Annual Conference (2004), apoiou a visita à University 
of Illinois at Urbana-Champaign (2007) e possibilitou o desenvolvimento de atividades de pesquisa e aplicação do conhecimento no Centro de Educação a Distância. Ambos fatos, somados ao convívio com excelentes profissionais com os quais conta a Instituição, contribuíram muito para o meu aprimoramento profissional e pessoal.

À Valéria Lourenção, Maria Aparecida de Jesus Sales, Luciene Cibelle Soares Luiz, Francisco Costa e Melisa Maria de Freitas Andrade, da Secretaria de Pós-graduação da FEA/USP, e à Eloisa Martins Aléssio, Daniela Alves Martins e Fabiana de Cassia Caseira Chiuratto, da Secretaria do Programa de Pós-graduação do Departamento de Administração, pelo atendimento, simpatia e apoio durante todo o curso. À Regina Maria Mattos Macedo de Almeida pela ajuda em vários momentos.

Ao amigo, Márcio Shoiti Kuniyoshi, com quem pude compartilhar experiências e dividir preocupações. À todos os amigos do Programa de Pós-graduação, com os quais desenvolvi trabalhos em conjunto, agradeço pela amizade e companheirismo. Aos amigos Flávio, Márcio, Patrícia e Sérgio, especial obrigado pela participação no pré-teste do questionário.

À Reni Berezin, pelo apoio na condução e revisão das análises estatísticas.

À minha mãe, Regina Araújo de Almeida, meu exemplo de competência e dedicação, agradeço o amor e o apoio incondicionais, que possibilitaram conciliar meus projetos de vida e profissionais.

Aos meus irmãos, Adriano e André Vasconcellos, pelo apoio, paciência e amizade.

À minha madrinha, Carmem Marega, pelo carinho.

Ao meu amor, Luís Fernando Ascenção Guedes, sempre presente, que trouxe equilíbrio e segurança, contribuindo de forma decisiva nos momentos mais desafiadores. Também pelos trabalhos desenvolvidos em parceria, fonte constante de aprendizado e troca.

A todos que contribuíram para este trabalho, inclusive aqueles não citados, muito obrigada! 
viii

“Qualquer novo conhecimento provoca dissoluções e novas integrações”

Hugo Hofmannsthal 


\section{RESUMO}

A efetivação dos benefícios esperados com a implementação do e-learning na empresa depende da adoção desta inovação pelos colaboradores. Desta forma, a compreensão da adoção individual do e-learning fornece subsídios importantes para identificar potenciais resistências, possibilitando conduzir ações para maximizar a aceitação e aumentar a freqüência de uso. Assim, o objetivo geral desta pesquisa é analisar os fatores que influenciam a adoção individual do e-learning pelos colaboradores da organização, utilizando como base o Modelo TAM - Technology Acceptance Model, proposto por DAVIS et al (1989). Inicialmente foi conduzida uma revisão bibliográfica tanto sobre Adoção de Inovações pelo indivíduo e pela organização, quanto sobre a Implementação do e-learning, visando a construção da fundamentação teórica do estudo. A primeira etapa da pesquisa empírica consistiu na revisão do modelo conceitual a partir de entrevistas com especialistas em $e$ learning. Na segunda etapa, foi pesquisada uma grande empresa do setor de telecomunicações no Brasil, através de uma abordagem de múltiplos métodos, incluindo entrevistas com a equipe de e-learning, aplicação de questionário e análise de documentos. Com base nos 312 questionários válidos, respondidos por colaboradores, foram conduzidas as análise, incluindo análise fatorial, teste não paramétrico e regressão logística. O Modelo TAM mostrou-se adequado para compreender a adoção do e-learning e a inclusão no modelo do fator Ambiente Propício à Aprendizagem destaca-se como uma contribuição importante do presente trabalho. Os resultados da pesquisa confirmaram que a experiência com a inovação e o perfil do respondente podem alterar os fatores explicativos da adoção do e-learning. $\mathrm{O}$ fator Ambiente Propício à Aprendizagem destaca-se dos demais, uma vez que influencia positivamente tanto a intenção quanto o comportamento de uso do e-learning, reforçando a importância do ambiente organizacional na adoção da inovação. A Utilidade Percebida apresenta a influência mais importante na explicação da intenção de uso e uma influência negativa em relação ao comportamento de uso, resultado que pode ser explicado por uma possível frustração relacionada à participação em cursos de e-learning. Dentre as sugestões para ampliação da adoção do e-learning na empresa pesquisada, destacam-se: alinhamento dos conteúdos oferecidos com a necessidade, inovação na metodologia de e-learning, aumento do envolvimento da liderança e apoio para participação no e-learning durante a jornada de trabalho, identificação de grupos por afinidade para definição de ações específicas, melhor esclarecimento sobre o suporte técnico disponível, ampliação da divulgação e aprimoramento da navegação no e-learning. 


\begin{abstract}
The expected benefits of e-learning for an organization depend upon its employees adopting this innovation. Therefore, understanding how individuals adopt e-learning, or resist doing so, can identify potential barriers to acceptance, and suggest actions which can be taken to maximize both e-learning's acceptance and its frequency of use. The main goal of this research is to analyze the factors which influence individual adoption of e-learning by the organization's employees, based on the Technology Acceptance Model - TAM, proposed by DAVIS et al (1989). Initial bibliographical research on individual and organizational adoption of innovation and of e-learning implementation was used to develop the theoretical framework. The conceptual model was tested through empirical research using interviews with e-learning specialists. In the second stage, a large organization from the telecommunication sector in Brazil was chosen to be studied through a multiple methods approach, including interviews with the organization's e-learning team, employee survey and document analysis. Factor analysis, non-parametric tests and logistic regression were conducted on the 312 valid questionnaires answered by the company's employees. The results show TAM is adequate for understanding the factors influencing e-learning adoption. The inclusion of the factor, Favorable Learning Environment, in the analytical framework proved to be an important contribution of the present study. The results confirmed that experience with this innovation and the survey participant's profile both can impact employees' perceptions regarding e-learning. The Favorable Learning Environment factor surpasses the others, since it influences both the e-learning Intention and Use Behavior factors in a positive way, and reinforces the relevance of the organization's environment in innovation adoption. The Perceived Usefulness factor is the most important in explaining Intention to Use; at the same time, it can be a negative influence for Use Behavior, which could be explained by possible frustration related to e-learning courses. Among the suggestions given to increase the e-learning adoption in the researched organization, the following could be mentioned: match the e-learning content with both employees' and organizational needs, innovate e-learning methodology, increase leadership involvement and support, encourage e-learning participation during work hours, give better information on available technical support, and improve e-learning communication and quality of system navigation.
\end{abstract}




\section{SUMÁRIO}

LISTA DE QUADROS _ _ 3

LISTA DE TABELAS 4

LISTA DE GRÁFICOS 5

LISTA DE FIGURAS 6

1 INTRODUÇÃO 7

2 OBJETIVOS DA PESQUISA

3 REVISÃO BIBLIOGRÁFICA 115

3.1 Adoção de Inovações 15

3.1.1 Adoção Individual de Inovações _ 21

3.1.2 Adoção Organizacional de Inovações __ 35

3.2 Implementação do e-Learning __ 44

3.2.1 O e-Learning na Empresa 45

3.2.2 Barreiras e Prontidão para a Implementação do e-Learning ___ 47

3.2.3 Adoção do e-Learning ___ 54

3.3 Resumo da Revisão Bibliográfica __ 57

4 METODOLOGIA DA PESQUISA 67

4.1 Modelo de Adoção Individual do e-Learning ___ 67

4.2 Abordagem da Pesquisa__ 72

4.2.1 O Setor de Telecomunicações 75

4.2.2 Descrição da Empresa Pesquisada e seu Projeto de e-Learning ___ 79

4.3 Necessidades e Fontes de Dados 81

4.4 Técnicas e Instrumentos de Coleta dos Dados_ 83

4.4.1 O Questionário Auto-Preenchido $\quad 83$

4.4.2 A Entrevista Individual___ 93

4.4.3 Análise Documental 95

4.5 A População e a Amostra 95

4.5.1 Representatividade da Amostra__ 96

4.5.2 O Uso do e-Learning pelos Colaboradores da Empresa ___ 100

4.6 Análise dos Dados 104

4.6.1 Análise Fatorial 105

4.6.2 Prova de Mann-Whitney ___ 106

4.6.3 Análise Descritiva 106

4.6.4 Análise de Conteúdo 106

4.6.5 Regressão Logística 106

5 APRESENTAÇÃO E ANÁLISE DOS RESULTADOS ___ 109

5.1 Comparar as dimensões do modelo conceitual proposto com aquelas observadas na empresa estudada, identificando aprimoramentos no Modelo Preliminar de

Adoção Individual do e-Learning _ـ 109

5.1.1 Fator 1: Utilidade Percebida 112

5.1.2 Fator 2: Ambiente Propício à Aprendizagem __ 115

5.1.3 Fator 3: Facilidade de Uso Percebida 117

5.1.4 Fator 4: Habilidade com Informática \& Pré-disposição para Inovar 119

5.1.5 Fator 5: Desconfiança em Relação à Inovação _ 120

5.2 Analisar as diferenças de percepção entre os colaboradores que realizaram e que não realizaram curso de e-learning na empresa, desde 2006__ 127

5.2.1 Utilidade Percebida __ 131

5.2.2 Ambiente Propício à Aprendizagem __ 140 
5.2.3 Facilidade de Uso Percebida 150

5.2.4 Habilidade com Informática \& Pré-disposição para Inovar ___ 156

5.2.5 Desconfiança em Relação à Inovação___ 158

5.2.6 Intenção de Uso do e-Learning ____ _ _ 161

5.3 Analisar as diferenças de percepção em função do perfil do respondente __ 163

5.3.1 Experiência com e-Learning Fora da Plataforma da Empresa ___ 164

5.3.2 Gênero _ 165

5.3.3 Demais Aspectos do Perfil do Respondente ___ 170

5.4 Identificar as variáveis que melhor explicam a intenção de realizar ou não cursos de e-learning na empresa

5.5 Identificar as variáveis que melhor explicam a realização ou não de cursos de e-learning na empresa, desde $2006 \_179$

5.6 Consolidação da Análise de Resultados _ـ 184

6 CONSIDERAÇÕES FINAIS ___ 193

6.1 Conclusões e Contribuições da Pesquisa___ 193

6.1.1 O Modelo de Adoção Individual do e-Learning ___ 193

6.1.2 A Influência do Uso da Inovação na Percepção dos Fatores de Adoção ___ 194

6.1.3 As Diferenças em Função do Perfil do Respondente ___ 195

6.1.4 Explicando a Intenção e o Comportamento de Uso do e-Learning___ 195

6.1.5 Sugestões para Ampliação da Adoção do e-Learning na Empresa Pesquisada 197

6.2 Limitações da Pesquisa 198

6.3 Sugestões para Estudos Futuros 200

7 REFERÊNCIAS _ 203

APÊNDICE 1 - Itens Originais do Instrumento - Modelo TAM _ 215

APÊNDICE 2 - Questionário da Pesquisa __ 217

APÊNDICE 3 - Roteiros de Entrevista___ 223

APÊNDICE 4 - Tabela de Comunalidades__ 225

APÊNDICE 5 - Distribuição da Concordância Total em Relação às Variáveis da Pesquisa 226

APÊNDICE 6 - Prova de Mann-Whitney para a Variável Realização de Cursos

de e-Learning Fora da Plataforma da Empresa 227

APÊNDICE 7 - Prova de Mann-Whitney para a Variável Gênero __ 229

APÊNDICE 8 - Prova de Mann-Whitney para a Variável Idade__ 231

APÊNDICE 9 - Prova de Mann-Whitney para a Variável Tempo de Empresa___ 233

APÊNDICE 10 - Prova de Mann-Whitney para a Variável Grau de Instrução __ 235

APÊNDICE 11 - Prova de Mann-Whitney para a Variável Localidade de Trabalho ___ 237

APÊNDICE 12 - Prova de Mann-Whitney para a Variável Nível Hierárquico___ 239

APÊNDICE 13 - Teste de Kruskal Wallis para a Variável Área Funcional $\_241$

ANEXO A - Barreiras para Difusão do e-Learning (TYAN, 2003) ___ 243 


\section{LISTA DE QUADROS}

Quadro 1 - Estágios de Interesse em Relação à Inovação 22

Quadro 2 - Modelos e Constructos de Maior Influência na Aceitação de Tecnologia Analisados por Venkatesh et al (2003) 30

Quadro 3 - Estágios Decisórios na Assimilação de Inovações Médicas __ 40

Quadro 4 - Alternativas de Foco do Esforço de E-Learning na Organização ___ 46

Quadro 5 - Benefícios e Problemas do e-Learning __ 48

Quadro 6 - Adoção Individual de Inovações: Variáveis e Autores __ 58

Quadro 7 - Adoção Organizacional de Inovações: Variáveis e Autores ___ 61

Quadro 8 - Implementação do e-Learning: Variáveis e Autores ___ 63

Quadro 9 - Variáveis do Modelo Preliminar de Adoção do e-Learning ___ 69

Quadro 10 - Hipóteses da Pesquisa __ 71

Quadro 11 - Fontes de Dados__ 82

Quadro 12 - Vantagens e Limitações do Uso do Questionário Eletrônico via Internet __ 86

Quadro 13 - Itens do Questionário da Pesquisa __ 90

Quadro 14 - Vantagens e Desvantagens da Entrevista Individual em Profundidade __ 93

Quadro 15 - Técnicas Usadas para Análise dos Dados _ 105

Quadro 16 - Hipóteses Detalhadas da Pesquisa ___ 124

Quadro 17 - Objetivo Específico 1: Comparar os fatores propostos no modelo conceitual com aqueles observados na empresa estudada, identificando aprimoramentos no Modelo de Adoção Individual do e-Learning

Quadro 18 - Objetivo Específico 2: Analisar as diferenças de percepção entre os colaboradores que realizaram e que não realizaram curso de e-learning na empresa, desde 2006.

Quadro 19 - Objetivo Específico 3: Analisar as diferenças de percepção em função do perfil do respondente

Quadro 20 - Objetivo Específico 4: Identificar as variáveis que melhor explicam a intenção de realizar ou não cursos de e-learning na empresa

Quadro 21 - Objetivo Específico 5: Identificar as variáveis que melhor explicam a realização ou não de cursos de e-learning na empresa 


\section{LISTA DE TABELAS}

Tabela 1 - Ordem de Importância dos Fatores para Desenvolvimento de uma Cultura Inovadora

Tabela 2 - Telefonia Fixa: Market Share de Acessos em Serviço (2006) __ 78

Tabela 3 - Market Share das Operadoras de Telefonia Celular Atuantes no Brasil ___ 79

Tabela 4 - Análise Comparativa dos Métodos de Coleta de Dados__ 85

Tabela 5 - Distribuição da Variável Gênero na Amostra e na População __ 96

Tabela 6 - Distribuição das Variáveis Idade e Tempo de Empresa na População____ 97

Tabela 7 - Distribuição das Variáveis Idade e Tempo de Empresa na Amostra ___ 97

Tabela 8 - Resultado da Prova t-Student para Idade e Tempo de Empresa____ 97

Tabela 9 - Distribuição da Variável Grau de Instrução na Amostra e na População ___ 98

Tabela 10 - Distribuição da Variável Localidade de Trabalho na Amostra e na População _ 98

Tabela 11 - Distribuição da Variável Cargo na Amostra e na População ___ 99

Tabela 12 - Distribuição da Variável Área Funcional na Amostra e na População ___ 100

Tabela 13 - Total da Variância Explicada___ 110

Tabela 14 - Variáveis do Fator Utilidade Percebida __ 112

Tabela 15 - Variáveis do Fator Ambiente Propício à Aprendizagem ___ 116

Tabela 16 - Variáveis do Fator Facilidade de Uso Percebida ___ 118

Tabela 17 - Variáveis do Fator Habilidade com Informática \& Pré-disposição para Inovar 119

Tabela 18 - Variáveis do Fator Desconfiança em Relação à Inovação__ 120

Tabela 19 - Número de Cursos Inscritos e Cursos Concluídos pelos Respondentes, com Base nos Registros da Plataforma de e-Learning da Empresa

Tabela 20 - Resultados da Prova Mann-Whitney comparando os respondentes que realizaram cursos de e-learning desde 2006 e os que não realizaram, por Fator 129

Tabela 21 - Teste t-Student para Comportamento de Uso do e-Learning _ 131

Tabela 22 - Variáveis do Modelo Intenção de Uso do e-Learning _ _ 175

Tabela 23 - Variáveis do Modelo Ajustado Intenção de Uso do e-Learning (*) __ 175

Tabela 24 - Nível de Acerto do Modelo Ajustado Intenção de Uso do e-Learning __ 176

Tabela 25 - Teste t-Student para Intenção de Uso do e-Learning ___ 177

Tabela 26 - Variáveis do Modelo Comportamento de Uso do e-Learning __ 179

Tabela 27 - Variáveis do Modelo Ajustado Comportamento de Uso do e-Learning __ 180

Tabela 28 - Nível de Acerto do Modelo Ajustado Comportamento de Uso do e-Learning _ 181

Tabela 29 - Teste t-Student para Comportamento de Uso do e-Learning _ 181 


\section{LISTA DE GRÁFICOS}

Gráfico 1 - Número de Participantes nos Cursos de e-Learning da Empresa, por Mês 101

Gráfico 2 - Horas de Treinamento de e-Learning na Empresa, por Mês 102

Gráfico 3 - Distribuição dos Participantes de Cursos de e-Learning no $1^{\circ}$ Semestre/2007, por Cargo

Gráfico 4 - Distribuição dos Participantes de Cursos de e-Learning, por Categoria de Curso

Gráfico 5 - Número de Inscrições nos Cursos de e-Learning no $1^{\circ}$ Semestre/2007, por Categoria de Curso e Cargo

Gráfico 6 - Distribuição das Variáveis Relacionadas à Importância para o Trabalho, à Flexibilidade para Aprender e à Participação ser Uma Boa Idéia

Gráfico 7 - Distribuição das Variáveis Relacionadas à Contribuição para Melhora do Desempenho e ao Sentimento em Relação ao e-Learning

Gráfico 8 - Distribuição das Variáveis Relacionadas à Obtenção de Resultados de Aprendizagem, à Utilidade no Trabalho e à Satisfação em Relação ao Uso

Gráfico 9 - Distribuição das Variáveis Relacionadas ao Potencial do e-Learning e ao Atendimento Adequado do Projeto Existente

Gráfico 10 - Distribuição das Variáveis Relacionadas ao Apoio do Superior Imediato e ao Apoio da Alta Administração

Gráfico 11 - Distribuição das Variáveis Relacionadas à Cultura Favorece a Adoção e ao Sucesso da Campanha de Incentivo

Gráfico 12 - Distribuição das Variáveis Relacionadas à Influência dos Colegas e ao Prestígio Resultante de Participação

Gráfico 13 - Distribuição das Variáveis Relacionadas à Facilidade para Usar e à Clareza e Inteligibilidade da Interação com o Sistema

Gráfico 14 - Distribuição das Variáveis Relacionadas ao Suporte no Uso do e-Learning _ 152

Gráfico 15 - Distribuição das Variáveis Relacionadas à Facilidade em Explicar os Benefícios, à Suficiência dos Recursos Tecnológicos e ao Sucesso da Campanha de Comunicação

Gráfico 16 - Distribuição das Variáveis Relacionadas à Habilidade para Utilizar Um Novo Software e à Pré-disposição para Inovar

Gráfico 17 - Distribuição das Variáveis Relacionadas à Desconfiança em Relação à Inovação

Gráfico 18 - Distribuição das Variáveis Relacionadas à Intenção de participar do e-learning em 2007

Gráfico 19 - Distribuição das Variáveis Relacionadas à Intenção de Uso do e-Learning _ 162

Gráfico 20 - Distribuição da Intenção de Participar do e-Learning em 2007, por Gênero _ 166 


\section{LISTA DE FIGURAS}

Figura 1 - Modelo da Pesquisa

Figura 2 - Variáveis Determinantes da Taxa de Adoção de Inovações ___ 19

Figura 3 - Processos de Inovação Tecnológica __ 20

Figura 4 - Estágios do Processo de Decisão sobre Inovação ___ 21

Figura 5 - Technology Acceptance Model (TAM)__ 24

Figura 6 - TAM2 - Extensão do Technology Acceptance Model __ 28

Figura 7 - Modelo Unificado Proposto por Venkatesh et al (2003) 31

Figura 8 - Aceitação da Tecnologia de Informação pela Força de Vendas Modelo Revisado 32

Figura 9 - Variáveis Independentes Relacionadas à Predisposição Organizacional para Inovar

Figura 10 - Cinco Estágios do Processo de Inovação em uma Organização ___ 37

Figura 11 - O Contexto da Inovação Tecnológica ___ 38

Figura 12 - Modelo de Assimilação da Inovação _ 39

Figura 13 - Estrutura Conceitual da Adoção Organizacional de Inovações ___ 41

Figura 14 - Estrutura Conceitual da Aceitação Individual de Inovações em Organizações_ 41

Figura 15 - Cadeia de Valor do e-Learning __ 45

Figura 16 - Barreiras para a Implementação do e-Learning__ 49

Figura 17 - Os Sete Componentes da Prontidão do e-Learning __ 52

Figura 18 - Fatores que Impactam o Comprometimento com e-Learning __ 53

Figura 19 - Modelo Testado para Aceitação de Um Sistema de Aprendizagem na Web _ 55

Figura 20 - Modelo Final de Aceitação do Sistema de Curso Baseado na Web ___ 56

Figura 21 - Modelo Preliminar de Adoção Individual do e-Learning ___ 68

Figura 22 - Triângulo Metodológico para o Estudo de Cultura Organizacional ___ 73

Figura 23 - Esquema da Pesquisa __ 74

Figura 24 - Modelo em camadas para o setor de telecomunicações

Figura 25 - Estágio de Evolução das Tecnologias de Conectividade

Figura 26 - Resultado da Comparação entre o Modelo Preliminar de Adoção Individual do e-Learning e os Fatores Observados na Empresa Pesquisada___ 122

Figura 27 - Representação Gráfica do Modelo Ajustado Intenção de Uso do e-Learning _ 178

Figura 28 - Representação Gráfica do Modelo Ajustado Comportamento de Uso do e-Learning

Figura 29 - Modelo de Adoção Individual do e-Learning na Empresa Estudada 196 


\section{INTRODUÇÃO}

Um dos principais desafios enfrentados pelas organizações contemporâneas está relacionado à implementação de estratégias adequadas para lidar com a alta velocidade de inovação, a internacionalização dos negócios e a concorrência crescente; em suma, as corporações inseridas em mercados competitivos estão constantemente engajadas na elaboração e implementação de estratégias que façam frente de modo eficaz a um cenário em constante transformação. De acordo com Brown e Eisenhardt (1990, p. 3), as estratégias tradicionais não são mais suficientes para gerenciar a mudança intensa observada no ambiente de negócios.

Conforme afirmou Laurence Prusak, da IBM, "A única coisa que fornece vantagem competitiva para uma organização é o que esta conhece, como usa esse conhecimento e o quão rapidamente é capaz de aprender algo novo"1 (2000). Os resultados da Pesquisa Delphi RH 2010, com participação de 186 profissionais da área de Recursos Humanos, confirmam essa visão: de acordo com os respondentes, para lidar com o desafio de "alinhar as pessoas, o desempenho e as competências humanas às estratégias do negócio e objetivos organizacionais" duas das três estratégias consideradas mais relevantes são aumentar o investimento em capacitação de desenvolvimento dos líderes e aumentar o investimento em educação, treinamento e desenvolvimento de pessoas (FISCHER; ALBUQUERQUE, 2004, p.27).

"Para enfrentar os desafios da mudança constante e da necessidade insaciável por conhecimento, as organizações adotaram a aprendizagem baseada em tecnologia como uma forma de manterem-se atualizadas" ${ }^{2}$ (ROSENBERG, 2006, p. 11). Assim, o e-learning ${ }^{3}$ está entre as estratégias disponíveis para responder às “[...] necessidades de conhecimento rápido da organização moderna que consiste de uma força de trabalho em mudança e

\footnotetext{
1 "The only thing that gives competitive advantage to an organisation is what it knows, how it uses that knowledge and how fast it can learn something new."

2 "Faced with the ongoing challenges of constant change and an insatiable need for knowledge, organizations have embraced technology-enabled learning as a way to keep up."

${ }^{3}$ E-learning é uma modalidade de educação a distância que utiliza a Internet para a sua operacionalização. Este conceito está detalhado no capítulo de revisão bibliográfica.
} 
geograficamente dispersa"4, contribuindo para a redução de custos, melhoria do desempenho das equipes e para o estabelecimento de uma cultura de aprendizagem contínua (PSYCHARIS, 2005, p. 2).

De acordo com Kaufman (2002), a adoção do e-learning é estimulada pela globalização, redução dos ciclos do negócio, racionalização dos custos, consolidação e desregulamentação, maior acesso à tecnologia e à Internet e crescimento da aceitação dessa metodologia de ensino.

Embora o e-learning tenha potencial para satisfazer necessidades do negócio, "[...] $62 \%$ de todas as tecnologias de aprendizagem falham no atendimento às expectativas" (SLOMAN; Van BUREN, 2003). As dificuldades encontradas na implementação de tecnologias para aprendizagem, apontadas por vários autores (PRICEWATERHOUSECOOPERS, 2001; SCHANK, 2002, p. 9; TYAN, 2003; DOWNES, 2003), ocorrem porque o "e-learning é na verdade uma revolução na forma como as pessoas aprendem e melhoram seu desempenho", (ROSENBERG, 2006, p.11) e, para que "a tecnologia melhore a produtividade, esta precisa ser aceita e utilizada pelos funcionários nas organizações" "7 (VENKATESH et al, 2003, p. 426).

Este trabalho está estruturado nos seguintes capítulos, além dessa introdução: apresentação dos objetivos da pesquisa, revisão bibliográfica sobre adoção de inovações e implementação do e-learning, descrição da metodologia utilizada na pesquisa, análise dos resultados em função de cada objetivo específico, exposição das considerações finais, incluindo as principais contribuições da pesquisa, suas limitações e sugestões para estudos futuros e, por fim, as referências bibliográficas, apêndices e anexo.

\footnotetext{
4 "[...] needs of the modern organizations that consist of a changing and geographically dispersed workforce $[\ldots] "$

5 " $62 \%$ of all learning technologies fail to meet expectations"

6 "E-learning is indeed a revolution in the way people learn and improve their performance"

7 "Yet, for technologies to improve productivity, they must be accepted and used by employees in organizations"
} 


\section{OBJETIVOS DA PESQUISA}

\section{O objetivo geral desta pesquisa é analisar os fatores que influenciam a adoção individual} do e-learning pelos colaboradores da organização. A adoção individual é um aspecto crítico no sucesso da implementação do e-learning, sendo que a sua compreensão fornece subsídios importantes para identificar potenciais resistências à adoção, possibilitando conduzir ações para maximizar a aceitação e aumentar a freqüência de uso. O Modelo TAM - Technology Acceptance Model, inicialmente proposto por DAVIS et al (1989), foi utilizado como base para a realização da pesquisa. Considerado uma das teorias mais influentes sobre o tema (LEE et al, 2003, p. 2), o Modelo TAM analisa a aceitação de sistemas de informação pelo usuário a partir da influência da Utilidade Percebida e Facilidade de Uso Percebida na Atitude e Intenção de Uso, que por sua vez determinam o Comportamento de Uso do sistema.

Desta forma, para operacionalização do estudo foram definidos cinco objetivos específicos:

(1) Comparar as dimensões do modelo conceitual proposto com aquelas observadas na empresa estudada, identificando aprimoramentos no Modelo Preliminar de Adoção Individual do e-Learning;

(2) Analisar as diferenças de percepção entre os colaboradores que realizaram e que não realizaram curso de e-learning na Empresa, desde 2006;

(3) Analisar as diferenças de percepção em função do perfil do respondente;

(4) Identificar as variáveis que melhor explicam a intenção de realizar ou não cursos de $e$ learning na Empresa;

(5) Identificar as variáveis que melhor explicam a realização ou não de cursos de $e$ learning na Empresa, desde 2006.

O primeiro objetivo específico consiste na comparação das dimensões propostas no modelo conceitual, desenvolvido a partir da revisão bibliográfica, com os fatores observados na empresa estudada. Essa análise possibilitará aprimorar o Modelo Preliminar de Adoção Individual do e-Learning, base para condução das demais análises.

Considerando a influência observada em pesquisas anteriores das variáveis analisadas na adoção do e-learning (GONG et al , 2004; SELIM, 2003; MARTINS; KELLERMANNS, 
2004; ONG et al, 2004; FUSILIER; DURLABHJI, 2005), o segundo objetivo foca a análise das diferenças de percepção em relação a estas variáveis entre os colaboradores que realizaram curso de e-learning na plataforma da Empresa e os que não realizaram, desde 2006. Com base na literatura, espera-se que os respondentes que participaram de cursos na plataforma da Empresa apresentem maior concordância em relação às variáveis que influenciam positivamente a adoção do e-learning.

O terceiro objetivo consiste na análise das diferenças de percepção sobre as variáveis pesquisadas em função do perfil do respondente. As variáveis do perfil pesquisadas incluem: experiência com e-learning fora da empresa, gênero, idade, tempo de empresa, grau de instrução, localidade de trabalho, nível hierárquico e área funcional. Tendo em vista o grande número de variáveis, optou-se por analisar em maior profundidade as diferenças relacionadas à realização de curso de e-learning fora da empresa e ao gênero, escolha realizada com base na reiterada presença destas variáveis na literatura pesquisada.

Visando consolidar as análises fruto dos objetivos específicos anteriores, o quarto e quinto objetivos tratam da identificação das variáveis que melhor explicam a intenção de realizar e a efetiva realização de cursos de e-learning, respectivamente.

O ineditismo deste estudo está na aplicação do Modelo TAM à adoção do e-learning na empresa, uma vez que a maior parte das pesquisas sobre o tema foi realizada em instituições de ensino (MARTINS; KELLERMANNS, 2004; GONG et al, 2004; SELIM, 2003; IGNATIUS; RAMAYAH, 2005; FUSILIER; DURLABHJI, 2005; GABBARD, 2004; WANG, 2003). Além disso, a inclusão no modelo de variáveis relacionadas ao ambiente organizacional, uma das críticas ao Modelo TAM (SACCOL, 2005), também constitui contribuição relevante ao conhecimento sobre o tema.

Com base nos objetivos propostos, inicialmente foi conduzida uma revisão bibliográfica tanto sobre Adoção de Inovações pelo indivíduo e pela organização, quanto sobre a Implementação do e-learning, visando a construção da fundamentação teórica do estudo. A pesquisa empírica foi realizada em duas fases: (1) revisão dos fatores que influenciam a adoção do e-learning identificados na revisão bibliográfica, a partir de entrevistas com especialistas e pré-teste do questionário, resultando no Modelo Preliminar de Adoção Individual do e-Learning; (2) análise dos fatores de adoção individual em uma empresa do setor de telecomunicações que 
utiliza o e-learning, com levantamento de dados realizado através de uma abordagem de múltiplos métodos, incluindo entrevistas, aplicação de questionário e análise de documentos. A Figura 1, a seguir, apresenta o modelo da pesquisa.

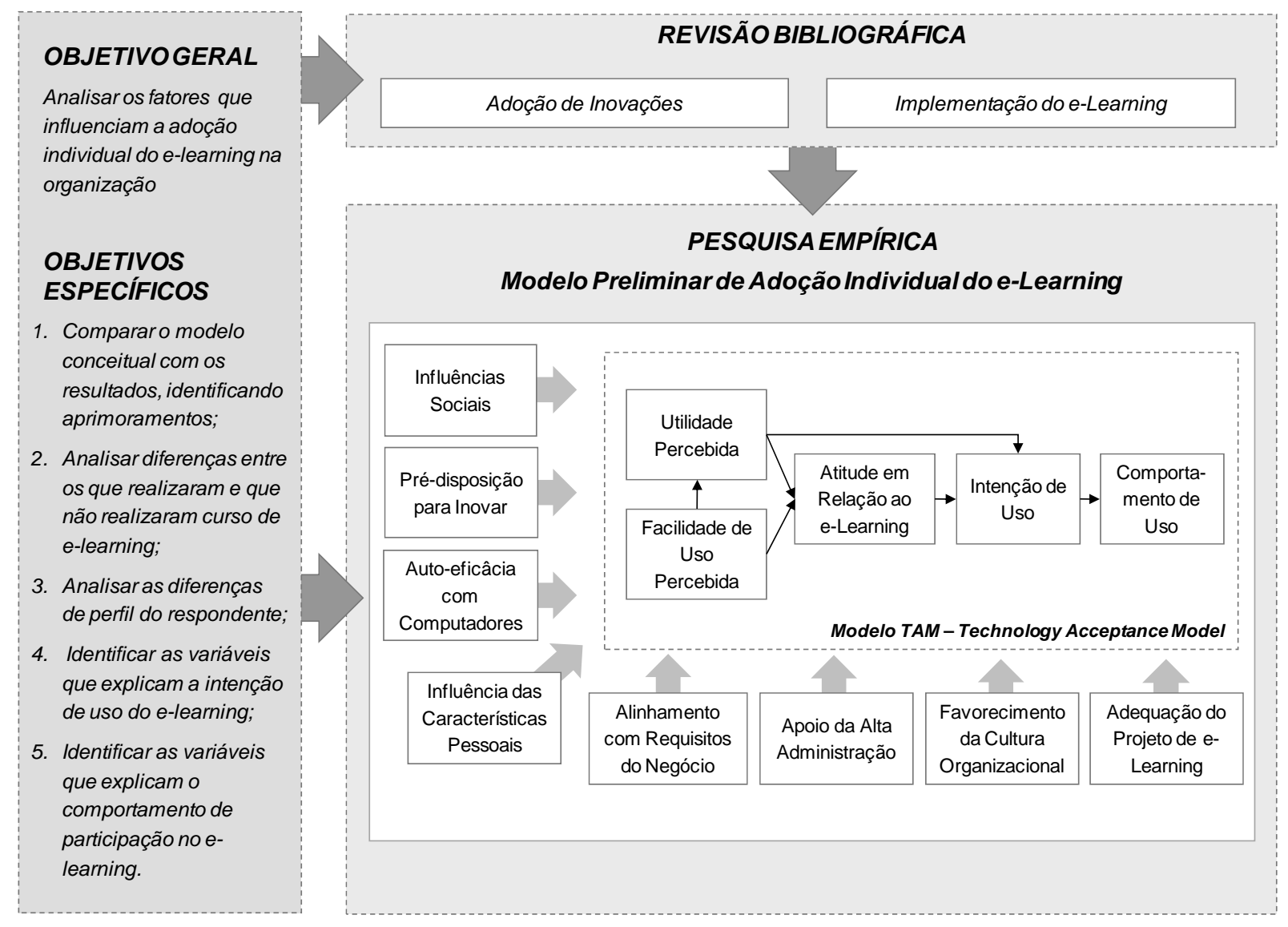

Figura 1 - Modelo da Pesquisa

A relevância desta pesquisa é justificada em função dos seguintes aspectos: (a) potencial de crescimento e contribuição do e-learning para as corporações; (b) dificuldades encontradas na implantação de inovações e na implantação do e-learning e (c) relevância e atualidade do tema adoção do e-learning. A seguir, cada um dos itens será brevemente comentado.

O resultado de uma pesquisa realizada pela PricewaterhouseCoopers (2001) demonstrou um grande potencial de desenvolvimento do e-learning na América Latina: 40\% das 190 empresas pesquisadas expressaram interesse estratégico em e-learning, embora somente $20 \%$ estivessem utilizando essa modalidade de educação a distância de forma significativa. Corroborando esse resultado, a pesquisa realizada no Brasil com 100 executivos de empresas 
de vários setores indicou que $46 \%$ das empresas pesquisadas utilizam ferramenta de $e$ learning, sendo que desses $61 \%$ pretendem estender sua utilização (O ENSINO..., 2003).

Os resultados de uma "pesquisa realizada ${ }^{8}$ em 2001, com trinta empresas de destaque na gestão de Recursos Humanos do Estado de São Paulo, com o objetivo de obter informações sobre o modelo de educação corporativa existente", revelou que entre $60 \%$ e $70 \%$ dessas empresas "adotaram múltiplos meios de aprendizagem (virtual e presencial) e estruturaram processos para criar oportunidades de aprendizagem contínua" (EBOLI, 2004, p. 65).

Se de um lado observa-se uma tendência de crescimento do uso do e-learning nas organizações, por outro, o uso intensivo de meios informatizados de autodidatismo foi considerado uma das tendências de grande dificuldade de implementação, conforme a demonstrou o resultado da pesquisa Delphi RH 2010 (FISCHER; ALBUQUERQUE, 2004, p. 44).

Insucessos observados na implementação de inovações relacionadas à tecnologia da informação em organizações resultam em um interesse prático para compreender melhor esse desafio. De acordo com Rogers,

Inovações relacionadas a computadores criam incerteza na organização, um estado desconfortável em um sistema que, na maioria das vezes, leva à resistência da tecnologia. Essa incerteza é uma das razões para as freqüentes dificuldades encontradas por tecnologias de informática no subprocesso de implementação. Quanto mais 'radical' a inovação, indicada pela quantidade de conhecimento que os membros da organização precisam adquirir para adotar, maior é a incerteza criada e mais difícil sua implementação ${ }^{9}$ (ROGERS, 1995, p. 397).

\footnotetext{
${ }^{8}$ Pesquisa realizada por Elizabeth Ayres Gdikian e Moisés Correia da Silva no trabalho de monografia do Programa de MBA-RH da FIA.

9 "Computer-related innovations create uncertainty in an organization, an uncomfortable state in a system that often leads to resistance to the technology. This uncertainty is one reason for the special difficulties that computer technologies frequently encounter in the implementation subprocess. The more 'radical' an innovation, indexed by the amount of knowledge that organization members must acquire in order to adopt, the more uncertainty it creates and the more difficult its implementation."
} 
Conforme descrição de Kline e Rosenberg, “o processo de inovação é um exercício de gestão e redução da incerteza" ${ }^{\prime 10}$ (1986, p. 275), e que, apesar de todas as mudanças tecnológicas já realizadas, a dificuldade de condução desses processos se mantém, em parte pela dificuldade de se aplicar experiências anteriores a situações totalmente novas (TORNATZKY; FLEISCHER, 1990, p. 11).

De acordo com Jonathon Levy, vice-presidente da Harvard Business School Publishing Corporation, o e-learning está sendo redescoberto e redirecionado, após ter fracassado nos moldes utilizados no final dos anos 90, quando se verificou a ineficiência de literalmente transferir cursos para o computador. "Mesmo assim, [o e-learning] ainda está longe de ser utilizado em sua potência máxima como uma ferramenta de fato revolucionária capaz de reinventar o aprendizado" (CAMPOS, 2002).

Um desafio importante do e-learning enfrentado pelas organizações relaciona-se às baixas taxas de finalização de cursos (Van DAM, 2004, p.6), confirmando que "a aceitação e uso do e-learning pelo aluno são pré-requisitos para a implementação de sucesso"11 (MARTINS; KELLERMANNS, 2004). Na mesma linha, Macpherson et al apontam para a necessidade de "avaliar o impacto do e-learning entre os vários stakeholders [...]”, e, mais especificamente, “[...] identificar questões chaves de 'aceitação do aprendiz' [...]”(2005, p. 42).

A pesquisa realizada por Tyan (2003) identificou a prontidão organizacional para adoção e a maturidade do e-learning como as principais barreiras para a difusão do e-learning .

Relacionada ao contexto da empresa, a cultura organizacional tem sido apontada como aspecto crucial para o sucesso de programas de aprendizagem mediada por tecnologia, uma vez que os colaboradores precisam assumir uma "nova atitude perante seu papel de alunos, a qual deve ser necessariamente proativa e acompanhada por uma postura constante de autoconhecimento e autodesenvolvimento", aspecto que deve ser "reforçado por uma cultura organizacional que valorize a iniciativa, a inovação, a responsabilidade, a autonomia, a liberdade, a comunicação intensa e o compartilhar de experiências" (EBOLI, 2004, p. 151).

\footnotetext{
10 "the process of innovation is an exercise in the management and reduction of uncertainty"

11 "the student acceptance and use of e-learning are prerequisites to successful implementation"
} 
Reforçando esta questão, a já citada pesquisa realizada pela PricewaterhouseCoopers (2001) identificou a cultura organizacional como a principal barreira para implementação do $e$ learning, fato que pode ser considerado um grande desafio para as organizações, se for levada em conta a dificuldade envolvida na administração da cultura organizacional (PETTIGREW, 1992, p. 145)

Por fim, a investigação da adoção e uso do e-learning é um tópico relativamente novo (ONG; LAI, 2006, p. 826). De acordo com Selim, "Faltam na literatura estudos que tratem do uso e aceitação de websites de cursos como uma ferramenta de ensino e aprendizagem." ${ }^{12}$ (2003, p. 346).

Especificamente em relação à utilização do Modelo TAM, Gabbard aponta que "Apesar do TAM ter uma rica literatura, este foi raramente e somente recentemente aplicado para as áreas de ensino superior, faculdades ou cursos on-line." ${ }^{13}$ (2004, p.49).

\footnotetext{
12 "The literature lacks studies that address student use and acceptance of course websites as a teaching and learning tool."

13 "Though TAM has a rich literature, it has only rarely and Just recently been applied to the areas of higher education, community colleges, or online courses."
} 


\section{REVISÃO BIBLIOGRÁFICA}

A revisão da literatura foi realizada com a finalidade de identificar fatores que influenciam a adoção do e-learning na organização, tendo em vista os objetivos de pesquisa propostos. Assim, foram pesquisadas: (a) a adoção de inovações, em nível individual (com destaque para o Modelo TAM - Technology Acceptance Model), e em nível organizacional (com destaque para a cultura organizacional); e (b) as barreiras para implementação do e-learning, os fatores de prontidão organizacional e experiências sobre adoção do e-learning.

\subsection{Adocão de Inovações}

De acordo com Rogers, inovação é “uma idéia, prática ou objeto que é percebido como nova por um indivíduo ou por outra unidade de adoção" "14 (1995, p.5). Kruglianskas vai além: "Enquanto a invenção envolve a formulação de uma proposta inédita, a inovação constitui um processo. A inovação é o processo de tornar uma invenção rentável para a empresa" (1996, p. 17).

Jamrog et al também consideram a necessidade de criar valor: "Inovação é o termo usado para descrever como organizações criam valor através do desenvolvimento de novo conhecimento ou usando conhecimento existente de novas formas." ${ }^{15}$ (2006, p. 10). Esse é um processo extremamente complexo, cujo

\footnotetext{
desafio para a empresa não está somente na criação de um ambiente propício à geração de novas idéias para o aprimoramento de seus produtos e processos. É preciso muito trabalho para vencer as resistências naturais que surgem sempre que uma nova idéia é proposta, bem como muita perseverança e, às vezes, muitos gastos até se comprovar a viabilidade desta nova idéia e, finalmente, implantá-la (KRUGLIANSKAS, 1996, p. 17).
}

\footnotetext{
14 “[...] an idea, practice, or object that is perceived as new by an individual or other unit of adoption [...]"

15 "Innovation is the term used to describe how organizations create value by developing new knowledge or by using existing knowledge in new ways."
} 
Em função da dificuldade de adoção de uma nova idéia, mesmo quando existem vantagens evidentes, muitas organizações enfrentam a necessidade de acelerar a taxa de difusão da inovação (ROGERS, 1995). De acordo com Rogers, "Difusão é o processo de comunicação ${ }^{16}$ de uma inovação, realizado através de determinados canais durante um período de tempo e para os membros de um sistema social"17 $(1995$, p.5).

A literatura sobre difusão de inovações teve início em diferentes áreas do conhecimento, com foco em um tipo de inovação; “[...] por exemplo, sociólogos rurais pesquisaram a difusão de inovações para fazendeiros, enquanto educadores estudaram a expansão de novas técnicas de ensino dentre os funcionários de escolas"18 (ROGERS, 1995, p. 38).

Rogers identificou diferentes enfoques da pesquisa sobre difusão (1995, p. 88-94), como por exemplo: forma com que as pessoas tomam conhecimento da inovação, taxa de adoção de diferentes inovações em um sistema social, índice de pré-disposição da organização ou do indivíduo para inovar (innovativeness), comportamento da liderança, papel das redes interpessoais, uso de canais de comunicação, conseqüências da inovação, taxa de adoção de uma mesma inovação em diferentes sistemas sociais.

Enquanto difusão se refere ao nível acumulado de usuários de uma inovação, adoção se refere à decisão de utilizar uma inovação (ROGERS, 1995; FRAMBACH; SCHILLEWAERT, 1999), ou seja, uma “[...] decisão de utilizar plenamente uma inovação como a melhor alternativa de ação disponível"19 (ROGERS, 1995, p. 21).

De acordo com Tornatzky e Fleischer, o conceito de adoção "normalmente se refere a um ponto do processo de inovação em que o usuário passa de uma situação de não ter a inovação

\footnotetext{
16 "Communication is a process in which participants create and share information with on another in order to reach a mutual understanding. This definition implies that communication is a process of convergence (or divergence) as two or more individuals exchange information in order to move toward each other (or apart) in the meanings that they give to certain events." (ROGERS, 1995, p.6).

17 "Diffusion is the process by which an innovation is communicated through certain channels over time among the members of a social system"

18 "[...] for example, rural sociologists investigated the diffusion of agricultural innovations to farmers while educational researchers studied the spread of new teaching ideas among school personnel"

19 "[...] decision to make full use of an innovation as the best course of action available"
} 
para outra em que a possui" ${ }^{20}$ (1990, p. 179). A definição de adoção da inovação depende do contexto em que é utilizado: enquanto que em pesquisa de mercado, a adoção pode ser considerada como a compra de determinado produto, a adoção de um novo programa educacional definida pelo conselho de uma instituição só será efetiva se envolver a diretoria e os professores. "A principal dificuldade de definir o termo adoção está no fato do processo de adoção ser, freqüentemente, formado por uma série (ou mesmo conjuntos paralelos) de decisões que não são visíveis a todos os participantes" ${ }^{21}$ (TORNATZKY; FLEISCHER, 1990, p.179).

Com relação ao processo de decisão em relação à inovação, tem destaque uma questão importante a ser respondida: "Quais características das inovações afetam a taxa em estas são difundidas e adotadas?"22 (ROGERS, 1995, p. 204); onde "Taxa de adoção consiste na velocidade relativa com que uma inovação é adotada por membros de um sistema social",23 (ROGERS, 1995, p. 250).

Pesquisas anteriores identificaram as características mais importantes das inovações que explicam sua taxa de adoção (ROGERS, 1995, p. 15-16):

- Vantagem relativa (Relative advantage): “[...] grau em que uma inovação é percebida como melhor que a idéia que é substituída" 24 , podendo ser medido em termos econômicos, prestígio social, conveniência e satisfação.

- Compatibilidade (Compatibility): “[...] grau em que a inovação é percebida como sendo consistente com os valores existentes, experiências passadas e necessidades dos adotantes potenciais", 25 .

- Complexidade (Complexity): "[...] grau em que a inovação é percebida como difícil de entender e usar",26.

\footnotetext{
20 "[...] usually refers to the point in the innovation process where the user moves from not having the innovation to having it"

21 "The main difficulty in defining the term adoption is that the adoption process is often made up of a series (or even parallel sets) of decisions that are not visible to all the participants"

22 "What characteristics of innovations affect the rate at which they diffuse and are adopted?"

23 "Rate of adoption is the relative speed with which an innovation is adopted by members of a social system"

24 "[...] degree to which an innovation is perceived as better than the idea it supersedes"

25 "[...] degree to which an innovation is perceived as being consistent with the existing values, past experiences, and needs of potential adopters"

26 "[...] degree to which an innovation is perceived as difficult to understand and use"
} 
- Possibilidade de experimentação (Trialability): “[...] grau em que a inovação pode ser experimentada com algumas limitações"27.

- Visibilidade (Observability): "[...] grau em que os resultados de uma inovação são visíveis para outros" 28

"Inovações que são percebidas pelos indivíduos como tendo maior vantagem relativa, compatibilidade, possibilidade de experimentação, visibilidade e menor complexidade serão adotadas mais rapidamente que outras inovações" ${ }^{29}$ (ROGERS, 1995, p. 16).

Rogers identifica um possível problema na medição desses atributos da inovação: “[...] essas podem não ser, em todos os casos, as cinco características percebidas como as mais importantes por um determinado grupo de respondentes"30 (1995, p.209), embora, conclua que possam ser usadas na maioria dos casos. Frambach e Schillewaert (1999), por outro lado, orientam sobre a importância da estrutura genérica de conceitos e inter-relações ser adaptada conforme a inovação e seu contexto. Aspecto também mencionado por Tornatzky e Fleischer (1990, p.179).

Além dos atributos percebidos de uma inovação, existem outras variáveis que influenciam sua taxa de adoção, entre as quais destacam-se (ROGERS, 1995, p. 206-208):

- Tipo de decisão sobre a inovação;

- Natureza dos canais de comunicação que divulgam a inovação durante os vários estágios do processo de decisão;

- Natureza do sistema social; e

- Extensão dos esforços dos agentes de mudança na difusão da inovação"31.

\footnotetext{
27 "[...] degree to which an innovation may be experimented with on a limited basis"

28 "[...] degree to which the results of an innovation are visible to others"

29 "Innovations that are perceived by individuals as having greater relative advantage, compatibility, trialability, observability, and less complexity will be adopted more rapidly than other innovations"

30 "[...] they may not in all cases be the five most important perceived characteristics for a particular set of respondents"

31 "(1) the type of innovation-decision, (2) the nature of communication channels diffusing the innovation at various stages in the innovation-decision process, (3) the nature of the social system, and (4) the extent of change agents' efforts in diffusing the innovation"
} 
A Figura 2 apresenta o modelo proposto por Rogers para analisar a taxa de adoção de inovações.

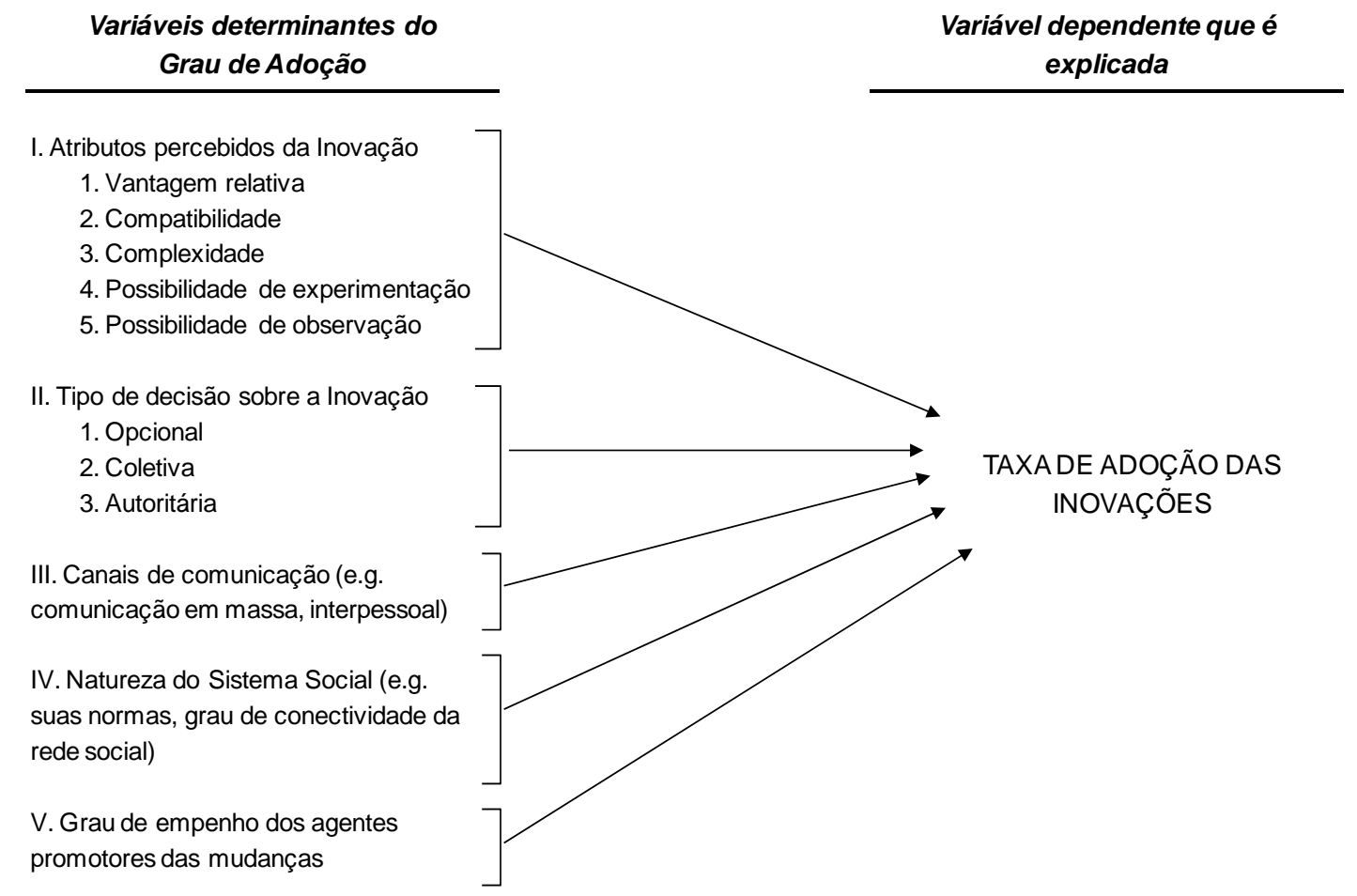

Figura 2 - Variáveis Determinantes da Taxa de Adoção de Inovações FONTE: ROGERS, 1995, p. 207

Tornatzky e Fleischer (1990, p. 28) analisam a questão de forma mais abrangente, uma vez que consideram a adoção apenas uma das etapas do processo de inovação, e discutem a importância dos processos relacionados à criação, desenvolvimento e entrega de novas tecnologias e ainda aqueles relacionados à adoção e uso dessas tecnologias envolvendo participações distintas dos diferentes níveis de agregação social (Figura 3). É importante ressaltar que modelos com estágios definidos podem induzir à presunção de existência de uma seqüência obrigatória (por exemplo, a pesquisa básica conduzir ao desenvolvimento), o que não necessariamente se verifica. 


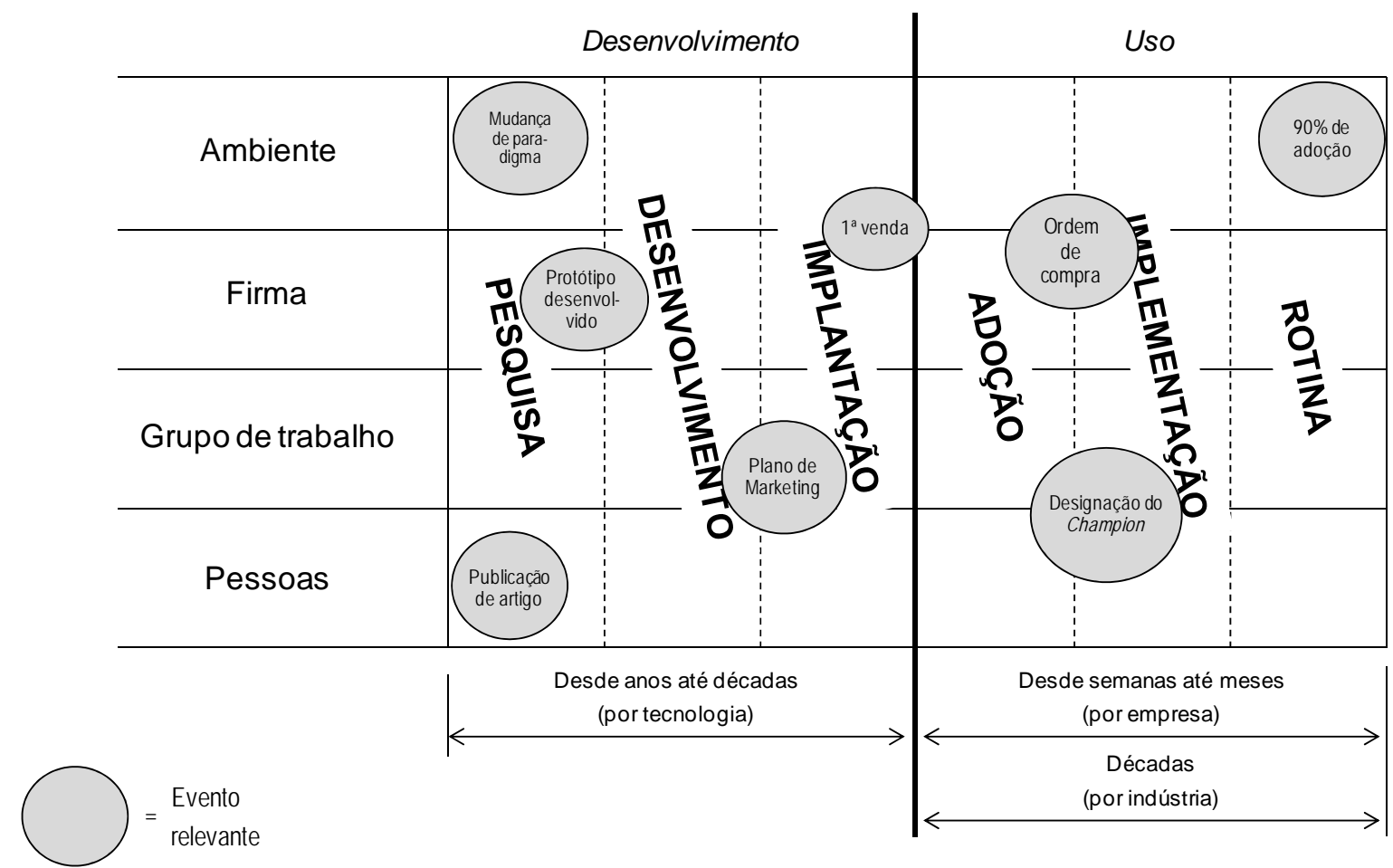

Figura 3 - Processos de Inovação Tecnológica

FONTE: TORNATZKY; FLEISCHER, 1990, p. 32

Embora os autores tratem especificamente da inovação tecnológica, o conceito é abrangente:

“[...] a palavra tecnologia inclui não apenas os artefatos físicos, mas também o comportamento social e organizacional; na verdade, o aspecto físico é frequentemente o menos importante. Como veremos, o processo chave de distribuição não é apenas o posicionamento de artefatos físicos nas mãos dos usuários, mas a comunicação do conhecimento necessário para usar os artefatos de forma efetiva" $^{\text {32 }}$ (TORNATZKY; FLEISCHER, 1990, p.117).

A partir do modelo apresentado na Figura 3 é possível apontar o foco desta pesquisa: as fases de adoção e implementação de uma inovação na empresa, com ênfase no aspecto individual.

Embora, "o tema de pesquisa mais popular em difusão tem sido o estudo de variáveis relacionadas à predisposição individual para inovar"33 (ROGERS, 1995, p. 88) a decisão de

32 "[...] the word technology embodies not only physical artifacts but social and organizational behavior as well; in fact, the former is often the less important aspect. As we shall see, the key process of technology deployment is not only the placement of physical artifacts into users' hands but the communication of the knowledge needed to use the artifacts effectively"

33 "[...] by far the most popular diffusion research topic has been variables related to individual innovativeness" 
adotar uma inovação pode ser analisada tanto em termos individuais, quanto organizacionais, tópicos que serão abordados a seguir.

\subsubsection{Adoção Individual de Inovações}

A decisão individual de adotar uma inovação é um processo composto por um conjunto de ações e não um ato instantâneo. O processo de decisão sobre a inovação é aquele através do qual um indivíduo (ou outra unidade de decisão) "[...] passa de tomar conhecimento de uma inovação, para formar uma atitude em relação à inovação, para a decisão de adotar ou rejeitar, para a implementação e uso da nova idéia e confirmação desta decisão" "34 (ROGERS, 1995, p. 20). Embora a principal preocupação em relação aos Estágios do Processo de Decisão sobre Inovação (Figura 4), proposto por Rogers (1995), seja com as decisões realizadas por indivíduos, o autor sugere que o modelo pode ser usado como base para discussão do processo de decisão nas organizações, tema discutido no próximo tópico.

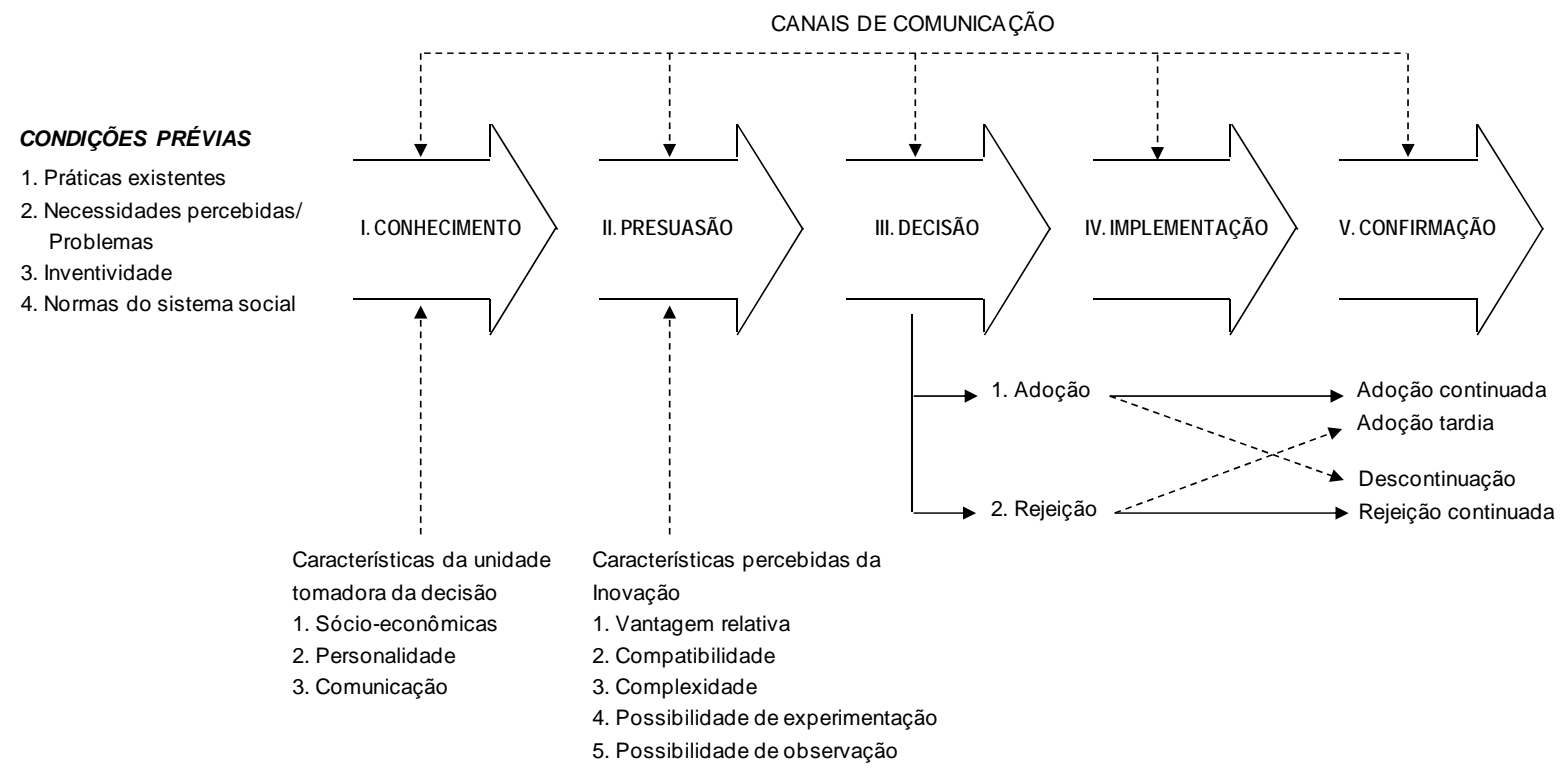

Figura 4 - Estágios do Processo de Decisão sobre Inovação FONTE: ROGERS, 1995, p. 163

Na mesma linha do modelo proposto por Rogers (1995), o Modelo de Adoção Baseado em Interesses (Concerns-Based Adoption Model - CBAM), proposto inicialmente por Hall, 
Wallace e Dosset em 1973, identifica os estágios de interesse associados a inovações educacionais com o objetivo de implementar ações que possam minimizar os problemas e facilitar o processo de adoção (CHANG, 2005, p. 22). O Quadro 1, a seguir, apresenta os sete estágios do modelo CBAM.

\section{Quadro 1 - Estágios de Interesse em Relação à Inovação}

\begin{tabular}{|c|c|c|}
\hline \multirow[t]{3}{*}{ Impacto } & 6 & $\begin{array}{l}\text { Refocalizar: } \\
\text { O foco está na exploração de benefícios universais da inovaçãa, } \\
\text { incluindo a possibilidade de importantes mudanças ou substituições } \\
\text { por uma alternativa mais eficaz. O indivíduo tem idéias definitivas } \\
\text { acerca das alternativas à forma proposta da inovação. }\end{array}$ \\
\hline & 5 & $\begin{array}{l}\text { Colaboração: } \\
\text { O foco está na coordenação e cooperação entre indivíduos com } \\
\text { relação ao uso da inovação }\end{array}$ \\
\hline & 4 & $\begin{array}{l}\text { Conseqüências: } \\
\text { Focos de atenção a respeito dos impactos da inovação sobre o aluno } \\
\text { e sua esfera imediata de influência. O foco está na relevância da } \\
\text { inovação para o aluno, na avaliação dos resultados obtidos por esse } \\
\text { aluno, incluindo desempenho e competências, e mudanças } \\
\text { necessárias para aumentar a qualidade dos resultados. }\end{array}$ \\
\hline Tarefa & 3 & $\begin{array}{l}\text { Gerenciamento: } \\
\text { A atenção está focada nos processos e tarefas envolvidos no uso da } \\
\text { inovação e na utilização das fontes de informação disponíveis. } \\
\text { Questões relativas à eficiência, organização, gerenciamento, } \\
\text { organização do tempo são as mais significativas. }\end{array}$ \\
\hline \multirow[t]{2}{*}{ Indivíduo } & 2 & $\begin{array}{l}\text { Pessoais: } \\
\text { O indivíduo é inseguro com relação às demandas da inovação, suas } \\
\text { limitações pessoais para lidar com tal inovação e qual exatamente } \\
\text { seu papel. Essa análise inclui definição dos papéis e } \\
\text { responsabilidades no contexto da inovação, modelos de tomada de } \\
\text { decisão e considerações sobre potenciais conflitos com estruturas } \\
\text { pré-existentes ou falta de compromissos pessoais. Implicações de } \\
\text { ordem financeira ou mesmo de status para o indivíduo e seus colegas } \\
\text { próximos também devem ser endereçadas. }\end{array}$ \\
\hline & 1 & $\begin{array}{l}\text { Informação: } \\
\text { É indicado que se tenha um ambiente de prontidão para facilitar o } \\
\text { aprendizado sobre os impactos da inovação. O indivíduo tende a ser } \\
\text { despreocupado com relação à inovação. Os interesses tendem a ser } \\
\text { sobre os aspectos substantivos da inovação, tais como características } \\
\text { gerais, esforço envolvido e pré-requisitos para adoção. }\end{array}$ \\
\hline $\begin{array}{l}\text { Não } \\
\text { relacionado }\end{array}$ & 0 & $\begin{array}{l}\text { Prontidão: } \\
\text { Baixa preocupação a respeito ou envolvimento com a inovação são } \\
\text { indicados. }\end{array}$ \\
\hline
\end{tabular}
34 "[...] passes from first knowledge of an innovation to forming an attitude toward the innovation, to a decision
to adopt or reject, to implementation and use of the new idea, and to confirmation of this decision" 
A literatura de Sistemas de Informação também tem estudando como e porque indivíduos adotam novas tecnologias de informação. Dentre as principais correntes, destacam-se três: as pesquisas com foco na aceitação individual da tecnologia utilizando como variável dependente a intenção ou uso; as pesquisas sobre o sucesso da implementação no nível organizacional; e os estudos sobre a adequação entre tarefa e tecnologia (VENKATESH et al, 2003, p. 427).

A teoria TAM - Technology Acceptance Model tem sido considerada uma das mais influentes para descrever a aceitação individual de sistemas de informação, tendo como resultado seu uso freqüente (LEE et al, 2003, p. 2). De acordo com o Social Science Citation Index ${ }^{\circledR}$, do Institute for Scientific Information, até 2003 foram listadas 698 citações (LEE et al, 2003, p. 3) em revistas científicas dos trabalhos de Davis (DAVIS, 1989; DAVIS et al, 1989), autor que introduziu o Modelo TAM (VENKATESH; DAVIS, 2000, p.187). A teoria tem sido aplicada na análise de diferentes tecnologias tais como processadores de texto, e-mail, Internet, e-commerce e educação on-line. A seguir, o Modelo TAM é detalhado, incluindo sua evolução, aplicações e limitações.

\section{Modelo TAM - Technology Acceptance Model}

Adaptado da Teoria da Ação Fundamentada ${ }^{35}$ (TRA - Theory of Reasoned Action), desenvolvida por Fishbein e Ajzen e amplamente utilizada, Davis propõe o Modelo TAM de aceitação da tecnologia (Technology Acceptance Model), em sua tese de doutorado, defendida no MIT em $1986^{36}$, “[...] especificamente ajustado para analisar a aceitação de sistemas de informação pelo usuário"37 (DAVIS et al, 1989, p. 985). O objetivo principal do TAM “é disponibilizar uma referência para traçar o impacto de fatores externos nas crenças internas, atitudes e intenções"38 (DAVIS et al, 1989, p. 985), assim, duas variáveis principais foram

\footnotetext{
${ }^{35}$ Modelo desenvolvido por Fischbein e Ajzen, em 1975, com o objetivo de prever e explicar o comportamento humano, através da intenção de comportamento, que por sua vez é determinada pela atitude do indivíduo e norma subjetiva (DAVIS et al, 1989, p. 983).

${ }^{36}$ DAVIS, F.D. A Technology Acceptance Model for Empirically Testing New End-User Information Systems: Theory and Results. Doctoral dissertation, Sloan School of Management, Massachusetts Institute of Technology, 1986.

37 "[...] specifically tailored for modeling user acceptance of information systems"

38 "[...] is to provide a basis for tracing the impact of external factors on internal beliefs, attitudes, and intentions"
} 
identificadas como influenciadoras do comportamento de aceitação da tecnologia de informação (DAVIS, 1989, p. 320):

- Utilidade percebida (Perceived usefulness): "grau em que uma pessoa acredita que utilizar um determinado sistema irá melhorar sua performance ${ }^{\text {"39; }}$;

- Facilidade de uso percebida (Perceived ease of use): "grau em que uma pessoa acredita que utilizar determinado sistema não envolverá esforço" ${ }^{40}$.

Da mesma forma que na TRA (Theory of Reasoned Action), o Modelo TAM estabelece que o uso do sistema é determinado pela intenção de comportamento (Behavioral Intention), definido como "uma medida da força da intenção do indivíduo em desempenhar um comportamento específico" ${ }^{41}$ (DAVIS et al, 1989, p. 984), que, por sua vez, é influenciada pela Atitude em Relação ao Comportamento (Attitude Toward Behavior), "os sentimentos negativos ou positivos de um indivíduo (sentimento de avaliação) sobre desempenhar o comportamento em questão"42 (DAVIS et al, 1989, p. 984). Mas, diferente da TRA, no Modelo TAM a intenção é determinada também pela utilidade percebida, além da atitude em relação ao uso do sistema, mudança baseada em estudos anteriores da área de sistemas de informação (Figura 5).

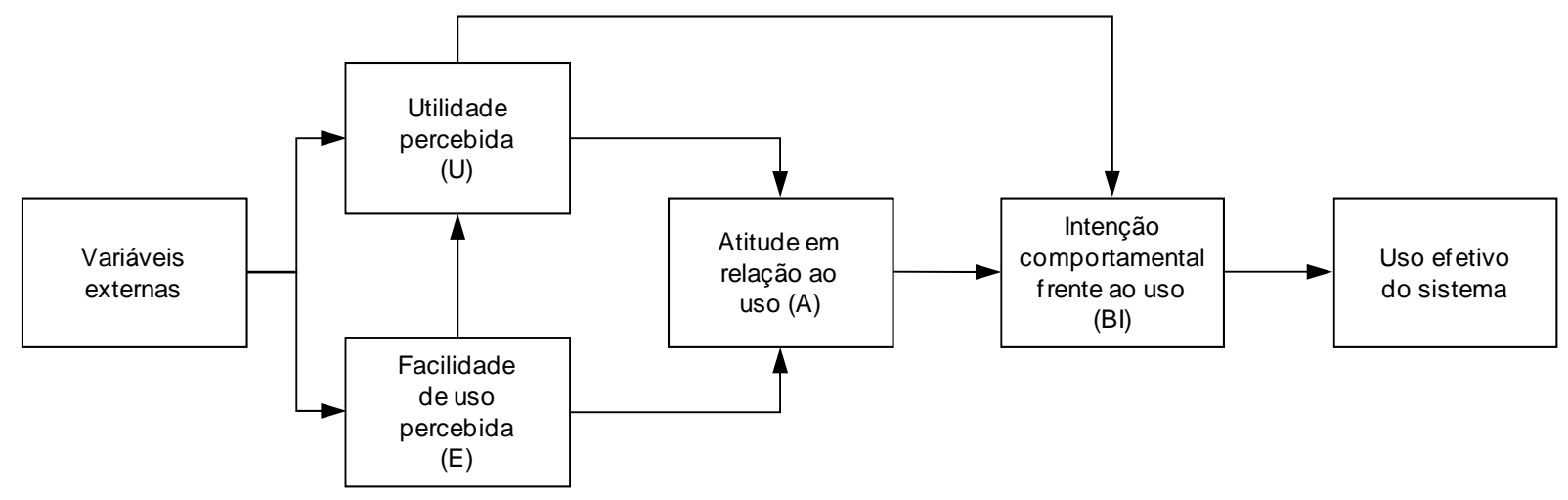

Figura 5 - Technology Acceptance Model (TAM)

FONTE: DAVIS et al, 1989, p. 985

\footnotetext{
39 "the degree to which a person believes that using a particular system would enhance his or her job performance"

40 "the degree to which a person believes that using a particular system would be free of effort"

41 "[...] a measure of the strength of one's intention to perform a specified behavior"

42 "[...] an individual's positive or negative feelings (evaluative affect) about performing the target behavior"
} 
Além disso, no Modelo TAM o constructo norma subjetiva não foi incluído como determinante da atitude em relação ao sistema, com a justificativa de ser um aspecto ainda pouco compreendido da TRA, caracterizado por uma situação teórica incerta (DAVIS et al, 1989, p. 986), embora tenha sido apontada nas conclusões a necessidade de pesquisas adicionais sobre o impacto das influências sociais (DAVIS et al, 1989, p. 999). Dentre as variáveis externas, os autores incluem aspectos como: qualidade do resultado obtido com o uso do sistema, características e funcionalidades do sistema, divulgação dos benefícios do sistema, treinamento, documentação e suporte ao usuário.

Para avaliar a teoria TAM, Davis et al (1989, p. 989) realizaram uma pesquisa sobre o uso voluntário de um software processador de texto por 107 alunos de MBA, com utilização de questionários para medir as variáveis dos modelos TAM e TRA, aplicados no início do semestre, após a apresentação do software, e ao final do semestre. Também foram conduzidas 40 entrevistas com alunos.

Os resultados da pesquisa indicaram três aspectos importantes sobre o uso do computador no contexto administrativo (DAVIS et al, 1989, p. 997):

1. "O uso do computador pelas pessoas pode ser razoavelmente bem prognosticado através de suas intenções";

2. "A utilidade percebida é um determinante importante da intenção das pessoas em utilizar computadores";

3. “A facilidade de uso percebida é um determinante secundário significativo da intenção das pessoas em utilizar computadores"

\section{Evolução do Modelo TAM}

Com o objetivo de ampliar o Modelo TAM, através da inclusão de aspectos adicionais determinantes na percepção de utilidade e na intenção de uso, e de compreender como os efeitos destes determinantes são alterados com o aumento da experiência do usuário em

\footnotetext{
43 “(1) People's computer use can be predicted reasonably well from their intentions. (2) Perceived usefulness is a major determinant of people's intentions to use computers. (3) Perceived ease of use is a significant secondary determinant of people's intentions to use computers"
} 
relação ao sistema em questão, os autores Venkatesh e Davis propõem o TAM2 (2000, p. 187). O Modelo TAM2 incorpora novos constructos relacionados à influência social (norma subjetiva, voluntariedade e imagem) e ao instrumental cognitivo (relevância para o trabalho, qualidade do resultado, demonstrabilidade do resultado e facilidade de uso percebida), definidos a seguir (VENKATESH; DAVIS, 2000, p. 187-192):

- Norma subjetiva: “[...] percepção da pessoa sobre o que pessoas que são importantes para ela pensam em relação a dever ou não realizar o comportamento em questão" ${ }^{44}$. Definição baseada na teoria TRA (Theory of Reasoned Action) e na TPB (Theory of Planned Behavior). O Modelo TAM2 analisa a influência direta da norma subjetiva na intenção de uso, explicada pela escolha de determinada conduta com base na crença do que uma ou mais pessoas importantes consideram que deva ser seu comportamento. Além disso, a norma subjetiva pode influenciar indiretamente a intenção de uso, através da utilidade percebida, uma vez que o indivíduo pode internalizar as crenças das pessoas que considera referências importantes.

- Voluntariedade: "[...] a extensão pela qual os potenciais adotantes percebem que a decisão de adoção não é obrigatória" ${ }^{45}$. É considerada uma variável mediadora entre norma subjetiva e a intenção de uso, uma vez que pesquisas anteriores identificaram que a influência social tem impacto maior em contextos nos quais o novo sistema tem uso obrigatório. Esse aspecto é relevante, pois mesmo quando os usuários percebem que o uso do sistema é obrigatório na organização, a intenção de uso pode variar, uma vez que alguns usuários podem não estar dispostos a seguir tal orientação.

- Imagem: "grau em que o uso de uma inovação é percebido como uma forma de melhorar [...] o status do indivíduo em seu sistema social" ${ }^{\text {46 }}$. De acordo com o Modelo TAM2, a imagem é positivamente influenciada pela norma subjetiva, visto que, se membros importantes do grupo social do indivíduo acreditam que ele deve ter determinado comportamento, uma conduta condizente tenderá a elevar sua posição no grupo, processo definido como identificação.

\footnotetext{
44 "person's perception that most people who are important to him think he should or should not perform the behavior in question"

45 "the extent to which potential adopters perceive the adoption decision to be non-mandatory"

46 "[...] the degree to which use of an innovation is perceived to enhance one's [...] status in one's social system"
} 
- Relevância para o trabalho: “[...] percepção do indivíduo em relação ao grau em que o sistema em questão é aplicável em sua função" ${ }^{, 47}$, tendo um efeito direto na utilidade percebida.

- Qualidade do resultado: consiste na “[...] qualidade com que o sistema realiza as tarefas $[\ldots]^{, 48}$ previstas, influenciando diretamente a utilidade percebida.

- Demonstrabilidade do resultado: “[...] tangibilidade dos resultados obtidos com o uso da inovação" ${ }^{49}$, influenciando diretamente a utilidade percebida.

- Facilidade de uso: variável mantida do Modelo TAM, indicando que "[...] com todo o resto mantido igual, quanto menos trabalhoso é o uso do sistema, mais seu uso pode aumentar o desempenho da tarefa" $" 50$.

A variável experiência também foi acrescentada no TAM2, influenciando o impacto da norma subjetiva na utilidade percebida e na intenção de uso. Pesquisas anteriores indicaram que após a implementação do sistema, quando os benefícios e fraquezas são conhecidos pelo usuário através da experiência, o efeito da norma subjetiva diminui (VENKATESH; DAVIS, 2000, p. 189-190).

Visando testar este novo modelo, Venkatesh e Davis (2000, p. 193) realizaram quatro estudos longitudinais, em organizações que estavam prestes a implementar novas tecnologias, com uso obrigatório em duas delas e uso facultativo nas outras duas. Em cada empresa, os questionários foram aplicados a aproximadamente 50 usuários potenciais, em três momentos diferentes: após o treinamento inicial, um mês e três meses após a implementação.

A pesquisa demonstrou que o Modelo TAM2 possibilita identificar aspectos que influenciam a percepção de utilidade, explicando até $60 \%$ da variância deste importante direcionador das intenções de uso da tecnologia em questão (VENKATESH; DAVIS, 2000, p. 198); ou seja, consistente com pesquisas anteriores, a utilidade percebida foi considerada uma forte determinante da intenção de uso, mediando os efeitos das demais variáveis em relação à intenção de uso. A Figura 6, abaixo, consolida os resultados obtidos no estudo.

\footnotetext{
47 "[...] individual's perception regarding the degree to which the target system is applicable to his or her job"

48 "[...] how well the system performs those tasks [...]"

49 "[...] tangibility of the results of using the innovation [...]"

50 "[...] all else being equal, the less effortful a system is to use, the more using it can increase job performance"
} 


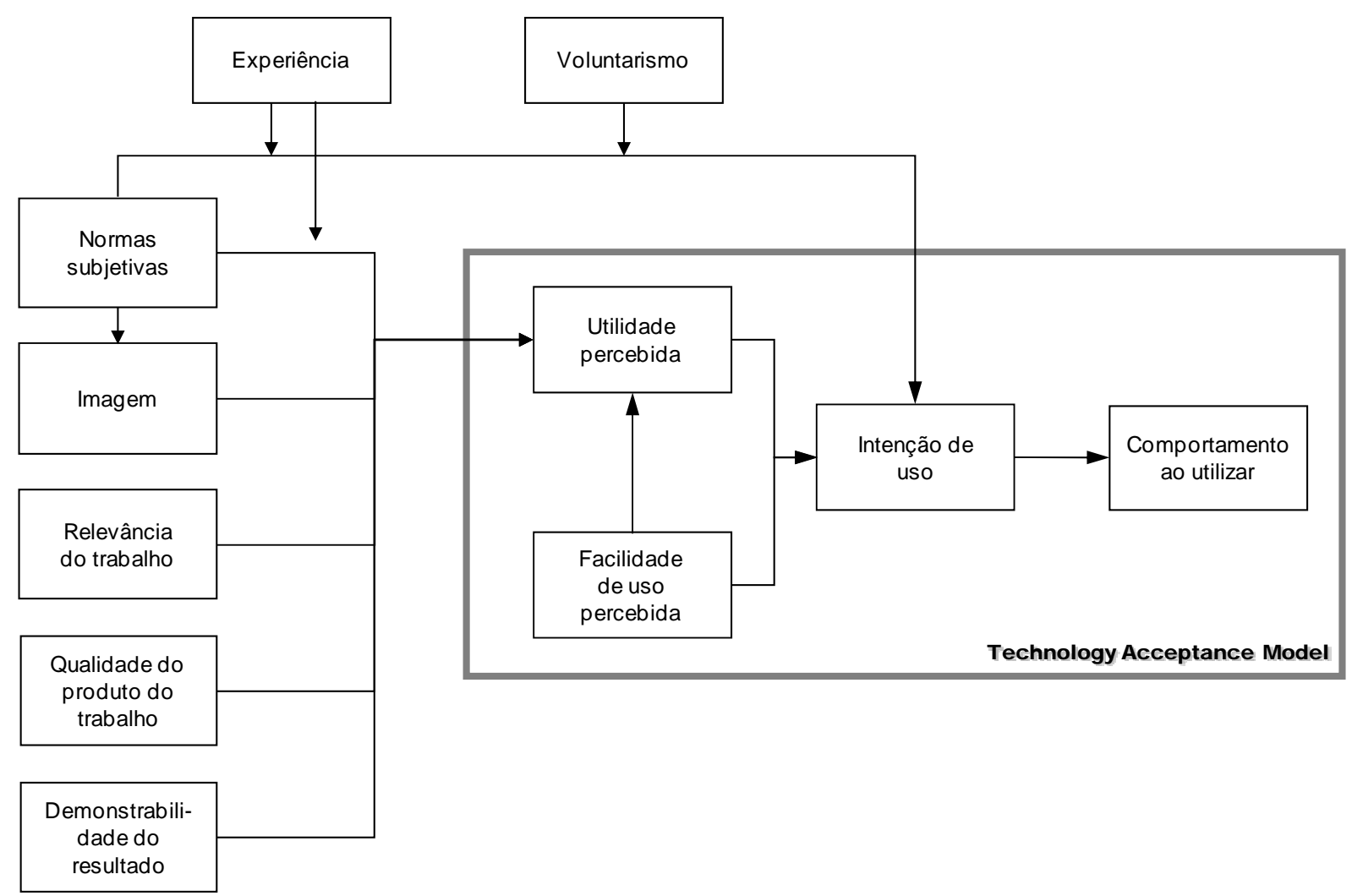

Figura 6 - TAM2 - Extensão do Technology Acceptance Model FONTE: VENKATESH; DAVIS, 2000, p. 197

Dentre as contribuições e implicações da pesquisa realizada por Venkatesh e Davis, destacamse (2000, p. 199-200):

- A identificação de uma influência direta do constructo norma subjetiva na intenção de uso apenas em sistemas de uso obrigatório ou quando o usuário possui pouca experiência com a tecnologia, indicando que a influência social pode ser mais efetiva quando voltada para alterar positivamente a percepção de utilidade em relação ao sistema. Desta forma, alternativas como aumentar a credibilidade das fontes de informações e desenhar campanhas de comunicação são ações cujos efeitos devem ser testados em pesquisas futuras.

- Além de desenhar sistemas alinhados às necessidades do trabalho, melhorar a qualidade do resultado e facilitar o uso, intervenções para aumentar a demonstrabilidade de resultados podem facilitar a adoção pelo usuário.

- Os resultados relacionados ao uso da autoridade como alavanca para aumentar a utilização do novo sistema e aqueles relacionados à decisão individual de adoção demandam alguma revisão, tendo em vista a tendência de mudança de estruturas 
hierarquizadas para modelos de gestão com ênfase em maior autonomia e no trabalho em equipe.

Posteriormente, uma nova pesquisa foi realizada por Venkatesh et al (2003, p.426) com o objetivo de comparar modelos de aceitação existentes e propor um modelo unificado. Oito modelos identificados na literatura foram empiricamente analisados, com dados de quatro organizações e medições em três momentos durante seis meses. Para cada modelo foi apontado pelo menos um constructo significativo durante todo o período, identificado como aquele que mais influenciou a aceitação da tecnologia. Os resultados estão listados no Quadro 2 (VENKATESH et al, 2003, p.428-433).

Corroborando os resultados obtidos na validação do TAM2, a análise dos modelos também demonstrou que o contexto voluntário versus obrigatório impacta significativamente os constructos relacionados à influência social: norma subjetiva (TPB e TAM), fatores sociais (MPCU) e imagem (IDT) foram significantes somente em implementações de uso obrigatório (VENKATESH et al, 2003, p.446). 
Quadro 2 - Modelos e Constructos de Maior Influência na Aceitação de Tecnologia Analisados por Venkatesh et al (2003)

\begin{tabular}{|c|c|c|}
\hline Modelo & $\begin{array}{l}\text { Constructo de } \\
\text { maior influência }\end{array}$ & Definição \\
\hline $\begin{array}{l}\text { Theory of Reasoned Action } \\
\text { (TRA) }\end{array}$ & \multirow[t]{2}{*}{$\begin{array}{l}\text { Atitude em relação } \\
\text { ao comportamento }\end{array}$} & \multirow[t]{2}{*}{$\begin{array}{l}\text { "os sentimentos positivos ou negativos do indivíduo em } \\
\text { relação a determinado comportamento" } 51\end{array}$} \\
\hline $\begin{array}{l}\text { Theory of Planned Behavior } \\
\text { (TPB) }\end{array}$ & & \\
\hline $\begin{array}{l}\text { Technology Acceptance } \\
\text { Model (TAM/TAM2) }\end{array}$ & \multirow[t]{2}{*}{ Utilidade percebida } & \multirow[t]{2}{*}{$\begin{array}{l}\text { "o grau em que uma pessoa acredita que utilizar um } \\
\text { determinado sistema irá melhorar sua performance"52 }\end{array}$} \\
\hline $\begin{array}{l}\text { Combinação dos modelos } \\
\text { TAM e TPB }\end{array}$ & & \\
\hline Motivational Model (MM) & $\begin{array}{l}\text { Motivação } \\
\text { extrínseca }\end{array}$ & $\begin{array}{l}\text { "A percepção de que os usuários irão querer realizar } \\
\text { determinada atividade, porque esta é percebida como } \\
\text { forma de atingir resultados valiosos diferentes da } \\
\text { atividade em si, como melhor desempenho no trabalho, } \\
\text { remuneração ou promoções" } 53\end{array}$ \\
\hline $\begin{array}{l}\text { Model of PC Utilization } \\
\text { (MPCU) }\end{array}$ & $\begin{array}{l}\text { Adaptação ao } \\
\text { trabalho }\end{array}$ & $\begin{array}{l}\text { "a extensão com que as crenças do indivíduo em relação a } \\
\text { usar [uma tecnologia] pode aumentar o desempenho de } \\
\text { seu trabalho" }\end{array}$ \\
\hline $\begin{array}{l}\text { Innovation Diffusion Theory } \\
\text { (IDT) }\end{array}$ & Vantagem relativa & $\begin{array}{l}\text { "o grau em que a inovação é percebida como sendo } \\
\text { melhor que seu antecessor" } 55\end{array}$ \\
\hline $\begin{array}{l}\text { Social Cognitive Theory } \\
\text { (SCT) }\end{array}$ & $\begin{array}{l}\text { Expectativas de } \\
\text { resultado - } \\
\text { Desempenho }\end{array}$ & $\begin{array}{lll}\text { "As conseqüências do comportamento relacionadas ao } & \text { ao } \\
\text { desempenho. Especificamente, expectativas } & \text { de } \\
\text { desempenho tratam de resultados relacionados } & \text { ao } \\
\text { trabalho"56 } & & \end{array}$ \\
\hline
\end{tabular}

FONTE: Adaptado de Venkatesh et al (2003, p. 428-433)

Com relação ao modelo unificado proposto (Unified Theory of Acceptance and Use of Technology - UTAUT), os autores utilizam quarto constructos principais com influência direta na intenção e comportamento de uso e quatro fatores mediadores (VENKATESH et al, 2003, p.447). A Figura 7, a seguir, apresenta o modelo proposto pelos autores, adaptado de forma a incluir os componentes de cada constructo. Este modelo foi testado com os dados coletados em três organizações, confirmando os três determinantes diretos da intenção de comportamento (expectativa de desempenho, expectativa de esforço e influência social), os

\footnotetext{
51 "an individual's positive or negative feelings (evaluative affect) about performing the target behavior" (FISHBEIN; AJZEN, 1975, p. 216 apud VENKATESH et al, 2003, p. 428).

52 "the degree to which a person believes that using a particular system would enhance his or her job performance"

53 "The perception that users will want to perform an activity 'because it is perceived to be instrumental in achieving valued outcomes that are distinct from the activity itself, such as improved job performance, pay, or promotions" (DAVIS et al, 1992, p. 1112 apud VENKATESH et al, 2003, p. 428).

54 "the extent to which an individual believes that using [a technology] can enhance the performance of his or her job" (THOMPSON et al, 1991, p. 129 apud VENKATESH et al, 2003, p. 430).

55 "the degree to which an innovation is perceived as being better than its precursor" (MOORE; BENBASAT, 1991, p. 195 apud VENKATESH et al, 2003, p. 431).

56 "The performance-related consequences of the behavior. Specifically, performance expectations deal with jobrelated outcomes" (COMPEAU; HIGGINS, 1995 apud VENKATESH et al, 2003, p. 432).
} 
dois determinantes diretos do comportamento de uso (intenção e condições facilitadoras) e a influência da experiência, voluntariedade, gênero e idade.

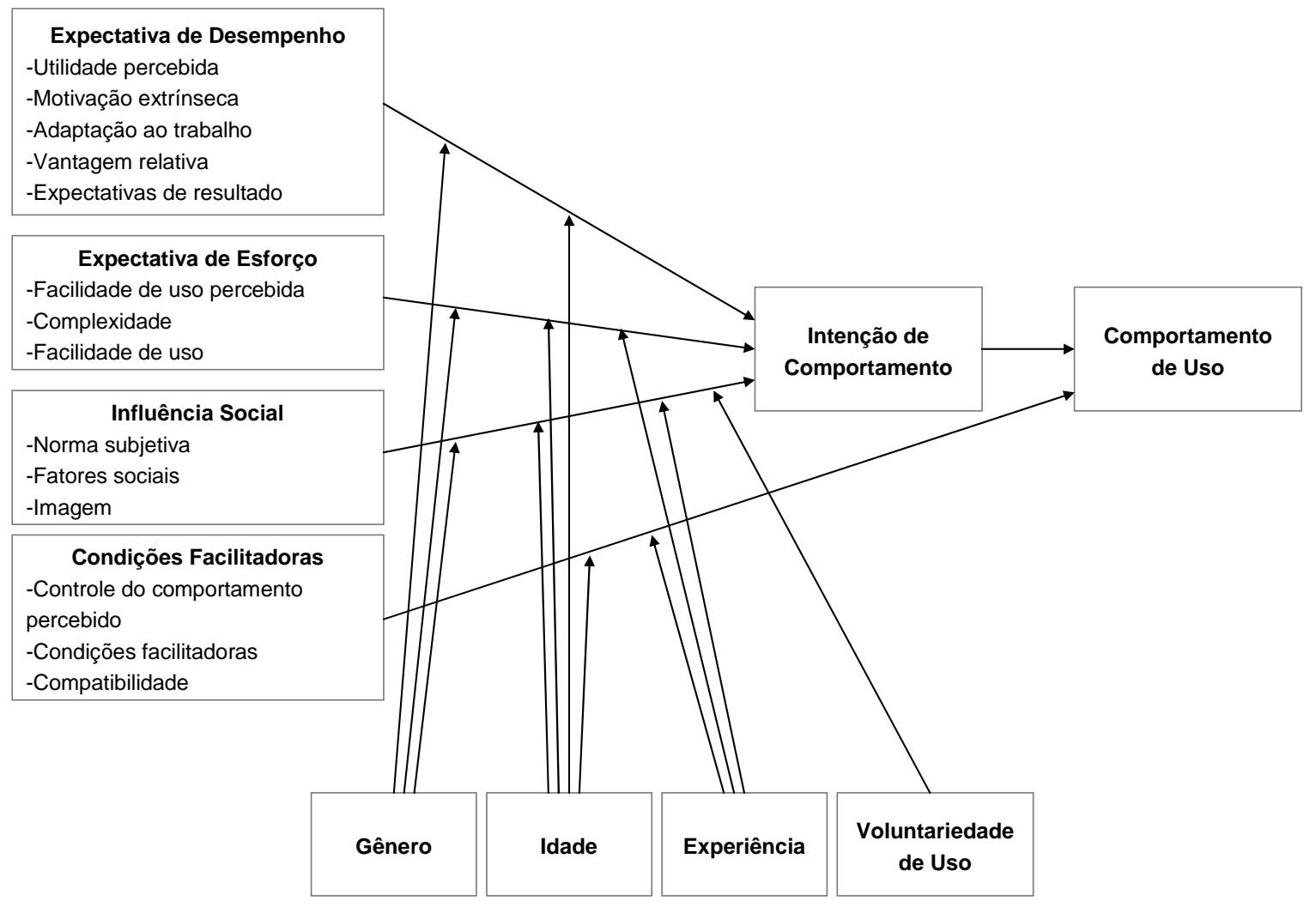

Figura 7 - Modelo Unificado Proposto por Venkatesh et al (2003)

FONTE: Adaptado de VENKATESH et al, 2003, p. 447

Apesar do modelo UTAUT explicar 70\% da variância da intenção de uso (VENKATESH et al, 2003, p. 467), deve ser considerado um modelo preliminar, sendo necessário o aprimoramento e validação das escalas utilizadas na medição de cada constructo (VENKATESH et al, 2003, p. 468).

\section{Aplicação do Modelo TAM}

Schillewaert et al (2000) adaptaram o Modelo TAM para analisar a aceitação da tecnologia de informação por profissionais de vendas. Os autores adicionaram ao modelo as seguintes variáveis externas (SCHILLEWAERT et al, 2000, p. 5): (a) características individuais (predisposição pessoal para inovar e auto-eficácia com computadores); (b) facilitadores organizacionais (treinamento do usuário, suporte técnico ao usuário e implementação organizacional) e (c) influência social (influência do supervisor, uso pelos colegas, influência do consumidor e pressão competitiva). O esforço de implementação organizacional se refere 
às percepções do usuário em relação à campanha interna de marketing e à abordagem de implementação da tecnologia na organização, incluindo, por exemplo, estímulo e comprometimento da alta administração. A pesquisa empírica foi conduzida em uma etapa qualitativa, em que os autores realizaram entrevistas com representantes de vendas e especialistas para revisar o modelo, e outra etapa quantitativa, através de questionários autopreenchidos enviados para gerentes de vendas e equipe, com a obtenção de 224 questionários válidos.

Os resultados obtidos por Schillewaert et al (2000, p. 29) reforçam a importância fundamental da utilidade percebida na aceitação da tecnologia de vendas e a importância secundária da facilidade de uso percebida, confirmando as premissas do Modelo TAM (DAVIS et al, 1989; VENKATESH; DAVIS, 2000). Com relação às variáveis externas que foram adicionadas ao modelo, foram identificadas influências na Utilidade e/ou na Aceitação, exceto no caso da Influência do Consumidor, que não afetou significativamente a aceitação da tecnologia. É interessante notar que, da mesma forma que no modelo UTAUT (VENKATESH et al, 2003), os Facilitadores Organizacionais influenciaram diretamente a Aceitação, desempenhando um papel central no modelo. A Figura 8 apresenta o modelo revisado a partir dos resultados da pesquisa.

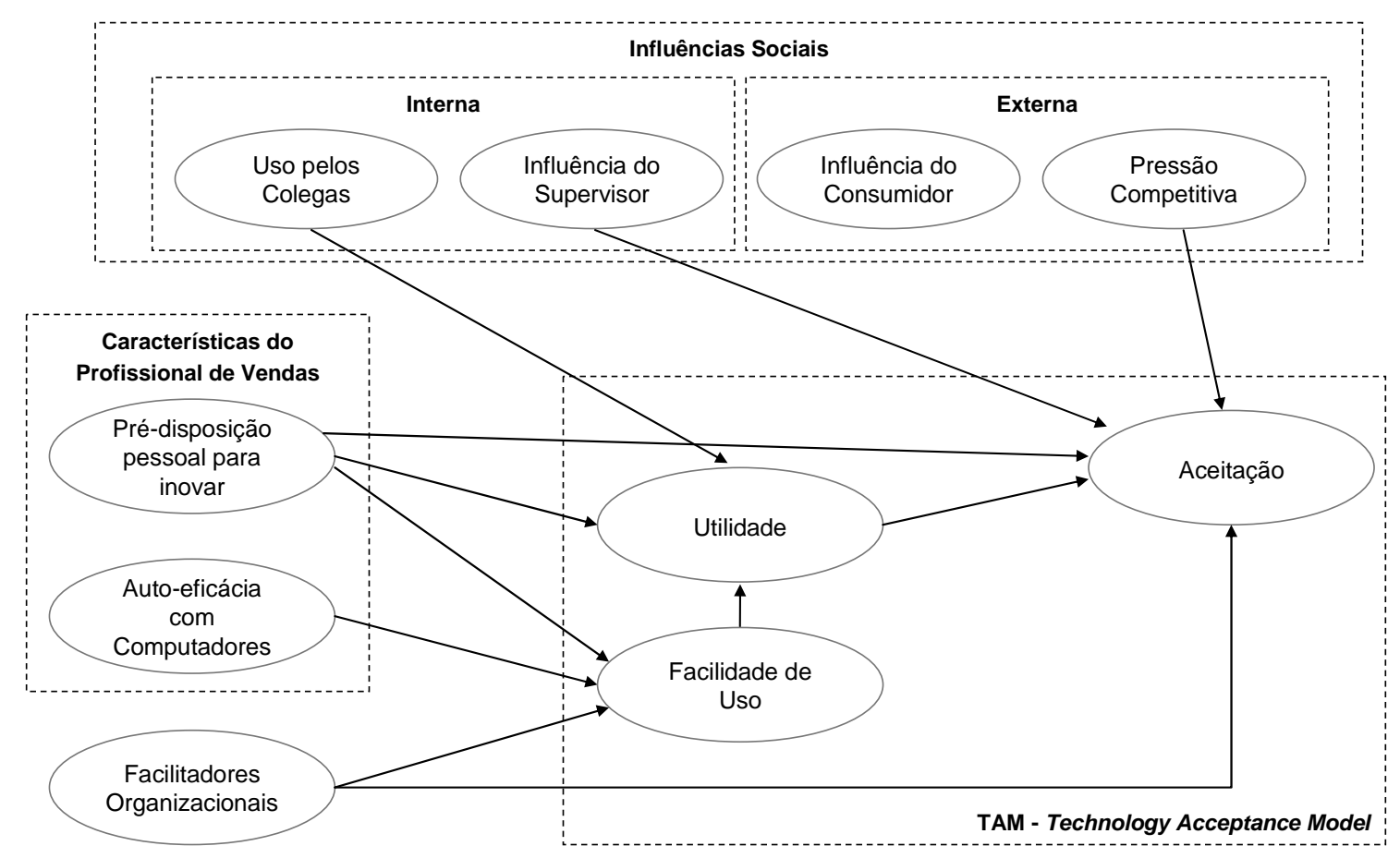

Figura 8 - Aceitação da Tecnologia de Informação pela Força de Vendas - Modelo Revisado FONTE: Adaptado de SCHILLEWAERT et al, 2000, p. 49 


\section{Limitações e Críticas ao Modelo TAM}

Saccol (2005) realizou um exame detalhado acerca dos modelos de aceitação de tecnologia, com foco no Modelo TAM. Dentre as principais críticas apresentadas, destacam-se (SACCOL, 2005, p. 74-78):

- Caráter individualista do modelo, tendo em vista o foco na decisão individual de adotar a tecnologia;

- Visão utilitarista da tecnologia, deixando de lado questões sociais e emocionais;

- Viés pró-tecnologia, que consiste na percepção de que a tecnologia deve ser adotada e que resistências à adoção são consideradas problemas a serem solucionados;

- Dificuldade do modelo em prever o uso de tecnologia em diferentes contextos;

- Excesso de simplificação do modelo em relação à realidade;

- Abordagem incompleta sobre a interação da tecnologia com as pessoas e com as organizações, não considerando a ação humana para desenvolver, apropriar-se e modificar a tecnologia;

- Utilização de percepções individuais em relação à tecnologia ao invés do comportamento efetivo;

- Limitações metodológicas, ligadas à falta de avaliação do uso efetivo do sistema em relação à intenção de uso e à realização de estudos cross-sectional e estudos longitudinais com tempo máximo de avaliação de 3 meses, considerado insuficiente.

As críticas apontadas por Saccol (2005) devem ser consideradas com cautela. Primeiramente, é importante notar que dos autores utilizados como base para a crítica, apenas dois se referem especificamente o Modelo TAM (TAYLOR; TODD, 1995; MATHIESON, 1991) e estes são anteriores à publicação do TAM2 (VENKATESH; DAVIS, 2000), que incorporou melhorias ao modelo, com destaque justamente para a inclusão dos construtos relacionados ao aspecto social. Os demais autores utilizados tratam da metodologia da pesquisa em ciências sociais (CROTTY, 1998) e de pesquisas em sistemas de informação (ORLIKOWSKI; BAROUDI, 1991; ORLIKOWSKI, 1992; DEVARAJ; KOHLI, 2000; MAHMOOD; MANN, 2000).

O caráter individualista do Modelo TAM, que analisa a decisão individual de adotar a tecnologia, não se configura como uma crítica ao modelo per si, mas ao foco de análise do 
modelo; a decisão individual de adotar uma inovação envolve fatores diferentes da decisão organizacional, sendo que o pesquisador deve definir o modelo mais adequado ao seu objetivo de pesquisa.

Além disso, a importância do constructo Utilidade no Modelo TAM, criticado por apresentar uma visão utilitarista, está coerente com o contexto atual das organizações, que buscam a maximização do retorno sobre os investimentos em um ambiente de forte concorrência.

Com relação à dificuldade do modelo adequar-se a diferentes contextos, Taylor e Todd apontam para a "[...] necessidade de uma exploração mais ampla de outros fatores além daqueles sugeridos pelos tradicionais modelos de intenção e de inovação." ${ }^{„ 57}$ (1995, p. 171), fatores específicos da situação em questão. Na mesma linha, a necessidade de adaptação do modelo ao contexto e tecnologia em análise é apontada pelos próprios autores do Modelo TAM (DAVIS et al, 1989, p. 991) e também por outros autores da literatura sobre adoção de inovações (FRAMBACH; SCHILLEWAERT, 1999; TORNATZKY; FLEISCHER, 1990). De acordo com Davis et al, “A definição e medição dos constructos do modelo correspondem em especificidade às características do critério comportamental, assim as medidas de intenções, atitudes e crenças são escritas em relação aos elementos específicos do objetivo, ação e contexto [...]." ${ }^{, 58}(1989$, p. 991).

Por outro lado, algumas das críticas apresentadas por Saccol (2005) são limitações importantes do Modelo TAM e da forma como vem sendo aplicado. É o caso de algumas pesquisas sobre o Modelo TAM que não atribuem a importância adequada aos efeitos da influência social no uso da tecnologia (LEE, 2003, p. 116-117), aspecto que foi incorporado ao Modelo TAM2 e que demanda aprofundamento.

Além disso, a presença do viés pró-tecnologia tem sido observada entre as limitações dos estudos sobre adoção de tecnologias (DAVIS et al, 1989). Limitação também apontada Rogers (1995, p. 106-109), que propõe alternativas para superar o viés da pró-inovação,

\footnotetext{
57 “[...] need for a broader exploration of factors beyond those suggested by the traditional intention and innovation models."

58 "The definition and measurement of model constructs correspond in specificity to these characteristics of the behavioral criterion, so that the measures of intentions, attitudes, and beliefs are worded in reference to the specific target, action and context elements [...]."
} 
como: a condução de pesquisas enquanto a difusão da inovação está em andamento, o cuidado na escolha da inovação a ser pesquisada, o reconhecimento de que uma rejeição da inovação pode ser uma decisão racional e apropriada do ponto de vista individual e o aumento da compreensão sobre os motivos de adoção da inovação.

De acordo com Lee et al (2003, p.18), a limitação mais freqüentemente reportada nos estudos que utilizam o Modelo TAM refere-se ao levantamento de dados sobre o uso da tecnologia, que são informados pelo respondente, ao invés de ser utilizada a informação objetiva sobre o uso real, aspecto também mencionado por Saccol (2005). Outra limitação importante "é a tendência de examinar somente um sistema de informação com um grupo homogêneo de sujeitos em relação a uma única tarefa em determinado momento do tempo, levantando o problema de generalização de um estudo único"59 (LEE et al, 2003, p. 19).

\subsubsection{Adoção Organizacional de Inovações}

Até 1970, muitos estudos foram realizados com o objetivo de investigar as características da organização inovadora, embora muitas pesquisas tenham se limitado a transferir os modelos e as metodologias desenvolvidos para analisar a inovação individual (ROGERS, 1995, p. 377). Dentre as dificuldades encontradas nessas pesquisas é possível apontar:

- a identificação de correlações fracas entre as características da organização (variáveis independentes) e a pré-disposição para inovar (variável dependente), onde prédisposição para inovar (innovativeness) indica o "[...] grau em que um indivíduo ou outra unidade de adoção está entre os primeiros a adotar novas idéias em relação a outros membros do sistema [...]" $]^{\prime 60}$ (ROGERS, 1995, p. 252). Uma explicação para este resultado seria a possibilidade das variáveis relacionadas à estrutura, por exemplo, terem influenciado em uma direção durante as fases iniciais do processo de inovação e na direção oposta durante as fases de implementação (ROGERS, 1995, p. 381).

\footnotetext{
59 " [...] is the tendency to examine only one information system with a homogeneous group of subjects on a single task at a single point of time, thus raising the generalization problem of any single study"

60 "[...] degree to which an individual or other unit of adoption is relatively earlier in adopting new ideas than other members of a system [...]"
} 
- a limitação dos dados obtidos, normalmente levantados apenas a partir da visão do executivo principal de cada organização, torna muito difícil definir objetivamente o comportamento de toda a empresa (ROGERS, 1995, p. 378).

A Figura 9 apresenta as variáveis independentes relacionadas à predisposição organizacional para inovar, conforme proposto por Rogers (1995, p. 380). Os sinais $(+)$ e $(-)$ indicam a influência positiva ou negativa, respectivamente, das variáveis na pré-disposição organizacional para inovar. Verifica-se que a centralização e a formalização têm sido identificadas como inibidoras da inovação, enquanto que as demais variáveis tendem a facilitar a inovação.

\section{Variáveis independentes}

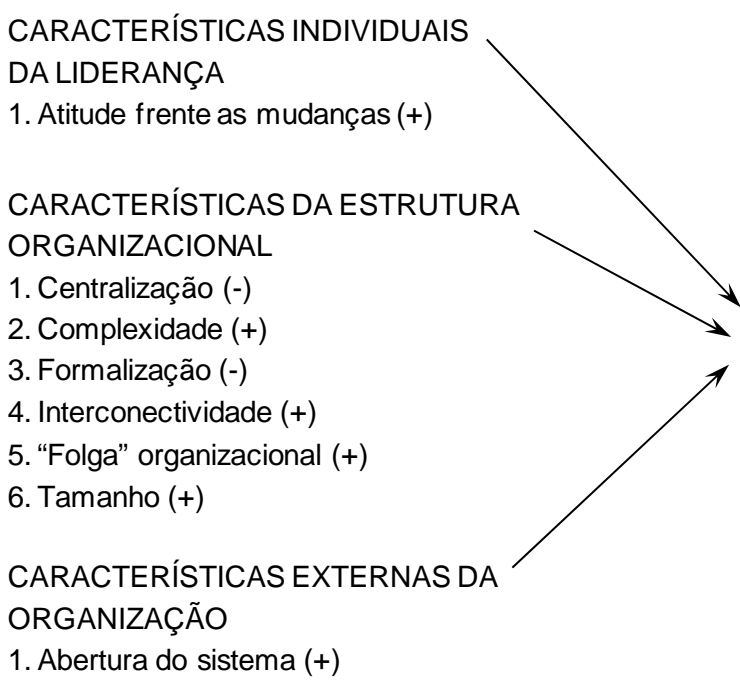

\section{Variável dependente}

DISPOSIÇÃOORGANIZACIONAL PARA INOVAR

Figura 9 - Variáveis Independentes Relacionadas à Predisposição Organizacional para Inovar FONTE: ROGERS, 1995, p. 380

Posteriormente, dá-se início a um novo tipo de pesquisa sobre difusão, com foco no processo de inovação organizacional. Na mesma linha do modelo apresentado anteriormente na Figura 3, desenvolvido por Tornatzky e Fleischer (1990), Rogers (1995) detalha as fases do processo de inovação na organização (Figura 10). 
PROCESSO DE INOVAÇÃO

NA ORGANIZAÇÃO

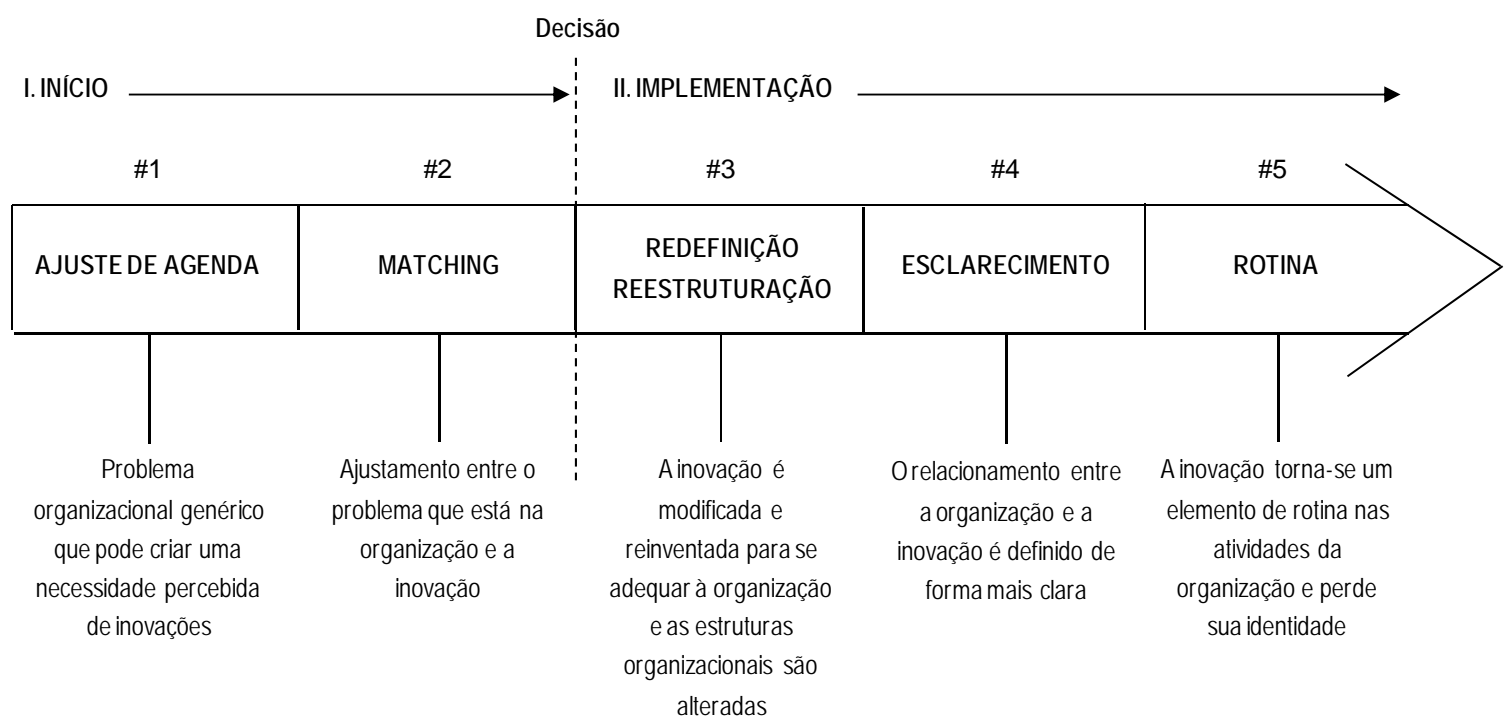

Figura 10 - Cinco Estágios do Processo de Inovação em uma Organização FONTE: ROGERS, 1995, p. 392

De acordo com Tornatzky e Fleischer, "Há três elementos do contexto de uma empresa que influenciam o processo através do qual esta adota e implementa inovações tecnológicas: contexto organizacional, contexto tecnológico e contexto ambiental"61 (1990, p.152), conforme apresentado na Figura 11.

61 "There are three elements of a firm's context that influence the process by which it adopts and implements technological innovations: organizational context, technological context, and environmental context" 


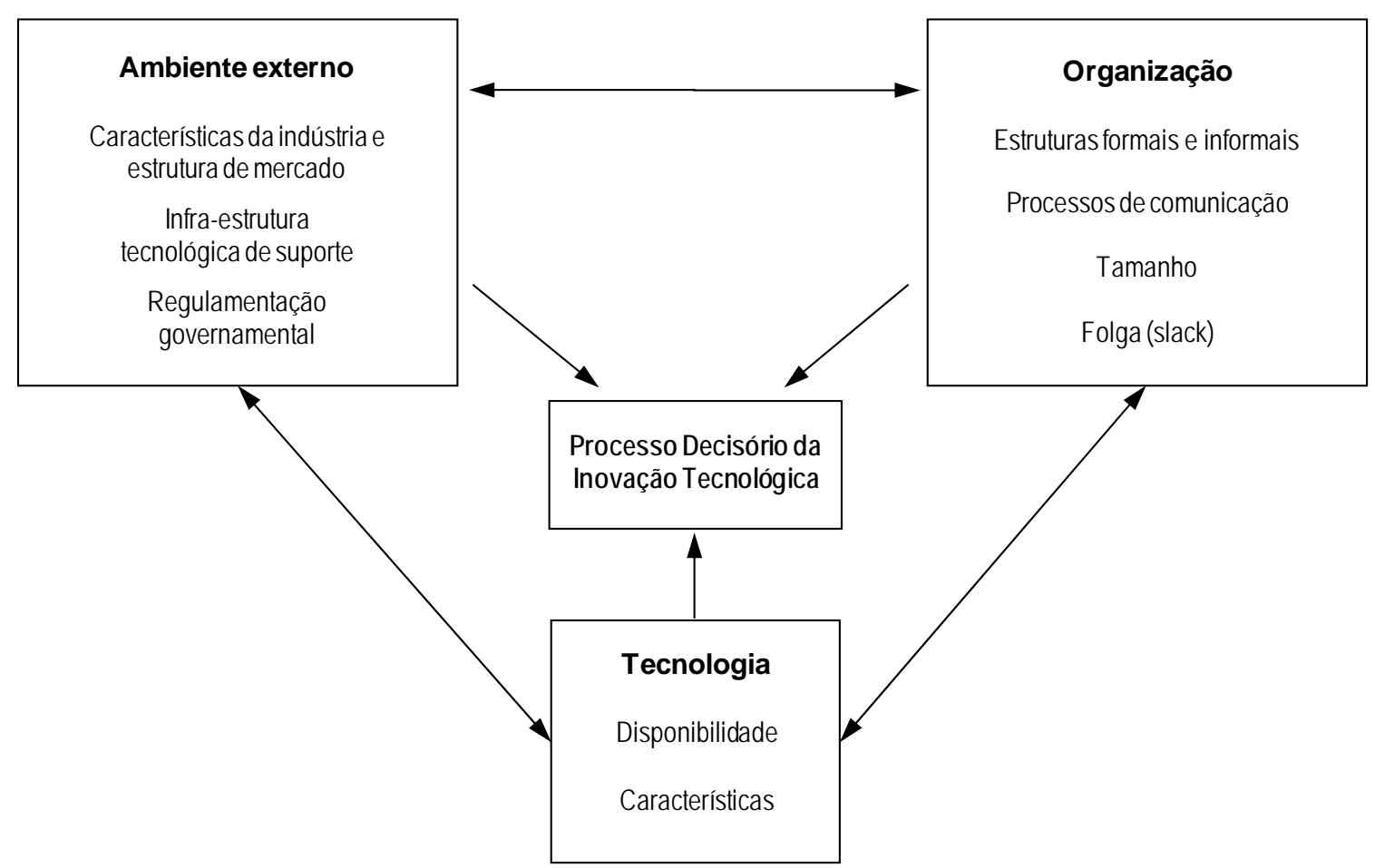

Figura 11 - O Contexto da Inovação Tecnológica

FONTE: TORNATZKY; FLEISCHER, 1990, p.153

Na mesma linha, Meyer e Goes (1988, p. 901) afirmam que "três fatores determinam a assimilação de inovações tecnológicas em organizações: atributos das inovações, atributos dos contextos organizacionais e atributos provenientes da interação entre as inovações e os contextos" $^{\text {"62 }}$, chamado de atributos da decisão de inovação.

Com base no Modelo de Assimilação da Inovação (Figura 12), os autores investigaram, durante seis meses, a difusão de 12 inovações médicas em 25 hospitais. Os resultados da pesquisa indicaram que o modelo proposto permite explicar razoavelmente bem a assimilação de uma inovação por determinado hospital (59\% da variância), com destaque para os seguintes aspectos (MEYER e GOES, 1988, p. 914-915):

- Os atributos do contexto examinados (líderes, estruturas e mercado) foram insuficientes na previsão da assimilação das inovações; apesar disso, os hospitais que serviam ambientes urbanos e eram de tamanho relativamente grande, com estrutura

62 "[...] three factors determine the assimilation of technological innovations into organizations: attributes of innovations, attributes of organizational contexts, and attributes arising from the interaction of innovations and contexts [...]" 
complexa e estratégias de mercado agressivas tiveram maior propensão a assimilar inovações.

- As inovações médicas examinadas apresentaram atributos que afetaram sua adoção (explicando aproximadamente $40 \%$ da variância), sendo que aquelas altamente visíveis, de baixos riscos e que demandavam relativamente poucas habilidades para usar foram assimiladas mais facilmente que outras inovações.

- A interação entre as inovações e os contextos melhorou significativamente a previsibilidade do modelo, com destaque para algumas variáveis que facilitam a assimilação: patrocínio do CEO, compatibilidade com padrões existentes da especialização médica, maior número de beneficiados pela inovação, habilidade e realização de treinamento recentemente.

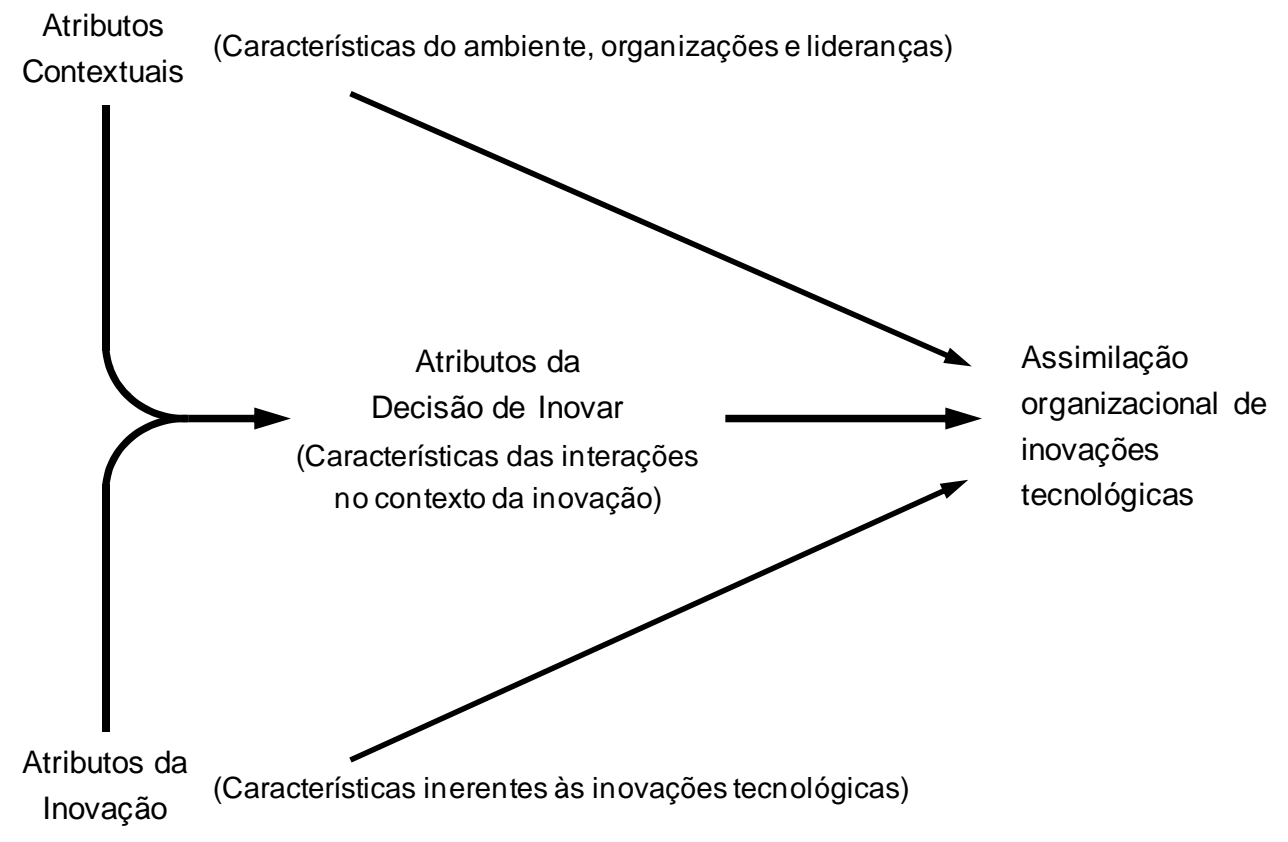

Figura 12 - Modelo de Assimilação da Inovação FONTE: MEYER; GOES, 1988, p. 901

Meyer e Goes (1988) também definem o processo de assimilação de inovações médicas em três estágios decisórios e nove sub-estágios (Quadro 3). 


\section{Quadro 3 - Estágios Decisórios na Assimilação de Inovações Médicas}

\section{Estágio de Prontidão-Conhecimento}

1. Apreensão. Membros da organização aprendem a respeito da inovação.

2. Consideração. Membros consideram a inovação é adequada à organização.

3. Discussão. Os indivíduos estabelecem um canal de diálogo sobre aspectos relativos à adoção.

4. Proposta de aquisição. A aquisição do equipamento que contém a inovação é proposta formalmente.

5. Avaliação Médico-fiscal. A proposta de investimento é avaliada de acordo com parâmetros médicos e financeiros.

6. Avaliação Político-estratégica. O investimento proposto é avaliado de acordo com critérios políticos e estratégicos.

7. Teste. O equipamento é adquirido, mas ainda em período de teste.

8. Aceitação. O equipamento torna-se aceito e utilizado com freqüência.

9. Expansão. O equipamento é expandido, recebe atualização de configuração ou é substituído pelo de geração seguinte

FONTE: MEYER; GOES, 1988, p. 903

Considerando as variáveis que influenciam a decisão de adoção e as etapas do processo, Frambach e Schillewaert propuseram um "modelo multi-nível de adoção organizacional de inovações que incorpora determinantes de ambos os níveis, organizacional e individual",63 (1999, p. 3), conforme apresentado nas Figuras 13 e 14. Diferentemente da abordagem proposta por Rogers (Figura 4), os autores analisam a aceitação individual de inovação especificamente no contexto organizacional, também chamada de aceitação intraorganizacional, etapa considerada essencial para o sucesso da inovação, após a decisão organizacional de adoção (FRAMBACH; SCHILLEWAERT, 1999, p. 5).

63 "multi-level model of organizational innovation adoption that incorporates determinants at both the organizational and the individual level" 


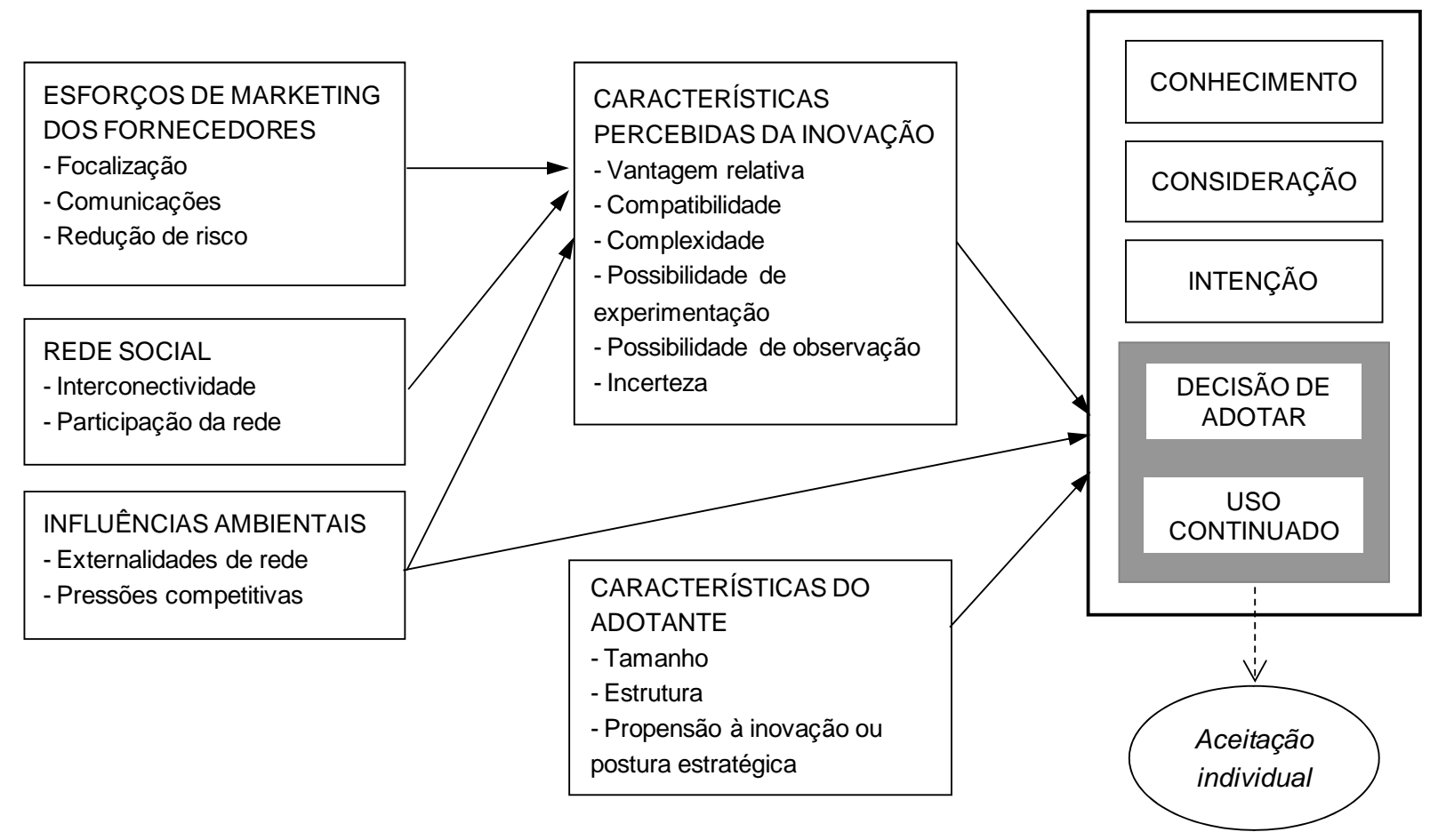

Figura 13 - Estrutura Conceitual da Adoção Organizacional de Inovações FONTE: FRAMBACH; SCHILLEWAERT, 1999, p. 34.
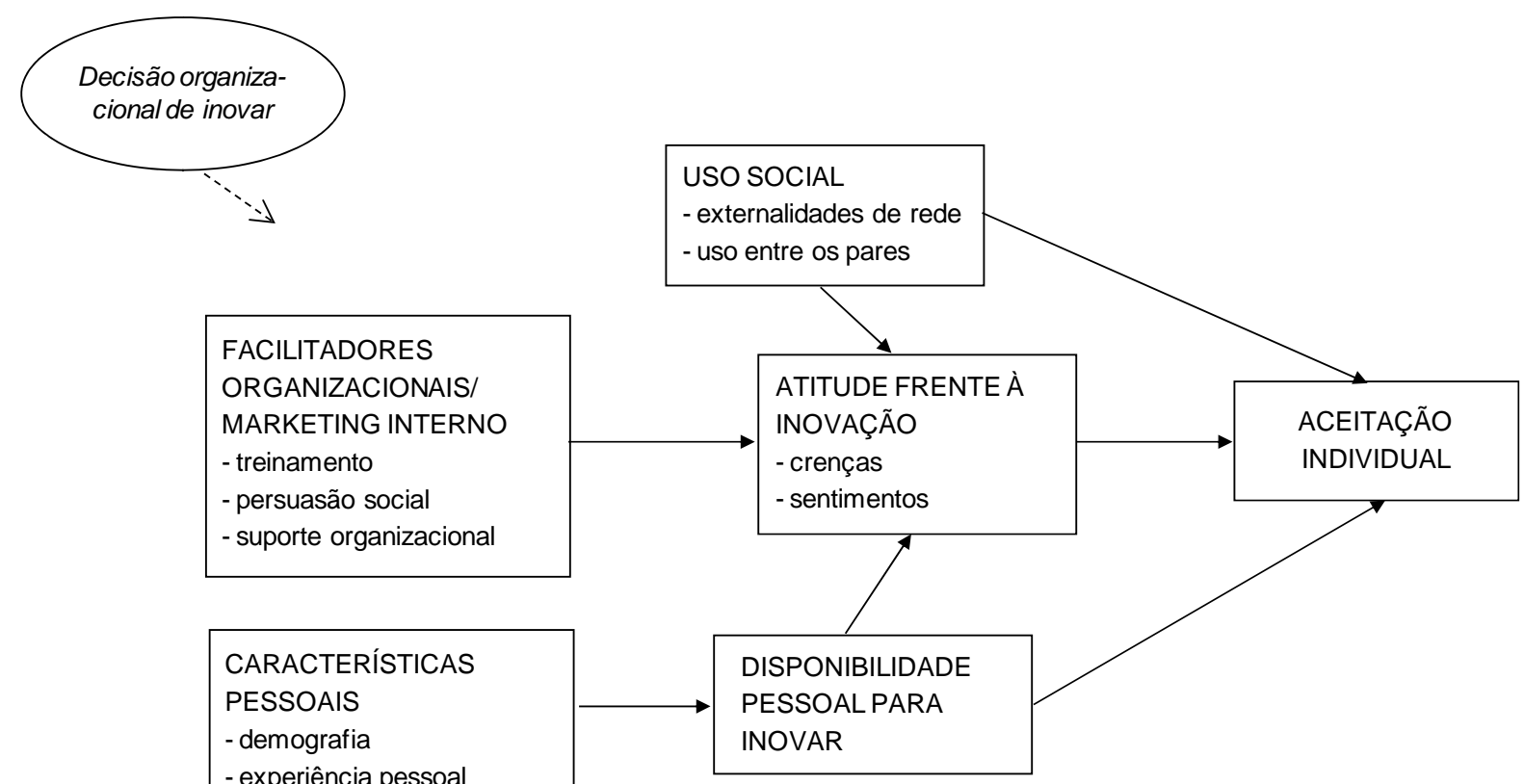

- experiência pessoal

- experiência com o produto

- valores pessoais

Figura 14 - Estrutura Conceitual da Aceitação Individual de Inovações em Organizações FONTE: FRAMBACH; SCHILLEWAERT, 1999, p. 36 


\title{
Cultura Organizacional e Inovação
}

De acordo com Henrich (2001, p. 1007), a cultura do grupo desempenha papel relevante na difusão de inovações, influenciando o aprendizado em relação ao custo-benefício da inovação e, consequentemente, o comportamento de adoção. Variáveis que podem ser relacionadas com a cultura organizacional estão presentes nos modelos já apresentados: natureza do sistema social (ROGERS, 1995), norma subjetiva (VENKATESH; DAVIS, 2000), influência social (VENKATESH et al, 2003, SCHILLEWAERT et al, 2000), redes sociais (FRAMBACH; SCHILLEWAERT, 1999), características da organização adotante (ROGERS, 1995; FRAMBACH; SCHILLEWAERT, 1999), estruturas e processos de comunicação (TORNATZKY; FLEISCHER, 1990). Além disso, a cultura organizacional é considerada um fator relevante para o sucesso do e-learning (PRICEWATERHOUSECOOPERS, 2001; EBOLI, 2004, p. 151).

O conceito elaborado por Edgard Schein, utilizado por muitos estudos sobre o tema, define a cultura de um grupo como

\begin{abstract}
Um padrão de pressupostos básicos (basic assumptions) que o grupo aprendeu na medida em que resolveram seus problemas de adaptação externa e integração interna, que funcionaram bem o suficiente para serem considerados válidos e serem ensinados a novos membros como a forma correta de perceber, pensar e sentir em relação a esses problemas. (SCHEIN, 1992, p. 12).
\end{abstract}

Fleury, partindo desse conceito de Schein, complementa:

\footnotetext{
“cultura organizacional é concebida como um conjunto de valores e pressupostos básicos expresso em elementos simbólicos, que em sua capacidade de ordenar, atribuir significações, construir a identidade organizacional, tanto agem como elemento de comunicação e consenso, como ocultam e instrumentalizam as relações de dominação" (FLEURY, 1992, p. 22).
}

Embora existam divergências em relação à definição de cultura organizacional ou corporativa, a maioria dos autores provavelmente concordaria que esta é historicamente determinada, socialmente construída e difícil de mudar (HOFSTEDE et al, 1990, p. 286). Reforçando a importância da mudança cultural, Coelho Junior e Borges-Andrade constataram que "[...] as 
variáveis antecedentes mais freqüentemente estudadas em percepção de cultura organizacional relacionam-se à investigação do processo de mudança nas organizações." (2004, p. 195).

Especificamente em relação à inovação, uma pesquisa realizada pela American Management Association \& Human Resource Institute, em 2005, buscou identificar características de uma cultura inovadora, com base na opinião de 1.356 respondentes de várias partes do mundo (JAMROG et al, 2006, p. 12). A Tabela 1 apresenta fatores que influenciam uma cultura inovadora, ordenados a partir da importância atribuída pelos respondentes, hoje e em 10 anos, do mais importante ( $1^{\circ}$ lugar $)$ para o menos importante $\left(14^{\circ}\right.$ lugar $)$.

Tabela 1 - Ordem de Importância dos Fatores para Desenvolvimento de uma Cultura Inovadora

\begin{tabular}{lcc}
\hline Fatores & Hoje & $\begin{array}{c}\text { Daqui a } \\
\mathbf{1 0} \text { anos }\end{array}$ \\
\hline Foco no cliente & 1 & 1 \\
\hline Colaboração & 2 & 2 \\
\hline Recursos apropriados (tempo e dinheiro) & 3 & 6 \\
\hline Comunicação organizacional & 4 & 3 \\
\hline Habilidade de selecionar idéias corretas para pesquisa & 5 & 4 \\
\hline Habilidade para identificar pessoas criativas & 6 & 5 \\
\hline Liberdade para inovar & 7 & 7 \\
\hline Habilidade para medir os resultados da inovação & 8 & 8 \\
\hline Encorajamento tanto de pequenas quanto grandes idéias & 9 & 9 \\
\hline Sentimento de posse sobre a inovação/Estabelecimento de metas & 10 & 10 \\
\hline Cultura de tolerância ao risco & 11 & 12 \\
\hline Estruturas organizacionais & 12 & 11 \\
\hline Diversidade & 13 & 13 \\
\hline Balanço entre melhorias incrementais e disruptivas & 14 & 14 \\
\hline
\end{tabular}

FONTE: JAMROG et al, 2006, p. 12

A pesquisa realizada por Twati e Gmmack (2006) identificou uma relação entre a cultura organizacional e a adoção de sistemas de informação, com base na análise de 15 organizações governamentais da Líbia.

Relacionando cultura e aprendizagem, a pesquisa realizada por Guimarães e Cartaxo “[...] teve como objetivo investigar, segundo a percepção de atores internos, o tipo de ambiente de aprendizagem organizacional existente no Estado-Maior do Exército (EME).” (2002, p. 1-2), através da avaliação de seis fatores: (a) visão compartilhada; (b) relacionamento, comunicação e trabalho em equipe; (c) ação monitorada; (d) visão sistêmica; (e) fluxo das informações e (f) receptividade à inovação. 
Já Hornik e Tupchiy (2006) investigaram o impacto de valores culturais do indivíduo na efetividade da aprendizagem mediada por tecnologia, com destaque para os aspectos individual e coletivo. A pesquisa foi realizada através da aplicação de questionários a alunos de um curso virtual, totalizando 524 respondentes. Os resultados indicaram que, embora os quatro padrões culturais apresentem aspectos positivos, indivíduos HC (Horizontal Collectivism $^{64}$ ) se adequaram melhor ao ambiente virtual. Esta pesquisa discute uma questão importante: o modelo de e-learning utilizado. Nesse caso, tratava-se de um modelo com ênfase na comunicação assíncrona, de forma que os resultados poderiam ser diferentes em outros tipos de cursos. O próximo tópico abordará aspectos específicos relacionados à adoção do e-learning.

\subsection{Implementação do e-Learning}

$\mathrm{Na}$ legislação brasileira, educação a distância é definida no Decreto $\mathrm{N}^{0} 5.622$, de 19 de dezembro de 2005, que regulamenta o Art. 80 da LDB,

[...] como modalidade educacional na qual a mediação didático-pedagógica nos processos de ensino e aprendizagem ocorre com a utilização de meios e tecnologias de informação e comunicação, com estudantes e professores desenvolvendo atividades educativas em lugares ou tempos diversos (BRASIL, 2005, p. 1).

Desta forma, o e-learning pode ser considerado uma modalidade de educação a distância, que utiliza as "[...] tecnologias da Internet para fornecer um amplo conjunto de soluções que melhoram o conhecimento e o desempenho" (ROSENBERG 2002, p. 25).

Com o objetivo de fornecer uma visão geral da área, Stacey elaborou a Cadeia de Valor do eLearning, indicando os diferentes focos de atuação das empresas atuantes e os principais mercados (Figura 15). 64 "Horizontal collectivists merge with in-groups [...]; the well-being of their in-groups is important to them.
However; they do no feel subordinate to their in-groups" (CHIOU, 2001, p. 668). 


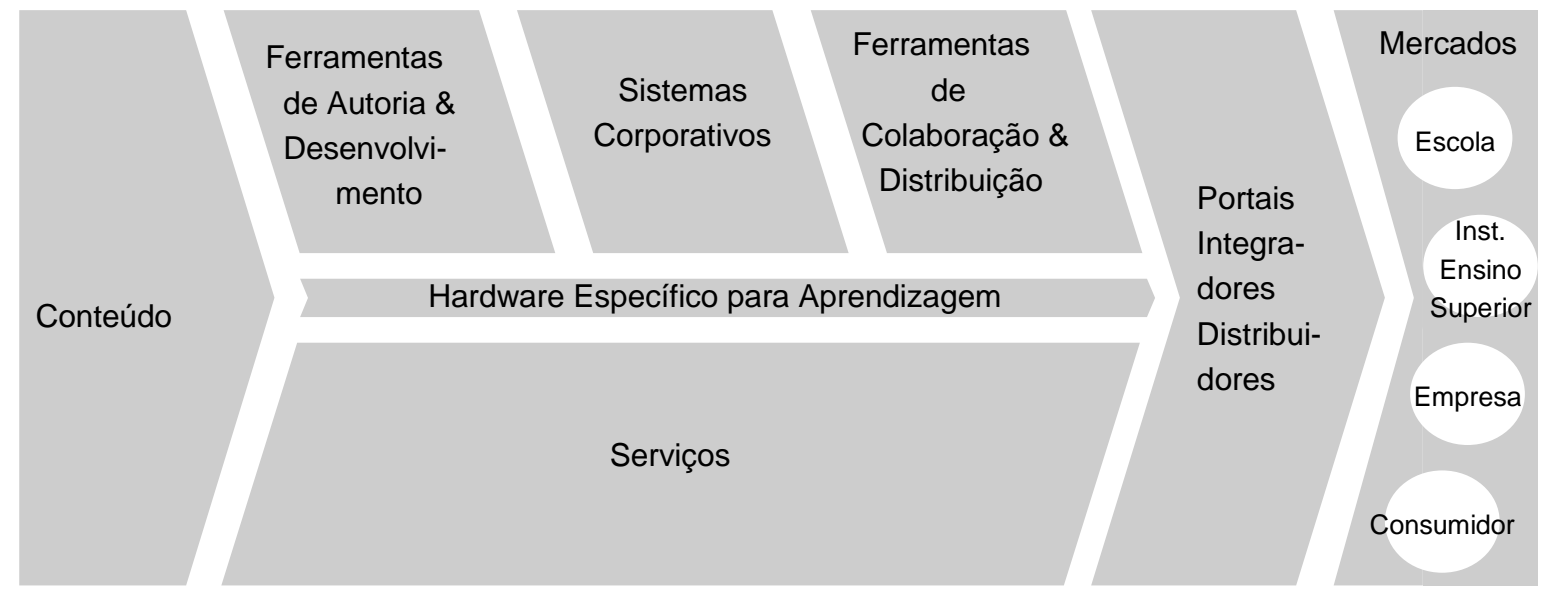

Figura 15 - Cadeia de Valor do e-Learning FONTE: STACEY, 2001

\subsubsection{O e-Learning na Empresa}

O principal objetivo da utilização do e-learning na empresa deve ser “[...] criar ou aumentar o valor para o acionista - o crescimento da companhia em lucratividade e valor no mercado através da ligação entre a iniciativa de e-learning e os direcionadores do negócio [...]"65 (Van DAM, 2004, p. 9). As organizações têm utilizado o e-learning para atingir diversos objetivos de negócio, entre os quais (Van DAM, 2004, p. 9):

- Reduzir o tempo para lançamento de novos produtos e serviços;

- Implementar com rapidez novos sistemas de informação e processos de negócio;

- Atender a normas legais e regulatórias;

- Integrar novos funcionários na organização;

- Criar uma forte cultura organizacional e integrar a força de trabalho global;

- Aprimorar a liderança e a geração de novos negócios;

- Aumentar vendas através do desenvolvimento da força de vendas;

- Reter consumidores e fornecedores através de treinamento sobre produtos e serviços.

Rosenberg (2006, p. 2) indica que as organizações direcionam seus esforços de e-learning segundo três diferentes enfoques, em função dos objetivos do negócio (Quadro 4).

\footnotetext{
65 “[...] create or enhance the shareholder value - the company's growth in profitability and value $n$ the
} marketplace - by linking the e-learning initiative to the business drivers" 
Quadro 4 - Alternativas de Foco do Esforço de E-Learning na Organização

\begin{tabular}{|c|c|c|}
\hline Foco & Características & Indicadores de Sucesso \\
\hline Quantidade & $\begin{array}{l}\text { Necessidade de começar com alguma iniciativa de e-learning, } \\
\text { através do oferecimento de cursos (migração de cursos } \\
\text { presenciais e compra de cursos prontos) e do investimento na } \\
\text { tecnologia para disponibilizá-los. }\end{array}$ & $\begin{array}{l}\text { O sucesso é medido em } \\
\text { função do quanto é realizado, } \\
\text { com que rapidez e do número } \\
\text { de cursos oferecidos. }\end{array}$ \\
\hline $\begin{array}{l}\text { Custo- } \\
\text { benefício }\end{array}$ & $\begin{array}{l}\text { Necessidade de fazer melhor. Quantidade não é mais uma } \\
\text { medida de sucesso viável, se não levar em consideração a } \\
\text { qualidade e o impacto. } \\
\text { Identificação dos programas de e-learning de maior custo- } \\
\text { benefício, mesmo que resulte na eliminação de outros. }\end{array}$ & \multirow[t]{2}{*}{$\begin{array}{l}\text { O sucesso está focado na } \\
\text { aplicação inovadora de } \\
\text { estratégias instrucionais e na } \\
\text { obtenção de altas taxas de } \\
\text { custo-benefício. }\end{array}$} \\
\hline & $\begin{array}{l}\text { Aumento da experimentação de novas formas de desenho e } \\
\text { entrega do curso, incluindo soluções mistas com presencial e } \\
\text { a implementação de salas de aula virtuais. }\end{array}$ & \\
\hline $\begin{array}{l}\text { Solução de } \\
\text { aprendizagem }\end{array}$ & $\begin{array}{l}\text { Necessidade de apoiar a aprendizagem no trabalho e o } \\
\text { desempenho em toda organização. A ênfase do e-learning é } \\
\text { alterada do desempenho do treinamento para o desempenho } \\
\text { do negócio. } \\
\text { O objetivo é ir além da aprendizagem formal, incluindo } \\
\text { também a aprendizagem informal, e desenhar soluções mais } \\
\text { adequadas que abrangem treinamento, compartilhamento de } \\
\text { conhecimento, colaboração e melhoria do desempenho no } \\
\text { contexto do trabalho. }\end{array}$ & $\begin{array}{l}\text { As métricas que importam } \\
\text { são as do negócio, como } \\
\text { produtividade, satisfação do } \\
\text { consumidor e do funcionário, } \\
\text { agilidade organizacional e } \\
\text { desempenho no mercado. }\end{array}$ \\
\hline
\end{tabular}

FONTE: Baseado em ROSENBERG, 2006, p.2

Embora esses três enfoques não indiquem uma seqüência, o oferecimento de soluções de aprendizagem é a tendência moderna, refletindo o alinhamento das iniciativas de e-learning com o negócio. Desta forma, conforme a necessidade, devem ser utilizadas diferentes tecnologias, ferramentas e metodologias para oferecer uma solução de aprendizagem efetiva, podendo incluir ações de treinamento formais (aulas presenciais e on-line) e outras ações de aprendizagem, tais como: soluções de apoio ao desempenho (guias de referência rápida, sistemas de assistência), soluções de gestão do conhecimento (comunidades e redes, repositórios de informações e contato com especialistas) e ainda apoio através de aconselhamento e aconselhamento profissional (Van DAM, 2004, p. 11; ROSENBERG, 2006, p. 83).

De acordo com Van Dam, “o desenho de um curso híbrido parece melhorar muito a aceitação do usuário"66 (2004, p. 98). Esse modelo, também chamado de blended learning, é considerado uma importante tendência pelos especialistas da área (ECONOMIST 
INTELLIGENCE UNIT; IBM, 2003, p.10). Conforme apontado por Singh “As organizações precisam usar uma combinação de abordagens de aprendizagem [...]. Blended learning combina mídias diversas para disponibilizar [o conteúdo], planejadas para se complementarem e promoverem o aprendizado [...]" (2003, p. 52). Desta forma, o desafio dos gestores do conhecimento consiste em combinar as diferentes estratégias didáticas (como por exemplo: sala de aula presencial, materiais impressos, CD-Rom, vídeos, páginas web, elearning auto-instrucional, webconferência, comunidades virtuais, tutoria e aconselhamento) tendo em vista as diversas variáveis intervenientes, entre as quais as características particulares do público-alvo, os objetivos de aprendizagem, os recursos disponíveis e seu custo e a natureza do conteúdo.

\subsubsection{Barreiras e Prontidão para a Implementação do e-Learning}

O Quadro 5 resume os principais benefícios e problemas envolvidos na utilização do $e$ learning, fatores esses que poderão estar mais ou menos presentes, dependendo do contexto e da forma de utilização.

66 "A blended course design appears to greatly improve user acceptance [...]” 
Quadro 5 - Benefícios e Problemas do e-Learning

\begin{tabular}{|c|c|c|}
\hline $\begin{array}{c}\text { Categoria de } \\
\text { Análise }\end{array}$ & Benefícios & Problemas \\
\hline $\begin{array}{l}\text { Recursos } \\
\text { financeiros }\end{array}$ & $\begin{array}{l}\text { - Redução de custos com viagens, tempo } \\
\text { de deslocamento e infra-estrutura } \\
\text { - Ganhos com custo de oportunidade do } \\
\text { aluno decorrente da menor duração do } \\
\text { curso } \\
\text { - } \quad \begin{array}{l}\text { Aumento do }{ }^{\circ} \text { de alunos com baixo } \\
\text { custo incremental }\end{array}\end{array}$ & $\begin{array}{ll}\text { - } & \text { Alto investimento inicial } \\
\text { - } & \text { Investimento em equipamentos } \\
\text { - } & \text { Estrutura para atendimento ao aluno } \\
\text { - } & \text { Alto custo envolvido com moderação } \\
\text { (comunicação mediada por } \\
\text { computador) } \\
\text { - } & \text { Consideração de custos ocultos }\end{array}$ \\
\hline Gestão do curso & 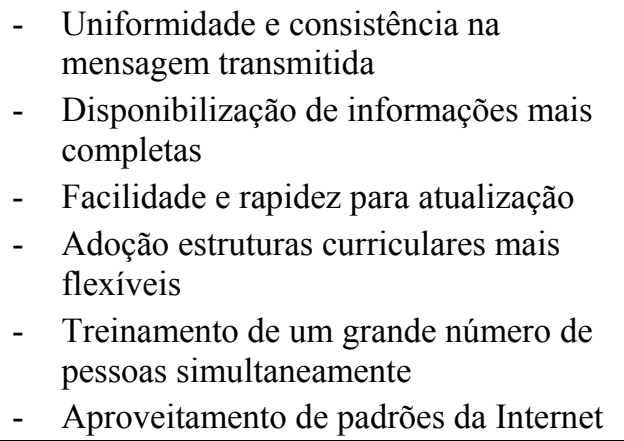 & $\begin{array}{l}\text { - Falta de preparo dos professores } \\
\text { - Aumento da dedicação do professor } \\
\text { - Falta de clareza do conteúdo do curso } \\
\text { - }\end{array}$ \\
\hline $\begin{array}{l}\text { Dinâmica do } \\
\text { grupo }\end{array}$ & $\begin{array}{l}\text { - Integração de pessoas distantes } \\
\text { geograficamente } \\
\text { - Construção de comunidades virtuais }\end{array}$ & $\begin{array}{l}\text { - Limitação do aspecto social do } \\
\text { aprendizado } \\
\text { - Sentimento de isolamento e solidão }\end{array}$ \\
\hline Aluno & 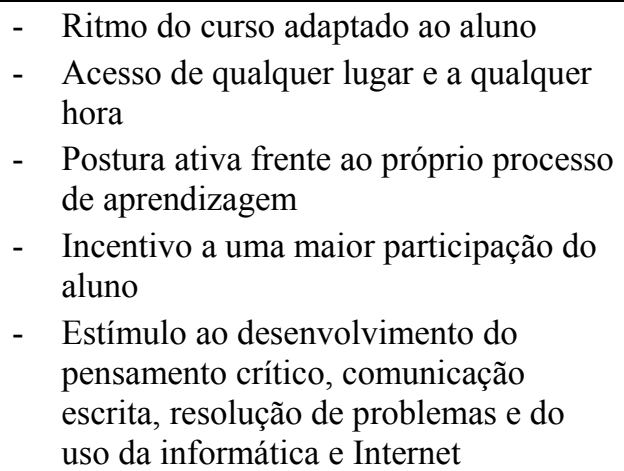 & $\begin{array}{ll}\text { - } & \text { Dificuldade de leitura e interpretação } \\
& \text { de textos } \\
\text { - } & \text { Manutenção da postura passiva } \\
\text { - } & \text { Medo da mudança } \\
\text { - } & \text { Dificuldade para usar a tecnologia } \\
\text { - } & \text { Baixa velocidade de digitação } \\
\text { - } & \text { Limitações no acesso à Internet } \\
\text { - } & \text { Falta de tempo }\end{array}$ \\
\hline
\end{tabular}

Relacionados a estes benefícios e problemas estão os facilitadores e barreiras da implementação do e-learning.

Conforme já comentado, a cultura organizacional pode atuar como uma barreira importante na implementação do e-learning. Segundo a pesquisa da PricewaterhouseCoopers (2001), Pessoas e Cultura foi a barreira mais significativa, seguida de barreiras relacionadas à Estratégia, Processos e Tecnologia (Figura 16). Dentre as razões apresentadas pela pesquisa para esse resultado estão o medo da mudança, a necessidade de atuação pró-ativa (ao invés de passiva) e a baixa alfabetização digital dos funcionários das empresas pesquisadas. 


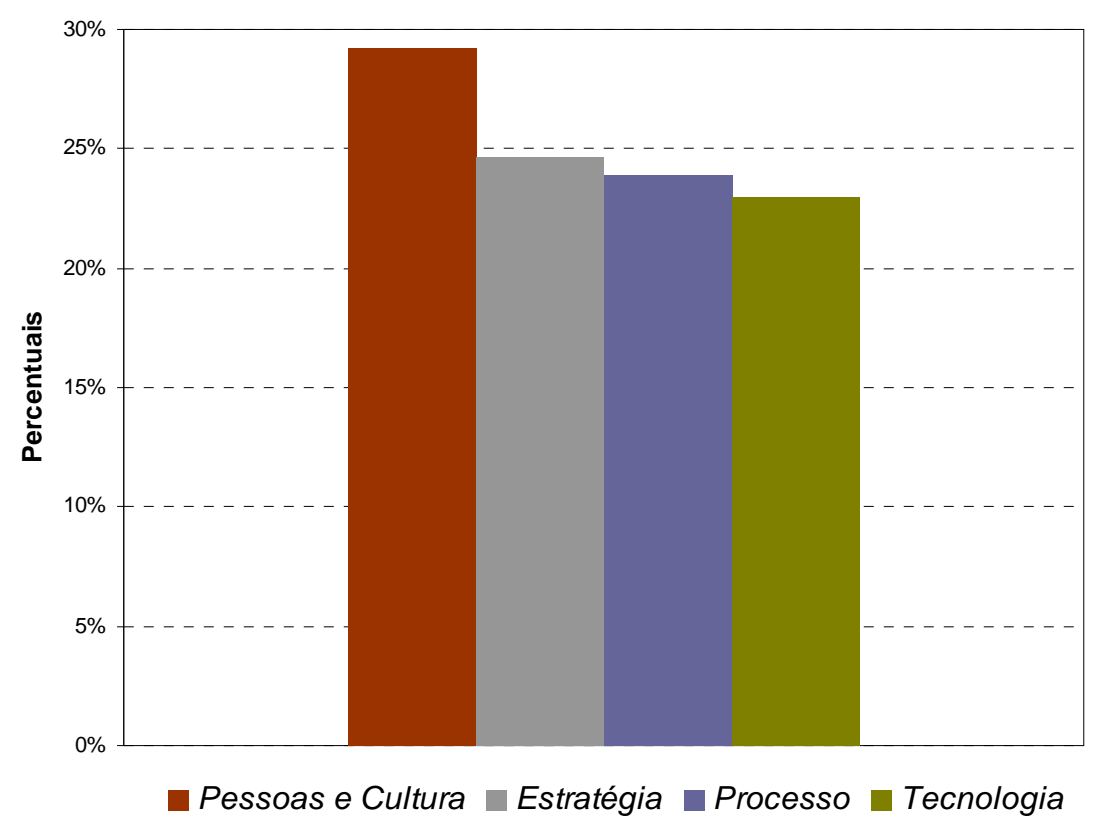

Figura 16 - Barreiras para a Implementação do $\boldsymbol{e}$-Learning FONTE: PRICEWATERHOUSECOOPERS, 2001

Tyan (2003), em sua pesquisa sobre difusão do e-learning em empresas de Taiwan, agrupou as barreiras analisadas em quatro fatores: (a) prontidão organizacional; (b) maturidade do $e$ learning; (c) custo de adoção e (d) apoio governamental. O autor realizou uma pesquisa com 132 respondentes, incluindo fornecedores de plataformas de e-learning, agências governamentais e empresas. Os resultados indicaram que todos os trinta aspectos analisados são barreiras relevantes na difusão do e-learning (vide Anexo A), sendo que as dez barreiras mais importantes estão relacionadas aos fatores considerados mais significativos: (a) prontidão organizacional ("grau em que a corporação é capaz de adotar o e-learning considerando as limitações atuais de orçamento, conhecimento, habilidade com computador, equipamentos, estilo de aprendizagem, cultura e estrutura" ${ }^{, 67}$ ) e (b) maturidade do e-learning ("grau em que o e-learning pode satisfatoriamente, eficientemente e efetivamente preencher as necessidades de treinamento das corporações" ${ }^{\text {"68 }}$ ), conforme indicado entre parênteses (TYAN, 2003, p. 69-75):

1. Falta de conhecimento sobre a gestão de sistemas de e-Learning (a);

67 “[...] degree to which a corporation is capable of adopting e-Learning based on its current constraints of budget, knowledge, computing skills, equipment, learning style, culture, and structure" (TYAN, 2003, p. 75) 
2. Falta de profissionais capacitados para desenvolver e-Learning (b);

3. Produtos e serviços oferecidos por fornecedores são insatisfatórios (b);

4. Adoção limitada para possibilitar economia de escala (a);

5. Redução no orçamento de treinamento (b);

6. Incerteza em relação ao custo/benefício do e-Learning (b);

7. Falta de cursos de e-learning disponíveis (a);

8. Treinamento não é valorizado na organização (b);

9. Baixa compatibilidade entre o e-learning e os sistemas de TI (a);

10. Processo de implementação do e-learning é muito demorado (a).

A pesquisa também indicou que as seguintes características dos respondentes influenciaram a avaliação das barreiras: “(1) status de adoção do e-learning na organização: não-adotantes significativamente classificaram o Custo de Adoção como uma barreira mais importante do que os adotantes" "69; “(2) experiência pessoal com e-learning: participantes experientes atribuíram significativamente maior importância aos quatro grupos de barreiras do que participantes não-experientes"70; “(3) otimismo em relação ao e-learning: respondentes otimistas significativamente consideraram o Suporte Governamental como uma barreira maior que os pessimistas"71 (TYAN, 2003, p. 90).

De acordo com Downes, "a adoção do e-learning tornou-se dramaticamente mais lenta a partir de 2002, por várias razões" (2003), dentre elas: cultura organizacional e gestão da mudança ("as pessoas precisam de fato usar o e-learning"72), dificuldades de aceitação pelo aprendiz ("eles testaram o e-learning e detestaram"73), custos de desenvolvimento de conteúdo e de implementação, prioridades de treinamento, limitações de orçamento e dificuldades tecnológicas (Ibid.).

\footnotetext{
68 " [...] degree to which e-Learning can satisfactorily, efficiently, and effectively fulfill the training needs of corporations" (TYAN, 2003, p. 73)

69 "(1) Organizational e-Learning adoption status: non-adopters significantly rated the Cost of Ownership a greater barrier than adopters did"

70 "(2) Personal e-Learning experience: Experienced participants significantly rated all four Barrier Constructs greater barriers than non-experienced participants"

71 "(3) Optimism toward e-Learning: optimistic participants significantly rated Government Support as a greater barrier than pessimistic participants"

72 "people need to actually use e-learning"

73 "they tried e-learning, they hated it"
} 
Testa (2002), com base em nove entrevistas realizadas com especialistas e dois estudos de casos, identificou seis fatores críticos de sucesso para programas de educação a distância $(\mathrm{EaD})$ via Internet:

- Capacitação e experiência da equipe: "as pessoas envolvidas [...] devem ter experiência em educação a distância ou receber treinamento específico";

- Envolvimento dos membros da organização: "buscar o apoio de todas as pessoas da organização. E todos os membros da equipe, incluindo professores, deverão estar realmente envolvidos nas atividades do programa";

- Conhecimento e preocupação com as características e comportamento do estudante: "conhecer seus estudantes, para poderem desenvolver ações com o objetivo de atender suas necessidades, auxiliá-los na ambientação à Internet e a na disciplina para realizar as exigências dos cursos a distância, e evitar que se sintam abandonados ou isolados";

- Modelo pedagógico: “definir um projeto pedagógico, baseado na interação e colaboração, tendo especial cuidado com o design instrucional, evitando excessiva padronização e respeitando os fatores culturais dos estudantes";

- Tecnologia: "evitar focar na tecnologia, apesar de ser fundamental a avaliação da infra-estrutura tecnológica e dos softwares que compõe o ambiente de aprendizagem";

- Realização de parcerias (terceirização): "buscar parcerias estratégicas ou terceirizar parte de suas atividades" (2002, p. 103-105).

Ao analisar a implementação do e-learning, a identificação dos fatores que definem a prontidão organizacional é uma das mais importantes chaves para o sucesso. A pesquisa realizada em 2003 pela Economist Intelligence Unit e pela IBM para avaliar a prontidão do $e$ learning em 60 países utilizou 4 dimensões de análise:

- "Conectividade (a qualidade e amplitude da infra-estrutura de Internet),

- Capacidade (a habilidade do país para entregar e consumir e-learning, baseada em taxa de alfabetização e tendências no treinamento e educação),

- Conteúdo (a qualidade e difusão de materiais para aprendizagem on-line) e 
- Cultura (comportamentos, crenças e instituições que apóiam o desenvolvimento de $e$ learning no país)"74 (2003, p. 3).

Complementando com aspectos relacionados à organização, Psycharis aponta que "entre os primeiros aspectos que devem ser considerados por uma organização que deseja adotar o $e$ learning estão sua cultura, sua estrutura, suas características, as políticas aplicadas e o papel de sua administração",75 (2005, p. 15).

Borotis e Poulymenakou (2004, p. 1) propõem um modelo de sete componentes interrelacionados para avaliar a prontidão para o e-learning (definida como "a prontidão mental ou física de uma organização para alguma experiência ou ação de e-Learning"76) de uma organizações que tem a intenção de adotar essa estratégia (Figura 17).

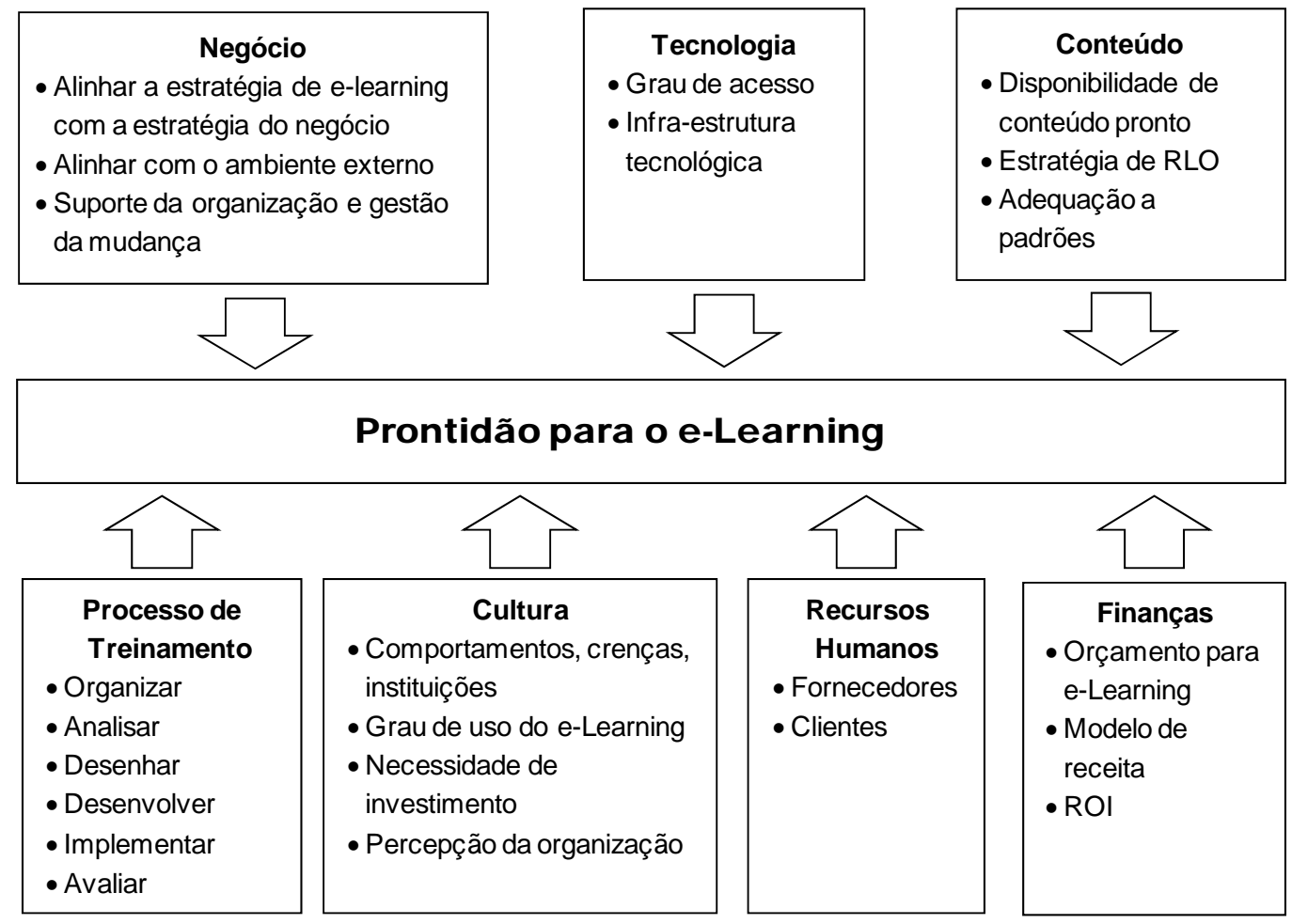

Figura 17 - Os Sete Componentes da Prontidão do e-Learning FONTE: BOROTIS; POULYMENAKOU, 2004, p. 2

\footnotetext{
74 "Connectivity (the quality and extent of Internet infrastructure), Capability (a country's ability to deliver and consume e-learning, based on literacy rates, and trends in training and education), Content (the quality and pervasiveness of online learning materials) and Culture (behaviors, beliefs and institutions that support eLearning development within country)"
} 
Além dos componentes apresentados por Borotis e Poulymenakou (2004), o modelo de Chapnick inclui o fator "prontidão psicológica", que "considera o impacto do estado de espírito do indivíduo no resultado da iniciativa de e-learning"77 (2000).

Rosenberg (2000, p. 1) desenvolveu o "E-Learning Readiness Survey", instrumento de 20 questões para analisar a sustentabilidade dos esforços de e-learning na empresa, organizado em sete áreas: prontidão do negócio, natureza variável da aprendizagem e do e-learning, valor do desing instrucional e informacional, papel da gestão da mudança, reinvenção do treinamento, indústria de e-learning e compromisso pessoal.

Com um enfoque mais voltado para o usuário, Van Dam (2004, p. 90) identifica três fatores importantes para o comprometimento dos colaboradores com e-learning: facilitadores, direcionadores e motivadores (Figura 18).

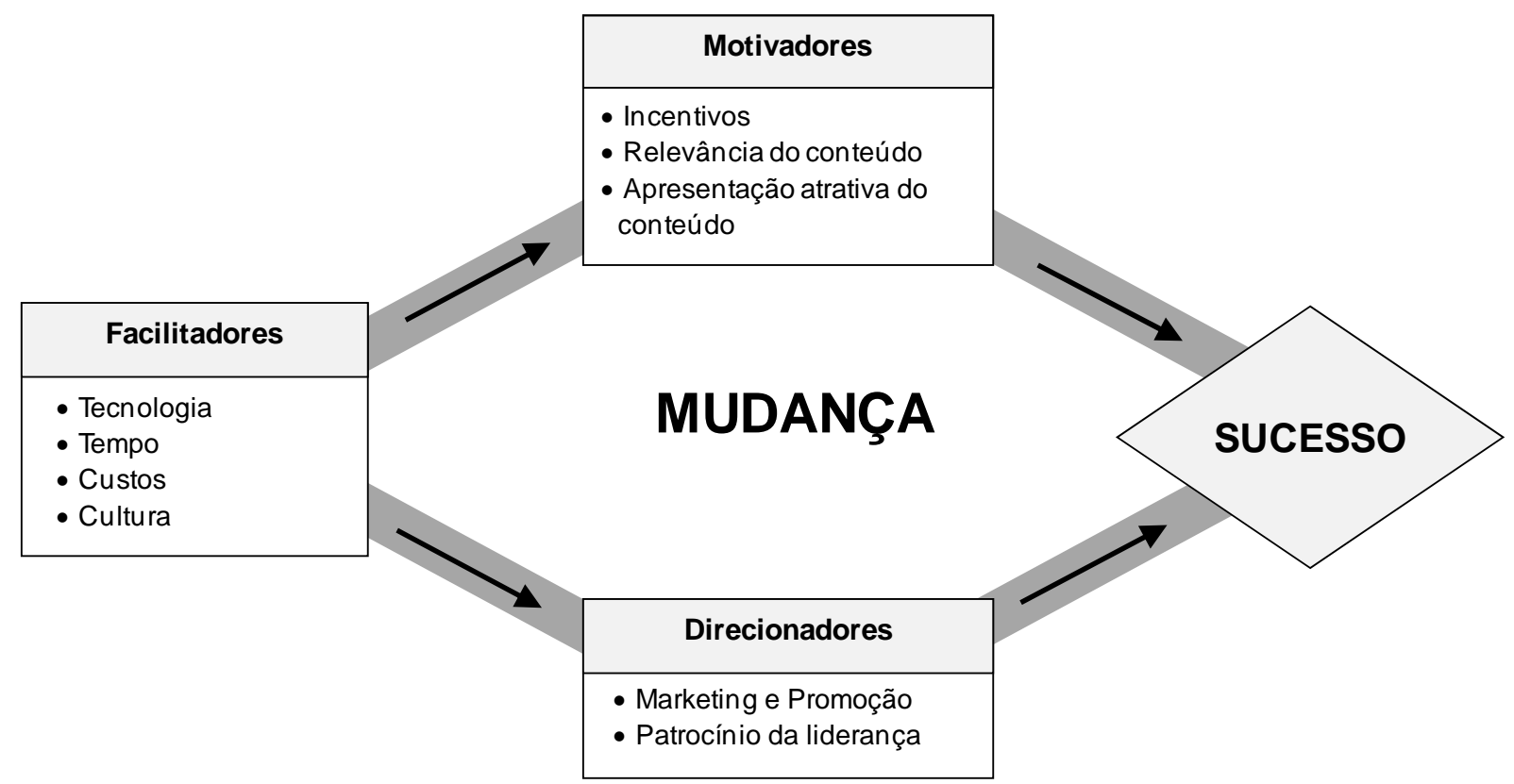

Figura 18 - Fatores que Impactam o Comprometimento com e-Learning FONTE: Van DAM, 2004, p. 91

75 "[...] the first things to be estimated by an organisation wishing to adopt e-learning are its culture, its structure, its characteristics, the policies applied and the role of its administration"

76 "the mental or physical preparedness of an organization for some e-Learning experience or action"

77 "considers the individual's state of mind as it impacts the outcome of the e-learning initiative" 
A seguir, uma breve descrição de cada fator (Van DAM, 2004, p. 90-98):

- Facilitadores (Enablers): tecnologias de e-learning adequadas (infra-estrutura e suporte); alocação de tempo pelo participante para completar o curso; investimentos viáveis e demonstração do retorno sobre investimento; existência de uma cultura organizacional de e-learning.

- Direcionadores (Drivers): engajamento dos líderes da organização como patrocinadores, através do estabelecimento do impacto do curso no negócio; ampla divulgação através de campanha de marketing sobre como o e-learning pode contribuir para melhorar o desempenho e eficácia no ambiente de trabalho.

- Motivadores (Motivators): incentivos individuais para iniciar e completar o curso; conteúdo relevante e atraente.

\subsubsection{Adoção do e-Learning}

Neste tópico, serão apresentados alguns estudos sobre a adoção do e-learning baseados no Modelo TAM, descrito anteriormente.

Gong et al (2004) aplicaram o Modelo TAM em conjunto com o conceito de auto-eficácia ${ }^{78}$ (sefl-efficacy), na explicação da aceitação de um sistema de aprendizagem baseado na web por 146 professores tempo integral, participantes de um programa educacional. Os resultados suportam o modelo proposto (Figura 19), indicando que (GONG et al, 2004, p. 371):

- As relações propostas no Modelo TAM foram confirmadas, com destaque para a utilidade percebida, que teve efeito direto e mais significativo na intenção de uso;

- Foi identificado um efeito significativo da facilidade de uso percebida nas atitudes dos professores, resultado divergente do Modelo TAM. De acordo com os autores, esse resultado se deve ao fato dos respondentes terem utilizado intensivamente o sistema por um mês antes da aplicação da pesquisa, o que pode ter aumentado a preocupação em relação ao sistema ser relativamente simples de ser utilizado.

\footnotetext{
${ }^{78}$ Se refere à percepção do indivíduo em relação à sua capacidade em utilizar um computador (GONG et al, 2004, p. 367).
} 
- Auto-eficácia com computadores teve uma influência direta mais forte na facilidade de uso do que na intenção de uso.

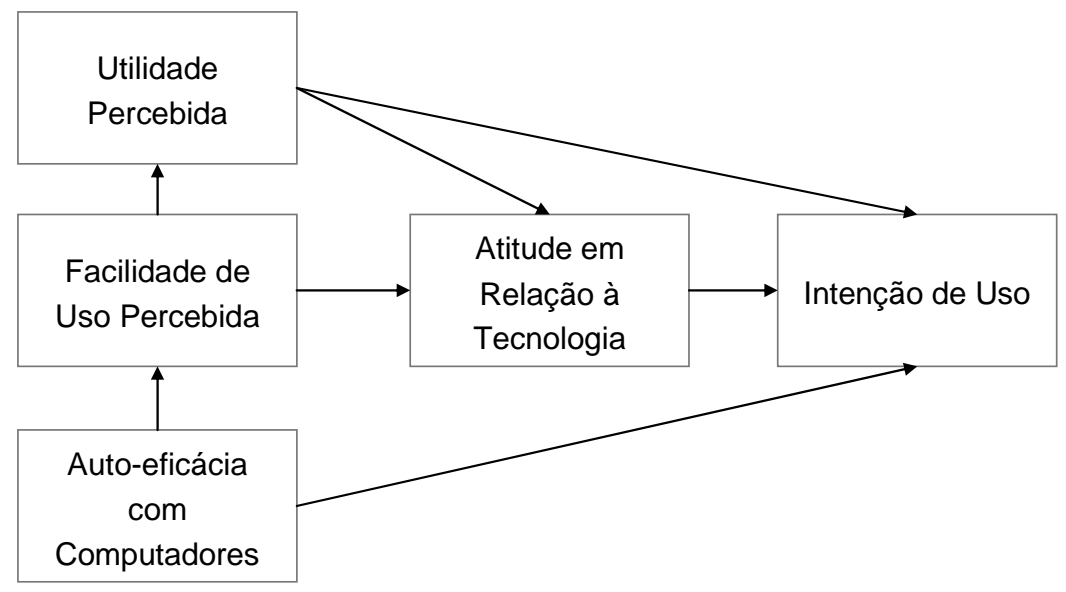

Figura 19 - Modelo Testado para Aceitação de Um Sistema de Aprendizagem na Web FONTE: GONG et al, 2004, p. 370

Outra pesquisa sobre o tema foi realizada por Martins e Kellermanns (2004), com o objetivo de desenvolver e testar um modelo para prever a aceitação de cursos baseados na web por alunos de administração. Os autores acrescentam ao Modelo TAM os fatores motivadores e facilitadores, provenientes da literatura de implementação da mudança. A pesquisa empírica foi realizada com 243 alunos de uma universidade americana, participantes de nove cursos com utilização do $\mathrm{WebCT}^{79}$ para acesso a materiais, atividades e notas (obrigatório) e para participação em discussões (facultativo). Os resultados obtidos foram coerentes com aqueles previstos no Modelo TAM e confirmaram as hipóteses estabelecidas pelos autores, indicando que os "fatores motivadores da mudança levam a uma percepção de maior utilidade do sistema e os fatores facilitadores da mudança levam a uma percepção de maior facilidade de uso do sistema" ${ }^{\prime 80}$ (MARTINS; KELLERMANNS, 2004, p. 17). O fator incentivo para usar demonstrou ter influência direta na intenção de uso, o que se presume ser conseqüência do caráter obrigatório de algumas das atividades.

\footnotetext{
${ }^{79}$ Software desenvolvido por Murray Goldberg, da University of British Columbia, em 1997, com o objetivo de criar ferramentas baseadas na Web que facilitassem a criação e disponibilização de conteúdos pelos professores e o uso pelos alunos (HUTCHINS, 2001).

80 "[...] change-motivating factors led to greater perceived usefulness of the system and change-enabling factors led to greater perceived ease of use of the system"
} 
A Figura 20 a seguir, apresenta o modelo final validado pelos autores, adaptado de forma a indicar os motivadores e facilitadores, conforme o modelo proposto (MARTINS; KELLERMANNS, 2004, p. 11).

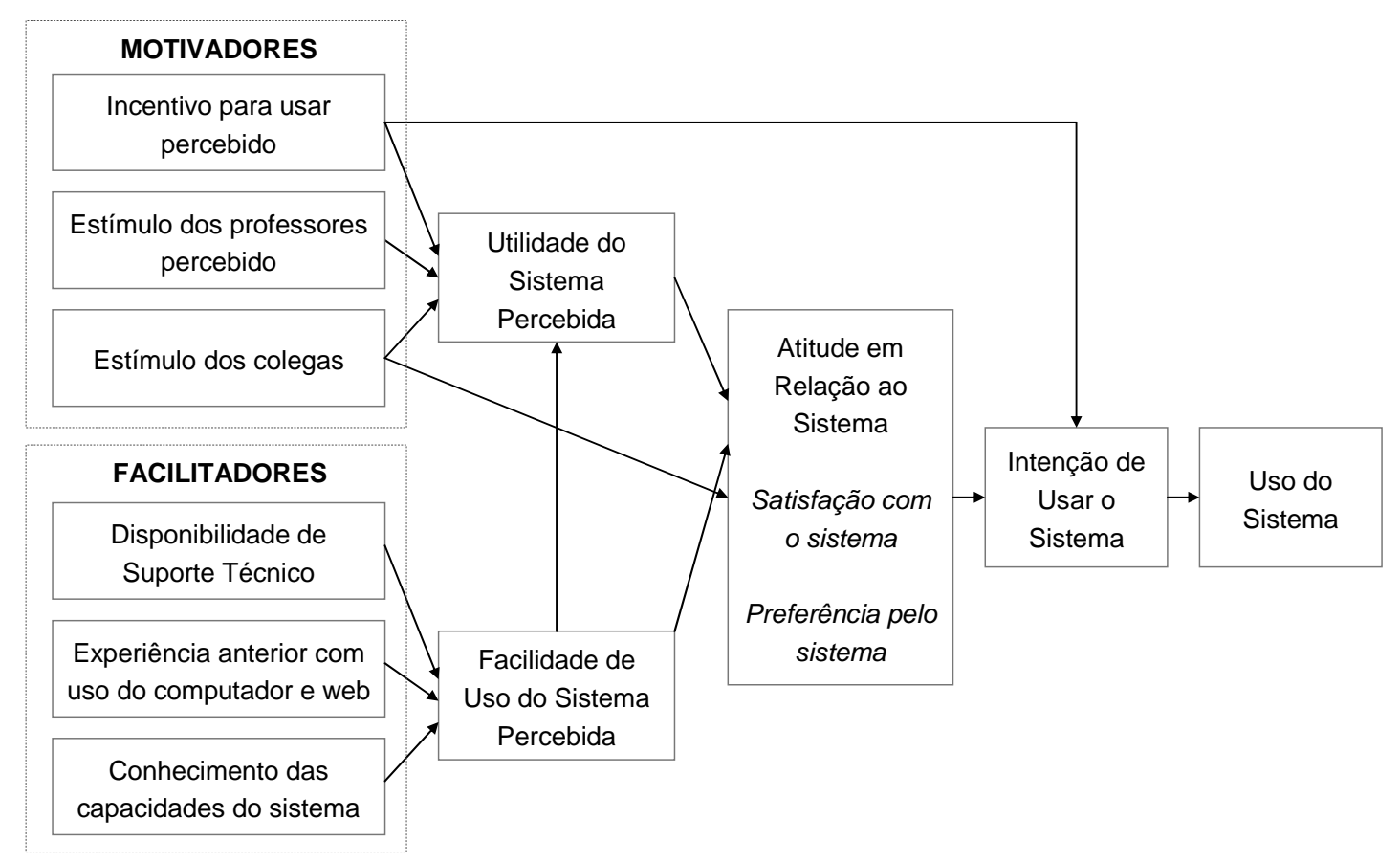

Figura 20 - Modelo Final de Aceitação do Sistema de Curso Baseado na Web FONTE: Adaptado de MARTINS; KELLERMANNS, 2004, p. 17

O fator facilitador auto-eficácia no uso da web não demonstrou ter impacto significativo na facilidade de uso percebida, razão pela qual foi retirado do modelo final. Este resultado pode ser explicado pelo fato dos participantes da pesquisa, com idade média de 22 anos, serem de uma geração que teve maior exposição à Internet, de forma que a utilização do ambiente web não apresenta dificuldades relevantes (MARTINS; KELLERMANNS, 2004, p. 19).

Outras pesquisas realizadas em instituições de ensino superior também indicaram que o Modelo TAM foi apropriado para explicar o uso de ambientes virtuais de aprendizagem pelos alunos (TROTTER, 1993; LANDRY, 2003; STOEL; LEE, 2003; PAN, 2003; GABBARD, 2004; KIM, 2004; FUSILIER; DURLABJHI, 2005). 


\subsection{Resumo da Revisão Bibliográfica}

Tendo em vista o objetivo desta pesquisa, os Quadros 6, 7 e 8, a seguir, resumem os principais fatores que influenciam: a adoção individual de inovações (utilizando como ponto de partida o Modelo TAM), a adoção organizacional de inovações e a implementação do $e$ learning encontrados na revisão da literatura. As pesquisas sobre adoção do e-learning baseadas no Modelo TAM foram incluídas no Quadro 6. 
Quadro 6 - Adoção Individual de Inovações: Variáveis e Autores

\begin{tabular}{|c|c|c|c|c|c|c|c|}
\hline DIMENSÃO & $\begin{array}{c}\text { Processo de Decisão } \\
\text { sobre Inovação } \\
\text { Rogers (1995) }\end{array}$ & $\begin{array}{c}\text { Technology } \\
\text { Acceptance Model } \\
\text { (TAM) } \\
\text { Davis et al (1989) }\end{array}$ & $\begin{array}{c}\text { Extensão do } \\
\text { Technology } \\
\text { Acceptance Model } \\
\text { (TAM2) } \\
\text { Venkatesh e Davis } \\
(2000)\end{array}$ & $\begin{array}{l}\text { Unified Theory of } \\
\text { Acceptance and Use } \\
\text { of Technology } \\
\text { (UTAUT) } \\
\text { Venkatesh et al } \\
(2003)\end{array}$ & $\begin{array}{c}\text { Aceitação da TI } \\
\text { pela Força de } \\
\text { Vendas } \\
\text { Schillewaert et al } \\
\text { (2000) }\end{array}$ & $\begin{array}{l}\text { Aceitação de } \\
\text { Sistema de } \\
\text { Aprendizagem } \\
\text { Web } \\
\text { Gong et al } \\
\text { (2004) }\end{array}$ & $\begin{array}{c}\text { Aceitação de } \\
\text { Sistema de Curso } \\
\text { Baseado na Web } \\
\text { Martins e } \\
\text { Kellermanns } \\
(2004)\end{array}$ \\
\hline $\begin{array}{l}\text { Utilidade } \\
\text { Percebida }\end{array}$ & $\begin{array}{l}\text { Características } \\
\text { Percebidas da } \\
\text { Inovação: } \\
\text { - Vantagem relativa } \\
\text { - Visibilidade } \\
\\
\text { Condições anteriores: } \\
\text { - Necessidade/ } \\
\quad \text { problemas }\end{array}$ & 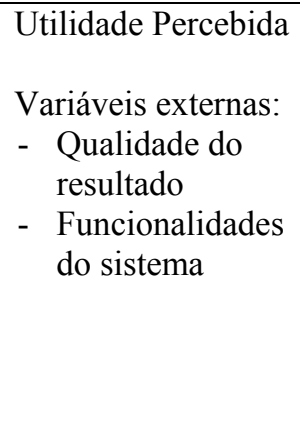 & $\begin{array}{l}\text { Utilidade Percebida } \\
\text { Relevância para o } \\
\text { trabalho } \\
\text { Qualidade do } \\
\text { resultado } \\
\text { Demonstrabilidade } \\
\text { do resultado }\end{array}$ & $\begin{array}{l}\text { Expectativa de } \\
\text { Desempenho } \\
\text { - } \text { Utilidade } \\
\text { percebida } \\
\text { - } \text { Motivação } \\
\text { extrínseca } \\
\text { - } \text { Adaptação ao } \\
\text { trabalho } \\
\text { - Vantagem relativa } \\
\text { - Expectativas de } \\
\text { resultado }\end{array}$ & Utilidade & $\begin{array}{l}\text { Utilidade } \\
\text { Percebida }\end{array}$ & $\begin{array}{l}\text { Utilidade } \\
\text { Percebida do } \\
\text { Sistema }\end{array}$ \\
\hline $\begin{array}{l}\text { Facilidade de } \\
\text { Uso Percebida }\end{array}$ & $\begin{array}{l}\text { Características } \\
\text { Percebidas da } \\
\text { Inovação: } \\
\text { - Complexidade } \\
\text { - Possibilidade de } \\
\quad \text { experimentação }\end{array}$ & $\begin{array}{l}\text { Facilidade de Uso } \\
\text { Percebida }\end{array}$ & $\begin{array}{l}\text { Facilidade de Uso } \\
\text { Percebida }\end{array}$ & $\begin{array}{l}\text { Expectativa de } \\
\text { Esforço } \\
\text { - Facilidade de uso } \\
\text { percebida } \\
\text { - Complexidade } \\
\text { - } \text { Facilidade de uso }\end{array}$ & Facilidade de Uso & $\begin{array}{l}\text { Facilidade de } \\
\text { Uso Percebida }\end{array}$ & $\begin{array}{l}\text { Facilidade } \\
\text { Percebida de Uso } \\
\text { do Sistema } \\
\text { Facilitadores } \\
\text { - Conhecimento } \\
\text { das } \\
\text { capacidades do } \\
\text { sistema } \\
\end{array}$ \\
\hline $\begin{array}{l}\text { Influência } \\
\text { Social }\end{array}$ & $\begin{array}{l}\text { Natureza do sistema } \\
\text { social }\end{array}$ & & $\begin{array}{l}\text { Norma subjetiva } \\
\text { Imagem }\end{array}$ & $\begin{array}{l}\text { Influência Social } \\
\text { - Norma subjetiva } \\
\text { - } \text { Fatores sociais } \\
\text { - Imagem }\end{array}$ & 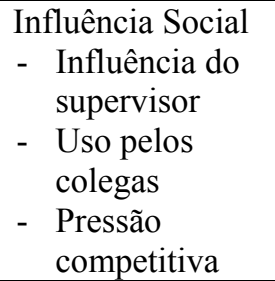 & & $\begin{array}{l}\text { Motivadores } \\
\text { - } \text { Estímulo dos } \\
\text { professores } \\
\text { percebido } \\
\text { - Estímulo dos } \\
\quad \text { colegas }\end{array}$ \\
\hline
\end{tabular}


Quadro 6 - Adoção Individual de Inovações: Variáveis e Autores

\begin{tabular}{|c|c|c|c|c|c|c|c|}
\hline DIMENSÃO & $\begin{array}{c}\text { Processo de Decisão } \\
\text { sobre Inovação } \\
\text { Rogers (1995) }\end{array}$ & $\begin{array}{c}\text { Technology } \\
\text { Acceptance Model } \\
\text { (TAM) } \\
\text { Davis et al (1989) }\end{array}$ & $\begin{array}{c}\text { Extensão do } \\
\text { Technology } \\
\text { Acceptance Model } \\
\text { (TAM2) } \\
\text { Venkatesh e Davis } \\
\text { (2000) }\end{array}$ & $\begin{array}{l}\text { Unified Theory of } \\
\text { Acceptance and Use } \\
\text { of Technology } \\
\text { (UTAUT) } \\
\text { Venkatesh et al } \\
(2003)\end{array}$ & $\begin{array}{c}\text { Aceitação da TI } \\
\text { pela Força de } \\
\text { Vendas } \\
\text { Schillewaert et al } \\
\text { (2000) }\end{array}$ & $\begin{array}{l}\text { Aceitação de } \\
\text { Sistema de } \\
\text { Aprendizagem } \\
\text { Web } \\
\text { Gong et al } \\
\text { (2004) }\end{array}$ & $\begin{array}{c}\text { Aceitação de } \\
\text { Sistema de Curso } \\
\text { Baseado na Web } \\
\text { Martins e } \\
\text { Kellermanns } \\
\text { (2004) }\end{array}$ \\
\hline $\begin{array}{l}\text { Condições } \\
\text { Facilitadoras }\end{array}$ & $\begin{array}{l}\text { Características } \\
\text { Percebidas da } \\
\text { Inovação: } \\
\text { - Compatibilidade } \\
\text { Condições anteriores: } \\
\text { - Normas do sistema } \\
\quad \text { social } \\
\text { - Prática anterior } \\
\text { - Pré-disposição para } \\
\quad \text { inovar } \\
\text { Canais de } \\
\text { comunicação que } \\
\text { divulgam a inovação }\end{array}$ & $\begin{array}{l}\text { Variáveis externas: } \\
\text { - } \text { Divulgação dos } \\
\text { benefícios } \\
\text { - } \text { Treinamento } \\
\text { - Documentação e } \\
\text { suporte aos } \\
\text { usuário }\end{array}$ & & $\begin{array}{l}\text { Condições } \\
\text { Facilitadoras } \\
\text { - Controle do } \\
\text { comportamento } \\
\text { percebido } \\
\text { - Condições } \\
\text { facilitadoras } \\
\text { - } \text { Compatibilidade }\end{array}$ & $\begin{array}{l}\text { Facilitadores } \\
\text { Organizacionais } \\
\text { - } \text { Treinamento } \\
\text { do usuário } \\
\text { - Suporte } \\
\text { técnico ao } \\
\text { usuário } \\
\text { - Implementação } \\
\text { organizacional } \\
\text { (ex.: campanha } \\
\text { interna de } \\
\text { marketing e } \\
\text { apoio da alta } \\
\text { administração) }\end{array}$ & & $\begin{array}{l}\text { Motivadores } \\
\text { - Incentivo } \\
\text { percebido para } \\
\text { o uso } \\
\text { Facilitadores } \\
\text { - Disponibilidade } \\
\quad \text { de Suporte } \\
\text { Técnico }\end{array}$ \\
\hline $\begin{array}{l}\text { Atitude em } \\
\text { Relação à } \\
\text { Inovação }\end{array}$ & & $\begin{array}{l}\text { Atitude em } \\
\text { Relação ao Uso }\end{array}$ & & $\begin{array}{l}\text { Atitude em Relação } \\
\text { ao Uso da Tecnologia } \\
\text { - Atitude em } \\
\text { relação ao } \\
\text { comportamento } \\
\text { - Motivação } \\
\text { intrínseca } \\
\text { - Sentimento em } \\
\text { relação ao uso } \\
\text { - Sentimento }\end{array}$ & & $\begin{array}{l}\text { Atitude em } \\
\text { Relação à } \\
\text { Tecnologia }\end{array}$ & 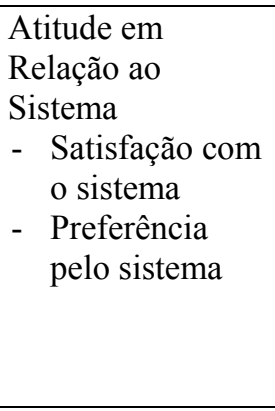 \\
\hline Intenção de Uso & & $\begin{array}{l}\text { Comportamento de } \\
\text { Intenção de Uso }\end{array}$ & Intenção de Uso & $\begin{array}{l}\text { Intenção de } \\
\text { Comportamento }\end{array}$ & & $\begin{array}{l}\text { Intenção de } \\
\text { Uso }\end{array}$ & $\begin{array}{l}\text { Intenção de Usar o } \\
\text { Sistema }\end{array}$ \\
\hline $\begin{array}{l}\text { Comportamento } \\
\text { de Uso }\end{array}$ & Adoção x Rejeição & $\begin{array}{l}\text { Uso Real do } \\
\text { Sistema }\end{array}$ & $\begin{array}{l}\text { Comportamento de } \\
\text { Uso }\end{array}$ & $\begin{array}{l}\text { Comportamento de } \\
\text { Uso }\end{array}$ & Aceitação & & Uso do Sistema \\
\hline
\end{tabular}


Quadro 6 - Adoção Individual de Inovações: Variáveis e Autores

\begin{tabular}{|c|c|c|c|c|c|c|c|}
\hline DIMENSÃO & $\begin{array}{c}\text { Processo de Decisão } \\
\text { sobre Inovação } \\
\text { Rogers (1995) }\end{array}$ & $\begin{array}{c}\text { Technology } \\
\text { Acceptance Model } \\
\text { (TAM) } \\
\text { Davis et al (1989) }\end{array}$ & $\begin{array}{c}\text { Extensão do } \\
\text { Technology } \\
\text { Acceptance Model } \\
\text { (TAM2) } \\
\text { Venkatesh e Davis } \\
(2000)\end{array}$ & $\begin{array}{l}\text { Unified Theory of } \\
\text { Acceptance and Use } \\
\text { of Technology } \\
\text { (UTAUT) } \\
\text { Venkatesh et al } \\
(2003)\end{array}$ & $\begin{array}{l}\text { Aceitação da TI } \\
\text { pela Força de } \\
\text { Vendas } \\
\text { Schillewaert et al } \\
\text { (2000) }\end{array}$ & $\begin{array}{l}\text { Aceitação de } \\
\text { Sistema de } \\
\text { Aprendizagem } \\
\text { Web } \\
\text { Gong et al } \\
\text { (2004) }\end{array}$ & $\begin{array}{c}\text { Aceitação de } \\
\text { Sistema de Curso } \\
\text { Baseado na Web } \\
\text { Martins e } \\
\text { Kellermanns } \\
(2004)\end{array}$ \\
\hline $\begin{array}{l}\text { Características } \\
\text { Pessoais }\end{array}$ & $\begin{array}{l}\text { Características do } \\
\text { indivíduo que decide: } \\
\text { - Características } \\
\text { socioeconômicas } \\
\text { - Variáveis de } \\
\text { personalidade } \\
\text { - Comportamento de } \\
\text { comunicação }\end{array}$ & & Experiência & $\begin{array}{l}\text { Gênero } \\
\text { Idade } \\
\text { Experiência }\end{array}$ & $\begin{array}{l}\text { Características } \\
\text { Individuais } \\
\text { - } \text { Predisposição } \\
\text { pessoal para } \\
\text { inovar } \\
\text { - } \text { Auto-eficácia } \\
\quad \text { com } \\
\text { computadores }\end{array}$ & $\begin{array}{l}\text { Auto-eficácia } \\
\text { com } \\
\text { Computadores }\end{array}$ & $\begin{array}{l}\text { Facilitadores } \\
\text { - Experiência } \\
\text { anterior com } \\
\text { uso do } \\
\text { computador e } \\
\text { web }\end{array}$ \\
\hline $\begin{array}{l}\text { Voluntariedade } \\
\text { de Uso }\end{array}$ & & & Voluntariedade & $\begin{array}{l}\text { Voluntariedade de } \\
\text { Uso }\end{array}$ & & & \\
\hline
\end{tabular}


Quadro 7 - Adoção Organizacional de Inovações: Variáveis e Autores

\begin{tabular}{|c|c|c|c|c|}
\hline DIMENSÃO & $\begin{array}{c}\text { Predisposição Organizacional } \\
\text { para Inovar } \\
\text { Rogers (1995) } \\
\end{array}$ & $\begin{array}{c}\text { Contexto da Inovação } \\
\text { Tecnológica } \\
\text { Tornatzky e Fleischer (1990) } \\
\end{array}$ & $\begin{array}{c}\text { Modelo de Assimilação da Inovação } \\
\text { Meyer e Goes (1988) } \\
\end{array}$ & $\begin{array}{c}\text { Adoção Organizacional de Inovação } \\
\text { Frambach and Schilewaert (1999) } \\
\end{array}$ \\
\hline Liderança & $\begin{array}{l}\text { Características Individuais do } \\
\text { Líder } \\
\text { - Atitude em relação à } \\
\text { mudança }\end{array}$ & & $\begin{array}{l}\text { Atributos do Contexto Organizacional: } \\
\text { - Líderes } \\
\text { Atributos da Decisão de Inovação } \\
\text { - Patrocínio do CEO }\end{array}$ & \\
\hline $\begin{array}{l}\text { Estrutura } \\
\text { Organizacional }\end{array}$ & $\begin{array}{l}\text { Características da Estrutura: } \\
\text { - Centralização } \\
\text { - Complexidade } \\
\text { - Formalização } \\
\text { - Interligação } \\
\text { - Flexibilidade } \\
\text { - Tamanho }\end{array}$ & $\begin{array}{l}\text { Organização: } \\
\text { - Estruturas formal e } \\
\text { informal } \\
\text { - Processos de comunicação } \\
\text { - } \text { Tamanho } \\
\text { - }\end{array}$ & $\begin{array}{l}\text { Atributos do Contexto Organizacional: } \\
\text { - Estruturas }\end{array}$ & $\begin{array}{l}\text { Características do Adotante: } \\
\text { - } \text { Tamanho } \\
\text { - Estrutura } \\
\text { - Predisposição organizacional para } \\
\quad \text { inovar / postura estratégica }\end{array}$ \\
\hline $\begin{array}{l}\text { Cultura } \\
\text { Organizacional }\end{array}$ & & & $\begin{array}{l}\text { Atributos da Decisão de Inovação } \\
\text { - Compatibilidade com padrões } \\
\text { existentes }\end{array}$ & $\begin{array}{l}\text { Rede Social } \\
\text { - Interligação / participação na rede }\end{array}$ \\
\hline $\begin{array}{l}\text { Ambiente } \\
\text { Externo }\end{array}$ & $\begin{array}{l}\text { Características Externas da } \\
\text { Organização: } \\
\text { Abertura do sistema }\end{array}$ & $\begin{array}{l}\text { Ambiente Externo: } \\
\text { - } \text { Características da indústria } \\
\text { e estrutura do Mercado } \\
\text { - } \text { Infra-estrutura de suporte } \\
\text { tecnológico } \\
\text { - } \\
\quad \text { Regulamentação } \\
\text { governamental }\end{array}$ & $\begin{array}{l}\text { Atributos do Contexto Organizacional: } \\
\text { - Mercado }\end{array}$ & $\begin{array}{l}\text { Esforço de Marketing do Fornecedor da } \\
\text { Inovação } \\
\text { - Definição do público-alvo } \\
\text { - Comunicação } \\
\text { - Redução do risco }\end{array}$ \\
\hline $\begin{array}{l}\text { Perfil dos } \\
\text { Usuários da } \\
\text { Inovação } \\
\end{array}$ & & & $\begin{array}{l}\text { Atributos da Decisão de Inovação } \\
\text { - Habilidade e realização de } \\
\text { treinamento recentemente }\end{array}$ & \\
\hline $\begin{array}{l}\text { Características } \\
\text { da Inovação }\end{array}$ & & $\begin{array}{l}\text { Tecnologia: } \\
\text { - Disponibilidade } \\
\text { - } \text { Características }\end{array}$ & $\begin{array}{l}\text { Atributos da inovação } \\
\text { Atributos da Decisão de Inovação } \\
\text { - Número de beneficiados pela } \\
\text { inovação }\end{array}$ & $\begin{array}{l}\text { Características Percebidas da Inovação } \\
\text { - Vantagem relativa } \\
\text { - Compatibilidade } \\
\text { - Complexidade } \\
\text { - Possibilidade de experimentação } \\
\text { - Visibilidade } \\
\text { - Incerteza }\end{array}$ \\
\hline
\end{tabular}


Quadro 7 - Adoção Organizacional de Inovações: Variáveis e Autores

\begin{tabular}{|l|l|l|l|l|}
\hline \multicolumn{1}{|c|}{ DIMENSÃo } & $\begin{array}{c}\text { Predisposição Organizacional } \\
\text { para Inovar } \\
\text { Rogers (1995) }\end{array}$ & $\begin{array}{c}\text { Contexto da Inovação } \\
\text { Tecnológica } \\
\text { Tornatzky e Fleischer (1990) }\end{array}$ & Modelo de Assimilação da Inovação & Adoção Organizacional de Inovação \\
\hline $\begin{array}{l}\text { Decisão de } \\
\text { Adoção }\end{array}$ & & $\begin{array}{l}\text { Decisão de Inovar } \\
\text { Tecnologicamente }\end{array}$ & & Frambach and Schilewaert (1999) \\
\hline $\begin{array}{l}\text { Assimilação } \\
\text { Organizacional } \\
\text { da Inovação }\end{array}$ & $\begin{array}{l}\text { Predisposição Organizacional } \\
\text { para Inovar }\end{array}$ & & $\begin{array}{l}\text { Assimilação Organizacional da } \\
\text { Inovação }\end{array}$ & Uso continuado \\
\hline
\end{tabular}


Quadro 8 - Implementação do e-Learning: Variáveis e Autores

\begin{tabular}{|c|c|c|c|c|c|}
\hline DIMENSÃO & $\begin{array}{c}\text { E-Learning Readiness Survey } \\
\text { Rosenberg (2000) }\end{array}$ & $\begin{array}{c}\text { Barreiras para Difusão do } \\
\text { e-Learning } \\
\text { Tyan (2003) }\end{array}$ & $\begin{array}{l}\text { Prontidão do } \boldsymbol{e}- \\
\text { Learning } \\
\text { Economist Intelligence } \\
\text { Unit e IBM (2003) }\end{array}$ & $\begin{array}{c}\text { Prontidão do } \text { e-Learning } \\
\text { Borotis e Poulymenakou } \\
(2004)\end{array}$ & $\begin{array}{c}\text { Comprometimento com } \boldsymbol{e}- \\
\text { Learning } \\
\text { Van Dam (2004) }\end{array}$ \\
\hline $\begin{array}{l}\text { Requisitos do } \\
\text { Negócio }\end{array}$ & $\begin{array}{l}\text { Prontidão do Negócio } \\
\text { - Uso da Internet e Intranet no } \\
\text { negócio }\end{array}$ & $\begin{array}{l}\text { Prontidão Organizacional: } \\
\text { - Clareza quanto ao } \\
\text { custo/benefício } \\
\text { Maturidade do e-Learning: } \\
\text { - } \text { Atendimento às } \\
\text { necessidades do negócio }\end{array}$ & & $\begin{array}{l}\text { Negócio } \\
\text { - Ligação da estratégia de } \\
\text { e-learning com } \\
\text { estratégia do negócio } \\
\text { - Alinhamento com } \\
\text { ambiente externo }\end{array}$ & \\
\hline $\begin{array}{l}\text { Infra-estrutura } \\
\text { Tecnológica }\end{array}$ & $\begin{array}{l}\text { Natureza da aprendizagem e do } \\
\text { e-learning } \\
\text { - Acesso das pessoas à web }\end{array}$ & $\begin{array}{l}\text { Prontidão Organizacional: } \\
\text { - Suficiência da infra- } \\
\text { estrutura } \\
\text { Maturidade do e-Learning: } \\
\text { - Compatibilidade do } e \text { - } \\
\text { learning com sistemas de } \\
\text { TI }\end{array}$ & $\begin{array}{l}\text { Conectividade } \\
\text { - } \text { Qualidade e } \\
\text { amplitude da infra- } \\
\text { estrutura de Internet }\end{array}$ & $\begin{array}{l}\text { Tecnologia } \\
\text { - Grau de acesso } \\
\text { - Infra-estrutura } \\
\text { tecnológica }\end{array}$ & $\begin{array}{l}\text { Facilitadores } \\
\text { - Infra-estrutura e suporte } \\
\text { adequados }\end{array}$ \\
\hline $\begin{array}{l}\text { Conteúdo e } \\
\text { Formato }\end{array}$ & & $\begin{array}{l}\text { Maturidade do e-Learning: } \\
\text { - Complexidade de } \\
\text { desenvolvimento e } \\
\text { revisão do conteúdo }\end{array}$ & $\begin{array}{l}\text { Conteúdo } \\
\text { - Qualidade dos } \\
\text { materiais } \\
\text { - } \text { Difusão dos } \\
\text { materiais }\end{array}$ & $\begin{array}{l}\text { Conteúdo } \\
\text { - } \text { Disponibilidade de } \\
\text { conteúdo pronto } \\
\text { - Estratégia de } \\
\text { personalização e } \\
\text { reutilização } \\
\text { - } \\
\end{array}$ & $\begin{array}{l}\text { Motivadores } \\
\text { - Conteúdo relevante } \\
\text { - Conteúdo atraente }\end{array}$ \\
\hline Cultura & $\begin{array}{l}\text { Valor da instrução e da } \\
\text { informação } \\
\text { - Prontidão para adotar } \\
\text { abordagem híbrida } \\
\text { Reinvenção do Treinamento } \\
\text { - Clima para aprender no } \\
\text { local de trabalho } \\
\text { - Disposição para permitir a } \\
\text { redução de alternativas } \\
\text { tradicionais }\end{array}$ & $\begin{array}{l}\text { Prontidão Organizacional: } \\
\text { - Valorização do } \\
\text { treinamento } \\
\text { - Aprovação do e-learning } \\
\text { pelos colaboradores } \\
\text { Maturidade do e-Learning: } \\
\text { - Preferência por cursos } \\
\text { presenciais }\end{array}$ & $\begin{array}{l}\text { Cultura } \\
\text { - Comportamentos } \\
\text { - Crenças } \\
\text { - Instituições que } \\
\quad \text { apóiam o e-learning }\end{array}$ & $\begin{array}{l}\text { Cultura } \\
\text { - Comportamentos, } \\
\text { crenças e instituições } \\
\text { - } \text { Grau de uso do } e- \\
\text { learning } \\
\text { - } \\
\text { Disponibilidade para } \\
\text { investimento } \\
\text { - Percepção da } \\
\text { organização }\end{array}$ & $\begin{array}{l}\text { Facilitadores } \\
\text { - Existência de cultura } \\
\text { organizacional de } e- \\
\quad \text { learning }\end{array}$ \\
\hline
\end{tabular}


Quadro 8 - Implementação do e-Learning: Variáveis e Autores

\begin{tabular}{|c|c|c|c|c|c|}
\hline DIMENSÃO & $\begin{array}{c}\text { E-Learning Readiness Survey } \\
\text { Rosenberg (2000) }\end{array}$ & $\begin{array}{c}\text { Barreiras para Difusão do } \\
\boldsymbol{e} \text {-Learning } \\
\text { Tyan }(2003)\end{array}$ & $\begin{array}{c}\text { Prontidão do } e^{-} \\
\text {Learning } \\
\text { Economist Intelligence } \\
\text { Unit e IBM (2003) }\end{array}$ & $\begin{array}{c}\text { Prontidão do e-Learning } \\
\text { Borotis e Poulymenakou } \\
\text { (2004) }\end{array}$ & $\begin{array}{c}\text { Comprometimento com } \boldsymbol{e} \text { - } \\
\text { Learning } \\
\text { Van Dam (2004) }\end{array}$ \\
\hline $\begin{array}{l}\text { Apoio da } \\
\text { Liderança / } \\
\text { Gestão da } \\
\text { Mudança }\end{array}$ & $\begin{array}{l}\text { Papel da Gestão da Mudança } \\
\text { - Suporte da alta } \\
\text { administração } \\
\text { - Plano de gestão da mudança } \\
\text { - Capacidade para demonstrar } \\
\text { benefícios }\end{array}$ & & & $\begin{array}{l}\text { Negócio } \\
\text { - Suporte da organização } \\
\text { e gestão da mudança }\end{array}$ & $\begin{array}{l}\text { Motivadores } \\
\text { - Incentivos } \\
\text { Direcionadores } \\
\text { - Líderes como } \\
\text { patrocinadores } \\
\text { - Ampla divulgação } \\
\text { através de campanha de } \\
\text { marketing } \\
\end{array}$ \\
\hline Financeiro & $\begin{array}{l}\text { Reinvenção do Treinamento } \\
\text { - Disposição para investir até } \\
\text { que o e-learning se } \\
\text { estabilize }\end{array}$ & $\begin{array}{l}\text { Custo de Adoção } \\
\text { - Custo de adotar e- } \\
\text { learning } \\
\text { - Custo da conexão banda } \\
\text { larga } \\
\text { - ROI } \\
\text { Prontidão Organizacional: } \\
\text { - Economia de escala para } \\
\text { adotar o e-learning a } \\
\text { custo viável } \\
\text { - Orçamento disponível }\end{array}$ & & $\begin{array}{l}\text { Financeiro } \\
\text { - Orçamento para } e \text { - } \\
\text { learning } \\
\text { - Modelo de receita } \\
\text { - } \text { ROI }\end{array}$ & $\begin{array}{l}\text { Facilitadores } \\
\text { - Investimentos viáveis } \\
\text { - Demonstrabilidade do } \\
\text { retorno }\end{array}$ \\
\hline $\begin{array}{l}\text { Perfil do } \\
\text { Usuário }\end{array}$ & $\begin{array}{l}\text { Prontidão do Negócio } \\
\text { - Preparo da força de trabalho } \\
\text { Natureza da aprendizagem e do } \\
e \text {-learning } \\
\text { - Superação de experiências } \\
\text { anteriores negativas } \\
\text { Compromisso pessoal com e- } \\
\text { learning }\end{array}$ & $\begin{array}{l}\text { Prontidão Organizacional: } \\
\text { - Habilidades com } \\
\text { informática dos } \\
\text { colaboradores }\end{array}$ & $\begin{array}{l}\text { Capacidade: } \\
\text { - Alta taxa de } \\
\text { alfabetismo }\end{array}$ & & $\begin{array}{l}\text { Facilitadores } \\
\text { - Alocação de tempo para } \\
\text { completar o curso }\end{array}$ \\
\hline
\end{tabular}


Quadro 8 - Implementação do e-Learning: Variáveis e Autores

\begin{tabular}{|c|c|c|c|c|c|}
\hline DIMENSÃO & $\begin{array}{c}\text { E-Learning Readiness Survey } \\
\text { Rosenberg (2000) }\end{array}$ & $\begin{array}{c}\text { Barreiras para Difusão do } \\
\boldsymbol{e} \text {-Learning } \\
\text { Tyan }(2003)\end{array}$ & $\begin{array}{c}\text { Prontidão do } \boldsymbol{e}- \\
\text { Learning } \\
\text { Economist Intelligence } \\
\text { Unit e IBM (2003) }\end{array}$ & $\begin{array}{c}\text { Prontidão do e-Learning } \\
\text { Borotis e Poulymenakou } \\
\text { (2004) }\end{array}$ & $\begin{array}{c}\text { Comprometimento com } \boldsymbol{e} \text { - } \\
\text { Learning } \\
\text { Van Dam }(2004)\end{array}$ \\
\hline $\begin{array}{l}\text { Gestão do } e \text { - } \\
\text { Learning }\end{array}$ & $\begin{array}{l}\text { Natureza da aprendizagem e do } \\
\text { e-learning } \\
\text { - Conceito de e-learning } \\
\text { utilizado } \\
\text { - Decisões adequadas sobre } \\
\text { treinamento } \\
\text { Valor da instrução e da } \\
\text { informação } \\
\text { - Conhecimento sobre design } \\
\text { instrucional } \\
\text { Reinvenção do Treinamento } \\
\text { - Plano da função de } \\
\text { treinamento na era digital } \\
\text { - Cobrança de matrículas x } \\
\text { decisão sobre orçamento } \\
\text { Indústria de e-Learning } \\
\text { - Preparo para lidar com o } \\
\text { mercado de e-learning } \\
\text { - Capacidade para diferenciar } \\
\text { produtos de qualidade } \\
\text { - Preparo para gerenciar } \\
\text { atividades terceirizadas }\end{array}$ & $\begin{array}{l}\text { Prontidão Organizacional: } \\
\text { - Conhecimento para } \\
\text { gerenciar sistemas de } e \text { - } \\
\text { learning }\end{array}$ & $\begin{array}{l}\text { Capacidade: } \\
\text { - Sistema } \\
\text { educacional forte } \\
\text { - Tradição de } \\
\text { treinamento no } \\
\text { trabalho } \\
\text { - Suporte para } \\
\text { aprendizagem por } \\
\text { toda vida }\end{array}$ & $\begin{array}{l}\text { Recursos Humanos } \\
\text { - Fornecedores } \\
\text { - Clientes } \\
\text { Processo de Treinamento } \\
\text { - Organizar } \\
\text { - Analisar } \\
\text { - Desenhar } \\
\text { - Desenvolver } \\
\text { - Implementar } \\
\text { - Avaliar }\end{array}$ & \\
\hline $\begin{array}{l}\text { Indústria de } e \text { - } \\
\text { Learning }\end{array}$ & & $\begin{array}{l}\text { Maturidade do e-Learning: } \\
\text { - Disponibilidade de } \\
\text { especialistas } \\
\text { - Produtos e serviços } \\
\text { oferecidos pelos } \\
\text { fornecedores }\end{array}$ & & & \\
\hline
\end{tabular}


Com base no Quadro 6, que trata da adoção individual de inovações, é possível destacar as dimensões que apresentaram relação com todos os autores analisados, são elas: utilidade percebida e facilidade de uso percebida. Já as dimensões influência social, condições facilitadoras e características pessoais relacionam-se à maioria dos autores.

É interessante notar que as dimensões da adoção organizacional de inovações (Quadro 7) são diferentes da adoção em nível individual, com exceção do perfil dos usuários da inovação e das características da inovação, que podem ser relacionadas às dimensões da decisão individual de adoção: características pessoais e utilidade percebida, respectivamente.

Por outro lado, algumas dimensões da adoção organizacional de inovações coincidem com a literatura de implementação do e-learning (Quadro 8): Cultura Organizacional, Liderança e Perfil do Usuário. Além disso, destaca-se entre os autores analisados da literatura de $e$ learning a relevante presença das dimensões Infra-estrutura Tecnológica e Cultura Organizacional, aspectos citados por todas as pesquisas. 


\section{METODOLOGIA DA PESQUISA}

A descrição da metodologia utilizada na condução desta pesquisa está organizada nos seguintes tópicos: Modelo de Adoção Individual do e-Learning utilizado, abordagem da pesquisa (incluindo uma descrição do setor de telecomunicações e da empresa pesquisada), as necessidades e fontes de dados, as técnicas e instrumentos de coleta dos dados (questionário auto-preenchido, entrevista individual e análise documental), a descrição da população e amostra e, por fim, as técnicas utilizadas para análise dos dados.

\subsection{Modelo de Adoção Individual do e-Learning}

Considerando o objetivo proposto de analisar os fatores que influenciam a adoção individual do e-learning pelos colaboradores da organização, foi elaborado o Modelo Preliminar de Adoção Individual do e-Learning (Figura 21), utilizando como ponto de partida o Modelo TAM - Technology Acceptance Model. Tendo em vista que a análise da adoção deve ser adaptada para a inovação ou tecnologia em questão (DAVIS et al, 1989, p.; FRAMBACH; SCHILLEWAERT, 1999; TORNATZKY; FLEISCHER, 1990), as variáveis do TAM foram ajustadas para tratarem especificamente da adoção do e-learning, no que se refere aos constructos: Utilidade Percebida, Facilidade de Uso Percebida, Atitude em Relação ao eLearning, Intenção de Uso e Comportamento de Uso. Além disso, com base na revisão da literatura, novas variáveis foram adicionadas ao modelo (variáveis externas). É importante ressaltar que foi encontrado um grande número de variáveis relacionadas à adoção de inovações e implementação do e-learning, tendo sido necessário selecionar aquelas mais relevantes tendo em vista os objetivos da pesquisa. A condução de entrevistas com especialistas e do pré-teste do questionário forneceram os subsídios de base para a escolha das variáveis a serem adicionadas ao modelo. 


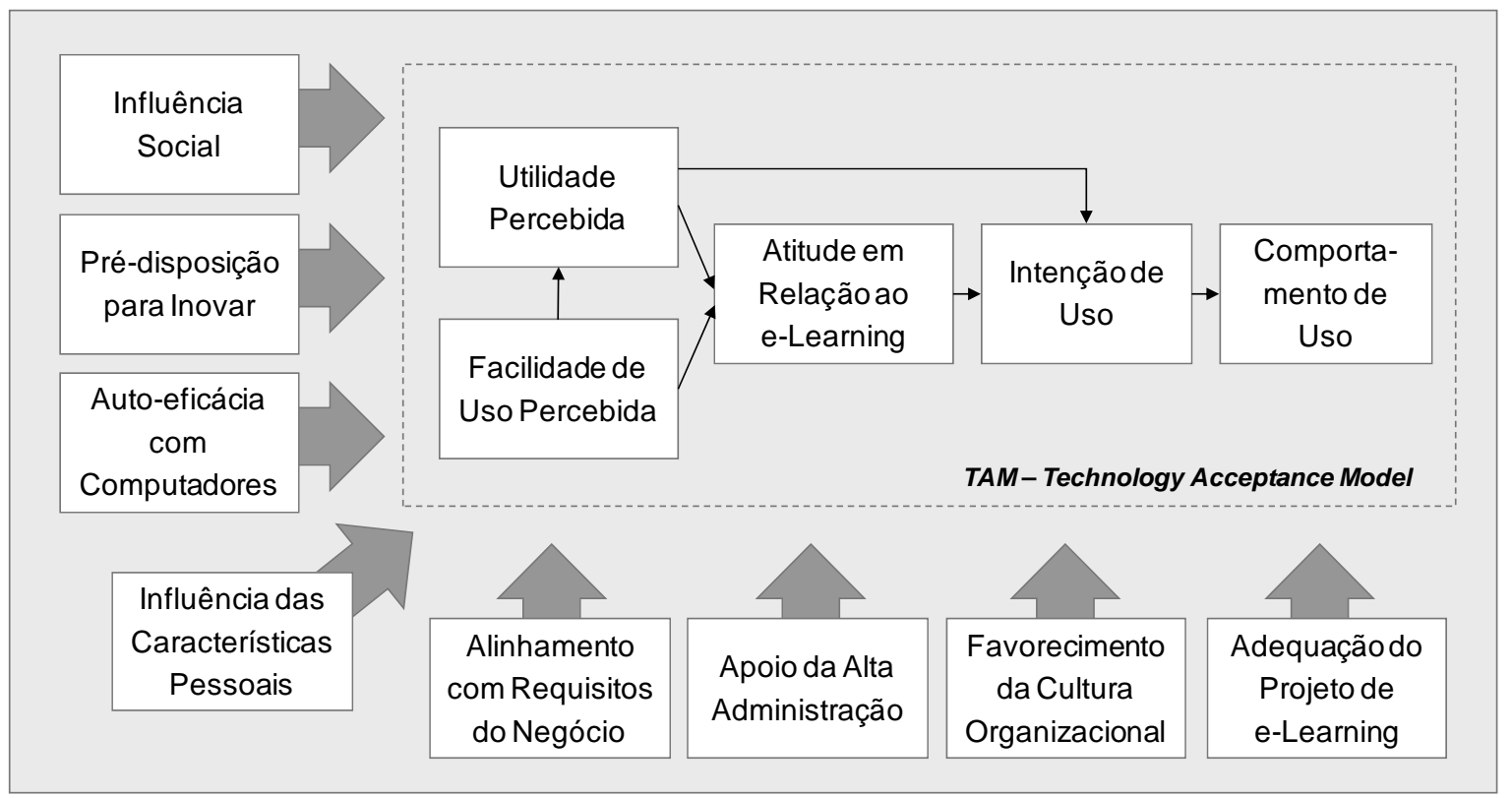

Figura 21 - Modelo Preliminar de Adoção Individual do e-Learning

O Quadro 9 a seguir, apresenta as dimensões do Modelo Preliminar de Adoção do e-Learning, incluindo uma breve definição, a base conceitual e as respectivas variáveis. 
Quadro 9 - Variáveis do Modelo Preliminar de Adoção do e-Learning

\begin{tabular}{|c|c|c|c|}
\hline Dimensão & Definição & Base Conceitual & Variáveis \\
\hline \multicolumn{4}{|c|}{ Variáveis do Modelo TAM } \\
\hline $\begin{array}{l}\text { Utilidade do } e- \\
\text { Learning Percebida }\end{array}$ & $\begin{array}{l}\text { Grau em que uma pessoa acredita } \\
\text { que utilizar um determinado } \\
\text { sistema irá melhorar sua } \\
\text { performance }\end{array}$ & $\begin{array}{l}\text { DAVIS et al, } 1989 ; \\
\text { VENKATESH; } \\
\text { DAVIS, } 2000\end{array}$ & $\begin{array}{l}\text { - Contribuição do e-learning para a melhora do desempenho no trabalho } \\
\text { - Utilidade do e-learning no trabalho } \\
\text { - Importância do e-learning para a realização do trabalho } \\
\text { - Obtenção de resultados de aprendizagem com o e-learning } \\
\text { - Flexibilidade para aprender através do e-learning } \\
\text { - Facilidade em explicar os benefícios do e-learning } \\
\text { - Aumento nas chances de promoção em função da participação no e-learning }\end{array}$ \\
\hline $\begin{array}{l}\text { Facilidade de Uso do } \\
\text { e-Learning Percebida }\end{array}$ & $\begin{array}{l}\text { Grau em que uma pessoa acredita } \\
\text { que utilizar determinado sistema } \\
\text { não envolverá esforço }\end{array}$ & $\begin{array}{l}\text { DAVIS et al, } 1989 ; \\
\text { VENKATESH; } \\
\text { DAVIS, } 2000\end{array}$ & $\begin{array}{l}\text { - Facilidade para usar o e-learning } \\
\text { - Clareza e inteligibilidade da interação com o sistema de e-learning }\end{array}$ \\
\hline $\begin{array}{l}\text { Atitude em Relação } \\
\text { ao e-Learning }\end{array}$ & $\begin{array}{l}\text { Sentimentos negativos ou positivos } \\
\text { do indivíduo em relação ao uso do } \\
\text { e-learning }\end{array}$ & DAVIS et al, 1989 & $\begin{array}{l}\text { - Sentimento em relação à participação no e-learning } \\
\text { - Satisfação em relação ao uso do e-learning }\end{array}$ \\
\hline $\begin{array}{l}\text { Intenção de Uso do } \\
\text { e-Learning }\end{array}$ & $\begin{array}{l}\text { Força da intenção do indivíduo em } \\
\text { utilizar o e-learning }\end{array}$ & $\begin{array}{l}\text { DAVIS et al, } 1989 \\
\text { VENKATESH; } \\
\text { DAVIS, } 2000\end{array}$ & $\begin{array}{l}\text { - Intenção de participar do e-learning em } 2007 \\
\text { - Intenção de uso do e-learning, em função do tempo disponível } \\
\text { - Intenção de uso do e-learning, em função dos cursos disponibilizados }\end{array}$ \\
\hline $\begin{array}{l}\text { Comportamento de } \\
\text { Uso do e-Learning }\end{array}$ & $\begin{array}{l}\text { Participação em curso de } e \text {-learning } \\
\text { na plataforma da empresa }\end{array}$ & $\begin{array}{l}\text { Adaptado de DAVIS et } \\
\text { al, 1989; } \\
\text { VENKATESH; } \\
\text { DAVIS, } 2000\end{array}$ & $\begin{array}{l}\text { - Participação em pelo menos um curso na plataforma de e-learning da empresa, } \\
\text { desde } 2006 \\
\text { - Motivos da não participação no e-learning } \\
\text { - Freqüência de uso do e-learning } \\
\text { - Aproveitamento dos cursos de e-learning } \\
\text { - Número de cursos on-line inscritos } \\
\text { - Número de cursos on-line abandonados } \\
\text { - Número de cursos on-line concluídos }\end{array}$ \\
\hline \multicolumn{4}{|l|}{ Variáveis Externas } \\
\hline Influência Social & $\begin{array}{l}\text { Percepção da pessoa sobre o que } \\
\text { pessoas que são importantes para } \\
\text { ela pensam em relação a dever ou } \\
\text { não realizar o comportamento em } \\
\text { questão }\end{array}$ & $\begin{array}{l}\text { SCHILLEWAERT et } \\
\text { al, 2000; } \\
\text { VENKATESH; } \\
\text { DAVIS, } 2000\end{array}$ & $\begin{array}{l}\text { - Indicação da importância do e-learning pelo superior imediato } \\
\text { - Estímulo do superior imediato para participar do e-learning } \\
\text { - Influência dos colegas em relação à participação no e-learning } \\
\text { - Prestígio resultante da participação no e-learning }\end{array}$ \\
\hline
\end{tabular}


Quadro 9 - Variáveis do Modelo Preliminar de Adoção do e-Learning

\begin{tabular}{|c|c|c|c|}
\hline Dimensão & Definição & Base Conceitual & \begin{tabular}{|l} 
Variáveis \\
\end{tabular} \\
\hline $\begin{array}{l}\text { Pré-disposição para } \\
\text { Inovar }\end{array}$ & $\begin{array}{l}\text { Tendência de experimentar e adotar } \\
\text { novas tecnologias de informação, } \\
\text { independentemente da experiência } \\
\text { informada por outros }\end{array}$ & $\begin{array}{l}\text { SCHILLEWAERT et } \\
\text { al, 2000; ROGERS, } \\
1995\end{array}$ & $\begin{array}{l}\text { - Disposição para experimentar novas tecnologias } \\
\text { - Necessidade de ver uma inovação sendo usada antes de usá-la } \\
\text { - Perfil de novo adotante }\end{array}$ \\
\hline $\begin{array}{l}\text { Auto-eficácia com } \\
\text { Computadores }\end{array}$ & $\begin{array}{l}\text { Nível de capacidade percebido pelo } \\
\text { indivíduo na utilização de um } \\
\text { computador }\end{array}$ & GONG et al, 2004 & $\begin{array}{l}\text { - Habilidade para utilizar um novo software } \\
\text { - Necessidade de ver um software sendo usado antes de usá-lo } \\
\text { - Facilidade com informática }\end{array}$ \\
\hline $\begin{array}{l}\text { Influência das } \\
\text { Características } \\
\text { Pessoais }\end{array}$ & $\begin{array}{l}\text { Grau em que o perfil do adotante } \\
\text { influencia a adoção do e-learning }\end{array}$ & $\begin{array}{l}\text { SCHILLEWAERT et } \\
a l, 2000\end{array}$ & $\begin{array}{l}\text { - Experiência com o e-learning fora da empresa } \\
\text { - Gênero }\end{array}$ \\
\hline $\begin{array}{l}\text { Alinhamento com } \\
\text { Requisitos do } \\
\text { Negócio }\end{array}$ & $\begin{array}{l}\text { Grau de alinhamento entre a } \\
\text { solução de e-learning e as } \\
\text { necessidades do negócio }\end{array}$ & $\begin{array}{l}\text { TYAN, 2003; } \\
\text { BOROTIS; } \\
\text { POULYMENAKOU, } \\
2004\end{array}$ & $\begin{array}{l}\text { - Potencial do e-learning para atender às necessidades de treinamento do negócio } \\
\text { - Atendimento adequado do projeto existente às necessidades do negócio }\end{array}$ \\
\hline $\begin{array}{l}\text { Apoio da Alta } \\
\text { Administração }\end{array}$ & $\begin{array}{l}\text { Nível de patrocínio e } \\
\text { comprometimento da Alta } \\
\text { Administração com o e-learning }\end{array}$ & $\begin{array}{l}\text { SCHILLEWAERT et } \\
a l, 2000\end{array}$ & $\begin{array}{l}\text { - Patrocínio da empresa para participação no e-learning } \\
\text { - Comprometimento da Alta Administração com o uso do e-learning }\end{array}$ \\
\hline $\begin{array}{l}\text { Favorecimento da } \\
\text { Cultura } \\
\text { Organizacional }\end{array}$ & $\begin{array}{l}\text { Grau em que o conjunto de valores } \\
\text { e pressupostos básicos } \\
\text { desenvolvidos pelo grupo favorece } \\
\text { a aprendizagem e o e-learning }\end{array}$ & $\begin{array}{l}\text { ROSENBERG, 2000; } \\
\text { TYAN, 2003; VAN } \\
\text { DAM, } 2004\end{array}$ & $\begin{array}{l}\text { - Cultura favorece a adoção do e-learning } \\
\text { - Cultura valoriza a aprendizagem }\end{array}$ \\
\hline $\begin{array}{l}\text { Adequação do } \\
\text { Projeto de } e- \\
\text { Learning }\end{array}$ & $\begin{array}{l}\text { Grau de adequação do projeto de } e \text { - } \\
\text { learning da empresa, considerando } \\
\text { suporte ao usuário, disponibilidade } \\
\text { de recursos tecnológicos, ações de } \\
\text { comunicação e política de incentivo }\end{array}$ & $\begin{array}{l}\text { SCHILLEWAERT et } \\
\text { al, 2000; } \\
\text { VENKATESH et al, } \\
2003\end{array}$ & $\begin{array}{l}\text { - Disponibilização de instruções e orientações para usar o e-learning } \\
\text { - Disponibilidade de uma pessoa (ou grupo) para auxiliar no uso do e-learning } \\
\text { - Suficiência dos recursos tecnológicos } \\
\text { - Conhecimento sobre o suporte disponível ao e-learning } \\
\text { - Sucesso das campanhas de comunicação do e-learning } \\
\text { - Sucesso da campanha de incentivo ao uso do e-learning } \\
\text { - Voluntariedade de uso }\end{array}$ \\
\hline
\end{tabular}


Com o objetivo de orientar a condução desta pesquisa, foram definidas hipóteses fundamentais $^{81}$ de forma a auxiliar o cumprimento dos objetivos específicos propostos, conforme apresentado no Quadro 10. As hipóteses se referem à $H_{0}$, a hipótese (nula) que se pretende rejeitar. Somente o primeiro objetivo específico que não possui hipótese relacionada, tendo em vista a natureza da análise envolvida.

\section{Quadro 10 - Hipóteses da Pesquisa}

\begin{tabular}{|c|c|}
\hline Objetivo Específico & Hipóteses \\
\hline $\begin{array}{l}\text { 1. Comparar as dimensões do modelo } \\
\text { conceitual proposto com aquelas } \\
\text { observadas na empresa estudada, } \\
\text { identificando aprimoramentos no Modelo } \\
\text { Preliminar de Adoção Individual do } e \text { - } \\
\text { Learning }\end{array}$ & (Não há hipótese relacionada) \\
\hline $\begin{array}{l}\text { 2. Analisar as diferenças de percepção entre } \\
\text { os colaboradores que realizaram e que não } \\
\text { realizaram curso de e-learning na } \\
\text { empresa, desde } 2006\end{array}$ & $\begin{array}{l}\text { Hipótese } \mathbf{1}-\boldsymbol{H}_{0} \text { : Mesmo grau de concordância entre os } \\
\text { respondentes que realizaram e que não realizaram curso de } e \text { - } \\
\text { learning na empresa, desde } 2006 \text {, em relação às variáveis que } \\
\text { influenciam a adoção do e-learning. }\end{array}$ \\
\hline \multirow[t]{2}{*}{$\begin{array}{l}\text { 3. Analisar as diferenças de percepção em } \\
\text { função do perfil do respondente }\end{array}$} & $\begin{array}{l}\text { Hipótese } 2 \text { - } \boldsymbol{H}_{0} \text { : Mesmo grau de concordância entre os } \\
\text { respondentes que realizaram e não realizaram curso de } \boldsymbol{e} \text { - } \\
\text { learning fora da plataforma da empresa em relação às } \\
\text { variáveis que influenciam a adoção do e-learning }\end{array}$ \\
\hline & $\begin{array}{l}\text { Hipótese } 3 \text { - } \boldsymbol{H}_{0} \text { : Mesmo grau de concordância entre os } \\
\text { respondentes homens e mulheres em relação às variáveis que } \\
\text { influenciam a adoção do e-learning }\end{array}$ \\
\hline $\begin{array}{l}\text { 4. Identificar as variáveis que melhor } \\
\text { explicam a intenção de realizar ou não cursos } \\
\text { de e-learning na empresa }\end{array}$ & $\begin{array}{l}\text { Hipótese } 4-\boldsymbol{H}_{0} \text { : As dimensões }{ }^{82} \text { do Modelo de Adoção } \\
\text { Individual do e-Learning não influenciam a Intenção de Uso do } \\
\text { e-learning }\end{array}$ \\
\hline $\begin{array}{l}\text { 5. Identificar as variáveis que melhor } \\
\text { explicam a realização ou não de cursos de } e \text { - } \\
\text { learning na empresa }\end{array}$ & $\begin{array}{l}\text { Hipótese } 5 \text { - } \boldsymbol{H}_{0} \text { : As dimensões }{ }^{82} \text { do Modelo de Adoção } \\
\text { Individual do e-Learning não influenciam o Comportamento de } \\
\text { Uso do e-learning }\end{array}$ \\
\hline
\end{tabular}

\footnotetext{
${ }^{81}$ A definição das hipóteses deste estudo não tem por objetivo possibilitar a generalização dos resultados, uma vez que estes estão limitados às particularidades da empresa pesquisada.

${ }^{82}$ Utilidade do e-Learning Percebida, Facilidade de Uso do e-Learning Percebida, Atitude em Relação ao eLearning, Influência Social, Pré-disposição para Inovar, Auto-eficácia com Computadores, Influência das Características Pessoais, Alinhamento com Requisitos do Negócio, Apoio da Alta Administração, Favorecimento da Cultura Organizacional e Adequação do Projeto de e-Learning.
} 


\subsection{Abordagem da Pesquisa}

A abordagem de métodos mistos é "útil para capturar as vantagens de ambas as abordagens quantitativa e qualitativa" 83 (CRESWELL, 2003, p. 22); ou seja, "A eficácia da triangulação fundamenta-se na premissa de que a fraqueza de um método será compensada pela força do outro" (FLEURY et al, 1997, p. 36). Esta foi selecionada como a abordagem mais adequada, uma vez que a presente pesquisa visa, ao mesmo tempo, identificar fatores que influenciam um resultado (comportamento de uso do e-learning), situação em que a pesquisa quantitativa é melhor, e analisar um tema pouco pesquisado (adoção do e-learning na organização), situação em que a abordagem qualitativa é apropriada.

O processo de combinar métodos qualitativos e quantitativos pode ser estruturado conforme vários fatores (BRANNEN, 1992, p.23):

- "a importância relativa que é atribuída a cada uma das abordagens dentro do projeto global";

- "o estágio do processo de pesquisa em que cada método entra em ação ou sai de evidência"; e,

- "a divisão de tarefas entre a equipe de pesquisadores" $" 84$.

De acordo com Creswell, "a abordagem de triangulação simultânea é provavelmente a mais conhecida [...]. Esta é selecionada como modelo, quando um pesquisador usa dois métodos diferentes em uma tentativa de confirmar, validar transversalmente ou corroborar os resultados dentro de um único estudo" ${ }^{\# 5}$ (2003, p. 217).

Essa estratégia múltipla de pesquisa, provavelmente, teve sua adoção iniciada em 1959 com o estudo de Campbell e Fiske sobre traços psicológicos (CRESWELL, 2003; BRANNEN,

\footnotetext{
83 "useful to capture the best of both quantitative and qualitative approaches"

84 "[...] the relative importance that is given to each approach within the overall project"; "[...] the extent to which methods are carried out consecutively or simultaneously"; "[...] the stage in the research process at which the respective methods come into play or cease to be in evidence"; "[...] the division of skills in the research team"

85 "The concurrent triangulation approach is probably the most familiar [...]. It is selected as the model when a researcher uses two different methods in an attempt to confirm, cross-validate, or corroborate findings within a single study"
} 
1992) e posteriormente foi desenvolvida por Denzin $\left(1970^{86}\right)$, que ampliou o termo triangulação para envolver "não só métodos e dados, mas também pesquisadores e teorias" ${ }^{87}$ (BRANNEN, 1992, p. 11).

A triangulação pode ser "definida como a combinação de metodologias no estudo de um mesmo fenômeno" (JICK, 1979), fornecendo ao pesquisador diferentes sinais, sendo que "mesmo quando estes inicialmente nos confundem, eventualmente podem nos fornecer informações úteis" $" 88$ (DUNCAN, 1989, p. 21).

A Figura 22 apresenta a combinação de técnicas sugerida por Duncan (1986 apud FLEURY et al, 1997).

\begin{tabular}{|l|l|l|}
\hline $\begin{array}{l}\text { Questionário Auto- } \\
\text { administrado } \\
\text { - Quantitativo } \\
\text { - Objetivo } \\
\text { - Visão do nativo }\end{array}$ & $\begin{array}{l}\text { Entrevista pessoal } \\
\bullet \text { Quantitativa } \\
\bullet \text { Subjetiva } \\
\bullet \text { Visão do nativo }\end{array}$ \\
\hline & & \\
\hline & & \\
\hline $\begin{array}{l}\text { Análise dos Arquivos } \\
\text { - Quantitativa } \\
\text { - Objetiva }\end{array}$ & $\begin{array}{l}\text { Observação Participante do nativo } \\
\text { • Quantitativa } \\
\bullet \text { Objetiva } \\
\text { •Visão Externa }\end{array}$ & $\begin{array}{l}\text { Observação Livre } \\
\text { das Redondezas } \\
\bullet \text { Quantitativa } \\
\bullet \text { Subjetiva } \\
\bullet \text { Visão Externa }\end{array}$ \\
\hline
\end{tabular}

Figura 22 - Triângulo Metodológico para o Estudo de Cultura Organizacional FONTE: DUNCAN, 1986 apud FLEURY et al, 1997, p. 35

Conforme já mencionado, o presente estudo iniciou-se com uma pesquisa bibliográfica sobre Adoção de Inovações e sobre Implementação do e-learning. Em seguida, a pesquisa empírica

\footnotetext{
${ }^{86}$ DENZIN, N.K. The Research Act in Sociology. London: Butterworth, 1970.

87 "[...] not merely involve methods and data but investigators and theories as well"

88 "[...] even when they initially confuse us, eventually can provide us with useful information"
} 
foi realizada em duas fases: (1) revisão dos fatores que influenciam a adoção do e-learning identificados na revisão bibliográfica, a partir de entrevistas com especialistas e pré-teste do questionário, resultando no Modelo Preliminar de Adoção Individual do e-Learning; (2) análise dos fatores de adoção individual em uma empresa do setor de telecomunicações que utiliza o e-learning, fase em que foi utilizada a abordagem de triangulação para analisar os dados obtidos a partir dos questionários, entrevistas e análise de documentos da empresa estudada. A Figura 23 apresenta o esquema da pesquisa, incluindo como resultado da Fase 1 da pesquisa empírica o Modelo Preliminar de Adoção do e-Learning e como resultado da Fase 2 o Modelo de Adoção Individual do e-Learning na Empresa Estudada.

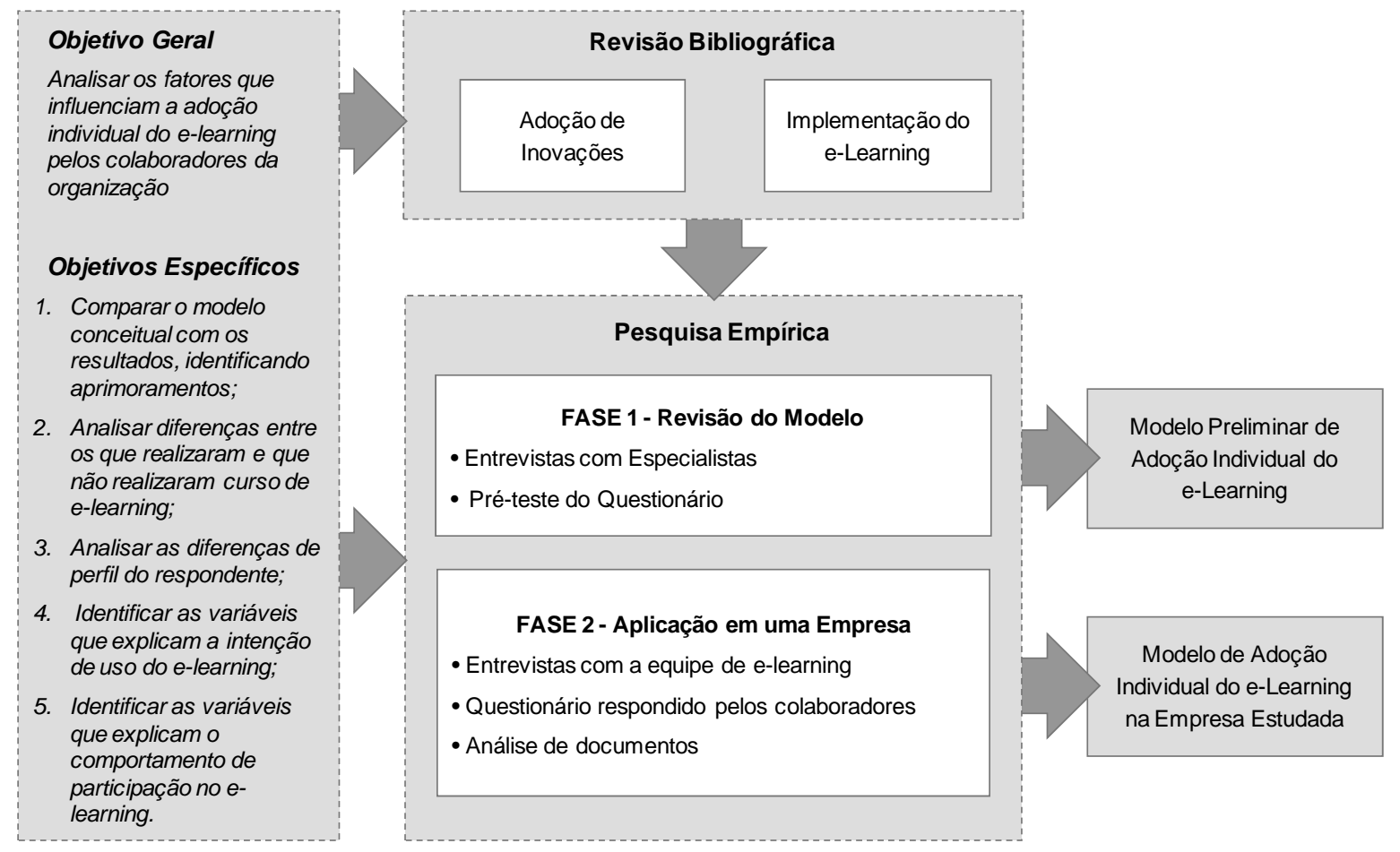

Figura 23 - Esquema da Pesquisa

Tendo em vista as dimensões do contexto organizacional que foram adicionadas ao modelo, optou-se por conduzir a pesquisa em uma única empresa, possibilitando analisar com maior profundidade essas variáveis, como a adequação do projeto de e-learning e o favorecimento da cultura organizacional. É importante ressaltar, que embora a pesquisa tenha sido realizada em uma empresa, a unidade de análise é o indivíduo; ou seja, o funcionário dessa empresa.

Outra escolha importante desta pesquisa se refere ao setor da empresa estudada. O setor de telecomunicações foi selecionado, uma vez que o uso das Tecnologias de Informação e 
Comunicação faz parte do próprio negócio dessas empresas; resultando na possibilidade de analisar uma empresa com menores limitações de infra-estrutura tecnológica para a condução do projeto de e-learning.

A seguir, é apresentada uma breve descrição do setor de telecomunicações e do perfil da empresa pesquisada e são apresentadas informações relevantes sobre o projeto de e-learning na empresa.

\subsubsection{O Setor de Telecomunicações}

"Em geral, o setor de telecomunicações é dividido nos seguintes segmentos: serviço telefônico fixo comutado; serviços móveis; serviço de comunicação de massa (radiodifusão e TV por assinatura); e serviços multimídia (comunicação de dados, linha dedicada etc.).” (NEVES, 2002, p. 16). Outra maneira de organizar o setor é proposta por Fransman (2002), que mapeou a indústria global de telecomunicações em seis camadas (Figura 24).

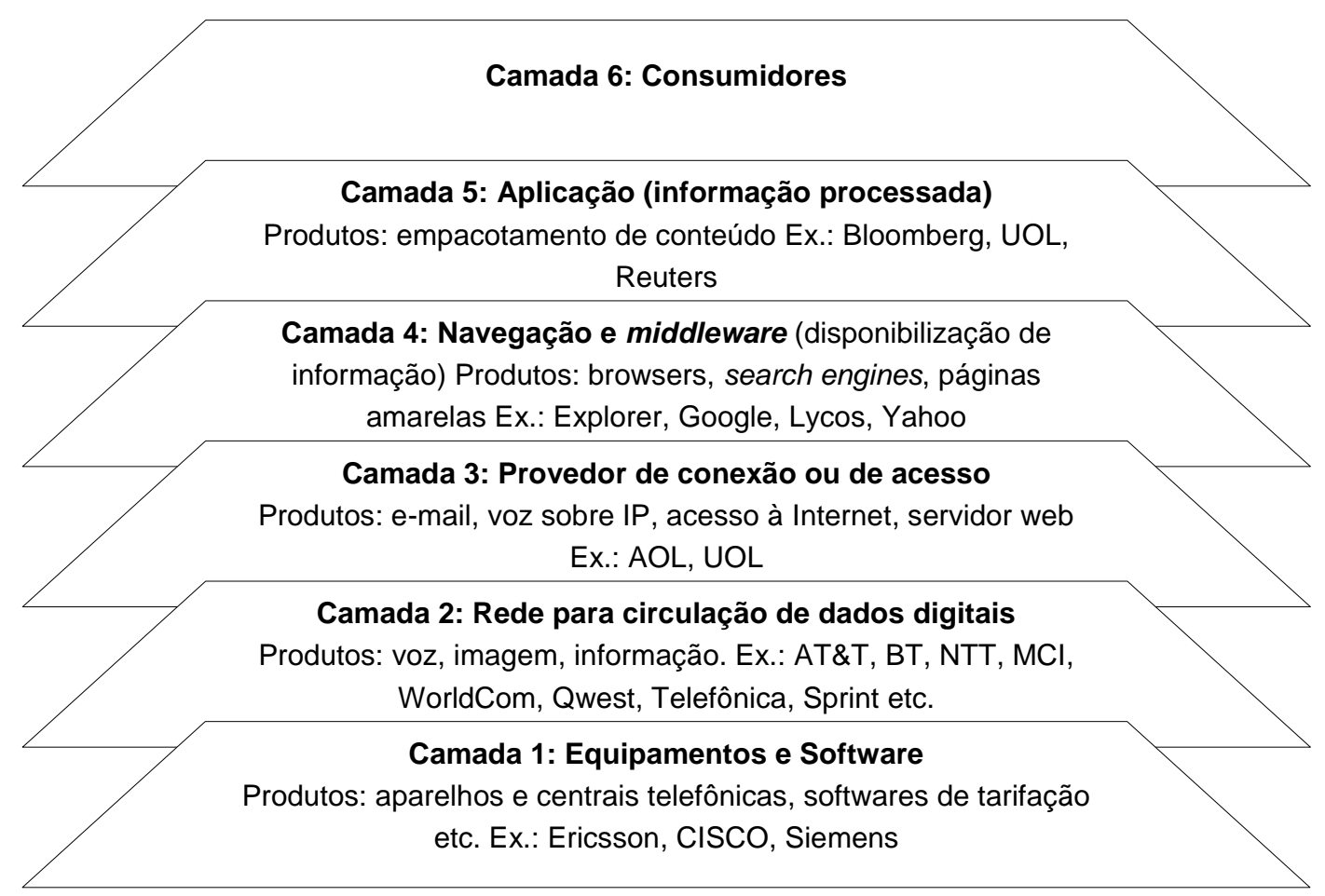

Figura 24 - Modelo em camadas para o setor de telecomunicações FONTE: SBRAGIA et al, 2006, p. 14 
"Nas cinco últimas décadas, o setor de telecomunicações passou por transformações estruturais significativas no Brasil e no mundo [...]” (NEVES, 2002, p. 1), envolvendo aspectos como: acervo tecnológico, dinâmicas concorrenciais e relações comerciais.

Neves (2002), ao analisar a evolução do setor de telecomunicações, identifica no tempo três períodos principais:

\section{- Período 1952-71 - O crescimento desordenado e a institucionalização da ação} governamental: Durante a década de 50, a comunicação telefônica se dava com auxílio de telefonista, serviço prestado por "cerca de mil companhias telefônicas, com grandes dificuldades operacionais, sem padronização e, consequentemente, sem interconexão" (Ibid., p. 2). Já na década de 60, as primeiras centrais eletromecânicas são introduzidas no país e o setor passa a ser controlado por uma autoridade federal, através de uma lei que definiu, também, "a política de telecomunicações, a sistemática tarifária e o plano para integrar as companhias [...]” (Ibid., p. 2). A ação governamental deveu-se ao resultado negativo na qualidade do serviço e preço praticado pelas várias operadoras urbanas da época.

\section{- Período 1972-96 - A expansão da Telebrás e o esgotamento do modelo estatal: No} início da década de 70, novas tecnologias permitiram às operadoras ampliar a capacidade de assinantes em cada central, possibilitando ganhos de escala. Em 1972, é criada a Telebrás, que passa a ser a prestadora estatal dos serviços de telecomunicações, promovendo a incorporação das companhias telefônicas existentes e instituindo uma empresa-pólo em cada estado. Esta ação acompanhou a tendência mundial de forte atuação do Estado, observada no período, tendo como conseqüência "a formação de cadeias produtivas locais, com empresas de base e de tecnologia nacional voltadas para atender às demandas específicas que as operadoras estatais induziam.” (Ibid., p. 4). Também nesse período, em 1976, é criado o CPqD, responsável pela condução de projetos de inovação tecnológica no setor. Nos anos 80 , fatores como "os reajustes das tarifas inferiores à inflação" e "a politização dos cargos executivos das estatais" (Ibid., p. 5) reduziram a capacidade de investimento, tendo como conseqüência a formação gradativa de uma grande demanda reprimida (Ibid.; GUILHOTO; RUBAL, 2006). “[...] na primeira metade da década de 90, o evidente 
esgotamento do modelo e as dificuldade de financiar o setor endossaram a necessidade de rever a estrutura prevista para as telecomunicações.” (NEVES, 2002, p. $6)$.

- Período 1997-2001 - A implantação de um novo modelo visando a universalização, qualidade e competição: $O$ processo foi iniciado com a mudança da Constituição Federal, seguida pela promulgação da Lei Mínima e da Lei Geral de Telecomunicações, em 1997, que implementou o órgão regulador e aprovou os planos para reestruturação. Em 1998, o Sistema Telebrás foi privatizado e, em 1999, foram criadas as empresas-espelhos de telefonia fixa e de longa distância. Neste período foi implantada a telefonia móvel. Os objetivos foram, em boa parcela, alcançados, como é possível observar, por exemplo, no crescimento do número de acessos instalados na telefonia fixa, de 16,5 milhões em 1996 para 47,8 milhões em 2001, e, no aumento da teledensidade de 1,7 acessos por cem habitantes em 1996 para 17 em 2001.

Ao discutir o futuro do setor, Marchetti e Prado (2006, p. 232) mencionam o estudo realizado pela Pyramid Research, no Brasil, que identificou o estágio de evolução das tecnologias de conectividade (Figura 25).

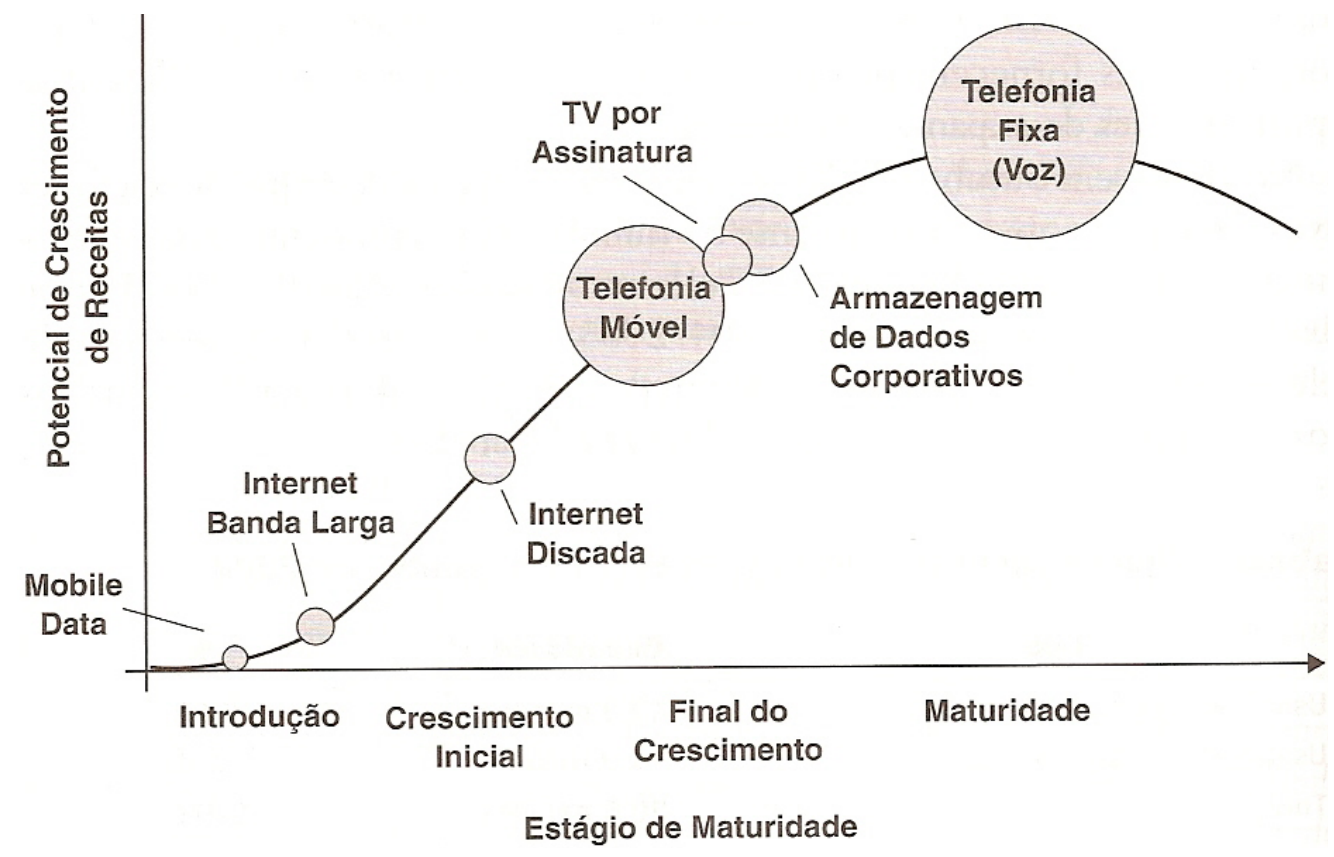

Figura 25 - Estágio de Evolução das Tecnologias de Conectividade FONTE: MARCHETTI; PRADO, 2006, p. 232

Observação: O tamanho das circunferências indica o volume de recursos movimentados em cada um dos estágios. 
Os resultados demonstram que "as tecnologias que possibilitam a conectividade de forma mais intensa, como acesso à Internet via banda larga e sistemas móveis sem fio (wireless), ainda estão no primeiro estágio de evolução" (MARCHETTI; PRADO, 2006, p. 232), já a tecnologia de telefonia fixa encontra-se no estágio de maturidade, movimentando maior volume de recursos.

O segmento de telefonia fixa, além de ser o único com tecnologia classificada no estágio de maturidade, possui um ambiente competitivo diferenciado. Diferentemente de outros segmentos, como o de celulares por exemplo, a telefonia fixa experimenta um ambiente competição ainda restrita (OLIVEIRA, 2006, p. 78), uma vez que as empresas espelho não conseguiram obter participação significativa no market share (Tabela 2).

Tabela 2 - Telefonia Fixa: Market Share de Acessos em Serviço (2006)

\begin{tabular}{lccc}
\hline & Região I & Região II & Região III \\
\hline $\begin{array}{l}\text { Concessionárias } \\
\text { (empresas privatizadas } \\
\text { do Sistema Telebrás) }\end{array}$ & $\mathbf{9 2 , 6 \%}$ & $\mathbf{9 0 , 7 \%}$ & $\mathbf{9 2 , 2 \%}$ \\
& $\begin{array}{c}\text { Empresas: Telemar e } \\
\text { CTBC }\end{array}$ & $\begin{array}{c}\text { Empresas: Brasil } \\
\text { Telecom, Sercomtel e } \\
\text { CTBC }\end{array}$ & $\begin{array}{c}\text { Empresas: Telefônica e } \\
\text { CTBC }\end{array}$ \\
$\begin{array}{l}\text { Empresas Espelho } \\
\text { (empresas que } \\
\text { receberam autorização, } \\
\text { em 1999) }\end{array}$ & $\begin{array}{c}\mathbf{7 , 4 \%} \\
\text { Principal Empresa: } \\
\text { Embratel }\end{array}$ & Principal Empresa: GVT & $\begin{array}{c}\text { Principal Empresa: } \\
\text { Embratel }\end{array}$ \\
\hline
\end{tabular}

A indústria mundial de comunicações móveis, por seu lado, tem experimentado um crescimento extraordinário nos últimos dez anos, fundamentalmente devido ao avanço tecnológico dos circuitos integrados e de radiofreqüência (RF), além de outras tecnologias que tornaram os telefones celulares portáteis, pequenos, baratos e mais confiáveis.

De modo geral, a telefonia celular passou por três gerações distintas, ditadas pelas pressões de mercado e pelo avanço tecnológico. A primeira geração caracterizava-se pela transmissão de voz analógica, a segunda pela transmissão de voz digital e provimento de alguns serviços, tais como envio de mensagens de texto, e finalmente a terceira geração tem como principais características a transmissão de voz digital e transferência de dados em banda larga (Internet, correio eletrônico, etc). 
Sob o ponto de vista da competição, em particular no Brasil, as empresas de telefonia celular já estabelecidas no mercado antes da privatização, a despeito de terem partido na frente na corrida por aquisição de clientes, sofrem hoje forte concorrência das operadoras entrantes e pode-se dizer que há ampla e acirrada concorrência nesse mercado. A Tabela 3 ilustra a participação de mercado de cada uma das operadoras atuantes no Brasil, numa perspectiva histórica.

Tabela 3 - Market Share das Operadoras de Telefonia Celular Atuantes no Brasil

\begin{tabular}{cccc}
\hline & $\mathbf{2 0 0 5}$ & $\mathbf{2 0 0 6}$ & $\mathbf{2 0 0 7}$ \\
\hline Vivo & $34,54 \%$ & $29,08 \%$ & $27,68 \%$ \\
\hline TIM & $23,42 \%$ & $25,45 \%$ & $25,85 \%$ \\
\hline Claro & $21,64 \%$ & $23,90 \%$ & $24,99 \%$ \\
\hline Oi & $11,99 \%$ & $13,09 \%$ & $13,21 \%$ \\
\hline Telemig Celular & \multirow{2}{*}{$5,30 \%$} & $3,44 \%$ & $3,22 \%$ \\
\cline { 1 - 3 } Amazônia Celular & & $1,21 \%$ & $1,17 \%$ \\
\hline BrT GSM & $2,57 \%$ & $3,38 \%$ & $3,52 \%$ \\
\hline CTBC & $0,45 \%$ & $0,37 \%$ & $0,30 \%$ \\
\hline Sercomtel & $0,09 \%$ & $0,08 \%$ & $0,06 \%$ \\
\hline Total (milhares) & $\mathbf{8 6 . 2 1 0}$ & $\mathbf{9 9 . 9 1 9}$ & $\mathbf{1 2 0 . 9 8 0}$ \\
\hline \multicolumn{5}{c}{ Fonte: ANATEL $(2008)$} \\
\end{tabular}

\subsubsection{Descrição da Empresa Pesquisada e seu Projeto de $e$-Learning}

A seguir é apresentada uma breve descrição da empresa pesquisada, além das informações sobre o seu projeto de e-learning (levantadas a partir das entrevistas).

\section{Perfil da Empresa Pesquisada}

Trata-se de uma empresa de mais de 80 anos que figura hoje entre as três maiores do mundo no setor de telecomunicações em número de clientes, com 212,6 milhões de acessos (soma de linhas fixas, celulares, banda larga, comunicação de dados), receita líquida de $€ 52,9$ bilhões (2006), presente em 23 países e com mais de 200.000 empregados (Relatório Semestral da empresa, Out/2007). 


\section{O Projeto de e-Learning da Empresa}

A plataforma de e-learning utilizada foi desenvolvida pela matriz (localizada fora do Brasil), de forma que a solução oferecida é global, atendendo a todos os empregados dos diferentes países nos quais a empresa tem presença. Atualmente, o ambiente disponibiliza mais de 1.500 cursos em 3 idiomas, havendo a possibilidade de, se necessário, ajustar determinados cursos à realidade local, resultando em economias de recursos se comparado ao desenvolvimento integral de tais conteúdos.

Além do catálogo global de cursos, a empresa pesquisada dispõe de aproximadamente 150 cursos on-line em português para participação livre pelos colaboradores. Conforme apontado na entrevista, a maioria dos cursos de e-learning pressupõe a participação voluntária. Diferentemente dessa política, a partir de julho de 2007 foi disponibilizado um curso on-line sobre ética com participação obrigatória de todos os funcionários mundialmente. Todos os cursos são gratuitos para o funcionário.

A organização da equipe de e-learning é diferente em cada país do grupo; há locais onde a equipe de operação do e-learning é formada por funcionários da própria empresa, sendo que em outros a gestão do e-learning é realizada com a colaboração de parceiros. A operação da plataforma global é conduzida por uma empresa específica pertencente ao grupo e, no caso do Brasil, um parceiro local fornece o suporte técnico e opera o gerenciamento das turmas.

A equipe local da empresa pesquisada é responsável pela gestão do programa, integração com o negócio e otimização das ações de treinamento e desenvolvimento por meio do e-learning. Essa equipe é formada por um especialista da área de Recursos Humanos e por facilitadores que, de modo complementar às suas atividades nas áreas de negócio, servem como postos avançados para o time de $\mathrm{RH}$ nas atividades relacionadas ao e-learning. No período de realização desta pesquisa, a empresa contava com aproximadamente 50 facilitadores do projeto de e-learning. Enquanto o especialista de RH estabelece as diretrizes de atuação do programa, define as ferramentas de acompanhamento e providencia as ações de comunicação, os facilitadores são responsáveis pela disseminação do e-learning na sua área e apoio local às demandas de formação. 
A integração do sistema de e-learning com o sistema de gestão de pessoas ainda não existe, porém foi relatada a presença de esforços nesse sentido, voltados para integrar o e-learning tanto ao sistema de Avaliação de Competências como ao sistema de gestão da empresa, mais especificamente o módulo de Recursos Humanos, permitindo registro dos cursos, geração de métricas de acompanhamento e consolidação com os dados presenciais.

A infra-estrutura disponível atualmente na empresa foi considerada adequada para o projeto de e-learning. Foi comentado que é oferecida a possibilidade do funcionário realizar o curso on-line a partir da sua própria residência e de disponibilizar o acesso a estes cursos para membros da família.

Os resultados do projeto de e-learning são acompanhados periodicamente através da avaliação de reação e de relatórios mensais, que indicam número de inscrições, conclusões, abandonos, total de horas, entre outras métricas.

\subsection{Necessidades e Fontes de Dados}

O Quadro 11 mostra as fontes para obtenção dos dados de cada variável, durante a condução da pesquisa na empresa (Fase 2), sendo a maioria deles primários ${ }^{89}$ (os dados secundários estão indicados entre parênteses).

89 Dados secundários: dados já coletados, tabulados, ordenados e até analisados para outros propósitos; Dados primários: aqueles que não foram coletados antes, estando ainda com os pesquisados (MATTAR, 1999, p. 134). 


\section{Quadro 11 - Fontes de Dados}

\begin{tabular}{|c|c|c|}
\hline Dimensão & Variáveis & Fonte \\
\hline \multicolumn{3}{|c|}{ Variáveis do Modelo TAM } \\
\hline $\begin{array}{l}\text { Utilidade do } e^{-} \\
\text {Learning } \\
\text { Percebida }\end{array}$ & $\begin{array}{l}\text { - Contribuição do e-learning para a melhora do desempenho } \\
\text { no trabalho } \\
\text { - Utilidade do e-learning no trabalho } \\
\text { - Importância do e-learning para a realização do trabalho } \\
\text { - Obtenção de resultados de aprendizagem com o e-learning } \\
\text { - Flexibilidade para aprender através do e-learning } \\
\text { - Facilidade em explicar os benefícios do e-learning } \\
\text { - Aumento nas chances de promoção em função da } \\
\text { participação no e-learning }\end{array}$ & Colaboradores \\
\hline $\begin{array}{l}\text { Facilidade de } \\
\text { Uso do } e- \\
\text { Learning } \\
\text { Percebida }\end{array}$ & $\begin{array}{l}\text { - Facilidade para usar o e-learning } \\
\text { - Clareza e inteligibilidade da interação com o sistema de } e \text { - } \\
\text { learning }\end{array}$ & Colaboradores \\
\hline $\begin{array}{l}\text { Atitude em } \\
\text { Relação ao } e- \\
\text { Learning }\end{array}$ & $\begin{array}{l}\text { - Sentimento em relação à participação no e-learning } \\
\text { - Satisfação em relação ao uso do e-learning }\end{array}$ & Colaboradores \\
\hline $\begin{array}{l}\text { Intenção de Uso } \\
\text { do e-Learning }\end{array}$ & $\begin{array}{l}\text { - Intenção de participar do e-learning em } 2007 \\
\text { - } \\
\text { Intenção de uso do e-learning, em função do tempo } \\
\text { disponível } \\
\text { - } \\
\text { Intenção de uso do e-learning, em função dos cursos } \\
\text { disponibilizados }\end{array}$ & Colaboradores \\
\hline $\begin{array}{l}\text { Comportamento } \\
\text { de Uso do e- } \\
\text { Learning }\end{array}$ & $\begin{array}{l}\text { - Participação em pelo menos um curso na plataforma de } e \text { - } \\
\text { learning da empresa, desde } 2006 \\
\text { - Motivos da não participação no e-learning } \\
\text { - Freqüência de uso do e-learning } \\
\text { - Aproveitamento dos cursos de } e \text {-learning } \\
\text { - Número de cursos on-line inscritos } \\
\text { - Número de cursos on-line abandonados } \\
\text { - Número de cursos on-line concluídos }\end{array}$ & $\begin{array}{l}\text { Relatório do sistema de } \\
\text { e-learning (dado } \\
\text { secundário) }\end{array}$ \\
\hline \multicolumn{3}{|c|}{ Variáveis Externas } \\
\hline Influência Social & $\begin{array}{l}\text { - Indicação da importância do e-learning pelo superior } \\
\text { imediato } \\
\text { - Estímulo do superior imediato para participar do e-learning } \\
\text { - Influência dos colegas em relação à participação no } e \text { - } \\
\text { learning } \\
\text { - Prestígio resultante da participação no e-learning }\end{array}$ & Colaboradores \\
\hline $\begin{array}{l}\text { Pré-disposição } \\
\text { para Inovar }\end{array}$ & $\begin{array}{l}\text { - Disposição para experimentar novas tecnologias } \\
\text { - Necessidade de ver uma inovação sendo usada antes de usá- } \\
\text { la } \\
\text { - Perfil de novo adotante }\end{array}$ & Colaboradores \\
\hline $\begin{array}{l}\text { Auto-eficácia } \\
\text { com } \\
\text { Computadores }\end{array}$ & $\begin{array}{l}\text { - Habilidade para utilizar um novo software } \\
\text { - Necessidade de ver um software sendo usado antes de usá-lo } \\
\text { - Facilidade com informática }\end{array}$ & Colaboradores \\
\hline $\begin{array}{l}\text { Características } \\
\text { Pessoais }\end{array}$ & $\begin{array}{l}\text { - Experiência com o e-learning fora da empresa } \\
\text { - Gênero }\end{array}$ & $\begin{array}{l}\text { Colaboradores } \\
\text { Dados do funcionário } \\
\text { (dado secundário) }\end{array}$ \\
\hline $\begin{array}{l}\text { Alinhamento } \\
\text { com Requisitos } \\
\text { do Negócio }\end{array}$ & $\begin{array}{l}\text { - Potencial do e-learning para atender às necessidades de } \\
\text { treinamento do negócio } \\
\text { - Atendimento adequado do projeto existente às necessidades } \\
\text { do negócio }\end{array}$ & $\begin{array}{l}\text { Colaboradores } \\
\text { Responsável pelo } e- \\
\text { learning }\end{array}$ \\
\hline $\begin{array}{l}\text { Apoio da Alta } \\
\text { Administração }\end{array}$ & $\begin{array}{l}\text { - Patrocínio da empresa para participação no e-learning } \\
\text { - Comprometimento da Alta Administração com o uso do } e \text { - } \\
\text { learning }\end{array}$ & $\begin{array}{l}\text { Colaboradores } \\
\text { Responsável pelo } e- \\
\text { learning }\end{array}$ \\
\hline
\end{tabular}


Quadro 11 - Fontes de Dados

\begin{tabular}{|c|c|c|}
\hline Dimensão & Variáveis & Fonte \\
\hline $\begin{array}{l}\text { Favorecimento } \\
\text { da Cultura } \\
\text { Organizacional }\end{array}$ & $\begin{array}{l}\text { - Cultura favorece a adoção do e-learning } \\
\text { - Cultura valoriza a aprendizagem }\end{array}$ & $\begin{array}{l}\text { Colaboradores } \\
\text { Responsável pelo e- } \\
\text { learning }\end{array}$ \\
\hline $\begin{array}{l}\text { Adequação do } \\
\text { Projeto de } e \text { - } \\
\text { Learning }\end{array}$ & $\begin{array}{l}\text { - Disponibilização de instruções e orientações para usar o e- } \\
\text { learning } \\
\text { - Disponibilidade de uma pessoa (ou grupo) para auxiliar no } \\
\text { uso do e-learning } \\
\text { - Suficiência dos recursos tecnológicos } \\
\text { - Conhecimento sobre o suporte disponível ao e-learning } \\
\text { - Sucesso das campanhas de comunicação do e-learning } \\
\text { - Sucesso da campanha de incentivo ao uso do e-learning } \\
\text { - Voluntariedade de uso }\end{array}$ & $\begin{array}{l}\text { Colaboradores } \\
\text { Responsável pelo } e \text { - } \\
\text { learning }\end{array}$ \\
\hline
\end{tabular}

\subsection{Técnicas e Instrumentos de Coleta dos Dados}

A coleta dos dados primários da pesquisa na empresa (Fase 2) foi realizada através de questionário disponibilizado na web para preenchimento pelos colaboradores e entrevistas individuais, conforme apresentado a seguir.

Quando a fonte de dados são os colaboradores (Quadro 11), os dados foram obtidos através do questionário auto-preenchido. No caso da fonte se tratar do responsável pelo e-learning na empresa, os dados foram levantados através de entrevistas semi-estruturadas.

\subsubsection{O Questionário Auto-Preenchido}

Para Silva et al (1997, p. 410) "questionário seria uma forma organizada e previamente estruturada de coletar na população pesquisada informações adicionais e complementares sobre determinado assunto sobre o qual já se detém certo grau de domínio." Silva et al (1997, p. 410) também citam o conceito proposto por Tull e Hawkins (1976, p. 373 apud SILVA et al, 1997) para a pesquisa do tipo survey: "coleta sistemática de informações a partir dos respondentes com o propósito de compreender e/ou prever alguns aspectos do comportamento da população em estudo". O principal ponto fraco do survey é sua "dependência da capacidade e da disposição dos respondentes em cooperar" (BATAGLIA, 2006, p. 80). 
O questionário pode ser aplicado de três formas: entrevista pessoal, entrevista por telefone ou questionário auto-preenchido (FRICKER et al, 2005; MATTAR, 1999). No caso do questionário auto-preenchido, existem diferentes maneiras de enviar e receber de volta o questionário (SILVA et al, 1997; MATTAR, 1999): pessoalmente (entrega e recolhimento), correio/fax, Internet, jornais/revistas (recolhimento pelo correio ou urnas), acompanhando o produto (recolhimento pelo correio) e colocado à disposição (recolhimento através de urna).

O questionário eletrônico (ou via web) é aquele que utiliza a Internet para sua aplicação (SILVA et al, 1997), podendo ser disponibilizado duas formas:

- Envio do questionário por e-mail: o questionário é enviado diretamente para o respondente, que deve responder a mensagem com as questões preenchidas. $\mathrm{O}$ questionário pode ser enviado como um arquivo anexo ou no próprio corpo da mensagem.

- Disponibilização do questionário em uma página web: o respondente é informado sobre o endereço da página do questionário na Internet, através de um e-mail, carta ou anúncio na Internet. Para responder as questões o participante da pesquisa deve acessar a página do questionário, responder e, normalmente, ao final, clicar em um botão que envia as informações para o responsável pela pesquisa. Neste caso, o respondente pode ou não precisar se identificar.

Weible e Wallace (1998) realizaram uma pesquisa com o objetivo de analisar a eficiência de quatro métodos de coleta de dados utilizando questionário: correio, fax, e-mail e formulário na Internet. A eficiência foi estudada em termos de tempo e custo necessários para: desenvolver o questionário, preparar para distribuição, entregar e receber o questionário e tabular as respostas. Foram escolhidos aleatoriamente 800 professores americanos com base na lista do MISRC (Directory of Management Information Systems Faculty) e 200 nomes foram designados para cada um dos quatro métodos de distribuição. A Tabela 4 a seguir resume as resultados obtidos pelos autores. 
Tabela 4 - Análise Comparativa dos Métodos de Coleta de Dados

\begin{tabular}{lccccc}
\hline \multicolumn{1}{c}{ Critério de Análise } & Correio & Fax & E-mail & $\begin{array}{c}\text { Formulário } \\
\text { Internet }\end{array}$ & $\begin{array}{c}\text { Todos os } \\
\text { métodos }\end{array}$ \\
\hline Endereços com problema & 4 & 38 & 39 & 49 & 130 \\
\hline Respostas obtidas & 70 & 50 & 48 & 52 & 220 \\
\hline Taxa de resposta com base no total de 800 & $35 \%$ & $25 \%$ & $24 \%$ & $26 \%$ & $27,5 \%$ \\
\hline Taxa de resposta ajustada & $35,7 \%$ & $30,9 \%$ & $29,8 \%$ & $34,4 \%$ & $32,7 \%$ \\
\hline Média do tempo de resposta (dias) & 12,9 & 8,8 & 6,1 & 7,4 & 9,6 \\
\hline Mediana do tempo de resposta (dias) & 12 & 12 & 2 & 5,5 & 12 \\
\hline Custo fixo & US\$ 59 & US\$ 57 & US\$ 57 & US\$ 57 & -- \\
\hline Custo unitário & US\$ 1,56 & US\$ 0,56 & US\$ 0,01 & US\$ 0,01 & -- \\
\hline Custo variável (200 unidades) & US\$ 312 & US\$ 112 & US\$ 2 & US\$ 2 & -- \\
\hline Custo total & US\$ 371 & US\$ 169 & US\$ 59 & US\$ 59 & -- \\
\hline
\end{tabular}

FONTE: WEIBLE; WALLACE, 1998, p. 19

Com base na literatura sobre o tema (EVANS; MATHUR, 2005; FRICKER et al, 2005;

FELSON, 2001; LITVIN; KAR, 2001; COUPER, 2000; PALMER, 2000; GORMAN, 2000;

WEIBLE; WALLACE, 1998; SILVA et al, 1997), o Quadro 12 a seguir apresenta uma descrição das principais vantagens e limitações do uso do questionário via Internet. 


\section{Quadro 12 - Vantagens e Limitações do Uso do Questionário Eletrônico via Internet}

\begin{tabular}{|c|c|c|}
\hline Fator & Vantagem & Limitação \\
\hline $\begin{array}{l}\text { População e } \\
\text { Amostra }\end{array}$ & $\begin{array}{l}\text { Em alguns casos a limitação da amostra ao público com acesso à } \\
\text { Internet não é fator restritivo } \\
\text { Opções para atingir públicos sem acesso à internet: instalação de } \\
\text { quiosques em locais públicos, utilização da internet através da televisão. } \\
\text { A utilização da Internet tende a continuar crescendo nos próximos anos. }\end{array}$ & $\begin{array}{l}\text { Resultados não representativos da população, devido à existência de diferenças sócio- } \\
\text { econômicas entre as pessoas que utilizam a Internet e o restante da população (nível } \\
\text { de escolaridade e renda mais altos e maior percentagem de solteiros) } \\
\text { Baixo controle amostral, devido à falta de conhecimento do respondente no caso do } \\
\text { formulário disponível em página da Internet } \\
\text { Limitação dos respondentes às pessoas com acesso à Internet } \\
\text { Respondentes precisam possuir grau de educação e familiaridade com informática } \\
\text { que permitam responder um questionário eletrônico } \\
\text { Dificuldade para selecionar endereços eletrônicos aleatoriamente } \\
\text { Grande número de endereços incorretos }\end{array}$ \\
\hline $\begin{array}{l}\text { Tempo e } \\
\text { custo da } \\
\text { pesquisa }\end{array}$ & $\begin{array}{l}\text { Menor tempo de realização: questionário chega mais rápido, recebe } \\
\text { respostas em menor tempo, recebe confirmação quase instantânea de } \\
\text { recebimento, agilizando a inclusão de novos nomes na amostra } \\
\text { Baixo custo de aplicação: não utiliza papel; atinge grande número de } \\
\text { respondente e geograficamente distantes; necessidade de infra-estrutura } \\
\text { mínima (computador, conexão com internet, profissional técnico) } \\
\text { Tabulação dos resultados facilitada: resultados transferidos para banco } \\
\text { de dados, reduzindo erro e custo de digitação }\end{array}$ & $\begin{array}{l}\text { Baixa taxa de resposta } \\
\text { Aumento da dificuldade de recrutar participantes, aumenta o custo. } \\
\text { Considerar o custo de compensar os e-mails incorretos. }\end{array}$ \\
\hline $\begin{array}{l}\text { Desenho do } \\
\text { questionário }\end{array}$ & $\begin{array}{l}\text { Cuidados semelhantes ao questionário em papel devem ser considerados } \\
\text { Possibilidade de utilizar novos estímulos, como cores, sons, imagens e } \\
\text { animação e diversas formas de apresentação visual a um menor custo }\end{array}$ & $\begin{array}{l}\text { Maior preocupação com layout e formatação, visto que a aparência pode variar } \\
\text { conforme o software e hardware do respondente } \\
\text { Inclusão de explicação sobre como reenviar o questionário eletrônico } \\
\text { Dificuldade de incluir incentivos específicos para envio da resposta, os incentivos } \\
\text { utilizados pelo correio não são diretamente aplicáveis }\end{array}$ \\
\hline $\begin{array}{l}\text { Aplicação } \\
\text { do } \\
\text { questionário }\end{array}$ & $\begin{array}{l}\text { Automatização de etapas operacionais para enviar questionários (ex.: } \\
\text { colocar conteúdo dos envelopes) } \\
\text { Possibilidade de facilitar a entrada de dados e validar as respostas de } \\
\text { acordo com critério determinado. } \\
\text { Possibilidade de automatizar o questionário, como por exemplo pular } \\
\text { questões }\end{array}$ & $\begin{array}{l}\text { Envio do formulário no corpo da mensagem resulta em formulários menos atrativos, } \\
\text { devido à falta de flexibilidade no layout } \\
\text { Envio do formulário como anexo da mensagem influenciou negativamente a taxa de } \\
\text { resposta (preocupação com vírus ou problemas para abrir o arquivo). } \\
\text { Respondentes podem considerar o recebimento da mensagem de e-mail como invasão } \\
\text { de privacidade } \\
\text { Aumento da dificuldade de recrutar participantes, devido ao excesso de pesquisas e } \\
\text { uso de questionários longos que criam barreiras para participações futuras } \\
\text { Desvio entre a resposta e os valores reais do respondente } \\
\text { Não garantia de anonimato na pesquisa por e-mail } \\
\text { Dificuldade de definir o erro de não resposta }\end{array}$ \\
\hline
\end{tabular}


A partir das vantagens e limitações do questionário eletrônico via Internet apresentadas, é possível sugerir algumas recomendações para aplicação eficaz deste instrumento:

- Restringir a população a ser pesquisada às pessoas com acesso à Internet, como por exemplo: pessoas que fazem compras através da Internet e alunos de um curso à distância.

- Utilizar listas existentes de endereços eletrônicos;

- Manter alguns endereços adicionais para incluir no lugar de endereços incorretos;

- Definir a melhor formatação possível, considerando a opção do anexo versus do envio no corpo da mensagem;

- Incluir incentivo à resposta, como, por exemplo, cupons de desconto ou pontos em programas já existentes na Internet;

- Disponibilizar atendimento para tirar dúvidas dos respondentes utilizando uma ferramenta de chat;

- Enviar uma mensagem (ou telefonar) antes de enviar o questionário, explicando os objetivos e importância da pesquisa e disponibilizando a possibilidade do participante optar por não participar da pesquisa.

Considerando que o questionário desta pesquisa tem como respondentes usuários atuais ou potenciais do e-learning, foi escolhida a aplicação através da web, já que o acesso à internet não representa uma limitação amostral.

Os itens do questionário utilizado nesta pesquisa (Quadro 13) foram construídos com base em instrumentos validados de pesquisas anteriores. Conforme procedimento adotado por Davis et al (1989, p. 991) os constructos do modelo e as medidas utilizadas devem ser ajustadas e escritas em função das especificidades da tecnologia e do contexto; necessidade também apontada por outros autores da literatura sobre adoção de inovações (FRAMBACH; SCHILLEWAERT, 1999; TORNATZKY; FLEISCHER, 1990). Desta forma, os itens do questionário foram traduzidos e ajustados para a inovação em questão (e-learning). $\mathrm{O}$ texto original das questões do Modelo TAM, utilizadas por Venkatesh e Davis (2000), Schillewaert et al (2000) e Venkatesh et al (2003), encontra-se no Apêndice 1. 
Conforme já comentado, além destes ajustes, foram incluídas novas variáveis com base na literatura de adoção organizacional de inovações e de implementação do e-learning.

Diferentemente do apresentado na literatura, no entanto, optou-se pela construção de questões diferenciadas das variáveis do Modelo TAM, sendo uma lista especificamente gerada para os respondentes que fizeram curso de e-learning na plataforma da empresa e outra para os que não fizeram. Essa opção pareceu mais adequada tendo em vista que não faria sentido para o respondente que não participou do e-learning responder a uma questão como "A participação em cursos de e-learning melhorou meu desempenho no trabalho". Desta forma, a questão foi reescrita: "A participação em cursos de e-learning pode melhorar meu desempenho no trabalho". Apesar dessa distinção não ter sido observada na literatura, a resposta para cada uma delas é muito diferente, aspecto que será verificado na análise dos resultados. Os itens do questionário apresentados no Quadro 13 apresentam o texto elaborado para os respondentes que participaram do e-learning, com as alterações entre parêntese, no caso dos respondentes que não participaram do e-learning.

A maioria das variáveis foi medida com uma escala Likert de 7 pontos, da mesma forma que nas pesquisas utilizadas como referência (VENKATESH e DAVIS, 2000; SCHILLEWAERT et al, 2000, p. 21; GONG et al, 2004; MARTINS; KELLERMANNS, 2004; LEE, 2001; BUSH, 2005; FUSILIER; DURLABJHI, 2005): 1 = discordo fortemente; 2 = discordo; 3 = discordo parcialmente; 4 = neutro (nem discorda nem concorda); 5 = concordo parcialmente; $6=$ concordo $; 7=$ concordo fortemente ${ }^{90}$. Nos demais casos, optou-se por estabelecer faixas de resposta, como foi o caso da variável sobre experiência com e-learning fora da plataforma da empresa e com algumas das variáveis das dimensões Intenção de Uso e Comportamento de Uso.

Antes da aplicação, foi realizado um pré-teste do questionário com 9 respondentes: 3 respondentes da área empresarial (sendo que 2 são funcionários da empresa pesquisada) e 6 respondentes da área acadêmica. De acordo com Marconi e Lakatos, através do pré-teste do questionário é possível identificar e corrigir falhas no instrumento, como: “inconsistência ou complexidade das questões; ambigüidade ou linguagem inacessível; perguntas supérfluas ou 
que causam embaraço ao informante; se as questões obedecem a determinada ordem ou se são muito numerosas etc.” (2005, p. 205). Assim, o pré-teste possibilitou a identificação da necessidade de ajustes em algumas das questões e na formatação do instrumento, resultando na versão final instrumento aplicado (Apêndice 2).

${ }^{90} 1$ = strongly disagree / 2 = moderately disagree / $3=$ somewhat disagree $/ 4=$ neutral (neither disagree or agree) $/ 5=$ somewhat agree $/ 6=$ moderately agree $/ 7=$ strongly agree 
Quadro 13 - Itens do Questionário da Pesquisa

\begin{tabular}{|c|c|c|}
\hline Dimensão & Variável & Item do Questionário \\
\hline \multicolumn{3}{|l|}{ Variáveis do TAM } \\
\hline \multirow[t]{7}{*}{$\begin{array}{l}\text { Utilidade do } e- \\
\text { Learning Percebida }\end{array}$} & $\begin{array}{l}\text { Contribuição do e-learning para a melhora do desempenho no } \\
\text { trabalho }\end{array}$ & $\begin{array}{l}\text { A participação em cursos de e-learning melhorou (pode melhorar) meu } \\
\text { desempenho no trabalho }\end{array}$ \\
\hline & Utilidade do e-learning no trabalho & O e-learning é (pode ser) útil em meu trabalho \\
\hline & Importância do e-learning para a realização do trabalho & $\begin{array}{l}\text { A participação em cursos de e-learning é importante para a realização do meu } \\
\text { trabalho }\end{array}$ \\
\hline & Obtenção de resultados de aprendizagem com o e-learning & $\begin{array}{l}\text { Eu obtive (poderia obter) ótimos resultados de aprendizagem com o } e \text { - } \\
\text { learning }\end{array}$ \\
\hline & Flexibilidade para aprender através do e-learning & $\mathrm{O}$ e-learning permite maior flexibilidade para aprender \\
\hline & Facilidade em explicar os benefícios do e-learning & Eu teria facilidade em explicar os benefícios do e-learning \\
\hline & $\begin{array}{l}\text { Aumento nas chances de promoção em função da participação no } e \text { - } \\
\text { learning }\end{array}$ & $\begin{array}{l}\text { Quando participo (se eu participasse) de cursos de e-learning, estou (estaria) } \\
\text { aumentando minhas chances de ser promovido(a) }\end{array}$ \\
\hline \multirow{2}{*}{$\begin{array}{l}\text { Facilidade de Uso } \\
\text { do } e \text {-Learning } \\
\text { Percebida }\end{array}$} & Facilidade para usar o e-learning & Achei o $(\mathrm{O})$ e-learning (parece) fácil de usar \\
\hline & Clareza e inteligibilidade da interação com o sistema de e-learning & $\begin{array}{l}\text { Minha (A) interação com o ambiente do e-learning foi (parece) clara e } \\
\text { compreensível }\end{array}$ \\
\hline \multirow{3}{*}{$\begin{array}{l}\text { Atitude em Relação } \\
\text { ao e-Learning }\end{array}$} & Sentimento em relação à participação no e-learning & Eu gosto (gostaria) de participar de cursos de e-learning \\
\hline & Percepção em relação à participação do e-learning ser uma boa idéia & Participar de cursos de e-learning é uma boa idéia \\
\hline & Satisfação em relação ao uso do e-learning & Sinto-me (eu ficaria) satisfeito(a) em utilizar o e-learning \\
\hline \multirow[t]{3}{*}{$\begin{array}{l}\text { Intenção de Uso do } \\
\text { e-Learning }\end{array}$} & Intenção de participar do e-learning em 2007 & $\begin{array}{l}\text { Você planeja realizar cursos na Plataforma de e-Learning da empresa durante } \\
\text { o segundo semestre de } 2007(\mathrm{em} 2007) ?(*)\end{array}$ \\
\hline & Intenção de uso do e-learning, em função do tempo disponível & $\begin{array}{l}\text { Se eu tivesse mais tempo, eu utilizaria o e-learning com maior freqüência (eu } \\
\text { utilizaria o e-learning) }\end{array}$ \\
\hline & Intenção de uso do e-learning, em função dos cursos disponibilizados & $\begin{array}{l}\text { Se a Plataforma de e-elearning disponibilizasse mais cursos do meu interesse, } \\
\text { eu a utilizaria com maior freqüência (eu a utilizaria) }\end{array}$ \\
\hline
\end{tabular}


Quadro 13 - Itens do Questionário da Pesquisa

\begin{tabular}{|c|c|c|}
\hline Dimensão & Variável & Item do Questionário \\
\hline \multirow[t]{7}{*}{$\begin{array}{l}\text { Comportamento de } \\
\text { Uso do e-Learning }\end{array}$} & $\begin{array}{l}\text { Participação em pelo menos um curso na plataforma de e-learning da } \\
\text { empresa, desde } 2006\end{array}$ & $\begin{array}{l}\text { Você já participou de algum curso da Plataforma de e-learning da empresa, } \\
\text { desde } 2006 ?(*)\end{array}$ \\
\hline & Motivos da não participação no e-learning & $\begin{array}{l}\text { Quais itens a seguir explicam os motivos de não participação em nenhum } \\
\text { curso da Plataforma de e-learning, desde } 2006 ?\left(^{*}\right)\end{array}$ \\
\hline & Freqüência de uso do e-learning & $\begin{array}{l}\text { Comparado com outras pessoas, eu considero que participo dos cursos de } e \text { - } \\
\text { learning com maior freqüência que a média }(* *)\end{array}$ \\
\hline & Aproveitamento dos cursos de e-learning & $\begin{array}{l}\text { Comparado com outras pessoas, eu tiro melhor proveito dos cursos de } e \text { - } \\
\text { learning disponíveis na Plataforma da empresa }(* *)\end{array}$ \\
\hline & Número de cursos on-line inscritos & \\
\hline & Número de cursos on-line abandonados & \\
\hline & Número de cursos on-line concluídos & \\
\hline \multicolumn{3}{|l|}{ Variáveis Externas } \\
\hline \multirow[t]{4}{*}{ Influência Social } & Indicação da importância do e-learning pelo superior imediato & Meu superior imediato freqüentemente aponta a importância do e-learning \\
\hline & Estímulo do superior imediato para participar do e-learning & $\begin{array}{l}\text { Eu sou continuamente encorajado pelo meu superior imediato a participar dos } \\
\text { cursos de e-learning }\end{array}$ \\
\hline & Influência dos colegas em relação à participação no e-learning & A maioria dos colegas da minha área participa de cursos de e-learning \\
\hline & Prestígio resultante da participação no e-learning & $\begin{array}{l}\text { As pessoas da minha empresa que participam de cursos de e-learning têm } \\
\text { mais prestígio do que aquelas que não participam }\end{array}$ \\
\hline \multirow[t]{4}{*}{$\begin{array}{l}\text { Pre-disposição para } \\
\text { inovar }\end{array}$} & Disposição para experimentar novas tecnologias & $\begin{array}{l}\text { Se eu fico sabendo de uma nova tecnologia, eu vou procurar caminhos para } \\
\text { experimentá-la }\end{array}$ \\
\hline & Necessidade de ver uma inovação sendo usada antes de usá-la & Eu preciso ver uma inovação sendo usada, antes de usá-la por mim mesmo \\
\hline & Perfil de novo adotante & $\begin{array}{l}\text { Entre meus pares, eu normalmente estou entre os primeiros a explorar novas } \\
\text { tecnologias }\end{array}$ \\
\hline & Atitude cética em relação a novas tecnologias & Eu freqüentemente tenho uma atitude cética em relação a novas tecnologias \\
\hline \multirow[t]{3}{*}{$\begin{array}{l}\text { Auto-eficácia com } \\
\text { computadores }\end{array}$} & Habilidade para utilizar um novo software & $\begin{array}{l}\text { Eu tenho habilidade para utilizar um software sem tê-lo visto operando } \\
\text { anteriormente }\end{array}$ \\
\hline & Necessidade de ver um software sendo usado antes de usá-lo & Eu preciso ver um software sendo usado, antes de usá-lo por mim mesmo \\
\hline & Facilidade com informática & Eu tenho facilidade no uso de informática \\
\hline \multirow{2}{*}{$\begin{array}{l}\text { Características } \\
\text { Pessoais }\end{array}$} & Experiência com o e-learning fora da empresa & Você já realizou cursos de e-learning fora da Plataforma da empresa? $(*)$ \\
\hline & Gênero & \\
\hline \multirow{2}{*}{$\begin{array}{l}\text { Alinhamento com } \\
\text { Requisitos do } \\
\text { Negócio }\end{array}$} & $\begin{array}{l}\text { Potencial do e-learning para atender às necessidades de treinamento } \\
\text { do negócio }\end{array}$ & $\begin{array}{l}\text { O e-learning tem grande potencial para atender às necessidades de } \\
\text { treinamento da minha área de negócio }\end{array}$ \\
\hline & $\begin{array}{l}\text { Atendimento adequado do projeto existente às necessidades do } \\
\text { negócio }\end{array}$ & $\begin{array}{l}\text { O projeto de e-learning existente na empresa atende adequadamente às } \\
\text { necessidades do negócio }\end{array}$ \\
\hline
\end{tabular}


Quadro 13 - Itens do Questionário da Pesquisa

\begin{tabular}{|c|c|c|}
\hline Dimensão & Variável & Item do Questionário \\
\hline \multirow[t]{2}{*}{$\begin{array}{l}\text { Apoio da Alta } \\
\text { Administração }\end{array}$} & Patrocínio da empresa para participação no e-learning & $\begin{array}{l}\text { A participação em cursos de e-learning é fortemente patrocinada e defendida } \\
\text { pela minha empresa }\end{array}$ \\
\hline & Comprometimento da Alta Administração com o uso do e-learning & $\begin{array}{l}\text { A alta administração da empresa demonstra claramente estar comprometida } \\
\text { com o uso do e-learning }\end{array}$ \\
\hline \multirow{2}{*}{$\begin{array}{l}\text { Favorecimento da } \\
\text { Cultura } \\
\text { Organizacional }\end{array}$} & Cultura favorece a adoção do e-learning & A cultura da organização favorece a adoção do $e$-learning pelos colaboradores \\
\hline & Cultura valoriza a aprendizagem & A empresa possui uma cultura que valoriza a aprendizagem \\
\hline \multirow{7}{*}{$\begin{array}{l}\text { Adequação do } \\
\text { Projeto de } e- \\
\text { Learning }\end{array}$} & Disponibilização de instruções e orientações para usar o e-learning & $\begin{array}{l}\text { A empresa disponibilizou instruções e orientações suficientes para o uso do } e \text { - } \\
\text { learning }\end{array}$ \\
\hline & $\begin{array}{l}\text { Disponibilidade de uma pessoa (ou grupo) para auxiliar no uso do } e \text { - } \\
\text { learning }\end{array}$ & $\begin{array}{l}\text { Uma pessoa específica (ou grupo) está à disposição para auxiliar no caso de } \\
\text { dificuldades com o e-learning }\end{array}$ \\
\hline & Suficiência dos recursos tecnológicos & $\begin{array}{l}\text { Eu possuo os recursos tecnológicos suficientes para participar dos cursos de } e \text { - } \\
\text { learning }\end{array}$ \\
\hline & Conhecimento sobre o suporte disponível ao e-learning & Eu sei onde procurar, caso precise de assistência para utilizar o e-learning \\
\hline & Sucesso das campanhas de comunicação do e-learning & $\begin{array}{l}\text { Há campanhas corporativas de comunicação interna que promovem o } e \text { - } \\
\text { learning com sucesso }\end{array}$ \\
\hline & Sucesso da campanha de incentivo ao uso do e-learning & $\begin{array}{l}\text { A campanha de incentivo realizada em } 2006 \text { estimulou o uso do e-learning na } \\
\text { empresa }\end{array}$ \\
\hline & Voluntariedade de Uso & \\
\hline
\end{tabular}

(*) Questão com escala específica

(**) Questão respondida apenas pelos colaboradores que realizaram curso de e-learning na plataforma da empresa. 


\subsubsection{A Entrevista Individual}

As vantagens e desvantagens da entrevista individual em profundidade analisadas por Gordon e Langmaid (1988, p. 15-16) são apresentadas no Quadro 14.

\section{Quadro 14 - Vantagens e Desvantagens da Entrevista Individual em Profundidade}

$\frac{\text { Vantagens }}{\text { Informações longitudinais podem ser obtidas de um respondente de cada }}$ vez (exemplo: processo de compras);

A opinião da maioria e da minoria pode ser notada independente do processo de grupo;

Um senso de perspectiva é possível, particularmente quando são realizadas várias entrevistas;

Assuntos muito íntimos e pessoais podem ser discutidos;

Não ocorre pressão de colegas de grupo;

As habilidades do entrevistador podem superar a tendência de expressar atitudes e comportamentos socialmente aceitos;

Dificuldades no recrutamento de participantes podem ser transpostas;

A amostra pode ser segmentada e dividida de forma a cobrir mais células do que normalmente é possível em entrevistas em grupo.

\section{Desvantagens}

Consome muito tempo, tanto na condução da entrevista quanto na análise das fitas gravadas;

O custo é alto;

Existe uma tendência de as pessoas pensarem logo em quantos ao invés de como, por que e o que.

FONTE: Baseado em Gordon e Langmaid (1988, p. 15-16)

A entrevista pode ser classificada de acordo com seu grau de estruturação, conforme apresentado por Fontana e Frey (1994, p. 363) e por Aaker e Day (1990, p. 163-164):

- Entrevista estruturada: o entrevistador faz uma série de perguntas pré-estabelecidas ao respondente, que possui limitação nas opções de respostas por categorias, resultando em pouca flexibilidade nas questões realizadas e nas respostas fornecidas. Este tipo de entrevista, normalmente, não é considerada como uma entrevista em profundidade, como ocorre nas outras duas classificações;

- Entrevista semi-estruturada: o entrevistador procura abordar uma lista específica de tópicos e subárea. As palavras exatas a serem utilizadas e o momento de questionar sobre cada tópico ficam a critério do entrevistador;

- Entrevista não estruturada: o respondente possui grande liberdade para responder dentro dos assuntos de interesse do entrevistador. Além disso, é estabelecida uma interação entre o entrevistador e o entrevistado, através da abertura existente para o 
entrevistador responder questões e da possibilidade de desvio do roteiro de acordo com os sentimentos do entrevistador.

A técnica de entrevista semi-estruturada foi utilizada nesta pesquisa para as entrevistas com especialistas em e-learning e para as entrevistas com a responsável pelo e-learning na empresa. Para tanto, foram elaborados roteiros para condução das entrevistas (Apêndice 3):

- Entrevista com Especialista em e-Learning, com o objetivo de revisar o modelo conceitual da pesquisa.

Conforme apresentado anteriormente no Esquema da Pesquisa (Figura 23), antes da realização da pesquisa na empresa, foram conduzidas entrevistas com especialistas, selecionados em função da área de atuação do entrevistado e de sua disponibilidade para participar do estudo. Foram realizadas 3 entrevistas, incluindo duas com especialistas da área acadêmica (um professor com atuação ligada à Tecnologia da Informação e uma professora com atuação ligada à Educação Corporativa) e uma entrevista com especialista da área corporativa, responsável pela coordenação do projeto de e-learning em um dos três maiores bancos do país.

Essas entrevistas confirmaram a importância dos fatores externos ao Modelo TAM que integram o Modelo Preliminar de Adoção Individual do e-Learning, com destaque para o atendimento aos requisitos do negócio, aos aspectos envolvidos no projeto de $e$ learning (como infra-estrutura tecnológica e conteúdo dos cursos) e à cultura organizacional.

- Entrevista com responsável pelo e-Learning na empresa pesquisada, para levantar informações sobre o alinhamento do e-learning com requisitos do negócio, o apoio da alta administração, o favorecimento da cultura organizacional e a adequação do projeto de e-learning existente. Foram realizadas três entrevistas durante a fase de coleta dos dados: uma com a Vice-Presidente de Recursos Humanos e duas com a coordenadora do projeto de e-learning. Após a coleta dos dados quantitativos foram realizados outros dois contatos com responsáveis pela área, visando complementar a interpretação dos resultados obtidos através dos questionários. Os dados coletados 
durante as entrevistas estão apresentados no tópico sobre a descrição do projeto de e-learning da empresa e foram integrados à análise dos resultados, quando pertinente.

\subsubsection{Análise Documental}

De acordo com Bardin,

Enquanto tratamento da informação contida nos documentos acumulados, a análise documental tem por objectivo dar forma conveniente e representar de outro modo essa informação, por intermédio de procedimentos de transformação. O propósito é o armazenamento sob uma forma variável e a facilitação do acesso ao observador, de tal forma que este obtenha o máximo de informação (aspecto quantitativo), com o máximo de pertinência (aspecto qualitativo). (2004, p. 40).

Desta forma, complementando os dados primários, foram analisados documentos da empresa em geral e referentes ao projeto da e-elearning: relatório anual da empresa, relatório de perfil da força de trabalho da empresa, catálogo dos cursos on-line oferecidos e relatórios de realização dos cursos na plataforma de e-elearning da empresa gerenciada pela Unidade do Brasil.

\subsection{A População e a Amostra}

De acordo com Martins, "População (ou universo) é a totalidade dos itens, objetos ou pessoas sob consideração." e "Amostra é uma parte da população que é selecionada para análise" (2001, p. 20).

A população da presente pesquisa é formada pelo quadro de funcionários da empresa escolhida para realização da pesquisa, composto por 7.013 colaboradores ativos na data da coleta dos dados (excluindo aqueles em licença).

A lista de funcionários convidados a participar da pesquisa foi gerada de forma estratificada em relação às áreas da empresa e à estrutura de cargo, totalizando 693 funcionários 
(aproximadamente 10\% do quadro). Além disso, na criação desta lista, evitou-se incluir pessoas que participaram recentemente de outras pesquisas realizadas na empresa.

Foram obtidas 312 respostas válidas do questionário, de um total de 693 convidados, resultando em uma taxa de resposta de $45 \%$.

A seguir, é apresentada a análise da representatividade da amostra e do uso do e-learning pelos colaboradores da empresa pesquisada.

\subsubsection{Representatividade da Amostra}

A representatividade da amostra foi avaliada através das variáveis: gênero, idade, tempo de empresa, grau de instrução, localidade de trabalho, cargo e área funcional. A partir dos testes realizados, é possível afirmar que a amostra é representativa em relação a gênero, idade, grau de instrução, localidade de trabalho e cargo dos respondentes. Por outro lado, a amostra é diferente da população no que se refere ao tempo de empresa, sendo que os respondentes da pesquisa apresentam em média 1,5 anos a menos de empresa do que a população, e à área funcional dos respondentes.

Abaixo, são apresentados o perfil da amostra e da população em relação a essas variáveis em conjunto com a análise de representatividade, baseada no teste Qui-quadrado (para variáveis nominais) e t-Student (para variáveis intervalares).

\section{Representatividade da Amostra em Relação ao Gênero}

Tabela 5 - Distribuição da Variável Gênero na Amostra e na População

\begin{tabular}{ccccc}
\hline & \multicolumn{2}{c}{ Amostra } & \multicolumn{2}{c}{ População } \\
Gênero & $\begin{array}{c}\text { Freqüência da } \\
\text { amostra }\end{array}$ & $\begin{array}{c}\text { Freqüência } \\
\text { percentual da } \\
\text { amostra }\end{array}$ & $\begin{array}{c}\text { Freqüência } \\
\text { população }\end{array}$ & $\begin{array}{c}\text { Freqüência } \\
\text { percentual } \\
\text { população }\end{array}$ \\
\hline Masculino & 208 & $66,7 \%$ & 4678 & $66,7 \%$ \\
Feminino & 104 & $33,3 \%$ & 2335 & $33,3 \%$ \\
\hline
\end{tabular}

- Hipótese $H_{0}$ : não há diferença entre o número esperado de respondentes por gênero e o efetivamente observado 


$$
\chi^{2}=0,001 ; 0,05<\mathrm{p}<0,90
$$

O valor descritivo do teste (p) está acima do nível de significância $(0,05)$, rejeitando-se a hipótese (nula), o que pode-se dizer que a amostra é representativa em relação ao gênero.

\section{Representatividade da Amostra em Relação à Idade e Tempo de Empresa}

Tabela 6 - Distribuição das Variáveis Idade e Tempo de Empresa na População

\begin{tabular}{cccccc}
\hline População & N & Mínimo & Máximo & Média & $\begin{array}{c}\text { Desvio- } \\
\text { padrão }\end{array}$ \\
\hline Idade & 7013 & 18,55 & 73,38 & 37,23 & 8,77 \\
Tempo de empresa & 7013 & 0 & 38,30 & 10,27 & 9,24 \\
\hline
\end{tabular}

Tabela 7 - Distribuição das Variáveis Idade e Tempo de Empresa na Amostra

\begin{tabular}{cccccc}
\hline Amostra & N & Mínimo & Máximo & Média & $\begin{array}{c}\text { Desvio- } \\
\text { padrão }\end{array}$ \\
\hline Idade & 312 & 18,55 & 56,29 & 36,43 & 8,82 \\
Tempo de empresa & 312 & 0 & 31,64 & 8,77 & 8,77 \\
\hline
\end{tabular}

Para essas variáveis foi realizada a prova estatística t-Student, para uma amostra cuja estatística amostral média foi comparada ao parâmetro média da população. Os resultados obtidos foram os seguintes:

Tabela 8 - Resultado da Prova t-Student para Idade e Tempo de Empresa

\begin{tabular}{ccccc}
\hline & $\mathbf{t}$ & $\begin{array}{c}\text { Graus de } \\
\text { Liberdade }\end{array}$ & P & $\begin{array}{c}\text { Média da } \\
\text { População }\end{array}$ \\
\hline $\begin{array}{c}\text { Idade } \\
\text { Tempo de } \\
\text { empresa }\end{array}$ & $-1,6$ & 311 & 0,111 & 37,23 \\
\hline
\end{tabular}

Tendo em vista o resultado do nível descritivo do teste (p), não se rejeita a hipótese de que a amostra tenha média igual à média populacional, no que diz respeito à idade.

Em relação ao tempo de empresa, a amostra apresenta média diferente da população da empresa $(\mathrm{p}<0,05)$; os respondentes da pesquisa têm em média 1,5 anos a menos de empresa que a população (8,77 versus 10,77 anos, respectivamente). 


\section{$\underline{\text { Representatividade da Amostra em Relação ao Grau de Instrução }}$}

Tabela 9 - Distribuição da Variável Grau de Instrução na Amostra e na População

\begin{tabular}{ccccc}
\hline Grau de instrução & $\begin{array}{c}\text { Amostra } \\
\text { Freqüência da } \\
\text { amostra }\end{array}$ & $\begin{array}{c}\text { Freqüência } \\
\text { percentual da } \\
\text { amostra }\end{array}$ & $\begin{array}{c}\text { Freqüência } \\
\text { população }\end{array}$ & $\begin{array}{c}\text { Freqüência } \\
\text { percentual } \\
\text { população }\end{array}$ \\
\hline Superior completo & 173 & $50 \%$ & 3501 & $50 \%$ \\
\hline Colegial/Técnico completo & 81 & $26 \%$ & 1960 & $28 \%$ \\
\hline Superior incompleto & 36 & $12 \%$ & 980 & $14 \%$ \\
\hline $\begin{array}{c}\text { Pós-graduação } \\
\text { incompleto/completo }\end{array}$ & 19 & $6 \%$ & 420 & $6 \%$ \\
\hline Colegial/Técnico incompleto & 3 & $1 \%$ & 70 & $1 \%$ \\
\hline Ginásio completo & 0 & $0 \%$ & 70 & $1 \%$ \\
\hline Ginásio incompleto & 0 & $0 \%$ & 0 & $0 \%$ \\
\hline Primário completo & 0 & $0 \%$ & 0 & $0 \%$ \\
\hline
\end{tabular}

- Hipótese $H_{0}$ : não há diferença entre o número esperado (de acordo com a população da Empresa) de respondentes por grau de instrução e o efetivamente observado

$$
\chi^{2}=5,743 ; 0,05<\mathrm{p}<0,50
$$

O valor descritivo do teste (p) está acima do nível de significância $(0,05)$, rejeitando-se a hipótese (nula), o que pode-se dizer que a amostra é representativa em relação ao grau de instrução.

\section{Representatividade da Amostra em Relação à Localidade de Trabalho}

Tabela 10 - Distribuição da Variável Localidade de Trabalho na Amostra e na População

\begin{tabular}{ccccc}
\hline & \multicolumn{2}{c}{ Amostra } & \multicolumn{2}{c}{ População } \\
$\begin{array}{c}\text { Localidade de } \\
\text { Trabalho }\end{array}$ & $\begin{array}{c}\text { Freqüência da } \\
\text { amostra }\end{array}$ & $\begin{array}{c}\text { Freqüência } \\
\text { percentual da } \\
\text { amostra }\end{array}$ & $\begin{array}{c}\text { Freqüência } \\
\text { população }\end{array}$ & $\begin{array}{c}\text { Freqüência } \\
\text { percentual } \\
\text { população }\end{array}$ \\
\hline Capital & 277 & $88,8 \%$ & 5965 & $85,2 \%$ \\
Interior & 35 & $11,2 \%$ & 1029 & $14,7 \%$ \\
\hline
\end{tabular}

- Hipótese $H_{0}$ : não há diferença entre o número esperado de respondentes por grau de instrução e o efetivamente observado 


$$
\chi^{2}=2,893 ; 0,05<\mathrm{p}<0,10
$$

O valor descritivo do teste $(p)$ está acima do nível de significância $(0,05)$, rejeitando-se a hipótese (nula), o que pode-se dizer que a amostra é representativa em relação à localidade na qual os respondentes exercem suas atividades.

\section{Representatividade da Amostra em Relação ao Cargo}

Tabela 11 - Distribuição da Variável Cargo na Amostra e na População

\begin{tabular}{ccccc}
\hline Cargo & \multicolumn{2}{c}{ Amostra } & \multicolumn{2}{c}{ População } \\
& $\begin{array}{c}\text { Freqüência da } \\
\text { amostra }\end{array}$ & $\begin{array}{c}\text { Freqüência } \\
\text { percentual da } \\
\text { amostra }\end{array}$ & $\begin{array}{c}\text { Freqüência } \\
\text { população }\end{array}$ & $\begin{array}{c}\text { Freqüência } \\
\text { percentual } \\
\text { população }\end{array}$ \\
\hline Analista & 85 & $27 \%$ & 2039 & $29 \%$ \\
\hline Gerente & 48 & $15 \%$ & 1255 & $18 \%$ \\
\hline Técnico & 48 & $15 \%$ & 1232 & $18 \%$ \\
\hline Assistente & 46 & $15 \%$ & 986 & $14 \%$ \\
\hline Consultor & 51 & $16 \%$ & 896 & $13 \%$ \\
\hline Engenheiro & 26 & $8 \%$ & 471 & $1 \%$ \\
\hline Secretária & 5 & $2 \%$ & 67 & $1 \%$ \\
\hline Diretor & 3 & $1 \%$ & 67 & $1 \%$ \\
\hline
\end{tabular}

- Hipótese $H_{0}$ : não há diferença entre o número esperado de respondentes por cargo e o efetivamente observado

$$
\chi^{2}=8,217 ; 0,05<\mathrm{p}<0,30
$$

Da mesma forma que o teste anterior, sendo $\mathrm{p}>0,05$ não há elementos para rejeitar a hipótese de nulidade e pode-se dizer que a amostra em relação aos cargos é representativa. 


\section{Representatividade da Amostra em Relação à Área Funcional}

Tabela 12 - Distribuição da Variável Área Funcional na Amostra e na População

\begin{tabular}{|c|c|c|c|c|}
\hline \multirow[b]{2}{*}{ Área Funcional } & \multicolumn{2}{|c|}{ Amostra } & \multicolumn{2}{|c|}{ População } \\
\hline & $\begin{array}{c}\text { Freqüência da } \\
\text { amostra }\end{array}$ & $\begin{array}{l}\text { Freqüência } \\
\text { percentual da } \\
\text { amostra }\end{array}$ & $\begin{array}{c}\text { Freqüência } \\
\text { população }\end{array}$ & $\begin{array}{l}\text { Freqüência } \\
\text { percentual } \\
\text { população }\end{array}$ \\
\hline Serviços de redes & 119 & $38 \%$ & 2875 & $41 \%$ \\
\hline Serviços com e adm & 57 & $18 \%$ & 1122 & $16 \%$ \\
\hline UN Negócios & 33 & $11 \%$ & 842 & $12 \%$ \\
\hline UN Empresas & 30 & $10 \%$ & 631 & $9 \%$ \\
\hline UN Residencial & 17 & $5 \%$ & 491 & $7 \%$ \\
\hline Controle de Gestão & 22 & $7 \%$ & 351 & $5 \%$ \\
\hline Presidência & 13 & $4 \%$ & 281 & $4 \%$ \\
\hline UN Atacado & 8 & $3 \%$ & 140 & $2 \%$ \\
\hline Estratégia e Regulatório & 3 & $1 \%$ & 140 & $2 \%$ \\
\hline $\mathrm{RH}$ & 6 & $2 \%$ & 70 & $1 \%$ \\
\hline Finanças & 4 & $1 \%$ & 70 & $1 \%$ \\
\hline Responsabilidade Social & 0 & $0 \%$ & 0 & $0 \%$ \\
\hline
\end{tabular}

- Hipótese $H_{0}$ : não há diferença entre o número esperado de respondentes em cada área e o efetivamente observado

$$
\chi^{2}=10,494 ; 0,05<\mathrm{p}<0,50
$$

O valor descritivo do teste (p) está acima do nível de significância $(0,05)$, rejeitando-se a hipótese (nula). Ou seja, não há razões objetivas para indicar que a amostra não seja representativa em relação à quantidade de respondentes por área.

\subsubsection{O Uso do e-Learning pelos Colaboradores da Empresa}

A partir dos relatórios disponíveis da plataforma de e-learning, foi possível analisar a utilização do e-learning pela população, ou seja, por todos os colaboradores da empresa pesquisada, considerando apenas os cursos gerenciados pela equipe do Brasil.

O Gráfico 1 apresenta a evolução no número de participantes nos cursos de e-learning por mês, indicando os que concluíram, abandonaram e os que não iniciaram os cursos em que se inscreveram. Dentre as possíveis explicações para a flutuação do número de participantes no e-learning durante o ano estão: crescimento no período seguinte à divulgação dos resultados 
da avaliação de desempenho individual (Janeiro/Fevereiro), em que está prevista a elaboração do plano individual de desenvolvimento do funcionário, forte queda em Setembro, mês de trabalho intenso para elaboração do orçamento da empresa para o ano seguinte, e em Janeiro, período em que muitos funcionários estão de férias.

Além disso, observa-se uma queda na participação do e-learning a partir de março de 2007, que se mantém, diferentemente do comportamento em meses anteriores. Na avaliação da responsável pelo e-learning, essa redução pode estar relacionada a uma mudança na estrutura organizacional da empresa ocorrida na época, possivelmente resultando em impactos na atuação da equipe de e-learning.

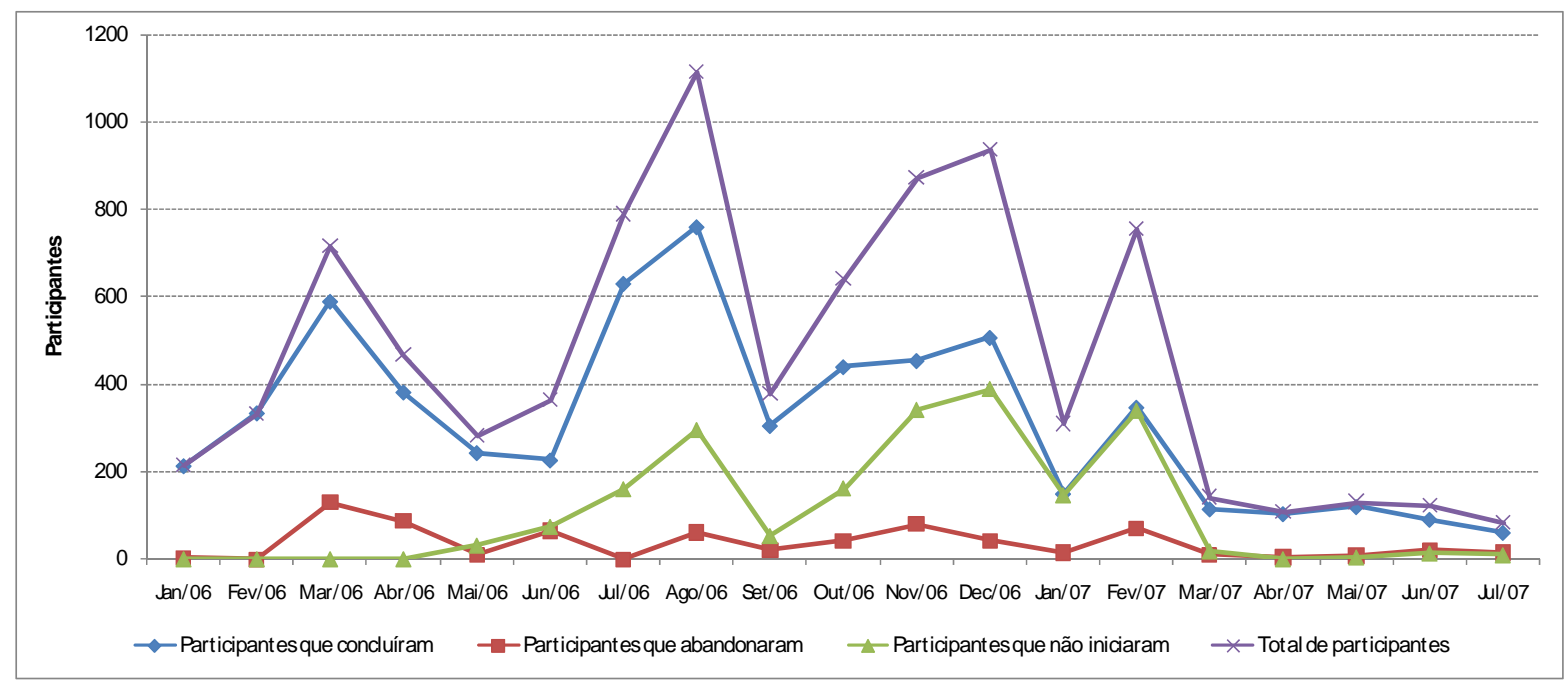

Gráfico 1 - Número de Participantes nos Cursos de e-Learning da Empresa, por Mês

Complementando a análise, o Gráfico 2 apresenta a evolução em horas de treinamento da participação nos cursos de e-learning, por mês. Embora os pontos de flutuação se mantenham em relação ao Gráfico 1, observa-se que o total de horas dos cursos abandonados tem maior variação que o número total de participantes, sugerindo uma tendência de maior abandono para os cursos mais longos. Esta tendência é confirmada ao analisar a duração média de 25 horas dos cursos que foram abandonados em comparação à duração média de 6 horas dos cursos que foram concluídos. 


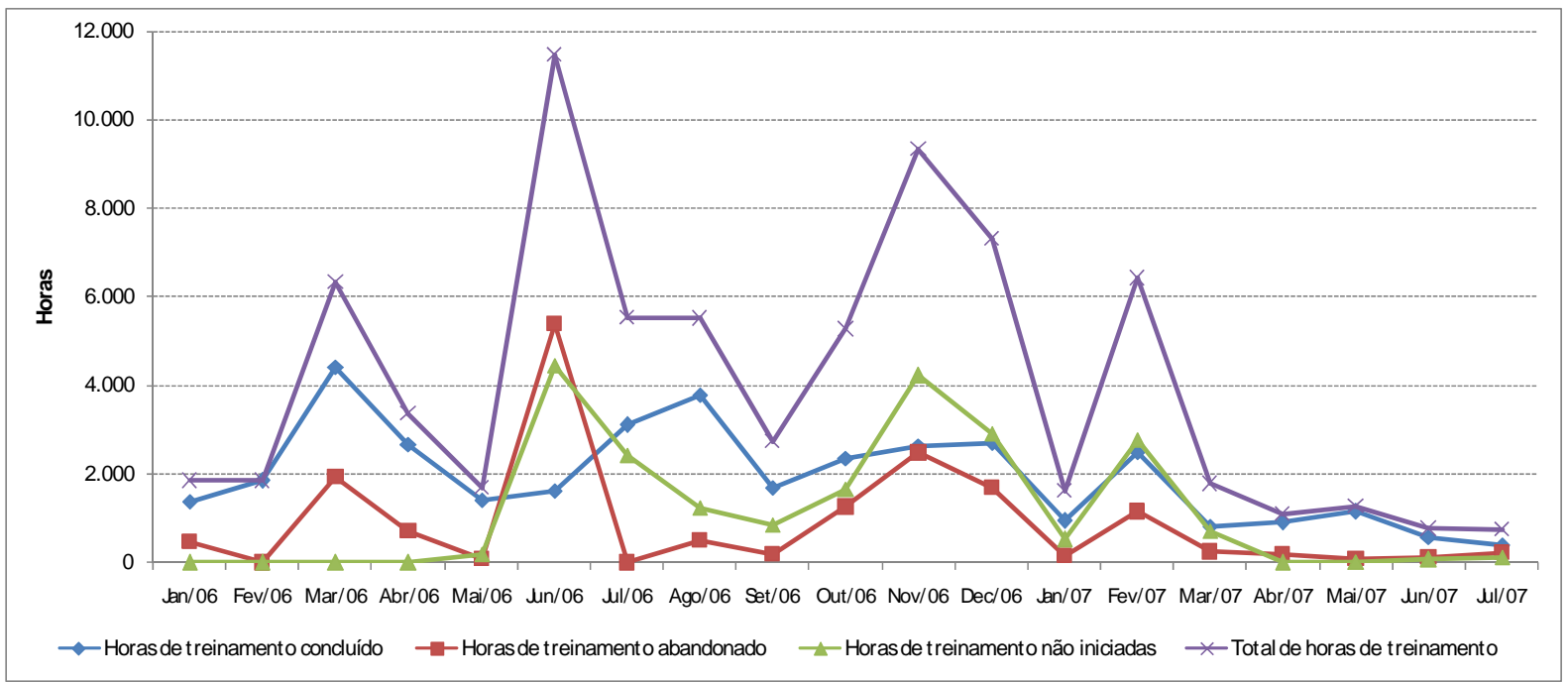

Gráfico 2 - Horas de Treinamento de e-Learning na Empresa, por Mês

Ao analisar a participação nos cursos de e-learning por cargo no $1^{\circ}$ Semestre de $2007^{91}$, verifica-se uma tendência de maior participação dos colaboradores de cargos técnicos (Gráfico 3), que também apresentam maior taxa de conclusão. Já os gestores, apresentam maior índice de não participação, situação em que o funcionário se inscreve e não inicia o curso.

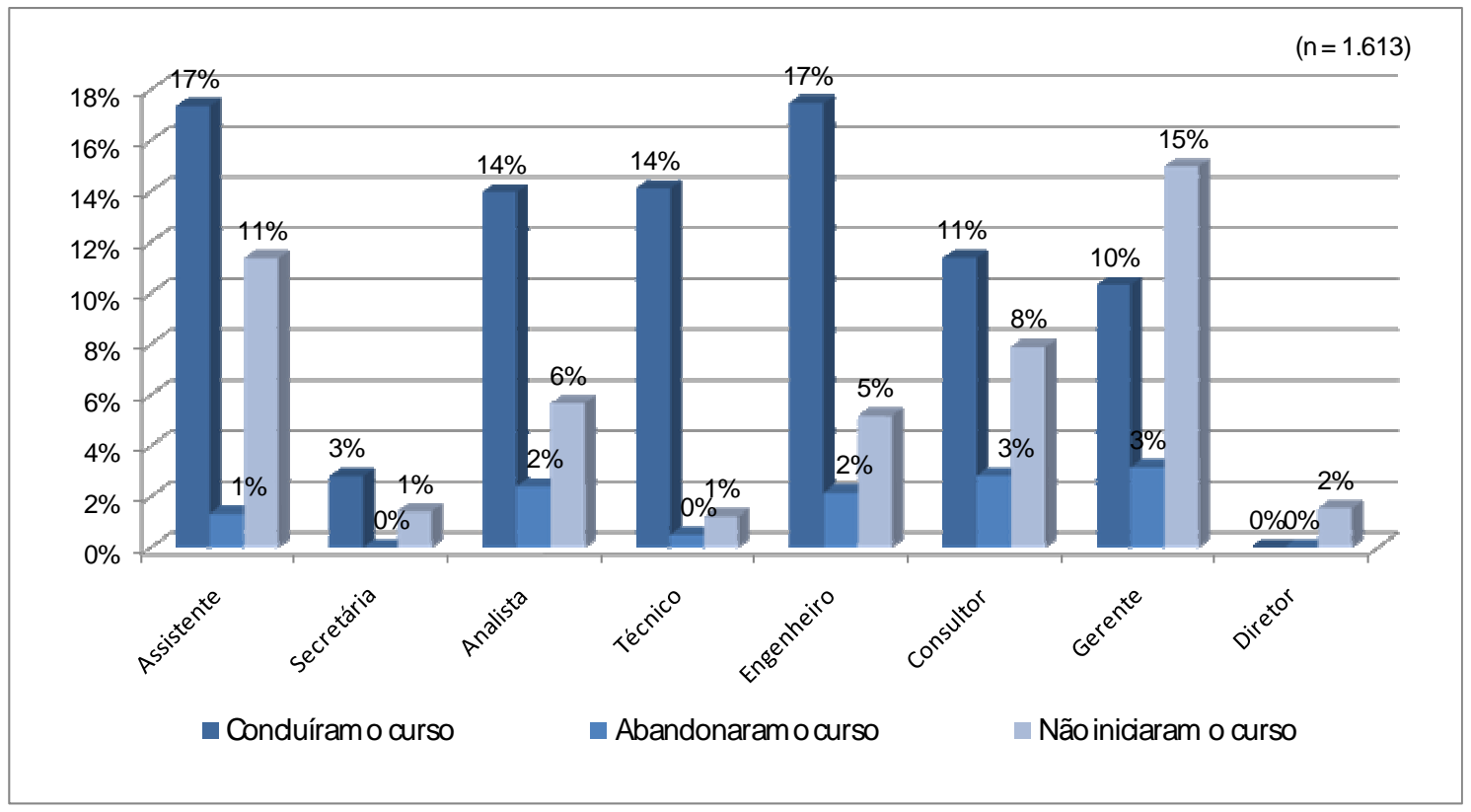

Gráfico 3 - Distribuição dos Participantes de Cursos de e-Learning no $1^{\circ}$ Semestre/2007, por Cargo

${ }^{91}$ O cargo do participante passou a constar dos relatórios da Plataforma de e-Learning a partir de Janeiro de 2007. 
Com relação ao tema dos cursos de e-learning realizados na empresa, o Gráfico 4 mostra a importância dos cursos sobre gestão e desenvolvimento pessoal, que representam $65 \%$ do total de inscrições no período (Janeiro de 2006 à Julho de 2007). Dados que devem ser analisados em conjunto com a duração dos cursos, uma vez que os cursos sobre conteúdo Técnico, Gestão/Desenvolvimento Pessoal e Processos da Empresa apresentam menor duração média (6 horas, 4 horas e 3 horas, respectivamente), se comparado aos cursos de Idiomas, que apresentam em média 58 horas de duração. Os cursos de Informática têm em média 11 horas de duração.

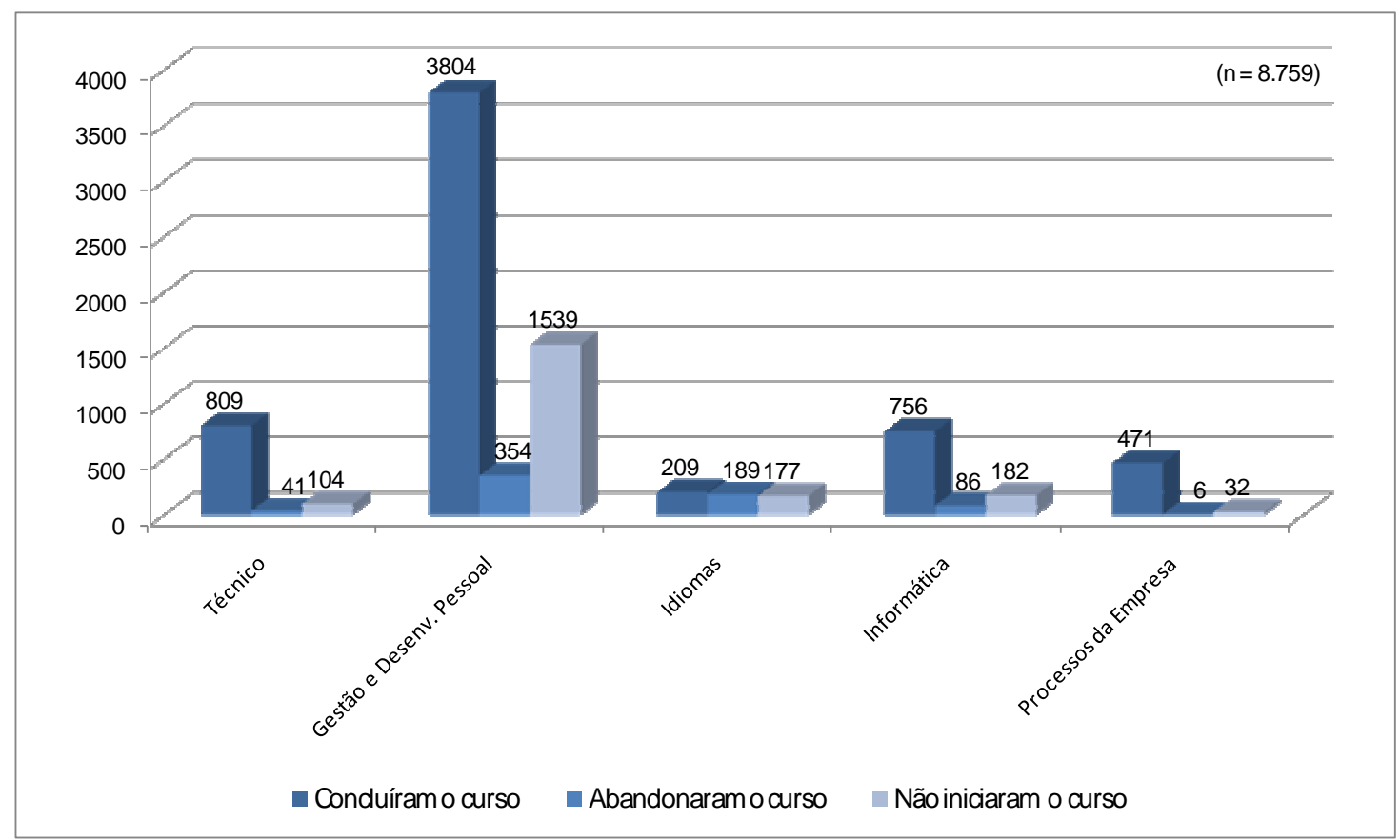

Gráfico 4 - Distribuição dos Participantes de Cursos de e-Learning, por Categoria de Curso

Por fim, o Gráfico 5 detalha a participação nos cursos de e-learning por categoria do curso e por cargo, no $1^{\circ}$ Semestre de 2007, indicando a predominância dos cursos se Gestão e Desenvolvimento Pessoal entre os funcionários de cargo gerencial e a maior variedade de cursos realizados pelos funcionários de cargos técnicos. 


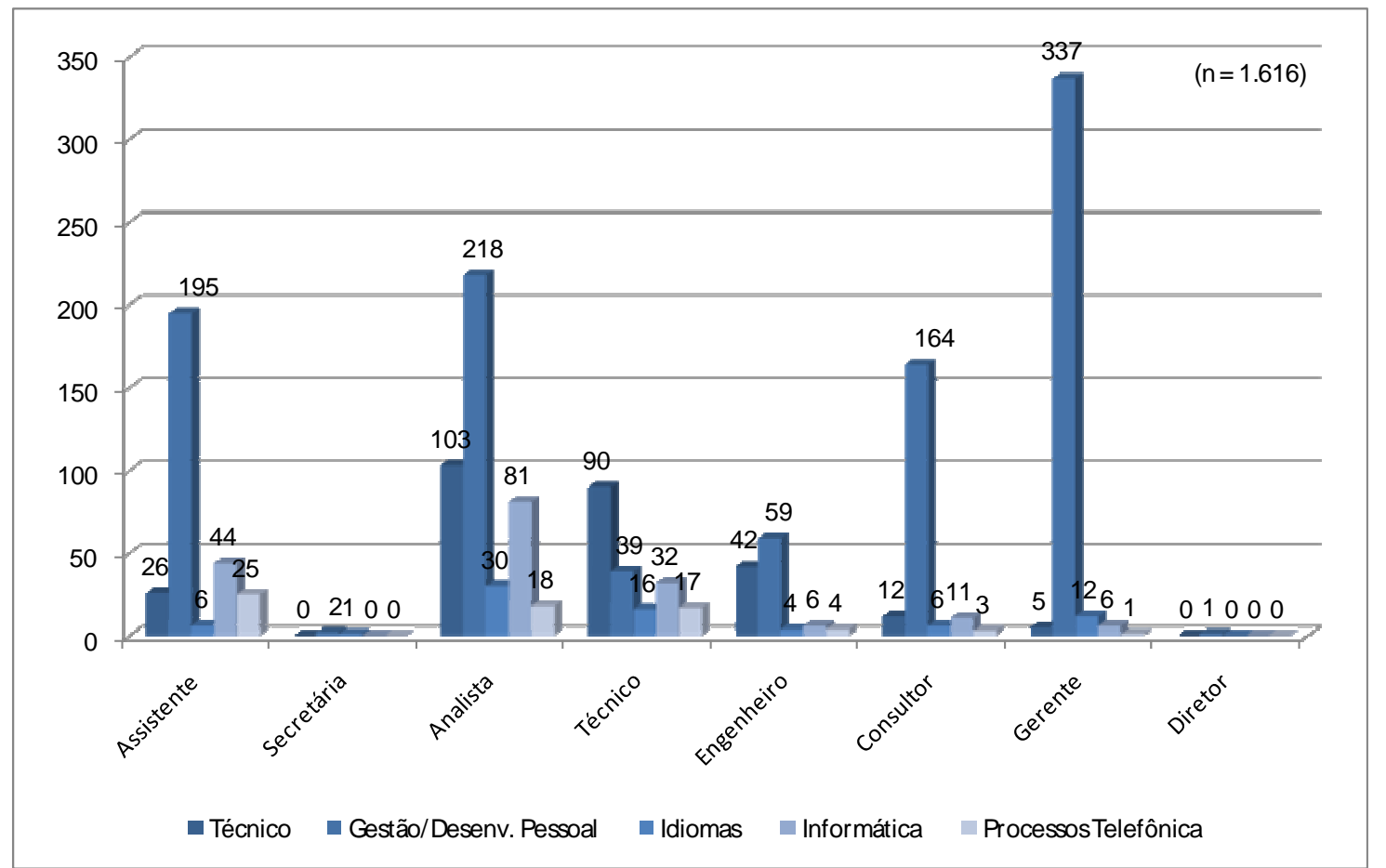

Gráfico 5 - Número de Inscrições nos Cursos de e-Learning no $1^{\circ}$ Semestre/2007, por Categoria de Curso e Cargo

\subsection{Análise dos Dados}

A escolha das técnicas para análise dos dados foi norteada pelo objetivo que se buscou atingir, pela natureza dos dados e pelos requisitos exigidos pela técnica de análise, quando aplicável. Considerando estas questões, o Quadro 15 apresenta as técnicas utilizadas para análise dos dados, por objetivo específico. Em seguida, cada uma das técnicas é brevemente descrita. 


\section{Quadro 15 - Técnicas Usadas para Análise dos Dados}

\begin{tabular}{ll}
\hline \multicolumn{1}{c}{ Objetivo Específico } & \multicolumn{1}{c}{ Técnicas de Análise } \\
\hline $\begin{array}{l}\text { 1. Comparar as dimensões do modelo conceitual proposto com } \\
\text { aquelas observadas na empresa estudada, identificando } \\
\text { aprimoramentos no Modelo Preliminar de Adoção Individual do e- } \\
\text { Learning }\end{array}$ & Análise Fatorial \\
\hline $\begin{array}{l}\text { 2. Analisar as diferenças de percepção entre os colaboradores que } \\
\text { realizaram e que não realizaram curso de e-learning na empresa, } \\
\text { desde 2006 }\end{array}$ & $\begin{array}{l}\text { Prova Mann-Whitney } \\
\text { Análise descritiva } \\
\end{array}$ \\
\hline $\begin{array}{l}\text { 3. Análise de conteúdo } \\
\text { respondente }\end{array}$ & $\begin{array}{l}\text { Prova Mann-Whitney } \\
\text { Análise descritiva }\end{array}$ \\
\cline { 2 - 2 } & $\begin{array}{l}\text { Prova Mann-Whitney } \\
\text { Análise descritiva }\end{array}$ \\
\hline $\begin{array}{l}\text { 4. Identificar as variáveis que melhor explicam a intenção de realizar ou } \\
\text { não cursos de } e \text {-learning na empresão Logística }\end{array}$ & \\
\hline $\begin{array}{l}\text { 5. Identificar as variáveis que melhor explicam a realização ou não de } \\
\text { cursos de } e \text {-learning na empresa }\end{array}$ & Regressão Logística \\
\hline
\end{tabular}

\subsubsection{Análise Fatorial}

De acordo com Hair et al, "Análise fatorial é uma técnica de interdependência em que todas as variáveis são simultaneamente consideradas, cada uma relacionada com todas as outras [...]" ${ }^{, 92}$, e os fatores são formados "[...] para maximizar a explicação de todo o conjunto de variáveis, não para prever uma variável(is) dependente." 93 (1998, p. 91). Desta forma, as "Variáveis que são correlacionadas entre si, mas amplamente independentes dos demais subconjuntos de variáveis são combinadas em fatores." 94 (TABACHNICK; FIDELL, 2001, p. $582)$.

Neste estudo, levantou-se, para cada entrevistado, um grande número (37) de variáveis; variáveis estas que são escores de avaliação ou de expectativa frente aos cursos de e-learning da empresa. A análise fatorial permitiu sumarizar os dados em fatores, possibilitando a interpretação de um número menor de conceitos.

\footnotetext{
92 "Factor analysis is an interdependence technique in which all variables are simultaneously considered, each related to all others [...]"

93 "[...] to maximize their explanation of the entire variables set, not to predict a dependent variable(s)."

94 "Variables that are correlated with one another but largely independent of other subsets of variables are combined into factors."
} 


\subsubsection{Prova de Mann-Whitney}

Não paramétrico, o teste Mann-Whitney "É usado para testar se duas amostras independentes foram retiradas de populações com médias iguais.” (MARTINS, 2001, p. 268). Pode ser aplicado para variáveis intervalares ou ordinais e não exige nenhuma hipótese sobre distribuições populacionais e suas variâncias. É uma alternativa interessante da Prova $t$ Student, quando não é possível fazer as suposições necessárias à prova paramétrica; uma vez que esta exige uma variável intervalar, com distribuição normal.

\subsubsection{Análise Descritiva}

A análise descritiva se refere à “"[...] organização, sumarização e descrição de um conjunto de dados [...]” (MARTINS, 2001, p. 19). Desta forma, a construção de gráficos e tabelas auxilia na compreensão do comportamento das variáveis expressas no conjunto dos dados em análise.

\subsubsection{Análise de Conteúdo}

No caso das entrevistas realizadas com os responsáveis pelo projeto de e-learning da empresa e dos comentários incluídos ao final do questionário, foi realizada uma análise de conteúdo. De acordo com Bardin, "a análise de conteúdo aparece como um conjunto de técnicas de análise das comunicações, que utiliza procedimentos sistemáticos e objectivos de descrição do conteúdo das mensagens.” (2004, p. 33).

\subsubsection{Regressão Logística}

A Regressão Logística (RL) é uma técnica estatística multivariada utilizada na previsão ou explicação das relações que impactam uma variável dependente não numérica (HAIR et al, 1998, p. 240). Assim, “[...] os objetos são classificados em grupos e é desejado que o grupo 
formado por cada objeto possa ser previsto ou explicado por um conjunto de variáveis independentes [...]"95 (HAIR et al, 1998, p. 240).

Quando a variável dependente é binária, ou seja, há apenas dois grupos, essa técnica é preferida em relação à análise discriminante. Conforme apontado por Hair et al (1998, p. 276), a regressão logística não exige normalidade multivariada e matrizes iguais de variânciacovariância entre os grupos e é mais robusta quando estas premissas não são cumpridas. Além disso, "[...] mesmo caso as premissas sejam atingidas, muitos pesquisadores preferem a regressão logística, porque esta é similar à regressão." 96 (HAIR et al, 1998, p. 276).

95 "[...] the objects fall into groups, and it is desired that the group membership for each object can be predicted or explained by a set of independent variables [...]"

96 "[...] even if the assumptions are met, many researchers prefer logistic regression because it is similar to regression." 


\section{APRESENTAÇÃO E ANÁLISE DOS RESULTADOS}

Com o objetivo de analisar os fatores que influenciam a adoção individual do e-learning pelos colaboradores da organização, a apresentação dos resultados desta pesquisa está estruturada de acordo com os objetivos específicos que se buscou atingir, mencionados no capítulo dois:

(1) Comparar as dimensões do modelo conceitual proposto com aquelas observadas na empresa estudada, identificando aprimoramentos no Modelo Preliminar de Adoção Individual do e-Learning;

(2) Analisar as diferenças de percepção entre os colaboradores que realizaram e que não realizaram curso de e-learning na empresa, desde 2006;

(3) Analisar as diferenças de percepção em função do perfil do respondente;

(4) Identificar as variáveis que melhor explicam a intenção de realizar ou não cursos de $e$ learning na empresa;

(5) Identificar as variáveis que melhor explicam a realização ou não de cursos de $e$ learning na empresa, desde 2006.

Ao final do capítulo, os principais resultados da pesquisa são consolidados.

\subsection{Comparar as dimensões do modelo conceitual proposto com aquelas observadas na empresa estudada, identificando aprimoramentos no Modelo Preliminar de Adoção Individual do e-Learning}

Conforme já apresentado no capítulo anterior, a condução da análise fatorial dos dados teve como objetivo “[...] analisar a estrutura das inter-relações (correlações) entre um grande número de variáveis [...] através da definição de um conjunto de dimensões fundamentais, conhecidas como fatores" $" 97$ (HAIR et al, 1998, p. 90). As variáveis combinadas em um fator são correlacionadas e independentes das variáveis agrupadas nos demais fatores

\footnotetext{
97 “[...] analyzing the structure of the interrelationships (correlations) among a large number of variables [...] by defining a set of common underlying dimensions, known as factors."
} 
(TABACHNICK; FIDELL, 2001, p. 582), conforme já mencionado no capítulo de metodologia. Tendo em vista o caráter exploratório da análise fatorial realizada, buscou-se estabelecer uma relação entre as variáveis para em seguida comparar os resultados com o modelo conceitual proposto.

Antes de se realizar a análise fatorial, foram elaboradas as análises do teste Kaiser-MeyerOlkin (KMO) e do teste de esfericidade de Bartlett (TEB; $\mathrm{p}<.05$ ), para verificar se as características dos dados seriam adequadas para se proceder uma análise fatorial. A medida KMO $=0,923$ e TEB $(7326,504 ; p<.000)$, indicam que a solução fatorial é possível de ser aplicada aos dados. Além disso, para realização da análise, foram retiradas as variáveis de comunalidade inferior a 0,5 (Apêndice 4), procedimento coerente com a orientação de HAIR et al (1998, p. 113), que indica que variáveis com comunalidade inferior a 0,50 não apresentam explicação suficiente e podem ser excluídas da análise.

A análise fatorial conduziu à extração de 5 fatores com critério de auto-valor superior a 1 . Estes 5 fatores explicam 64\% da variância dos dados (Tabela 13).

Tabela 13 - Total da Variância Explicada

\begin{tabular}{ccc}
\hline Componente & \% da Variância & \% Acumulada \\
\hline Fator 1 & 36,917 & 36,917 \\
Fator 2 & 10,261 & 47,178 \\
Fator 3 & 7,216 & 54,393 \\
Fator 4 & 5,113 & 59,506 \\
Fator 5 & 4,27 & 63,776 \\
\hline
\end{tabular}

O Fator 1 explica 37\% da estrutura dos dados; é o fator mais importante na explicação dos dados originais desta pesquisa. Os demais fatores têm, relativamente, menor importância em sumarizar as variáveis originais. Assim, o Fator 2 explica 10\% dos dados; o Fator 3 corresponde a 7\% de explicação; o Fator 4 explica 5\% da estrutura dos dados; e, por fim, o Fator 5 corresponde a 4\% na variância dos dados. 
As variáveis pouco explicadas pelos resultados da análise fatorial, por apresentarem baixa comunalidade $^{98}$, e que foram retiradas desta análise são as seguintes:

- Se a Plataforma de e-elearning disponibilizasse mais cursos do meu interesse, eu a utilizaria com maior freqüência (eu a utilizaria): comunalidade $=0,328$;

- Se eu tivesse mais tempo, eu utilizaria o e-learning com maior freqüência (eu utilizaria o e-learning): comunalidade $=0,406$.

Estas duas variáveis fazem parte da dimensão Intenção de Uso do modelo conceitual da pesquisa e apresentaram um comportamento que não é explicado por nenhum dos fatores gerados pela Análise Fatorial.

As duas variáveis da dimensão Comportamento de Uso do modelo conceitual que também utilizam a escala Likert não foram consideradas na Análise Fatorial, uma vez que só foram respondidas pelos colaboradores que afirmaram terem participado de cursos de e-learning desde 2006:

- Comparado com outras pessoas, eu considero que participo dos cursos de e-learning com maior freqüência que a média;

- Comparado com outras pessoas, eu tiro melhor proveito dos cursos de e-learning disponíveis na Plataforma de e-learning.

Para melhor interpretar os fatores, aplicou-se a rotação Varimax. O nome de cada fator foi atribuído com base em “[...] todas as variáveis subordinadas a um determinado fator e colocando maior ênfase naquelas variáveis com carga fatorial mais alta" "99 (HAIR et al, 1998, p. 114), resultando na seguinte denominação:

- Fator 1 - Utilidade Percebida;

- Fator 2 - Ambiente Propício à Aprendizagem;

- Fator 3 - Facilidade de Uso Percebida;

\footnotetext{
${ }^{98}$ Comunalidade se refere ao valor total de variância que determinada variável compartilha com as demais variáveis da análise (HAIR et al, 1998, p. 88).
} 
- Fator 4 - Habilidade com Informática \& Pré-disposição para Inovar

- Fator 5 - Desconfiança em Relação à Inovação

A seguir, cada um desses fatores é apresentado e comparado com o modelo conceitual de Adoção Individual do e-Learning.

\subsubsection{Fator 1: Utilidade Percebida}

Conforme proposto no Modelo TAM, o constructo Utilidade Percebida se refere ao "grau em que uma pessoa acredita que utilizar um determinado sistema irá melhorar sua performance” (DAVIS, 1989, p. 320). O fator Utilidade Percebida que resultou da análise fatorial inclui 5 das 7 variáveis que no modelo conceitual fazem parte da dimensão de mesmo nome (Tabela 14). Também inclui as 3 variáveis que no modelo conceitual formam a dimensão Atitude em Relação ao e-Learning e as duas variáveis da dimensão Alinhamento com Requisitos do Negócio.

Tabela 14 - Variáveis do Fator Utilidade Percebida

\begin{tabular}{|c|c|c|}
\hline Variável & $\begin{array}{c}\text { Carga } \\
\text { Fatorial }\end{array}$ & $\begin{array}{l}\text { Dimensão do Modelo } \\
\text { Teórico }\end{array}$ \\
\hline 1. Obtenção de resultados de aprendizagem com o e-learning & 0,814 & Utilidade Percebida \\
\hline 2. Utilidade do e-learning no trabalho & 0,799 & Utilidade Percebida \\
\hline 3. Sentimento em relação à participação no e-learning & 0,792 & $\begin{array}{l}\text { Atitude em Relação ao } \\
\text { e-Learning }\end{array}$ \\
\hline $\begin{array}{l}\text { 4. Contribuição do e-learning para a melhora do desempenho no } \\
\text { trabalho }\end{array}$ & 0,782 & Utilidade Percebida \\
\hline $\begin{array}{l}\text { 5. Percepção em relação à participação do e-learning ser uma boa } \\
\text { idéia }\end{array}$ & 0,746 & \multirow{2}{*}{$\begin{array}{l}\text { Atitude em Relação ao } \\
\text { e-Learning }\end{array}$} \\
\hline 6. Satisfação em relação ao uso do e-learning & 0,738 & \\
\hline 7. $\quad$ Flexibilidade para aprender através do e-learning & 0,584 & Utilidade Percebida \\
\hline $\begin{array}{l}\text { 8. Potencial do e-learning para atender às necessidades de } \\
\text { treinamento do negócio }\end{array}$ & 0,563 & $\begin{array}{c}\text { Alinhamento com } \\
\text { Requisitos do Negócio }\end{array}$ \\
\hline 9. Importância do e-learning para a realização do trabalho & 0,556 & Utilidade Percebida \\
\hline $\begin{array}{l}\text { 10. Atendimento adequado do projeto existente às necessidades do } \\
\text { negócio }\end{array}$ & 0,459 & $\begin{array}{c}\text { Alinhamento com } \\
\text { Requisitos do Negócio }\end{array}$ \\
\hline
\end{tabular}

\footnotetext{
99 "[...] all the underlined variables for a particular factor and, placing greater emphasis on those variables with higher loadings [...]".
} 
Das cinco variáveis que foram incluídas nesse fator e tinham objetivo de medir a Utilidade Percebida no modelo conceitual, duas delas (itens 2 e 4 da Tabela 14) têm sido utilizadas com maior freqüência em pesquisas anteriores (VENKATESH; DAVIS, 2000; SCHILLEWAERT et al, 2000; VENKATESH et al, 2003; SILVA, 2005; OLIVEIRA, 2006). Já os resultados obtidos das variáveis dos itens 1 e 9 da Tabela 14, embora baseadas apenas na pesquisa de Venkatesh e Davis (2000), indicam que estão consistentes com o constructo Utilidade Percebida que se pretendeu medir. O mesmo ocorre com a variável Flexibilidade para aprender através do e-learning (item 7), que foi incorporada como uma adaptação do modelo à tecnologia em questão e que também se mostrou consistente em relação à medição da utilidade percebida.

Por outro lado, duas variáveis que fazem parte da dimensão Utilidade no modelo conceitual foram explicadas por outros fatores no resultado da análise fatorial. Embora essas variáveis tenham sido incorporadas posteriormente ao Modelo TAM original (VENKATESH et al, 2003; VENKATESH; DAVIS, 2000), os resultados indicam que os respondentes interpretaram de maneira diferente esses itens:

- A percepção em relação à possibilidade de promoção como resultado da participação em cursos de e-learning ${ }^{100}$ parece ter sido percebida como uma variável que contribui para a imagem e status do indivíduo ao invés de contribuir para melhorar o trabalho, uma vez que os resultados mostraram sua relação com o fator Ambiente Propício à Aprendizagem.

- Da mesma forma, a interpretação da variável Facilidade para explicar os benefícios do e-learning mostrou estar mais relacionada à facilidade de uso percebida do que à noção de utilidade.

Uma possível explicação para divergências nos resultados em relação a pesquisas anteriores são as diferenças culturais. Veiga et al (2001) discutem a influência das diferenças culturais do país na implementação e aceitação de Tecnologias da Informação, utilizando o Modelo TAM. Os autores concluem que "os efeitos de interação do conjunto de valores culturais de um país específico afetam a aceitação de Tecnologias da Informação em formas distintas para 
uma cultura em particular"101 (Veiga et al, 2001, p. 155). Além disso, a adaptação das variáveis para o e-learning e a tradução do questionário para o português também podem explicar eventuais diferenças na percepção dos respondentes.

Já o constructo Atitude em Relação ao e-Learning também apresentou diferença entre o modelo conceitual e os resultados da análise fatorial. De acordo com o modelo inicialmente proposto, a dimensão Atitude se refere aos sentimentos negativos ou positivos dos respondentes em relação ao uso do e-learning. Os resultados mostram que as três variáveis de atitude podem ser explicadas pelo fator Utilidade Percebida (itens 3, 5 e 6 da Tabela 14), indicando que o sentimento de satisfação em participar dos cursos de e-learning tem comportamento semelhante à percepção de utilidade. O Modelo TAM propõe uma relação positiva entre utilidade e atitude, uma vez que "resultados positivos de valor freqüentemente aumentam o sentimento do indivíduo em relação aos meios pelos quais os resultados foram atingidos"102 (DAVIS et al, 1989, p. 987); efeito identificado pelas pesquisas de Gong et al (2004) e Martins e Kellermanns (2004) que aplicaram o Modelo TAM para analisar a aceitação de sistemas de aprendizagem on-line.

Apesar disso, o constructo Atitude não está presente nos modelos que evoluíram do TAM, TAM 2 e UTAUT (VENKATESH; DAVIS, 2000; VENKATESH et al, 2003) e foi extraído de pesquisas anteriores que utilizam o Modelo TAM com o objetivo de simplificar o modelo (ONG et al, 2004, p. 796). Fusilier e Durlabhji (2005, p.242) não encontram relação entre atitude e intenção, sendo que os resultados apontam que a atitude teria uma interação com norma subjetiva, ao invés de um efeito principal.

É interessante notar que as variáveis da dimensão Alinhamento com Requisitos do Negócio do modelo conceitual também foram incorporadas ao fator Utilidade Percebida (itens 8 e 10 da Tabela 14). Em linha com o que descreve a literatura (ROSENBERG; 2000; TYAN; 2003; BOROTIS; POULYMENAKOU; 2004), o potencial do e-learning para atender os requisitos do negócio e a consistência do projeto existente com as necessidades do negócio são fatores

\footnotetext{
100 "Quando participo (se eu participasse) de cursos de e-learning, estou (estaria) aumentando minhas chances de ser promovido(a)"

101 "The 'interaction effects' from combinations of cultural values in a specific country are expected to affect IT acceptance in ways that are distinctive to that particular culture."

102 "[...] positively valued outcomes often increase one's affect toward the means to achieving those outcomes"
} 
de sucesso do projeto de e-learning e podem ser relacionados à percepção de utilidade. No modelo conceitual estas variáveis foram incluídas em um conjunto de dimensões separadas, pois se tratavam de variáveis adicionais ao Modelo TAM.

\subsubsection{Fator 2: Ambiente Propício à Aprendizagem}

Este fator agrupa variáveis relacionadas ao ambiente organizacional que influenciam a adoção do e-learning, incluindo: superior imediato, colegas e expectativa de melhorar o status, apoio da alta administração, cultura organizacional e projeto de e-learning (Tabela 15).

De forma geral, as variáveis desse fator relacionam-se aos valores da organização em relação à aprendizagem e ao e-learning, que são traduzidos em suas práticas organizacionais. Em outras palavras, relacionam-se à maneira "como o grupo de pessoas que criaram a organização foram aos poucos desenvolvendo formas próprias de lidar com os problemas de adaptação externa e integração interna" (FLEURY; FLEURY, 1997, p. 26).

Como resultado, a organização apresenta características que podem estimular ou limitar o processo de aprendizagem. Conforme apontado por Fleury (1997, p. 162-164), três pontos devem ser considerados para desenhar um ambiente propício à aprendizagem:

- "Tempo: o processo de aprendizagem requer tempo";

- "Espaço: em organizações voltadas para aprendizagem, as fronteiras são flexíveis e a comunicação flui";

- "Pessoas: as pessoas constituem peças-chave no processo de aprendizagem, que se configura como um processo coletivo, partilhado por todos e não o privilégio de uma minoria pensante". 
Tabela 15 - Variáveis do Fator Ambiente Propício à Aprendizagem

\begin{tabular}{|c|c|c|}
\hline Variável & $\begin{array}{c}\text { Carga } \\
\text { Fatorial }\end{array}$ & $\begin{array}{l}\text { Dimensão do Modelo } \\
\text { Teórico }\end{array}$ \\
\hline 1. Indicação da importância do e-learning pelo superior imediato & 0,867 & \multirow{2}{*}{ Influência Social } \\
\hline 2. Estímulo do superior imediato para participar do e-learning & 0,867 & \\
\hline 3. Patrocínio da empresa para participação no e-learning & 0,732 & Apoio da Alta \\
\hline 4. Comprometimento da Alta Administração com o uso do e-learning & 0,727 & Administração \\
\hline 5. Influência dos colegas em relação à participação no e-learning & 0,664 & Influência Social \\
\hline 6. Cultura favorece a adoção do e-learning & 0,66 & $\begin{array}{c}\text { Favorecimento da } \\
\text { Cultura Organizacional }\end{array}$ \\
\hline 7. Prestígio resultante da participação no e-learning & 0,574 & Influência Social \\
\hline $\begin{array}{l}\text { 8. Aumento nas chances de promoção em função da participação no } \\
\text { e-learning }\end{array}$ & 0,514 & Utilidade Percebida \\
\hline 9. $\quad$ Cultura valoriza a aprendizagem & 0,511 & Cultura Organizacional \\
\hline 10. Sucesso da campanha de incentivo ao uso do e-learning & 0,484 & $\begin{array}{l}\text { Adequação do Projeto } \\
\text { de } e \text {-Learning }\end{array}$ \\
\hline
\end{tabular}

Integram esse fator as variáveis da dimensão Influência Social no modelo conceitual, baseada nos constructos Norma Subjetiva ("[...] percepção da pessoa sobre o que pessoas que são importantes para ela pensam em relação a dever ou não realizar o comportamento em questão"103) e Imagem ("grau em que o uso de uma inovação é percebido como uma forma de melhorar [...] o status do indivíduo em seu sistema social" ${ }^{104}$ ) do Modelo TAM 2 (VENKATESH; DAVIS, 2000). Estas quatro variáveis (itens 1, 2, 5 e 7 da Tabela 15) podem ser relacionadas ao aspecto Pessoas, uma vez que abordam a influência das relações e o aspecto coletivo do processo de aprendizagem.

Especificamente no caso das duas variáveis de maior carga fatorial, que tratam da indicação de importância do e-learning e estímulo do superior imediato para participar do e-learning (itens 1 e 2 da Tabela 15) e que foram incluídas com base na pesquisa de Schillewaert et al (2000), há também uma relação importante com o aspecto Tempo. Considerando que as pessoas precisam de "[...] tempo para absorver novos conhecimentos, estruturá-los, interpretálos, individual ou coletivamente; disto podendo decorrer a orientação para a ação." (FLEURY, 1997, p. 163), o superior imediato tem papel importante ao influenciar na priorização das atividades do colaborador.

103 "person's perception that most people who are important to him think he should or should not perform the behavior in question"

104 "[...] the degree to which use of an innovation is perceived to enhance one's [...] status in one's social system" 
As variáveis que tratam do apoio da alta administração (itens 3 e 4 da Tabela 15) estão baseadas na literatura de e-learning (ROSENBERG, 2000; BOROTIS; POULYMENAKOU, 2004; VAN DAM, 2004) e por isso foram incluídas no modelo conceitual como variáveis adicionais ao Modelo TAM. Essas duas variáveis e a variável sobre a campanha de incentivo (dimensão Projeto de e-Learning do modelo conceitual) relacionam-se ao aspecto Pessoas, refletindo o estímulo ao processo de aprendizagem em todos os níveis da organização.

Apesar das limitações, as variáveis de cultura organizacional (itens 6 e 9 da Tabela 15), baseadas nas pesquisas sobre e-learning (ROSENBERG, 2000; TYAN, 2003; ECONOMIST INTELLIGENCE UNIT; IBM, 2003; BOROTIS; POULYMENAKOU, 2004; VAN DAM, 2004; PSYCHARIS, 2005), têm intenção de refletir de forma mais ampla a existência de um

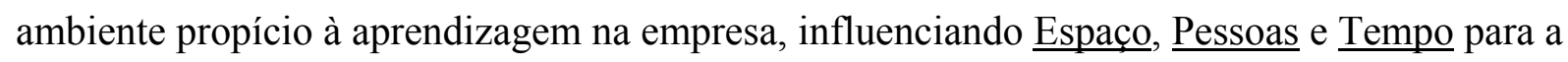
participação no e-learning.

Por fim, a variável que relaciona o uso do e-learning com um aumento nas chances de ser provido (item 8 da Tabela 15) faz parte da dimensão Utilidade Percebida do modelo conceitual, conforme pesquisado por Venkatesh e Davis (2000). Uma possível explicação para esta variável ter comportamento semelhante às variáveis de influência social, no caso da presente pesquisa, seria uma percepção dos respondentes de que a chance de promoção estaria mais relacionada ao status do que à percepção de utilidade.

\subsubsection{Fator 3: Facilidade de Uso Percebida}

O constructo Facilidade de Uso Percebida, baseado no Modelo TAM, se refere ao "grau em que uma pessoa acredita que utilizar determinado sistema não envolverá esforço"105 (DAVIS, 1989, p. 320). Fazem parte deste fator, as duas variáveis de facilidade de uso do modelo conceitual, 5 de um total de 6 variáveis da dimensão adequação do projeto de $e$-learning, e uma variável da dimensão utilidade percebida (Tabela 16).

105 "the degree to which a person believes that using a particular system would be free of effort" 
Tabela 16 - Variáveis do Fator Facilidade de Uso Percebida

\begin{tabular}{|c|c|c|}
\hline Variável & $\begin{array}{c}\text { Carga } \\
\text { Fatorial } \\
\end{array}$ & $\begin{array}{c}\text { Dimensão do } \\
\text { Modelo Teórico }\end{array}$ \\
\hline 1. Facilidade para usar o e-learning & 0,718 & $\begin{array}{l}\text { Facilidade de Uso } \\
\text { Percebida }\end{array}$ \\
\hline 2. Disponibilização de instruções e orientações para usar o $e$-learning & 0,689 & Adequação do Projeto \\
\hline 3. Conhecimento sobre o suporte disponível ao e-learning & 0,668 & de $e$-Learning \\
\hline 4. Clareza e inteligibilidade da interação com o sistema de $e$-learning & 0,661 & $\begin{array}{l}\text { Facilidade de Uso } \\
\text { Percebida }\end{array}$ \\
\hline 5. Suficiência dos recursos tecnológicos & 0,644 & \multirow{3}{*}{$\begin{array}{l}\text { Adequação do Projeto } \\
\text { de e-Learning }\end{array}$} \\
\hline 6. Sucesso das campanhas de comunicação do e-learning & 0,58 & \\
\hline $\begin{array}{l}\text { 7. Disponibilidade de uma pessoa (ou grupo) para auxiliar no uso do } e \text { - } \\
\text { learning }\end{array}$ & 0,494 & \\
\hline 8. Facilidade em explicar os benefícios do e-learning & 0,419 & Utilidade Percebida \\
\hline
\end{tabular}

As duas variáveis que tratam da facilidade de uso do sistema de e-learning (itens 1 e 4 ) estão entre as de maior carga fatorial na explicação do fator. Estas variáveis estão presentes nas pesquisas anteriores analisadas (VENKATESH; DAVIS, 2000; SCHILLEWAERT et al, 2000; VENKATESH et al, 2003; MARTINS; KELLERMANNS, 2004; SILVA, 2005; OLIVEIRA, 2006; COSTA FILHO et al, 2007) e se mostram significativas na compreensão do modelo de adoção, discussão abordada nos próximos tópicos.

Os resultados indicam que a percepção da facilidade de uso do sistema está relacionada à percepção de suporte disponível ao participante do e-learning, incluindo disponibilidade de orientações, de assistência, de equipe de apoio e de recursos tecnológicos (itens 2, 3, 5 e 7 da Tabela 16). O agrupamento destas variáveis no fator Facilidade de Uso Percebida faz sentido, embora fizessem parte das variáveis adicionadas ao Modelo TAM no modelo conceitual, uma vez que foram baseadas nas condições facilitadoras que se observou na literatura de adoção individual de inovações (DAVIS et al, 1989; ROGERS, 1995; SCHILLEWAERT et al, 2000; VENKATESH et al, 2003; MARTINS; KELLERMANNS, 2004) e na literatura de e-learning (ROSENBERG, 2000; VAN DAM, 2004).

Outra variável da dimensão Adequação do Projeto de e-Learning no modelo conceitual e que passou a integrar o fator Facilidade de Uso Percebida, trata do sucesso das campanhas de comunicação do e-learning (item 6 da Tabela 16). Esse resultado corrobora com o modelo de Schillewaert et al (2000), que apresenta a campanha de marketing interno da nova tecnologia como um dos itens da dimensão Facilitadores Organizacionais, que também integra treinamento e suporte técnico ao usuário. 
Por fim, o fator Facilidade de Uso Percebida também inclui a variável que avalia a facilidade do respondente em explicar os benefícios do e-learning, utilizada por Venkatesh e Davis (2000) como parte do constructo Demonstrabilidade do Resultado, que, conforme proposto pelos autores, consiste em um dos quatro determinantes cognitivos da utilidade percebida, além da Relevância para o trabalho, Qualidade do resultado e Facilidade de uso. Considerando que a percepção dos benefícios do e-learning estaria relacionada à noção de utilidade, optou-se por incluir essa variável na dimensão Utilidade Percebida do modelo conceitual. Dentre as possíveis explicações para os resultados indicarem a presença dessa variável no fator Facilidade de Uso Percebida estão: a simplificação e modificação da afirmação original para estava na forma negativa ("Eu teria dificuldade em explicar porque usar os sistema pode ou não ser benéfico" ${ }^{106}$ ), o uso da palavra facilidade e a tradução para o português.

\subsubsection{Fator 4: Habilidade com Informática \& Pré-disposição para Inovar}

Este fator reúne variáveis que tratam da auto-eficácia com computadores e pré-disposição pessoal para inovar, que integram a dimensão Características Pessoais do modelo conceitual (Tabela 17).

Tabela 17 - Variáveis do Fator Habilidade com Informática \& Pré-disposição para Inovar

\begin{tabular}{|c|c|c|}
\hline Variável & $\begin{array}{c}\text { Carga } \\
\text { Fatorial }\end{array}$ & $\begin{array}{c}\text { Dimensão do } \\
\text { Modelo Teórico }\end{array}$ \\
\hline 1. Habilidade para utilizar um novo software & 0,792 & Auto-eficácia com \\
\hline 2. Facilidade com informática & 0,774 & Computadores \\
\hline 3. Disposição para experimentar novas tecnologias & 0,768 & Pre-disposição para \\
\hline 4. Perfil de novo adotante & 0,749 & Inovar \\
\hline
\end{tabular}

A Habilidade para utilizar um novo software (item 1 da Tabela 17) faz parte do constructo Auto-eficácia com Computadores, estudado na literatura sobre adoção de tecnologias (SCHILLEWAERT et al, 2000) e especialmente nas pesquisas sobre aceitação do e-learning (GONG et al, 2004; MARTINS; KELLERMANNS, 2004; ONG et al, 2004; LEE, 2006),

106 “I would have difficulty explaining why using the system may or may not be beneficial." (VENKATESH; DAVIS, 2000, p. 201). 
tendo como objetivo medir a confiança do usuário no uso de novos sistemas de informação. $\mathrm{Na}$ literatura sobre implementação do e-learning, a habilidade do aluno com informática (item 2 da Tabela 17) é mencionada como fator relevante (ROSENBERG, 2000; TYAN, 2003). Estas duas variáveis apresentam comportamento semelhante e, embora façam parte da dimensão auto-eficácia com computadores do modelo conceitual, optou-se por resumi-las no termo Habilidade com Informática, que apresenta maior facilidade de compreensão.

Já as outras duas variáveis que integram este fator, referem-se à pré-disposição para inovar, constructo baseado nas pesquisas de Rogers (1995) e Schillewaert et al (2000), consistindo da "[...] atitude que reflete a tendência de experimentar e adotar novas tecnologias de informação, independentemente da experiência informada por outros"107 (SCHILLEWAERT et al, 2000, p. 10).

\subsubsection{Fator 5: Desconfiança em Relação à Inovação}

A análise fatorial resultou em um último fator (Tabela 18), cujas variáveis se esperava que estivessem no Fator 4 (apresentado acima), uma vez que também foram baseadas nos constructos auto-eficácia com computadores (item 3) e pré-disposição para inovar (itens 1 e 2).

Tabela 18 - Variáveis do Fator Desconfiança em Relação à Inovação

\begin{tabular}{lcc}
\hline Variável & $\begin{array}{c}\text { Carga } \\
\text { Fatorial }\end{array}$ & $\begin{array}{c}\text { Dimensão do } \\
\text { Modelo Teórico }\end{array}$ \\
\hline 1. Necessidade de ver uma inovação sendo usada antes de usá-la & 0,807 & $\begin{array}{c}\text { Pré-disposição para } \\
\text { Inovar }\end{array}$ \\
\hline 2. Atitude cética em relação a novas tecnologias & 0,806 & $\begin{array}{c}\text { Auto-eficácia com } \\
\text { Computadores }\end{array}$ \\
\hline 3. Necessidade de ver um software sendo usado antes de usá-lo & 0,773 & nnn \\
\hline
\end{tabular}

O esperado seria que as variáveis do Fator 5 tratassem das mesmas atitudes do Fator 4, apenas com o sentido inverso. Por exemplo: uma variável avaliando a capacidade de usar um software sem tê-lo visto operando anteriormente e a outra variável avaliando a necessidade de ver um software sendo utilizado antes de efetivamente utilizá-lo. Porém, de acordo com a 
amostra, o Fator 5 tem sentido oposto ao fator 4 apenas para 53\% dos respondentes. Desta forma, o resultado da análise ter gerado um novo fator indica que as variáveis medem dimensões diferentes.

Com base nas variáveis agrupadas, o Fator 5 pode ser relacionado com a desconfiança do indivíduo em relação à inovação ou à tecnologia a ser adotada. De acordo com Lippert e Forman, "A mudança para uma nova solução tecnológica inclui risco e a possibilidade de experimentar uma perda de informação associada com a adoção ou comportamento de uso." ${ }^{108}$ (2006, p. 271).

Rogers (1995, p. 397) menciona a incerteza envolvida na implementação de inovações ligadas a computadores, o que, freqüentemente, gera resistência à tecnologia. De acordo com o autor, “[...] o processo de decisão em relação à inovação é uma atividade de procura e processamento de informação em que um indivíduo obtém informação para reduzir a incerteza sobre a inovação"109 (ROGERS, 1995, p. 20).

A confiança na inovação envolve uma disposição para assumir riscos e experiências passadas que estabelecem o nível de familiaridade com determinada tecnologia; assim, os autores definiram o construto Confiança na Tecnologia (Technology Trust) como "A disposição de um indivíduo em ficar vulnerável para a tecnologia com base nas expectativas de previsibilidade, confiabilidade e utilidade da tecnologia e influenciado pela preferência do indivíduo em confiar na tecnologia" $" 110$ (LIPPERT; FORMAN, 2006, p. 278).

Desta forma, como as variáveis do Fator estão no sentido negativo, este foi denominado Desconfiança em Relação à Inovação, se referindo à pré-disposição do indivíduo em perceber a inovação com receio e incerteza, influenciada por suas experiências anteriores com novas tecnologias.

\footnotetext{
107 “[...] attitude which reflects his/her tendency to experiment with and adopt new information technologies, independently of the communicated experience of others."

108 "The change to a new technological solution includes risk and the possibility of experiencing an information loss associated with the adoption or usage behavior."

109 "[...] the innovation-decision process is an information-seeking and information-processing activity in which an individual obtains information in order to decrease uncertainty about the innovation"

110 "An individual's willingness to be vulnerable to the technology based on expectations of technology predictability, reliability and utility and influenced by the individual's predilection to trust technology"
} 
Visando consolidar o resultado da comparação entre as dimensões do modelo conceitual (Modelo Preliminar de Adoção Individual do e-Learning) e o resultado da análise fatorial, a Figura 26 apresenta os fatores que passaram a compor o Modelo de Adoção Individual do $e$ Learning na Empresa Estudada, com a indicação (subitens) das dimensões do modelo conceitual que passaram a compor cada fator, conforme já explicado nos tópicos acima. $\mathrm{O}$ layout dos fatores foi baseado no modelo conceitual, incluindo as variáveis originais do Modelo TAM em destaque (Utilidade Percebida, Facilidade de Uso Percebida, Intenção de Uso e Comportamento de Uso) e as variáveis externas ao modelo ao lado esquerdo. Figura não indica relações entre os fatores, uma vez que a análise fatorial resulta apenas nos fatores explicativos dos dados e a influência entre os fatores e a Intenção e Comportamento de Uso será analisada posteriormente (tópicos 5.4 e 5.5).
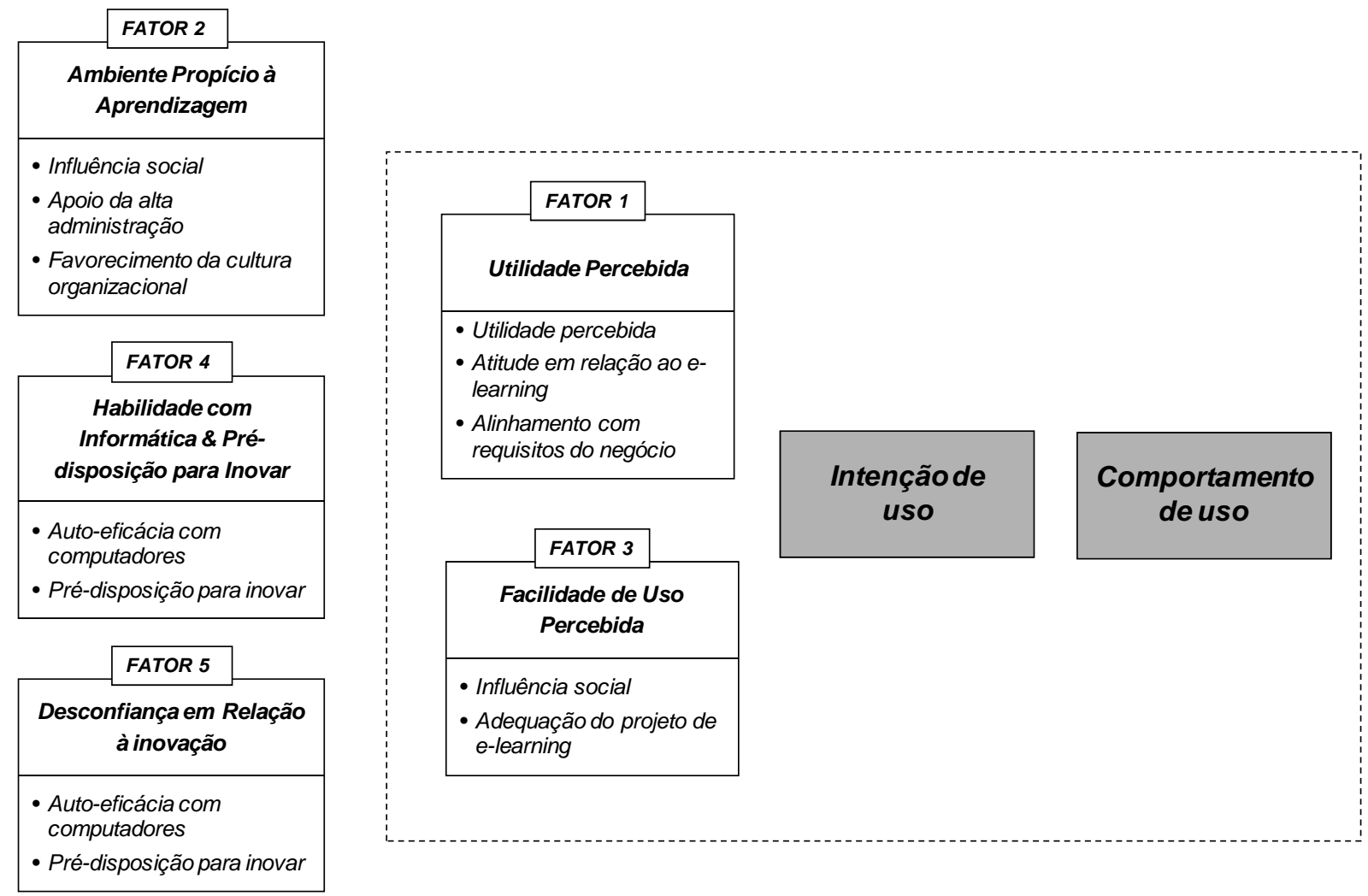

Figura 26 - Resultado da Comparação entre o Modelo Preliminar de Adoção Individual do e-Learning e os Fatores Observados na Empresa Pesquisada

Para a condução das demais análises propostas, as hipóteses da pesquisa apresentadas anteriormente no Quadro 10 foram detalhadas com base nos fatores gerados pela análise fatorial (Quadro 16), exceto as hipóteses do terceiro objetivo específico, caso em que não houve necessidade de maior detalhamento. 
Tendo em vista que as hipóteses foram formuladas como hipóteses nulas $\left(H_{0}\right)$, com base na literatura, espera-se que todas sejam rejeitadas. Nas hipóteses relacionadas ao objetivo 2 , espera-se que os respondentes que participaram de cursos de e-learning na plataforma da empresa apresentem maior concordância em relação às variáveis que influenciam a adoção do e-learning. No objetivo 3, são esperadas diferenças no grau de concordância em função da realização de e-learning fora da empresa e em função do gênero. Por fim, nos objetivos 4 e 5 espera-se que os fatores do Modelo de Adoção Individual influenciem positivamente a intenção de uso e o comportamento de uso, com exceção do fator Desconfiança em Relação à Inovação, que influenciaria negativamente. 
Quadro 16 - Hipóteses Detalhadas da Pesquisa

\begin{tabular}{|c|c|c|}
\hline Objetivo Específico & Hipóteses por Fator & Base Conceitual \\
\hline \multirow{11}{*}{$\begin{array}{l}\text { 2. Analisar as } \\
\text { diferenças de } \\
\text { percepção entre os } \\
\text { colaboradores que } \\
\text { realizaram e que } \\
\text { não realizaram } \\
\text { curso de } \text {-learning } \\
\text { na empresa, desde } \\
2006\end{array}$} & \multirow{2}{*}{$\begin{array}{l}\mathbf{1 . 1} \text { - } \boldsymbol{H}_{0} \text { : Mesmo grau de concordância entre os respondentes } \\
\text { que participaram do e-learning e os que não participaram em } \\
\text { relação à Utilidade Percebida do e-learning }\end{array}$} & Premissas do TAM: DAVIS et al, 1989; VENKATESH; DAVIS, 2000 \\
\hline & & $\begin{array}{l}\text { Pesquisas sobre adoção do e-learning: GONG et al , 2004; SELIM, 2003; } \\
\text { MARTINS; KELLERMANNS, 2004; ONG et al, 2004; FUSILIER; } \\
\text { DURLABHJ, } 2005\end{array}$ \\
\hline & \multirow[t]{2}{*}{$\begin{array}{l}1.2-H_{0}: \text { Mesmo grau de concordância entre os respondentes que } \\
\text { participaram do e-learning e os que não participaram em relação } \\
\text { à percepção do Ambiente Propício à Aprendizagem }\end{array}$} & $\begin{array}{l}\text { Literatura sobre os fatores de sucesso do e-learning: ROSENBERG, 2000; } \\
\text { MACPHERSON et al, 2004; CHANG, 2005; TYAN, 2003; ECONOMIST } \\
\text { INTELLIGENCE UNIT; IBM, 2003; BOROTIS; POULYMENAKOU, 2004; } \\
\text { VAN DAM, 2004; PSYCHARIS, 2005; PRICEWATERHOUSECOOPERS, } \\
\text { 2001; DOWNES, 2003; IGNATIUS; RMAYAH, } 2005\end{array}$ \\
\hline & & $\begin{array}{l}\text { Pesquisas que analisaram as influências sociais: MARTINS; } \\
\text { KELLERMANNS, 2004; VENKATESH; DAVIS, 2000; SCHILLEWAERT et } \\
\text { al, } 2000\end{array}$ \\
\hline & \multirow{2}{*}{$\begin{array}{l}1.3 \text { - } \boldsymbol{H}_{0} \text { : Mesmo grau de concordância entre os respondentes que } \\
\text { participaram do e-learning e os que não participaram em relação } \\
\text { à Facilidade de Uso Percebida do e-learning }\end{array}$} & $\begin{array}{l}\text { Pesquisas sobre adoção do e-learning: MARTINS; KELLERMANNS, 2004; } \\
\text { GONG et al, 2004; ONG et al, 2004; SELIM, 2003; }\end{array}$ \\
\hline & & Importância do suporte contínuo: ROSENBERG, 2006; VAN DAM, 2004 \\
\hline & \multirow{2}{*}{$\begin{array}{l}1.4 \text { - } \boldsymbol{H}_{0} \text { : Mesmo grau de concordância entre os respondentes que } \\
\text { participaram do e-learning e os que não participaram em relação } \\
\text { à Habilidade com Informática \& Pré-disposição para Inovar }\end{array}$} & $\begin{array}{l}\text { Pesquisas sobre adoção do e-learning: GONG et al, 2004; ONG et al, 2004; } \\
\text { LEE, } 2006\end{array}$ \\
\hline & & Pesquisa sobre adoção de tecnologias: SCHILLEWAERT et al, 2000 \\
\hline & \multirow{2}{*}{$\begin{array}{l}1.5 \text { - } \boldsymbol{H}_{\boldsymbol{0}} \text { : Mesmo grau de concordância entre os respondentes que } \\
\text { participaram do e-learning e os que não participaram sobre a } \\
\text { Desconfiança em Relação à Inovação }\end{array}$} & $\begin{array}{l}\text { Pesquisas sobre adoção de tecnologias: KAMEL; HASSAN, 2003; LIPPERT; } \\
\text { FORMAN, 2006; VENKATESH et al, } 2003\end{array}$ \\
\hline & & Pesquisas sobre adoção do e-learning: ONG et al, 2004 \\
\hline & $\begin{array}{l}\text { 1.6 - } \boldsymbol{H}_{\mathbf{0}} \text { : Mesmo grau de concordância entre os respondentes que } \\
\text { participaram do e-learning e os que não participaram em relação } \\
\text { à Intenção de Uso do e-learning }\end{array}$ & $\begin{array}{l}\text { Pesquisas sobre adoção do e-learning: MARTINS; KELLERMANNS, 2004; } \\
\text { LEE, 2006; SELIM, 2003; GONG et al, 2004; ONG et al, 2004; FUSILIER; } \\
\text { DURLABHJI, } 2005\end{array}$ \\
\hline
\end{tabular}


Quadro 16 - Hipóteses Detalhadas da Pesquisa

\begin{tabular}{|c|c|c|}
\hline Objetivo Específico & Hipóteses por Fator & Base Conceitual \\
\hline \multirow[t]{2}{*}{$\begin{array}{l}\text { 3. Analisar as } \\
\text { diferenças de } \\
\text { percepção em função } \\
\text { do perfil do } \\
\text { respondente }\end{array}$} & $\begin{array}{l}2 \text { - } \boldsymbol{H}_{0} \text { : Mesmo grau de concordância entre os respondentes que } \\
\text { realizaram e não realizaram curso de } e \text {-learning fora da } \\
\text { plataforma da empresa em relação às variáveis que } \\
\text { influenciam a adoção do e-learning }\end{array}$ & $\begin{array}{l}\text { Literatura de e-learning (VAN DAM, 2004; LEE, 2006; ONG; LAI, 2006; } \\
\text { ANGEHRN et al, 2001) } \\
\text { Experiência com a tecnologia (FUSILIER; DURLABHJ, 2005) }\end{array}$ \\
\hline & $\begin{array}{l}3 \text { - } \boldsymbol{H}_{0} \text { : Mesmo grau de concordância entre os respondentes } \\
\text { homens e mulheres em relação às variáveis que influenciam a } \\
\text { adoção do e-learning }\end{array}$ & $\begin{array}{l}\text { Pesquisas sobre adoção de tecnologia (ONG; LAI, 2006; VENKATESH; } \\
\text { MORRIS, 2000; GEFEN; STRAUB, 1997) }\end{array}$ \\
\hline \multirow{6}{*}{$\begin{array}{l}\text { 4. Identificar as } \\
\text { variáveis que melhor } \\
\text { explicam a intenção } \\
\text { de realizar ou não } \\
\text { cursos de } \text {-learning } \\
\text { na empresa }\end{array}$} & $\begin{array}{l}4.1 \text { - } H_{0} \text { : O fator Utilidade Percebida não influencia a Intenção } \\
\text { de Uso do e-learning }\end{array}$ & $\begin{array}{l}\text { Pesquisas sobre adoção do e-learning (ONG et al, 2006; LEE, 2006; GONG et } \\
\text { al, 2004; SELIM, 2003) } \\
\text { Premissas do Modelo TAM (DAVIS et al, 1989; VENKATESH; DAVIS, } \\
\text { 2000) }\end{array}$ \\
\hline & $\begin{array}{l}\text { 4.2 - } \boldsymbol{H}_{0} \text { : O fator Ambiente Propício à Aprendizagem não } \\
\text { influencia a Intenção de Uso do e-learning }\end{array}$ & $\begin{array}{l}\text { Literatura de e-learning (ROSENBERG, 2000; TYAN, 2003; ECONOMIST } \\
\text { INTELLIGENCE UNIT; IBM, 2003; BOROTIS; POULYMENAKOU, 2004; } \\
\text { VAN DAM, 2004; PSYCHARIS, 2005) }\end{array}$ \\
\hline & $\begin{array}{l}4.3 \text { - } \boldsymbol{H}_{0} \text { : O fator Facilidade de Uso Percebida não influencia a } \\
\text { Intenção de Uso do e-learning }\end{array}$ & $\begin{array}{l}\text { Pesquisas sobre adoção do e-learning (MARTINS; KELLERMANNS, 2004; } \\
\text { GONG et al, 2004; ONG et al, 2004; SELIM, 2003) }\end{array}$ \\
\hline & $\begin{array}{l}\text { 4.4 - } H_{0} \text { : O fator Habilidade com Informática \& Pré- } \\
\text { disposição para Inovar não influencia a Intenção de Uso do e- } \\
\text { learning }\end{array}$ & $\begin{array}{l}\text { Literatura de e-learning (ROSENBERG, 2006; VAN DAM, 2004) e Pesquisas } \\
\text { sobre adoção do e-learning (LEE, 2006; GONG et al, 2004; ONG et al, 2004) }\end{array}$ \\
\hline & $\begin{array}{l}\text { 4.5 - } \boldsymbol{H}_{0} \text { : O fator Desconfiança em Relação à Inovação não } \\
\text { influencia a Intenção de Uso do e-learning }\end{array}$ & $\begin{array}{l}\text { Pesquisas sobre adoção de tecnologias: KAMEL; HASSAN, 2003; LIPPERT; } \\
\text { FORMAN, 2006; VENKATESH et al, } 2003\end{array}$ \\
\hline & & Pesquisas sobre adoção do e-learning: ONG et al, 2004 \\
\hline
\end{tabular}


Quadro 16 - Hipóteses Detalhadas da Pesquisa

\begin{tabular}{|c|c|c|}
\hline Objetivo Específico & Hipóteses & Base Conceitual \\
\hline \multirow{5}{*}{$\begin{array}{l}\text { 5. Identificar as } \\
\text { variáveis que melhor } \\
\text { explicam a realização } \\
\text { ou não de cursos de } e \text { - } \\
\text { learning na empresa }\end{array}$} & $\begin{array}{l}5.1 \text { - } H_{0}: \text { O fator Utilidade Percebida não influencia o } \\
\text { Comportamento de Uso do e-learning }\end{array}$ & $\begin{array}{l}\text { Pesquisas sobre adoção do e-learning (MARTINS; KELLERMANNS, 2004) } \\
\text { Premissas do Modelo TAM (DAVIS et al, 1989; VENKATESH; DAVIS, } \\
\text { 2000) }\end{array}$ \\
\hline & $\begin{array}{l}5.2 \text { - } H_{0} \text { : O fator Ambiente Propício à Aprendizagem não } \\
\text { influencia o Comportamento de Uso do e-learning }\end{array}$ & $\begin{array}{l}\text { Literatura de e-learning (ROSENBERG, 2000; TYAN, 2003; ECONOMIST } \\
\text { INTELLIGENCE UNIT; IBM, 2003; BOROTIS; POULYMENAKOU, 2004; } \\
\text { VAN DAM, 2004; PSYCHARIS, 2005) }\end{array}$ \\
\hline & $\begin{array}{l}5.3 \text { - } \boldsymbol{H}_{0}: \text { O fator Facilidade de Uso Percebida não influencia o } \\
\text { Comportamento de Uso do e-learning }\end{array}$ & $\begin{array}{l}\text { Pesquisas sobre adoção do e-learning (MARTINS; KELLERMANNS, 2004; } \\
\text { GONG et al, 2004; ONG et al, 2004; SELIM, 2003) }\end{array}$ \\
\hline & $\begin{array}{l}5.4 \text { - } \boldsymbol{H}_{0} \text { : O fator Habilidade com Informática e Pré-disposição } \\
\text { para Inovar não influencia o Comportamento de Uso do } e \text { - } \\
\text { learning }\end{array}$ & $\begin{array}{l}\text { Literatura de e-learning (ROSENBERG, 2006; VAN DAM, 2004; LEE, 2006; } \\
\text { GONG et al, 2004; ONG et al, 2004) }\end{array}$ \\
\hline & $\begin{array}{l}5.5 \text { - } H_{0} \text { : O fator Desconfiança em Relação à Inovação não } \\
\text { influencia o Comportamento de Uso do e-learning }\end{array}$ & $\begin{array}{l}\text { Literatura sobre adoção de tecnologias (KAMEL; HASSAN, 2003; LIPPERT; } \\
\text { FORMAN, 2006; VENKATESH et al, 2003) e pesquisas sobre adoção do e- } \\
\text { learning (ONG et al, 2004) }\end{array}$ \\
\hline
\end{tabular}




\subsection{Analisar as diferenças de percepção entre os colaboradores que realizaram e que não realizaram curso de e-learning na empresa, desde 2006}

A amostra da pesquisa, representada pelos 312 respondentes, foi separada em dois subgrupos: os colaboradores que participaram de pelo menos um curso de e-learning na plataforma da empresa desde 2006, que representam 58\% da amostra, e os colaboradores que não participaram, representando $42 \%$ da amostra.

Esse agrupamento foi baseado na resposta à primeira pergunta do questionário: "Você já participou de algum curso da Plataforma de e-learning da empresa, desde 2006?”. No caso dos colaboradores que responderam "sim" à questão, foi possível confirmar a resposta de 53\% do grupo através dos relatórios da Plataforma de e-elearning da empresa no Brasil. Os demais respondentes desse grupo provavelmente participaram de cursos de e-learning oferecidos pela matriz (fora do Brasil), dos quais a coordenação do programa na Unidade de Negócios no Brasil não tem acesso aos relatórios. Desta forma, foi possível analisar os cursos realizados pelos 97 respondentes que dispõem de registro de inscrição em cursos de e-learning na plataforma da empresa (Tabela 19).

Tabela 19 - Número de Cursos Inscritos e Cursos Concluídos pelos Respondentes, com Base nos Registros da Plataforma de e-Learning da Empresa

\begin{tabular}{|c|c|c|c|}
\hline & & $\begin{array}{l}\mathbf{N}^{\circ} \text { Cursos } \\
\text { Inscritos }\end{array}$ & $\begin{array}{l}N^{\circ} \text { Cursos } \\
\text { Concluídos }\end{array}$ \\
\hline Mediana & & 2 & 1 \\
\hline Moda & & 1 & 1 \\
\hline \multirow{3}{*}{ Percentis } & 25 & 1 & 1 \\
\hline & 50 & 2 & 1 \\
\hline & 75 & 4 & 3 \\
\hline
\end{tabular}

Com relação à Tabela 19, observa-se:

- Dos inscritos, é mais comum, a realização de 1 curso;

- $50 \%$ dos indivíduos da amostra tiveram inscrição em até 2 cursos, mas concluíram apenas 1;

- Apenas 25\% dos indivíduos da amostra se inscreveu em mais 4 cursos;

- Apenas 25\% dos indivíduos da amostra concluiu mais do que 3 cursos. 
Os cursos de desenvolvimento pessoal são os que tiveram maior número de inscrições pelos respondentes da pesquisa de janeiro de 2006 a julho de 2007 (41\% das 287 inscrições), seguidos pelos cursos de gestão (22\%), informática (14\%), idiomas (11\%) e conhecimentos técnicos $(10 \%)$.

Através da análise dos resultados da Prova de Mann-Whitney (Tabela 20), conclui-se que os dois subgrupos diferem quanto à opinião em relação à maioria das variáveis pesquisadas ${ }^{111}$ : de um total de 37 variáveis, 26 variáveis apresentaram diferença com nível de significância de 0,05 e 2 variáveis com nível de significância de 0,10. Em 9 variáveis, não foi possível apontar qualquer diferença no que diz respeito à distribuição de freqüência das respostas entre os dois subgrupos.

É importante ressaltar que a Prova de Mann-Whitney também foi aplicada para as duas variáveis da dimensão Intenção de Uso com escala Likert, embora estas não tenham sido explicadas pela análise fatorial.

\footnotetext{
${ }^{111}$ Nesta análise foram consideradas somente as variáveis com escala Likert; também não estão incluídas as duas variáveis respondidas apenas pelos colaboradores que realizaram cursos na plataforma de e-elearning da empresa.
} 
Tabela 20 - Resultados da Prova Mann-Whitney comparando os respondentes que realizaram cursos de $e$-learning desde 2006 e os que não realizaram, por Fator

\begin{tabular}{|c|c|c|c|c|c|}
\hline Variável & & $\begin{array}{c}\text { Mann- } \\
\text { Whitney } \\
\text { U }\end{array}$ & $\mathbf{Z}$ & $\mathbf{p}$ & \\
\hline \multirow[t]{10}{*}{$\begin{array}{l}\text { Utilidade } \\
\text { Percebida }\end{array}$} & $\begin{array}{l}\text { Obtenção de resultados de aprendizagem com o } e- \\
\text { learning }\end{array}$ & 11584,5 & $-0,086$ & 0,931 & \\
\hline & Utilidade do e-learning no trabalho & 11409,5 & $-0,327$ & 0,743 & \\
\hline & Sentimento em relação à participação no $e$-learning & 9943,5 & $-2,386$ & 0,017 & ** \\
\hline & $\begin{array}{l}\text { Contribuição do e-learning para a melhora do } \\
\text { desempenho no trabalho }\end{array}$ & 10294 & $-1,828$ & 0,068 & $*$ \\
\hline & $\begin{array}{l}\text { Percepção em relação à participação do e-learning ser } \\
\text { uma boa idéia }\end{array}$ & 10246,5 & $-1,977$ & 0,048 & $* *$ \\
\hline & Satisfação em relação ao uso do e-learning & 10908,5 & $-1,011$ & 0,312 & \\
\hline & Flexibilidade para aprender através do e-learning & 8485 & $-4,283$ & 0 & ** \\
\hline & $\begin{array}{l}\text { Potencial do e-learning para atender às necessidades de } \\
\text { treinamento do negócio }\end{array}$ & 8498 & $-4,176$ & 0 & ** \\
\hline & Importância do e-learning para a realização do trabalho & 7868 & $-5,158$ & 0 & $* *$ \\
\hline & $\begin{array}{l}\text { Atendimento adequado do projeto existente às } \\
\text { necessidades do negócio }\end{array}$ & 9228 & $-3,21$ & 0,001 & $* *$ \\
\hline \multirow{11}{*}{$\begin{array}{l}\text { Ambiente } \\
\text { Propício à } \\
\text { Aprendizage } \\
\mathrm{m}\end{array}$} & $\begin{array}{l}\text { Indicação da importância do e-learning pelo superior } \\
\text { imediato }\end{array}$ & 8243 & $-4,453$ & 0 & ** \\
\hline & $\begin{array}{l}\text { Estímulo do superior imediato para participar do } e \text { - } \\
\text { learning }\end{array}$ & 9069 & $-3,368$ & 0,001 & $* *$ \\
\hline & Patrocínio da empresa para participação no e-learning & 9285,5 & $-3,109$ & 0,002 & $* *$ \\
\hline & $\begin{array}{l}\text { Comprometimento da Alta Administração com o uso do } \\
\text { e-learning }\end{array}$ & 9027 & $-3,437$ & 0,001 & $* *$ \\
\hline & $\begin{array}{l}\text { Influência dos colegas em relação à participação no } e \text { - } \\
\text { learning }\end{array}$ & 8226 & $-4,473$ & 0 & ** \\
\hline & Cultura favorece a adoção do e-learning & 9925,5 & $-2,264$ & 0,024 & $* *$ \\
\hline & Prestígio resultante da participação no e-learning & & & & \\
\hline & & 10264,5 & $-1,836$ & 0,066 & $*$ \\
\hline & $\begin{array}{l}\text { Aumento nas chances de promoção em função da } \\
\text { participação no e-learning }\end{array}$ & 11354,5 & $-0,384$ & 0,701 & \\
\hline & Cultura valoriza a aprendizagem & 10729,5 & $-1,222$ & 0,222 & \\
\hline & Sucesso da campanha de incentivo ao uso do e-learning & 6672 & $-6,572$ & 0 & ** \\
\hline
\end{tabular}

Legenda:

** prova significativa a um nível de significância de 0,05 : foi possível apontar diferença entre as amostras * prova significativa a um nível de significância de 0,10 : foi possível apontar diferença entre as amostras Expressão sem qualquer indicador, prova estatística não significativa: não foi possível concluir pela diferença entre as duas amostras 
Tabela 20 - Resultados da Prova Mann-Whitney comparando os respondentes que realizaram cursos de elearning desde 2006 e os que não realizaram, por Fator (Continuação)

\begin{tabular}{|c|c|c|c|c|c|}
\hline Test Statistics & & $\begin{array}{c}\text { Mann- } \\
\text { Whitney } \\
\text { U }\end{array}$ & $\mathbf{Z}$ & $\begin{array}{l}\text { Asymp. } \\
\text { Sig. (2- } \\
\text { tailed) }\end{array}$ & \\
\hline \multirow{8}{*}{$\begin{array}{l}\text { Facilidade de } \\
\text { Uso } \\
\text { Percebida }\end{array}$} & Facilidade para usar o e-learning & 8063,5 & $-4,776$ & 0 & $* *$ \\
\hline & $\begin{array}{l}\text { Disponibilização de instruções e orientações para usar o } \\
\text { e-learning }\end{array}$ & 8226,5 & $-4,518$ & 0 & $* *$ \\
\hline & Conhecimento sobre o suporte disponível ao e-learning & 8329 & $-4,36$ & 0 & $* *$ \\
\hline & $\begin{array}{l}\text { Clareza e inteligibilidade da interação com o sistema de } e \text { - } \\
\text { learning }\end{array}$ & 6819 & $-6,408$ & 0 & $* *$ \\
\hline & Suficiência dos recursos tecnológicos & 9173 & $-3,377$ & 0,001 & $* *$ \\
\hline & Sucesso das campanhas de comunicação do e-learning & 8498,5 & $-4,152$ & 0 & $* *$ \\
\hline & $\begin{array}{l}\text { Disponibilidade de uma pessoa (ou grupo) para auxiliar } \\
\text { no uso do e-learning }\end{array}$ & 9424,5 & $-2,919$ & 0,004 & $* *$ \\
\hline & Facilidade em explicar os benefícios do e-learning & 7577 & $-5,405$ & 0 & $* *$ \\
\hline \multirow{4}{*}{$\begin{array}{l}\text { Habilidade } \\
\text { com } \\
\text { Informática \& } \\
\text { Pré- } \\
\text { disposição } \\
\text { para Inovar }\end{array}$} & Habilidade para utilizar um novo software & 10076 & $-2,093$ & 0,036 & ** \\
\hline & Facilidade com informática & 10833 & $-1,031$ & 0,303 & \\
\hline & Disposição para experimentar novas tecnologias & 10039 & $-2,05$ & 0,04 & $* *$ \\
\hline & Perfil de novo adotante & 9270 & $-3,097$ & 0,002 & $* *$ \\
\hline \multirow{3}{*}{$\begin{array}{l}\text { Desconfiança } \\
\text { em Relação à } \\
\text { Inovação }\end{array}$} & $\begin{array}{l}\text { Necessidade de ver uma inovação sendo usada antes de } \\
\text { usá-la }\end{array}$ & 11380 & $-0,351$ & 0,726 & \\
\hline & Atitude cética em relação a novas tecnologias & 11073 & $-0,67$ & 0,503 & \\
\hline & $\begin{array}{l}\text { Necessidade de ver um software sendo usado antes de } \\
\text { usá-lo }\end{array}$ & 11148,5 & $-0,654$ & 0,513 & \\
\hline \multirow[t]{2}{*}{$\begin{array}{l}\text { Intenção de } \\
\text { Uso }\end{array}$} & $\begin{array}{l}\text { Intenção de uso do e-learning, em função do tempo } \\
\text { disponível }\end{array}$ & 8395,5 & $-4,322$ & 0 & $* *$ \\
\hline & $\begin{array}{l}\text { Intenção de uso do e-learning, em função dos cursos } \\
\text { disponibilizados }\end{array}$ & 8922 & $-3,716$ & 0 & $* *$ \\
\hline
\end{tabular}

\section{Legenda:}

** prova significativa a um nível de significância de 0,05: foi possível apontar diferença entre as amostras * prova significativa a um nível de significância de 0,10: foi possível apontar diferença entre as amostras Expressão sem qualquer indicador, prova estatística não significativa: não foi possível concluir pela diferença entre as duas amostras

Descritivamente, pode-se notar que, quando a prova aponta diferença significativa, os respondentes que participaram de cursos de e-learning mostram-se, relativamente, mais propensos a concordar com os fatores que influenciam de forma positiva o uso, com algumas exceções. Essa discussão será detalhada a seguir, para cada um dos fatores apresentados na Tabela 20. O Apêndice 5 apresenta o nível de concordância geral da amostra de respondentes ( $n=312)$ em relação a cada variável.

Além disso, foi aplicado o Teste t-Student de comparação de médias para duas amostras independentes, considerando o Comportamento de Uso do e-Learning relatado pelo 
respondente da pesquisa. O resultado resume a comparação entre os dois grupos de respondentes em relação aos fatores de adoção do e-learning (Tabela 21), quanto ao nível médio de concordância.

Tabela 21 - Teste t-Student para Comportamento de Uso do e-Learning

\begin{tabular}{|c|c|c|c|c|c|}
\hline & \multicolumn{4}{|c|}{$\begin{array}{c}\text { Você já participou de algum curso da Plataforma de } e \text { - } \\
\text { learning da empresa, desde 2006? }\end{array}$} & \multirow{3}{*}{$\mathbf{P}$} \\
\hline & \multicolumn{2}{|c|}{ Média } & \multicolumn{2}{|c|}{ Desvio-Padrão } & \\
\hline & Não & Sim & Não & Sim & \\
\hline Utilidade Percebida & 0,119 & $-0,091$ & 0,950 & 1,031 & 0,072 \\
\hline $\begin{array}{l}\text { Ambiente Propício à } \\
\text { Aprendizagem }\end{array}$ & $-0,223$ & 0,151 & 0,935 & 1,020 & 0,001 \\
\hline Facilidade de Uso Percebida & $-0,405$ & 0,280 & 0,994 & 0,909 & 0 \\
\hline $\begin{array}{l}\text { Habilidade com Informática e } \\
\text { Pré-disposição para Inovar }\end{array}$ & $-0,167$ & 0,118 & 1,074 & 0,934 & 0,017 \\
\hline $\begin{array}{l}\text { Desconfiança em Relação à } \\
\text { Inovação }\end{array}$ & 0,047 & $-0,031$ & 1,019 & 0,987 & 0,501 \\
\hline
\end{tabular}

\subsubsection{Utilidade Percebida}

Hipótese 1.1 - $\boldsymbol{H}_{0}$ : Mesmo grau de concordância entre os respondentes que participaram do e-learning e os que não participaram em relação à Utilidade Percebida do e-learning.

Em pesquisas anteriores, a Utilidade percebida tem sido identificada como uma das principais variáveis que influenciam a intenção de uso de novas tecnologias. Gong et al realizou uma pesquisa sobre aceitação de um sistema de aprendizagem baseado na Internet com 146 professores e identificou que "entre os fatores determinantes, utilidade percebida apresentou o efeito direto mais forte na intenção de uso"112 (2004, p.370). A influência da utilidade percebida na aceitação de tecnologias de e-learning também foi apontada por outras pesquisas (SELIM, 2003; MARTINS; KELLERMANNS, 2004; ONG et al, 2004; FUSILIER; DURLABHJI, 2005), em linha com as premissas do Modelo TAM (DAVIS et al, 1989; VENKATESH; DAVIS, 2000).

\footnotetext{
112 "Among the determinant factors, perceived usefulness had the strongest direct effect on intention to use"
} 
Tendo em vista que as pesquisas anteriores identificaram um efeito positivo da utilidade percebida sobre a adoção, seria esperado que os indivíduos com maior percepção de utilidade do e-learning tivessem maior propensão a utilizá-lo. O resultado apresentado no Gráfico 6 corrobora com este resultado, uma vez que o grupo de respondentes que realizaram pelo menos um curso de e-learning na plataforma da empresa desde 2006 apresentou maior concordância do que o grupo de respondentes que não participou de cursos de e-learning, em três das variáveis do fator Utilidade Percebida, diferença com nível de significância de 0,05. As variáveis referem-se à importância do e-learning para o trabalho, à maior flexibilidade para aprender e à atitude positiva em relação à participação (boa idéia).

Diferentemente do esperado, esta tendência não é observada em outras 5 variáveis que integram o fator Utilidade Percebida, com diferença significativa em duas delas (Gráfico 7). Os respondentes que realizaram cursos de e-learning na plataforma da empresa desde 2006 apresentaram maior discordância em relação àqueles que não realizaram cursos de $e$-learning, nas variáveis:

- Contribuição do e-learning para a melhora do desempenho no trabalho - diferença em nível de significância de 0,10 ;

- Sentimento em relação à participação no e-learning - diferença em nível de significância de 0,05 . 


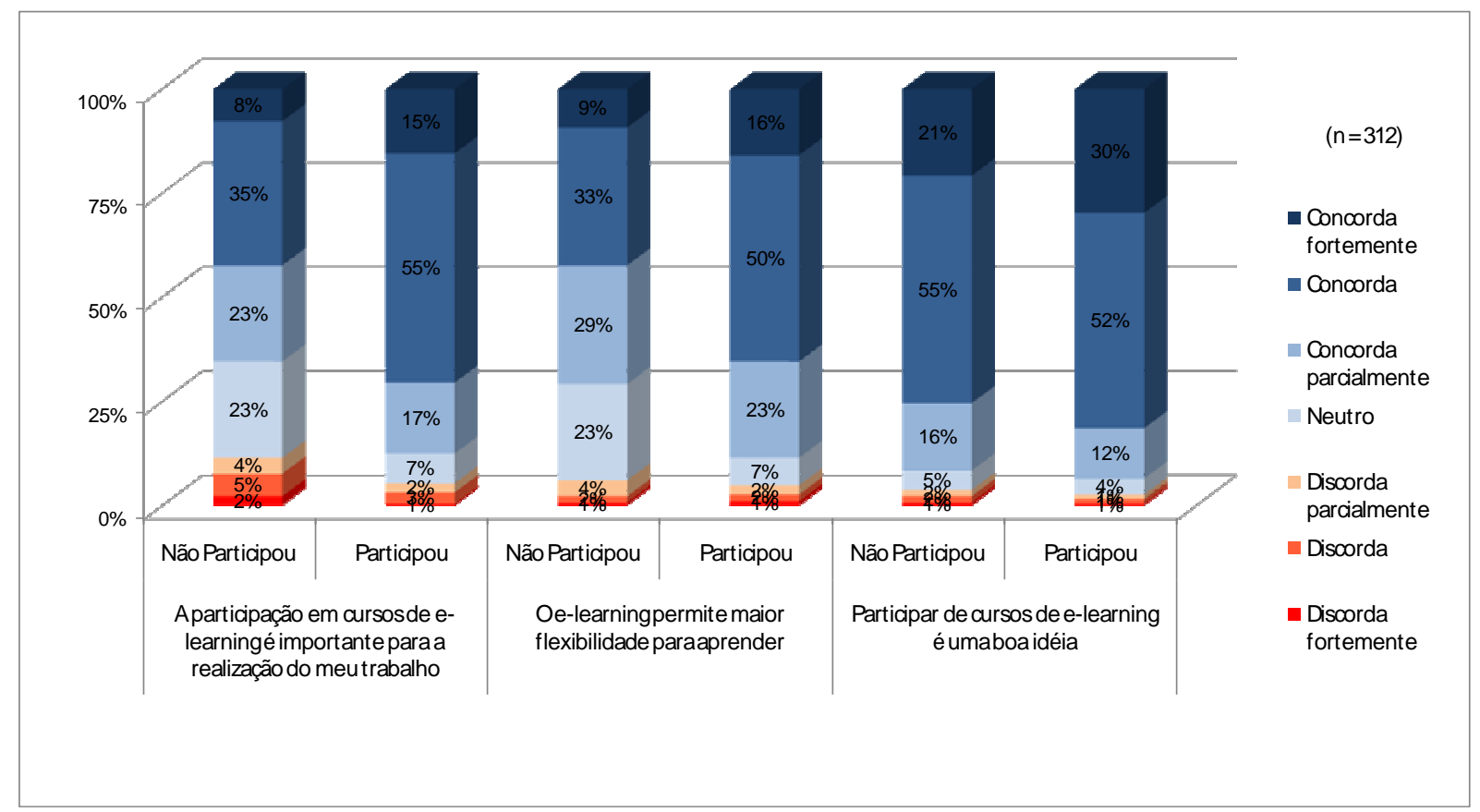

Gráfico 6 - Distribuição das Variáveis Relacionadas à Importância para o Trabalho, à Flexibilidade para Aprender e à Participação ser Uma Boa Idéia

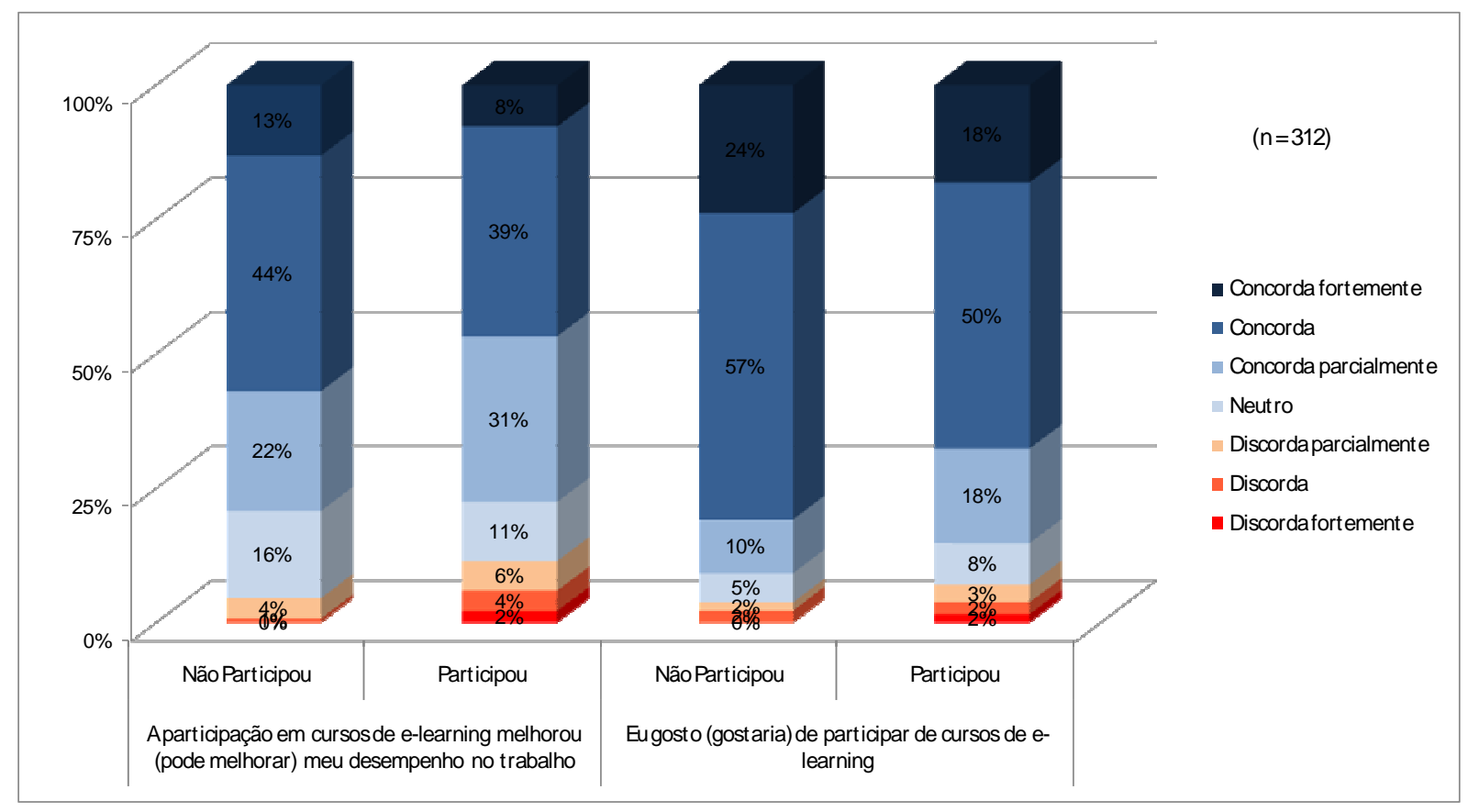

Gráfico 7 - Distribuição das Variáveis Relacionadas à Contribuição para Melhora do Desempenho e ao Sentimento em Relação ao e-Learning

Em outras três variáveis, observa-se a mesma tendência de maior discordância entre os respondentes que realizaram curso de e-learning na plataforma da empresa, apesar da diferença não ser significativa (Gráfico 8). Este resultado também pode ser observado na Tabela 21, em que os respondentes que participaram do e-learning apresentam menor média 
dos escores fatorias do fator Utilidade Percebida $(-0,091)$, se comparada á média dos que não participaram $(0,119)$.

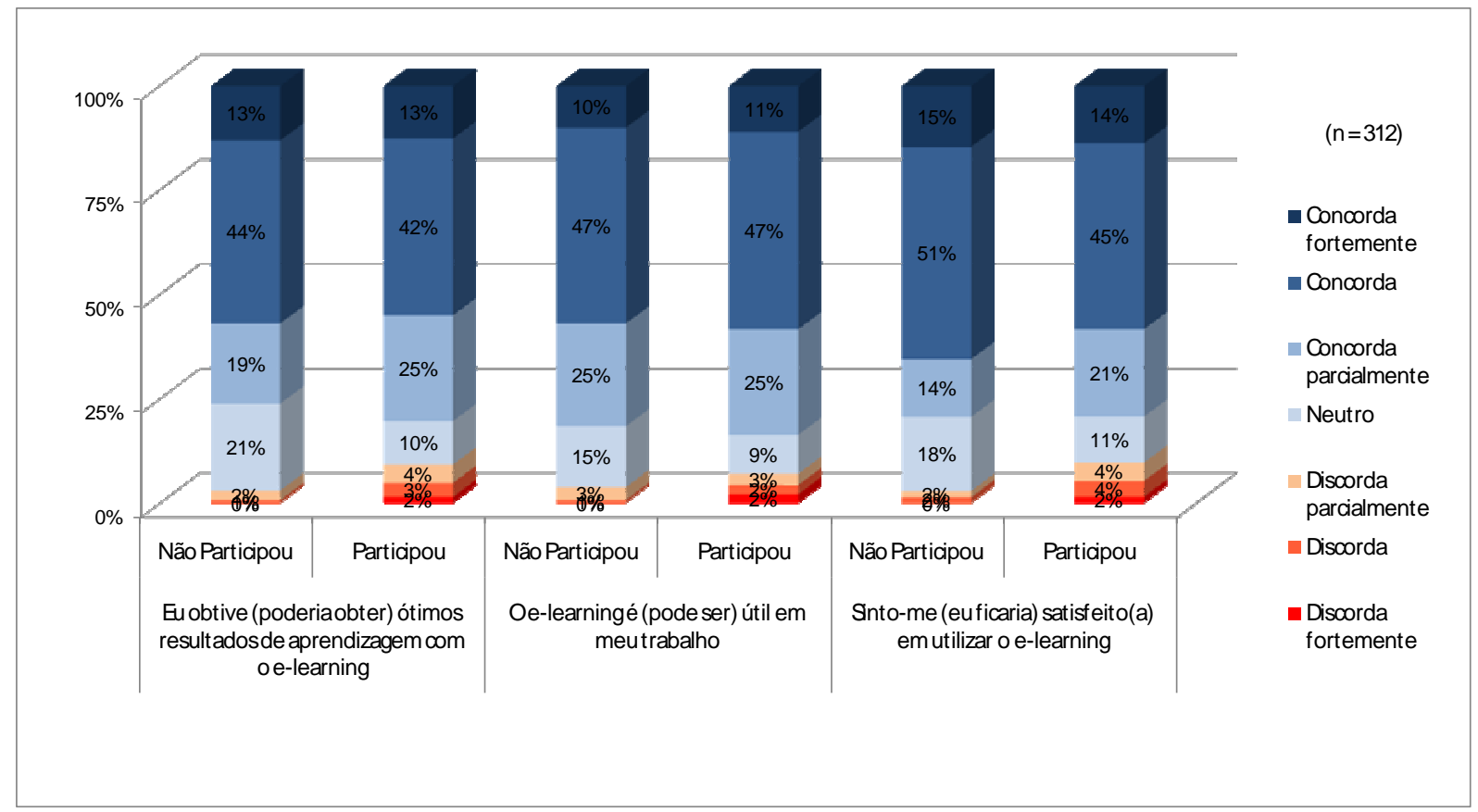

Gráfico 8 - Distribuição das Variáveis Relacionadas à Obtenção de Resultados de Aprendizagem, à Utilidade no Trabalho e à Satisfação em Relação ao Uso

Uma diferença importante entre esses dois grupos de respondentes está no fato de que um grupo respondeu com base na experiência real de participação nos cursos de e-learning da empresa, enquanto o outro respondeu com base na expectativa em relação à participação.

Conforme apontado por Davis (1989), estudos anteriores observaram discrepâncias entre desempenho percebido e real: as "pessoas podem superestimar os ganhos de desempenho que um sistema tem a oferecer e adotar sistemas que são disfuncionais."113 (DAVIS, 1989, p. $335)$.

Shih e Venkatesh explicam que a "frustração aparece porque a tecnologia falha em desempenhar com segurança ou em atender às expectativas do usuário"114 (2004, p. 62). Complementando, Mukherjee e Hoyer, ao analisarem o impacto de inovações tecnológicas

113 “[...] people may overrate the performance gains a system has to offer and adopt systems that are dysfunctional."

114 "Frustration arises because the technology fails to perform reliably or meet the expectations of the user." 
complexas na avaliação do consumidor, observam que "devido ao custo de aprendizado associado (ou dificuldade de compreensão), novas características podem ser fonte de frustração"115 (2001, p 470).

Desta forma, na empresa estudada, a frustração de parte dos respondentes que realizaram cursos de e-learning pode ser explicada por expectativas muito elevadas ou problemas em relação ao aprendizado através do e-learning ou ao projeto de e-learning existente na empresa.

Conforme já apresentado no capítulo de revisão bibliográfica, o e-learning apresenta limitações e problemas (VASCONCELLOS-JACOBSOHN; FLEURY, 2004; TYAN, 2003). Downes (2003) menciona especificamente o caso de participantes que testaram e não gostaram do e-learning e Tyan (2003) identificou que participantes experientes atribuíram significativamente maior importância às barreiras do e-learning. Complementando, Hara e Kling (1999) constataram um elevado grau de frustração dos alunos de um curso a distância em uma grande universidade americana, explicada por diferentes razões, como a dificuldade em usar a tecnologia, a limitação dos recursos disponíveis e a necessidade de estudar sozinho. Ou seja, a frustração em relação ao e-learning pode estar de um lado relacionada às limitações existentes nessa metodologia e de outro às competências dos participantes em obter bons resultados de aprendizagem.

Em uma pesquisa realizada com alunos de graduação em administração, foi analisado o desenvolvimento de novas competências relacionadas ao aprendizado e à comunicação em ambientes on-line, muito diferentes daquelas exigidas no ensino presencial. Além disso, a pesquisa mostrou haver uma influência do estilo de aprendizagem do aluno, indicando que algumas pessoas se adaptam mais facilmente ao e-learning do que outras (VASCONCELLOS-JACOBSOHN, 2003). Aspecto analisado por Snyder (2003, p. 72) que, com base no estudo de caso de uma organização militar, sugere uma influência da falta de alinhamento da solução de e-learning com os estilos de aprendizagem individuais na adoção desta inovação.

\footnotetext{
115 "Because of their associated learning cost (or comprehension difficulty), novel features may be one such source of frustration [...]."
} 
É interessante notar que ao separar os 312 respondentes em função da realização de cursos de e-learning fora da plataforma da empresa $(25 \%$ dos respondentes que não realizaram cursos de e-learning na plataforma da empresa apontaram ter realizado pelo menos um curso fora), $\mathrm{o}$ grupo com experiência anterior em e-learning não apresenta diferença significativa de maior discordância em relação às variáveis do fator Utilidade Percebida. Ou seja, uma possível frustração em relação à contribuição do e-learning para o trabalho e à satisfação em participar não foi verificada para os cursos realizados fora da empresa.

O que leva à segunda fonte potencial de frustração do participante de e-learning: expectativas irreais e limitações em relação ao projeto de e-learning da empresa.

A existência de conteúdo relevante e atraente foi apontada por Van Dam (2004) como um dos fatores motivadores para o comprometimento com e-learning e Lee (2006) identificou que a qualidade do conteúdo de e-learning, que inclui riqueza do conteúdo e regularidade de atualização, tem influência significativa na utilidade percebida, aspecto também apontado por Ong e Lai (2006). Esta é uma variável de difícil avaliação, uma vez a pesquisa de Gabbard não identificou uma relação significativa entre a satisfação do aluno em relação ao conteúdo do curso on-line e as variáveis do Modelo TAM, resultado que pode ser atribuído "ao tipo de questões do instrumento de avaliação que podem não ter conseguido refletir as preocupações e atitudes do aluno em reação ao conteúdo do curso"116 (2004, p. 91).

Embora a presente pesquisa não tenha incluído uma variável específica para avaliação do conteúdo dos cursos, os comentários de alguns dos respondentes indicam que o conteúdo dos cursos de e-learning na empresa pesquisada é um aspecto relevante e pode ter influenciado a percepção de utilidade de alguns respondentes De acordo com um dos respondentes, os cursos de $e$-learning "são muito genéricos e pouco profundos, não trazem muitas novidades ou algo que acrescente no meu trabalho". Os comentários sobre o assunto foram enviados por 14 respondentes e podem ser resumidos nos seguintes itens:

- Necessidade de maior diversidade de cursos e novos conteúdos;

\footnotetext{
116 “[...] type of questions asked in the assessment instrument which may not have reflected students' concerns
} or attitudes towards course content." 
- Necessidade de conteúdo técnico mais profundo e detalhado, incluindo, por exemplo, novas tecnologias, padrões, metodologias e sistemas;

- Disponibilização de mais conteúdos específicos, relacionados ao setor de trabalho.

Esse resultado não fornece informações suficientes para avaliar a qualidade de conteúdo dos cursos, apenas indica a possibilidade de ocorrer uma diferença relativa entre os cursos oferecidos e a expectativa e/ou necessidade de alguns colaboradores. Essa explicação é reforçada pelo comentário de um dos entrevistados, mencionando que em algumas situações o colaborador se inscreve em determinado curso on-line e depois se decepciona com o conteúdo, por considerá-lo elementar ou complexo demais.

Esse resultado corrobora um dos problemas identificados por Angehrn et al (2001, p.2):"sistemas de e-learning são freqüentemente desconectados das atividades e objetivos atuais do aprendiz" ${ }^{\prime 17}$, particularmente no quesito que se refere às necessidades, contexto e nível de detalhe demandado pelo usuário.

Outro ponto importante em relação ao projeto de e-learning da empresa é a metodologia dos cursos de e-learning disponíveis. De acordo com Testa (2002), a definição de um projeto pedagógico baseado na interação e colaboração está entre os fatores críticos de sucesso para programas de educação a distância, aspecto apontado também por outros autores (ANGEHRN et al, 2001). A pesquisa realizada por Selim (2003) revela que a experiência de atividades interativas durante o processo de aprendizado como um dos fatores críticos que influenciam a utilidade percebida em cursos via Internet tais como, por exemplo, por meio de discussões eletrônicas.

Cinco respondentes mencionaram a necessidade de aprimoramento da forma de apresentação do conteúdo de alguns dos cursos, muito baseados em texto e com pouca interatividade. Desta forma, a disponibilização de cursos com estratégias pedagógicas que possibilitem interação e colaboração tende a contribuir para a obtenção de melhores resultados de aprendizagem, podendo inclusive influenciar a utilidade percebida. Os resultados da pesquisa realizada por Gabbard sugerem que "existe uma relação significativa entre as variáveis TAM [utilidade

\footnotetext{
117 “E-learning systems are often too disconnected from the learner's current activities and goals.”
} 
percebida, facilidade de uso percebida e atitude em relação ao uso] e as variáveis de satisfação" 118 do aluno em relação ao curso on-line, principalmente relacionadas ao instrutor e à avaliação (2004, p. 75).

Em uma das entrevistas realizadas, foi mencionado o plano da equipe de partir para iniciativas que integrem o e-learning a um projeto mais amplo, incluindo encontros presenciais. $\mathrm{O}$ blended learning é uma tendência (ECONOMIST INTELLIGENCE UNIT; IBM, 2003) e pode facilitar a adoção ao e-learning (VAN DAM, 2004).

Apesar das potenciais limitações discutidas em relação ao e-learning e ao projeto da empresa sob o ponto de vista dos respondentes que participaram de cursos de e-learning, este mesmo grupo apresenta maior concordância em relação ao atendimento das necessidades do negócio, através do projeto existente na empresa e da utilização do e-learning (Gráfico 9), com um nível de significância de 0,05 . No entanto, no grupo que participou de cursos de e-learning há uma maior variabilidade das respostas:

- Em relação ao potencial do e-learning para atender às necessidades do negócio, $11 \%$ dos que participaram em cursos de e-learning discorda fortemente ou apenas discorda, em comparação a 10\% dos que não participaram que apresentam a mesma opinião;

- Em relação à adequação do projeto existente na empresa, 9\% dos que participaram em cursos de e-learning discorda fortemente ou apenas discorda, em comparação a 7\% que não participaram que apresentam a mesma opinião.

118 “[...] a significant relationship exists between TAM and the Satisfaction variables [...]”. 


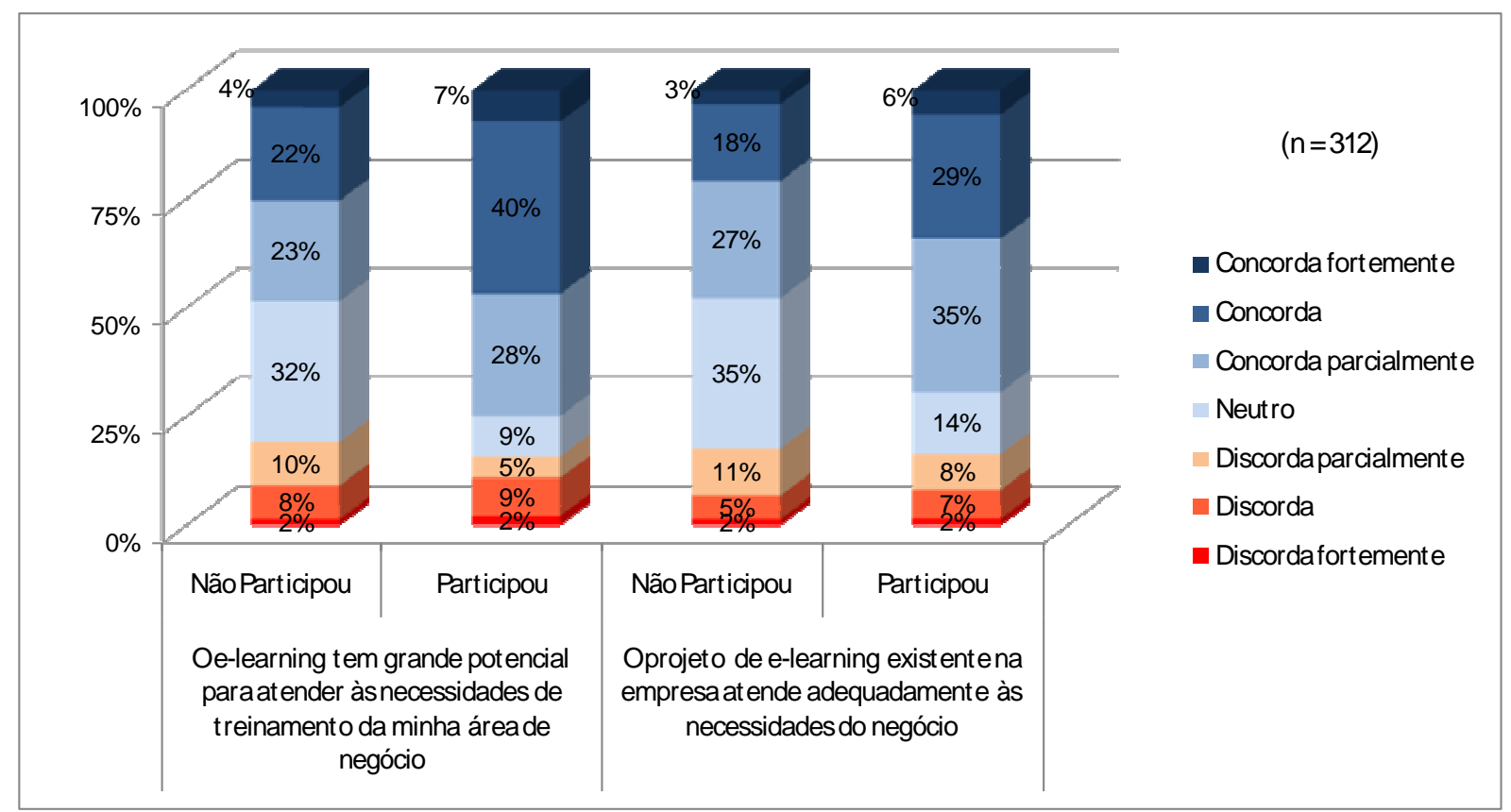

Gráfico 9 - Distribuição das Variáveis Relacionadas ao Potencial do e-Learning e ao Atendimento Adequado do Projeto Existente

Conforme apontado em uma das entrevistas, o e-learning possui alto potencial para atender as necessidades de treinamento da empresa, possibilitando criar e atualizar conteúdos com grande agilidade, requisito importante em um setor dinâmico como o de telecomunicações. Desta forma, opções mais flexíveis para disponibilizar oportunidades de aprendizagem ao colaborador são valorizadas. Além disso, o uso de tecnologias para aprendizagem tem forte relação com o negócio da empresa, já que mobilidade e acesso através de banda larga são os dois eixos importantes no setor das Telecomunicações e as ações de e-learning da empresa podem, em alguma medida, contribuir para fortalecer o negócio.

Por outro lado, é grande o desafio de concretizar o potencial do e-learning e efetivamente gerar contribuições para o negócio. Conforme apontado por um dos respondentes: "Os cursos de e-learning muitas vezes não estão alinhados com o planejamento estratégico de negócio e conseqüentemente tecnológico". Essa questão é apontada por Angehrn et al (2001) como um dos problemas importantes da dimensão organizacional de sistemas de e-learning:

A agenda de aprendizagem do usuário e da organização são dissociadas. Sistemas de e-learning não situam o aprendizado na perspectiva das necessidades organizacionais. Em particular, o estudante possui pouca indicação (ou nenhuma) sobre a importância do conhecimento que está adquirindo e como este conhecimento 
contribui para a agenda de aprendizagem da organização. ${ }^{119}$ (ANGEHRN et al 2001, p. 3).

Este desafio foi confirmado na entrevista com a responsável da empresa, que apresentou a integração do e-learning nos projetos estratégicos e sua aproximação do negócio como os principais focos das ações de desenvolvimento e expansão do projeto de e-learning da empresa. Nessa linha, foi citado o papel do e-learning no projeto de inovação da empresa, que visa fomentar a inovação e buscar empreendedores para atuar na incubadora de negócios, conduzindo projetos de inovação. Foi realizado um processo de seleção destes empreendedores, sendo uma das etapas a realização de um curso de e-learning com 60 horas de duração estimada que versava sobre diversos temas relativos à inovação e criatividade.

De um total de 10 variáveis que integram o fator Utilidade Percebida, foram observadas diferenças significativas em 7 delas, rejeitando a Hipótese 1.1. Conforme discutido neste tópico, a tendência de concordância dos respondentes que realizaram curso de e-learning na plataforma da empresa foi divergente em relação ao conjunto de variáveis: em 5 variáveis esse respondentes apresentam maior concordância e em 2 variáveis esses respondentes apresentam maior discordância (tendência também observada em outras 3 variáveis, mas sem diferença significativa).

\subsubsection{Ambiente Propício à Aprendizagem}

Hipótese 1.2 - $\boldsymbol{H}_{0}$ : Mesmo grau de concordância entre os respondentes que participaram do e-learning e os que não participaram em relação à percepção do Ambiente Propício à Aprendizagem.

De forma geral, as variáveis do fator Ambiente Propício à Aprendizagem apresentam menor concordância dos 312 respondentes, se comparadas aos fatores Utilidade Percebida e Facilidade de Uso Percebida (Apêndice 5).

\footnotetext{
119 "The learning agenda of the user and of the organisation are dissociated. Elearning systems do not situate learning in the perspective of the organisational need. In particular, the learner has very little indication (if any) about the importance of the knowledge he is currently acquiring, and how this knowledge contributes to the organisation's learning agenda."
} 
Ao comparar o nível de concordância entre os dois subgrupos, os respondentes que realizaram curso de e-learning desde 2006 apresentam maior concordância em relação ao grupo dos que não realizaram, nas 10 variáveis desse fator, rejeitando a Hipótese 1.2; sendo que em 8 delas há uma diferença significativa, como indicado na Tabela 20.

Conforme esperado, os respondentes que não participaram do e-learning apresentam maior discordância em relação às variáveis que refletem o apoio do superior imediato (Gráfíco 10), com nível de significância de 0,05 ; dessa forma, $46 \%$ dos respondentes que não participaram de cursos de e-learning indicaram que o superior imediato não aponta para a importância do e-learning e $42 \%$ indicaram que não são encorajados a participar em cursos dessa natureza, percentual maior se comparado aos $29 \%$ e $31 \%$ dos respondentes que participaram de cursos e também discordaram das afirmações, respectivamente. A mesma tendência é observada em relação ao comprometimento e patrocínio da alta administração em relação ao e-learning, embora o nível de discordância em geral seja menor.

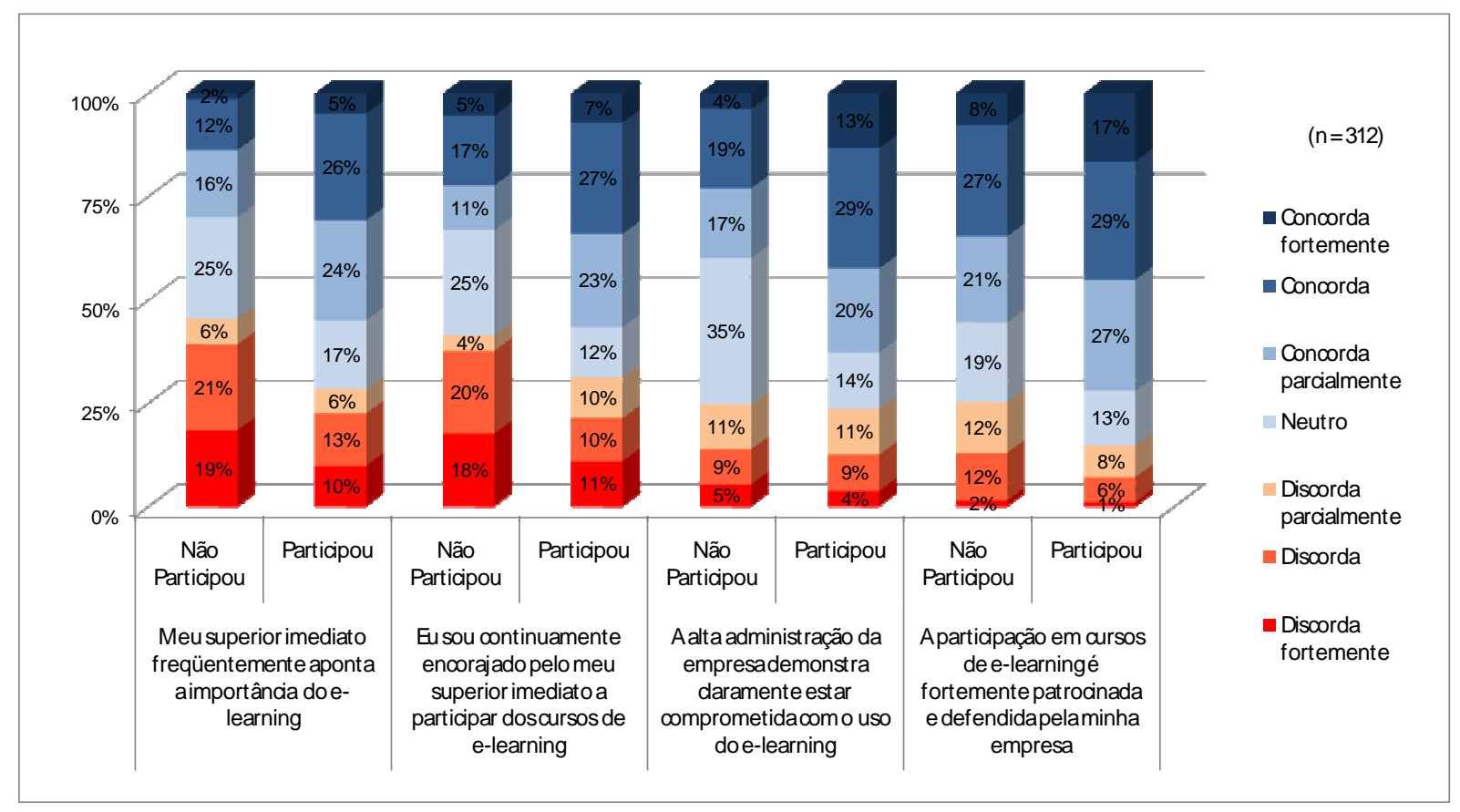

Gráfico 10 - Distribuição das Variáveis Relacionadas ao Apoio do Superior Imediato e ao Apoio da Alta Administração

O resultado encontrado reforça a importância da liderança para o sucesso de programas de $e$ learning, fato já relatado na literatura (ROSENBERG, 2000; MACPHERSON et al, 2004), uma vez que os "funcionários prestam mais atenção na pessoa ou pessoas que são seus superiores imediatos ou indivíduos bem conhecidos e respeitados dentre os executivos 
seniores"120 (VAN DAM, 2004, p. 96). Apesar da importante influência dos gestores na implementação de inovações, é importante apontar que esta pode variar em função de características individuais (LEONARD-BARTON; DESCHAMPS, 1988, p. 1252). De acordo com Chang (2005), a atuação do líder é crítica para o sucesso da implementação ou aprimoramento de programas de e-learning e, da mesma forma, o estilo de liderança influencia de modo importante o resultado:

Para serem bem sucedidos no novo ambiente global, líderes do século vinte e um precisam atuar como líderes justos, imparciais e abertos, fornecendo considerações honestas para os seguidores, se comunicando de forma efetiva com subordinados e se estabelecendo como exemplos da aprendizagem por toda a vida. ${ }^{121}$ (CHANG, 2005, p. 219).

Este aspecto torna-se ainda mais relevante, ao considerar os resultados apresentados por Macpherson et al, identificando que nas três empresas pesquisadas "[...] houve maior resistência à introdução, uso e desenvolvimento de soluções de e-learning nos níveis mais altos da organização do que nos níveis mais baixos [...]"122 $(2005$, p. 44).

Conforme apontado em uma das entrevistas com a responsável pelo projeto de e-learning na empresa pesquisada: “O programa possui total apoio da alta administração. Muitos líderes já compreendem o valor do e-learning e incentivam e apóiam suas equipes, porém ainda existem líderes em processo de conscientização.” Neste contexto, pode ser percebida uma evolução da aceitação do e-learning na empresa pesquisada, evidência obtida em função tanto das respostas aos consultores de Recursos Humanos no oferecimento do e-learning, quanto da ampliação nas solicitações de gestores.

Apesar da evolução observada, "Para garantir a adesão do alto nível, o estabelecimento do impacto do programa no negócio deve ser um elemento chave do plano de marketing do

\footnotetext{
120 “[...] employees pay more attention to the person or people who are either their immediate supervisors, or well-known and respected individuals among the senior executives"

121 "To be successful in the new global environment, twenty-first century leaders must act as just, equitable and open leaders, who give honest consideration to followers, have effective communication with subordinates, and set themselves as examples of lifelong learning."

122 "[...] there was more resistance to the introduction, use and development of e-learning solutions from the higher levels of the organization than the lower levels [...]"
} 
programa." 123 (VAN DAM, 2004, p. 96). Desta forma, no caso da empresa estudada, além da disponibilização de cursos alinhados ao negócio, discussão apresentada no tópico anterior (5.2.1), a comunicação sobre a utilidade do e-learning para gestores está entre as ações mais relevantes para a expansão do projeto de e-elearning.

Interligada à atuação das lideranças em relação ao e-learning está a cultura organizacional e o quanto esta favorece ou dificulta a adoção do e-learning e a aprendizagem em termos mais amplos. Aspecto recorrente na literatura de e-learning (ROSENBERG, 2000; TYAN, 2003; ECONOMIST INTELLIGENCE UNIT; IBM, 2003; BOROTIS; POULYMENAKOU, 2004; VAN DAM, 2004; PSYCHARIS, 2005), a cultura organizacional tem sido apontada como uma das principais barreiras para a disseminação do e-learning (PRICEWATERHOUSECOOPERS, 2001; DOWNES, 2003; IGNATIUS; RMAYAH, 2005).

O resultado da presente pesquisa mostra uma maior concordância dos respondentes que relataram participação em cursos de e-learning em relação à variável sobre a cultura organizacional como facilitadora da adoção do e-learning (Gráfico 11), com nível de significância de 0,05 .

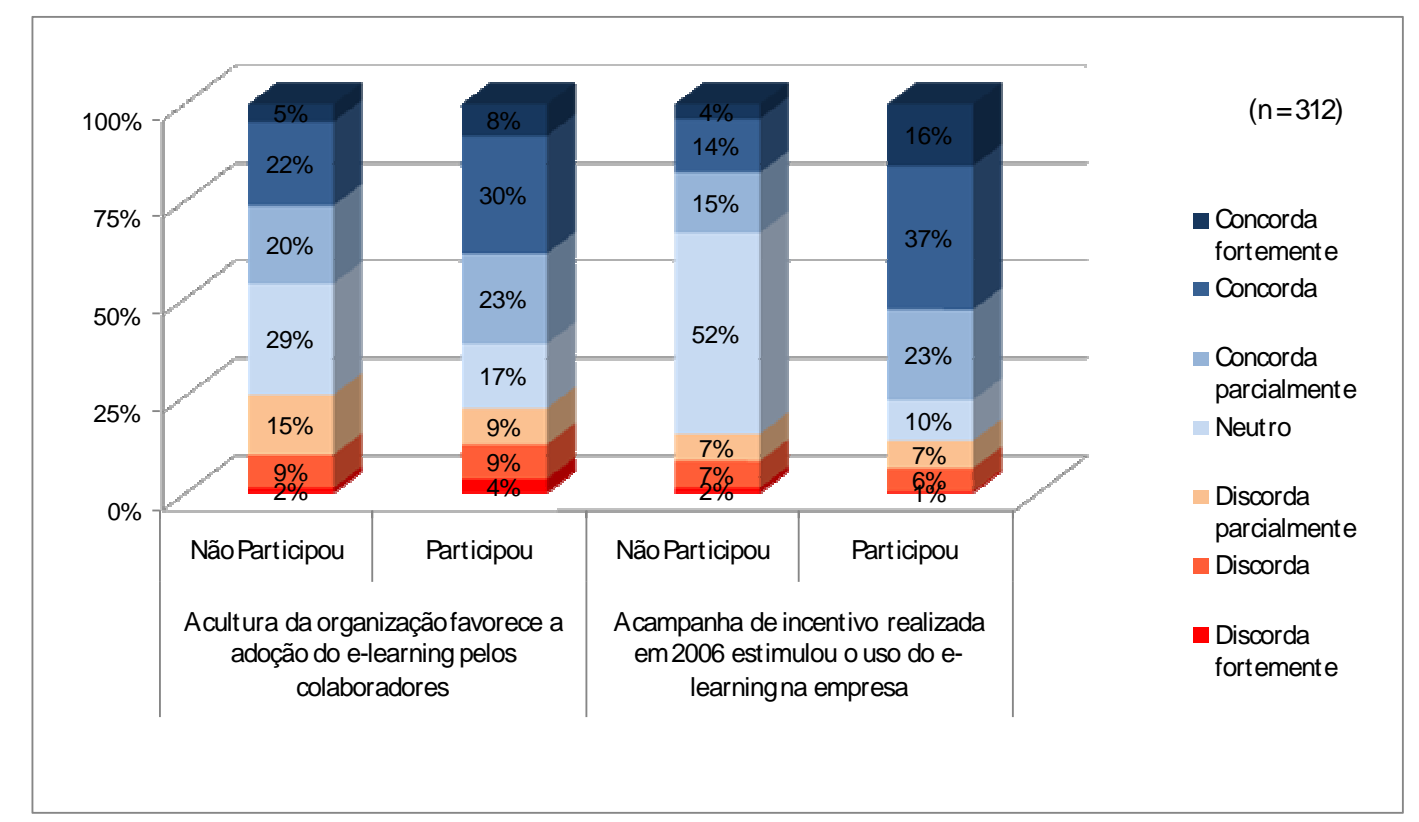

Gráfico 11 - Distribuição das Variáveis Relacionadas à Cultura Favorece a Adoção e ao Sucesso da Campanha de Incentivo

123 “To ensure top-level buy-in, establishing the business impact of a program should be a key element of the program marketing plan.” 
De acordo com Fleury e Fleury (1997, p. 26), o comportamento aparente das pessoas, as formas de comunicação e os rituais organizacionais são elementos simbólicos visíveis da cultura organizacional, constituindo formas explícitas de expressão de seus valores básicos.

Tendo em vista a dimensão do tema e a complexidade envolvida no diagnóstico da cultura organizacional, não foi objetivo da presente pesquisa conduzir esse tipo de análise. Entretanto, a partir das entrevistas e comentários dos respondentes foi possível identificar um comportamento com influência direta na adoção do e-learning: a falta de tempo.

Já mencionada no tópico anterior (5.1.2), a falta de tempo para realizar o e-learning foi apontada como o motivo mais freqüente de não participação nos cursos de e-learning da empresa: 57\% dos respondentes que não realizaram curso desde 2006 indicaram esse motivo.

A falta de tempo pode envolver diferentes questões como: excesso de trabalho, dificuldade de concentração devido a interrupções constantes, aprovação percebida do superior imediato, percepção de que o tempo de aprendizagem é improdutivo e falta de disciplina para dedicação ao e-learning, entre outras.

Borotis e Poulymenakou chamam a atenção para a falta de tempo disponível para participação do e-learning durante a jornada de trabalho: "carga pesada de tarefas, barulho, interrupções e telefones constantes, atrapalham a fluidez e atividade de aprendizagem ${ }^{124}$ (2007, p. 217). Isso porque, diferentemente do treinamento presencial em que, após a aprovação do superior, o colaborador deixa o local de trabalho para participar do curso, a participação no e-learning é flexível e para muitos é um desafio agendá-la durante o horário de trabalho, "o que pode ser interpretado como sendo improdutivo e onde eles podem também ser distraídos pelas atividades do trabalho diário"125 (VAN DAM, 2004, p. 92).

Além disso, conforme já discutido, a aprovação e apoio do superior imediato é importante: "Para muitos aprendizes, um dos aspectos negativos que dificultam a participação e término

\footnotetext{
124 "Heavy work duties, noise, frequent interruptions and telephones, hinder the smooth and unobstructed learning activity."

125 "[...] where it can be construed as being unproductive, and where they can also be distracted by everyday working activities [...]".
} 
do e-learning é a falta de aprovação percebida para alocação de tempo durante as horas de trabalho para realizar a aprendizagem" ${ }^{126}$ (VAN DAM, 2004, p. 92).

A questão da falta de tempo para realizar o e-learning e especificamente as dificuldades para participar durante a jornada de trabalho foram apontadas pelos respondentes no campo de observações do questionário:

Devido ao grande volume de trabalho não é possível utilizar no dia a dia o elearning. Em um aprendizado é necessário disponibilidade, concentração no tópico que está sendo abordado para se ter um resultado; ou seja, "foco" somente no aprendizado. Outro ponto importante utilizando o e-learning na própria máquina com telefone tocando, colegas conversando dos assuntos de trabalho não é possível ter concentração e foco em uma ferramenta para se ter um aprendizado (estudo).

Mediante autorização da gerência o funcionário poderá dedicar 01 hora de seu dia para estudar (não deixando-o constrangido), ou seja, se o gestor identificar que é um curso direcionado para a atividade, o funcionário terá a liberdade de estudar/dedicar 01 hora de seu dia de trabalho para aperfeiçoar seus conhecimento e isso trará maior qualidade e produtividade.

O ambiente de trabalho não é propício para fazer e-learning, pois gera uma falsa impressão de ter pouco trabalho a fazer.

Os desafios ligados à participação no e-learning durante o horário de trabalho e à obtenção de apoio do gestor também foram mencionados na entrevista, tendo em vista os esforços empreendidos para transformar a cultura organizacional. Nessa linha, foi implementada uma rede de facilitadores do e-learning, a ser detalhada no próximo tópico.

Além disso, para lidar com esses desafios, a proximidade do conteúdo de e-learning disponível com as necessidades do negócio é crítica, conforme já discutido. Também, relacionado ao conteúdo, Van Dam sugere que “disponibilizando conteúdo em blocos de

\footnotetext{
126 "For many learners, one of the overriding negative aspects of participation in, and completion of, e-learning
} is the perceived lack of approved, allocated time during work hours in which to complete the learning" 
aprendizagem, que podem ser completados em um breve período, parece promover tanto a retenção da aprendizagem quanto a probabilidade de término do e-learning" ${ }^{\text {"127 }}$ (2004, p. 92).

Com relação às interrupções durante a realização do e-learning, "Muitas empresas tiveram sucesso nas iniciativas de e-learning estabelecendo laboratórios de e-learning; espaços privados e isolados equipados com tecnologias apropriadas para a aprendizagem e acesso rápido à intranet corporativa e a Web sites externos"128 (Van Dam, 2004, p. 93). Na mesma linha, a criação de salas exclusivas para e-learning foi sugerida por quatro respondentes, no campo de observações do questionário.

Apesar dos desafios, $55 \%$ da amostra $(n=312)$ concordam em alguma medida que a cultura organizacional favorece a adoção do e-learning. Já em relação à cultura valorizar a aprendizagem, $74 \%$ de todos os respondentes concordam em alguma medida com a existência de uma cultura de aprendizagem na empresa. É importante ressaltar que, provavelmente, há diferenças importantes entre as diferentes áreas da empresa e níveis hierárquicos, sendo que alguns favorecem a adoção do e-learning e a aprendizagem mais que outros. De acordo com Schein (1996, p. 12), "premissas compartilhadas normalmente também são formadas em torno das unidades funcionais da organização. Elas são freqüentemente baseadas na formação educacional similar ou experiências organizacionais similares dos membros [...]"129. O autor também menciona que "Outro tipo de subcultura, reconhecida com menor freqüência, reflete experiências comuns de determinados níveis da hierarquia. Cultura nasce através de experiências compartilhadas de sucesso." "130 (SCHEIN, 1996, p. 12).

Corroborando esta questão, os resultados da presente pesquisa indicam, para determinadas variáveis, diferenças significativas de opinião entre os respondentes das áreas Comercial, Técnica e de Apoio e diferenças significativas de opinião entre os respondentes de nível gerencial e operacional. Esses resultados estão apresentados no tópico 5.3.

\footnotetext{
127 “[...] providing content in learning chuncks, which can be completed in a single sitting, seems to encourage both learning retention and the probability of e-learning completion."

128 "Many companies have experienced success with e-learning initiatives by establishing e-learning laboratories; secluded, private spaces equipped with appropriate learning technologies and high-speed access to the corporate intranet and to external Web sites."

129 "Shared assumptions also typically form around the functional units of the organization. They are often based on members' similar educational backgrounds or similar organizational experiences [...]”.
} 
Com relação à campanha de incentivo (Gráfico 11), observa-se uma freqüência maior de respondentes que não realizaram curso de e-learning e atribuíram uma opinião neutra para o resultado obtido; essa ocorrência pode ser explicada em parte pelos funcionários que ingressaram na empresa a partir de 2007 e não conheciam ou não se sentiram a vontade para avaliar a campanha de incentivo realizada em 2006: dos 52\% que optaram pela resposta neutro, quase a metade são funcionários com menos de 6 meses de empresa (48\%).

Apesar disso, mesmo desconsiderando os 39 respondentes que têm menos de 6 meses de empresa $^{131}$, observa-se uma tendência de maior concordância em relação à campanha de incentivo ter estimulado a participação no e-learning por parte dos respondentes que realizaram curso de e-learning (77\%), se comparado aos que não realizaram (40\%). Coerente com esse resultado, a pesquisa realizada por Martins e Kellermanns (2004, p. 16) identificou uma relação positiva entre o incentivo percebido e a intenção de uso do sistema pelo aluno.

Conforme ressaltado em uma das entrevistas, a campanha de incentivo realizada entre 2005 e 2006 premiava os funcionários com base na quantidade de cursos realizados através de sorteio. Com a proposta de maior integração do e-learning ao negócio, atualmente em andamento, a campanha de incentivo será reformulada.

Por fim, as outras duas variáveis com diferença significativa entre os respondentes que realizaram curso de e-learning e os que não realizaram são apresentadas no Gráfico 12: influência dos colegas em relação à participação no e-learning, com nível de significância de 0,05, e prestígio resultante da participação no e-learning, com nível de significância de 0,10.

\footnotetext{
130 "Another kind of subculture, less often acknowledged, reflects the common experiences of given levels within a hierarchy. Culture arises through shared experiences of success."

${ }^{131}$ Destes 39 respondentes, 36 não realizaram curso de e-learning desde 2006 na plataforma da empresa e 3 realizaram, aspecto a ser discutido no próximo tópico.
} 


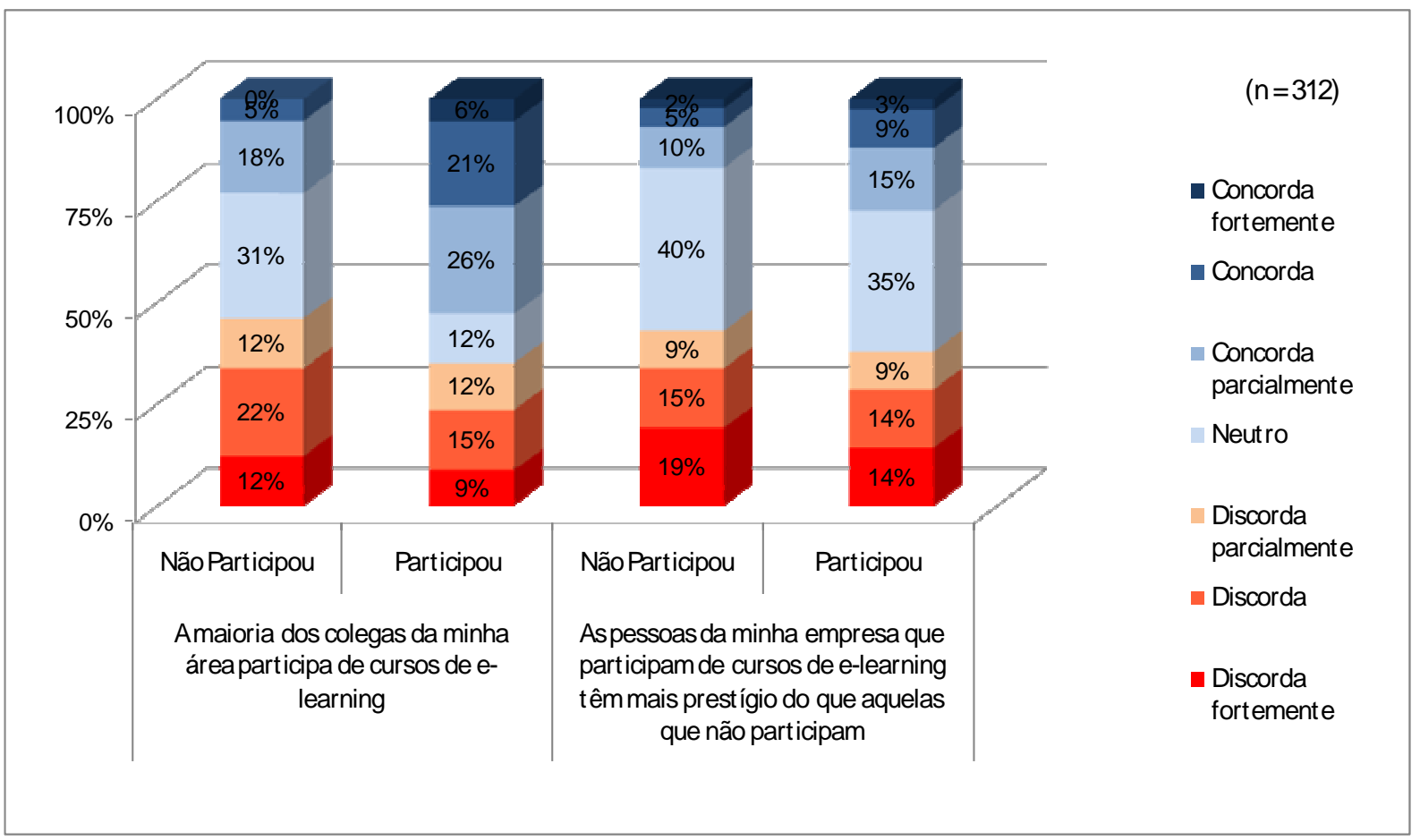

Gráfico 12 - Distribuição das Variáveis Relacionadas à Influência dos Colegas e ao Prestígio Resultante de Participação

A maior concordância dos respondentes que fizeram curso de e-learning com a participação dos colegas neste tipo de curso corrobora pesquisas anteriores que analisaram as influências sociais para adoção do e-learning. Na pesquisa realizada por Martins e Kellermanns (2004, p. $18), 0$

estímulo dos colegas foi um forte preditivo da utilidade percebida do sistema e um preditivo muito forte da atitude em relação ao sistema, indicando que estudantes são fortemente influenciados pelo que seus colegas pensam em sua avaliação de um novo sistema de cursos baseado na web. ${ }^{132}$

Por outro lado, na pesquisa conduzida por Lee (2006, p. 535), a influência dos colegas somente foi verificada nos ambientes em que o uso do e-learning era obrigatório, situação que fortalece a relevância desta variável como determinante da utilidade percebida e da intenção de uso, em conjunto com a influência do professor. De acordo com o autor, quando o uso é

132 "Peer encouragement was a strong predictor of perceived usefulness of the system, and a very strong predictor of attitude toward the system indicating that students are influenced strongly by what their peers think in their assessments of a new CMS [Course Management System]." 
voluntário, "o professor era a referência importante para encorajar o uso do ELS [sistema de e-learning]. Alunos podem usar o sistema para agradar o professor" ${ }^{\prime 133}$ (LEE, 2006, p. 537).

Apesar dessas variações, os resultados encontrados relacionados às influências dos colegas estão coerentes com as pesquisas anteriores que aplicam o Modelo TAM para analisar a aceitação de outras tecnologias (VENKATESH; DAVIS, 2000; SCHILLEWAERT et al, 2000).

Em relação ao prestígio das pessoas que participam do e-learning, os respondentes que participaram apresentaram maior concordância do que os que não participaram do e-learning, resultado coerente com os resultados da pesquisa de Venkatesh e Davis, em que a

\begin{abstract}
Norma subjetiva influencia significativamente a utilidade percebida através tanto da internalização, em que as pessoas incorporam influências sociais em suas próprias percepções de utilidade, e identificação, em que as pessoas usam um sistema para ganhar status e influência com o grupo de trabalho e dessa forma aprimorar seu desempenho no trabalho. ${ }^{134}$ (2000, p. 198).
\end{abstract}

É interessante notar que, de acordo com Venkatesh e Davis,

[...] quando os indivíduos adquirem experiência direta com o sistema no tempo, eles baseiam-se menos em informações sociais para formar sua percepção de utilidade e intenção, mas continuam a julgar a utilidade do sistema com base nos benefícios de status potenciais que podem resultar do uso. ${ }^{135}$ (2000, p. 199).

Dessa forma, conforme a experiência do respondente no uso do e-learning, a influência dos colegas pode ter variado. Por outro lado, considerando o alto nível de discordância em relação

133 "[...] the teacher was the important referent to encourage the use of the ELS. Students may use the system in order to please the teacher."

${ }_{134}$ "Subjective norm significantly influence perceived usefulness via both internalization, in which people incorporate social influences into their own usefulness perceptions, and identification, in which people use a system to gain status and influence within the work group and thereby improve their job performance."

135 "[...] as individuals gained direct experience with a system over time, they relied less on social information in forming perceived usefulness and intention but continued to judge a system's usefulness on the basis of potential status benefits resulting from use" 
a esta variável ( $40 \%$ do total de respondentes discordam em alguma medida), o prestígio parece ter pouca influência para adoção do e-learning na empresa pesquisada.

\subsubsection{Facilidade de Uso Percebida}

Hipótese 1.3 - $\boldsymbol{H}_{0}$ : Mesmo grau de concordância entre os respondentes que participaram do e-learning e os que não participaram em relação à Facilidade de Uso Percebida do e-learning.

Todas as variáveis que fazem parte deste fator apresentaram diferença significativa de percepção entre os respondentes que realizaram cursos de e-learning e os respondentes que não os realizaram, com nível de significância de 0,05 , rejeitando a Hipótese 1.3. Esse resultado é reforçado pelo motivo apontado por $35 \%$ dos respondentes que não realizaram curso desde 2006: dificuldades ou falta de informação no acesso à plataforma de e-learning da empresa (segundo motivo mais votado, após a falta de tempo).

Com relação à facilidade de uso do e-learning e à interação com o ambiente, observa-se uma maior discordância dos respondentes que não realizaram o e-learning (Gráfico 13), indicando possíveis dificuldades encontradas na utilização da plataforma de $e$-learning.

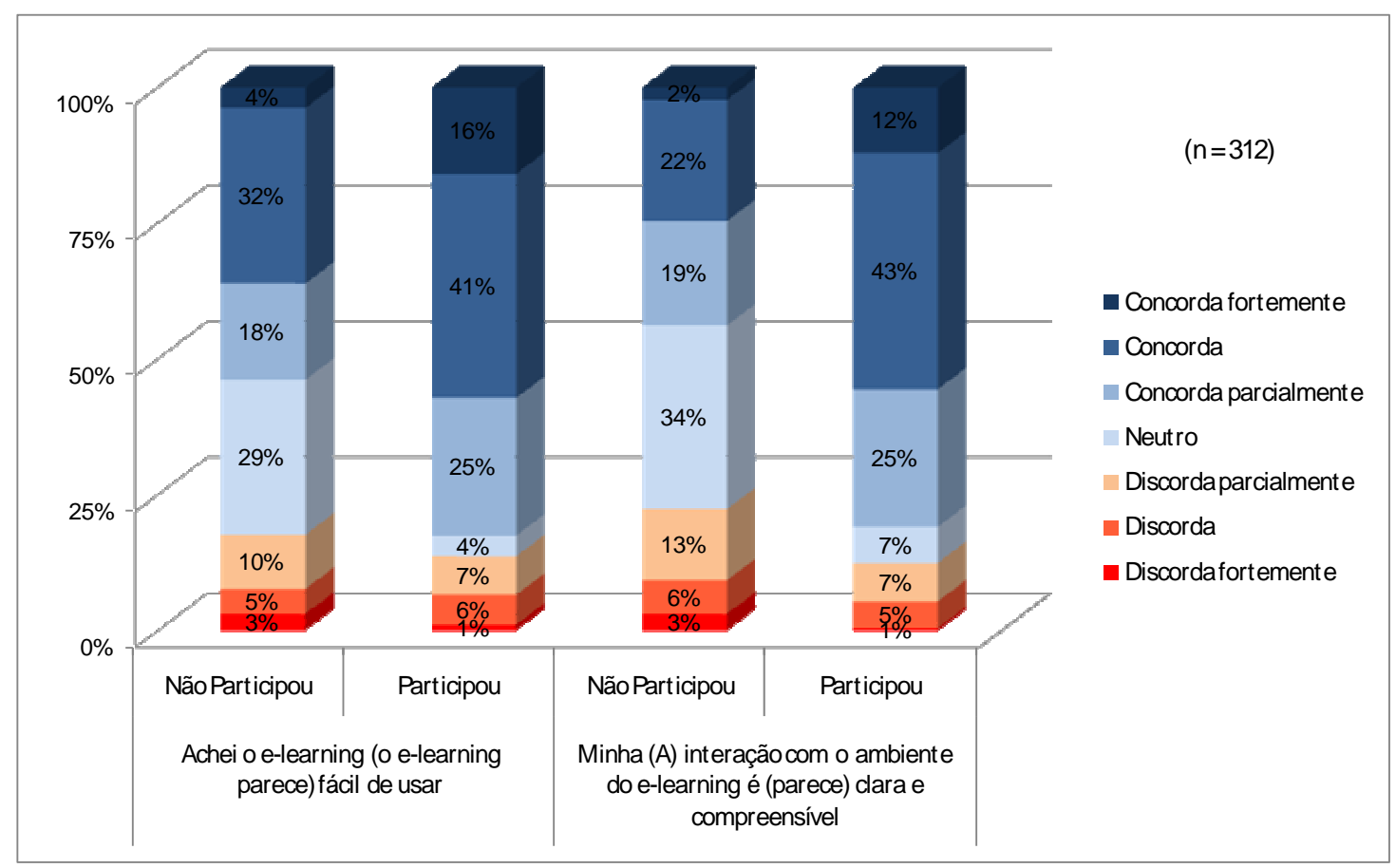

Gráfico 13 - Distribuição das Variáveis Relacionadas à Facilidade para Usar e à Clareza e Inteligibilidade da Interação com o Sistema 
Este resultado corrobora pesquisas anteriores que apontam a influência da facilidade de uso percebida na adoção do e-learning. Martins e Kellermanns (2004) identificaram uma relação positiva da facilidade de uso percebida na utilidade percebida e na atitude em relação ao sistema de aprendizagem on-line, resultado também encontrado por Gong et al (2004). De acordo com a pesquisa realizada por Ong et al, "Facilidade de uso percebida foi identificada como sendo um fator significativo na determinação da utilidade percebida, na intenção do comportamento para usar e na credibilidade percebida ${ }^{136} ., 137$ (2004, p. 800).

Na mesma linha, Selim (2003) concluiu que a "Facilidade de uso afeta significativamente a utilidade do estudante diretamente e a aceitação do website do curso indiretamente, mediada pelo constructo CWU [Utilidade do Website do Curso]."138 (SELIM, 2003, p. 357).

Ao analisar os determinantes da facilidade de uso do ambiente do curso, Selim (2003, p. 357) propõe três características:

- Consistência: uso de conceitos similares, terminologia, gráficos, layout e estrutura de navegação;

- Flexibilidade e eficiência do uso: adaptação de uma faixa de sofisticação e diversidade de objetivo do usuário;

- Inteligibilidade: é preferível o uso de documentos curtos com um assunto por página, com informações gerais e específicas organizadas hierarquicamente.

Além dos aspectos de usabilidade do ambiente on-line, a facilidade de uso percebida é positivamente influenciada de forma significativa pela disponibilidade de suporte técnico (MARTINS; KELLERMANNS, 2004, p. 16). O suporte disponível ao participante do elearning pode ser analisado a partir das três variáveis do Gráfico 14, que também apresentam diferença significativa entre os dois subgrupos de respondentes, com maior concordância dos respondentes que fizeram curso de e-learning.

\footnotetext{
${ }^{136}$ Credibilidade Percebida na pesquisa de Ong et al $(2004$, p.797) se refere à garantia do usuário em relação à privacidade e segurança do sistema de e-elearning.

137 "Perceived ease of use was found to be a significant factor in determining perceived usefulness, behavioral intention to use, and perceived credibility."
} 


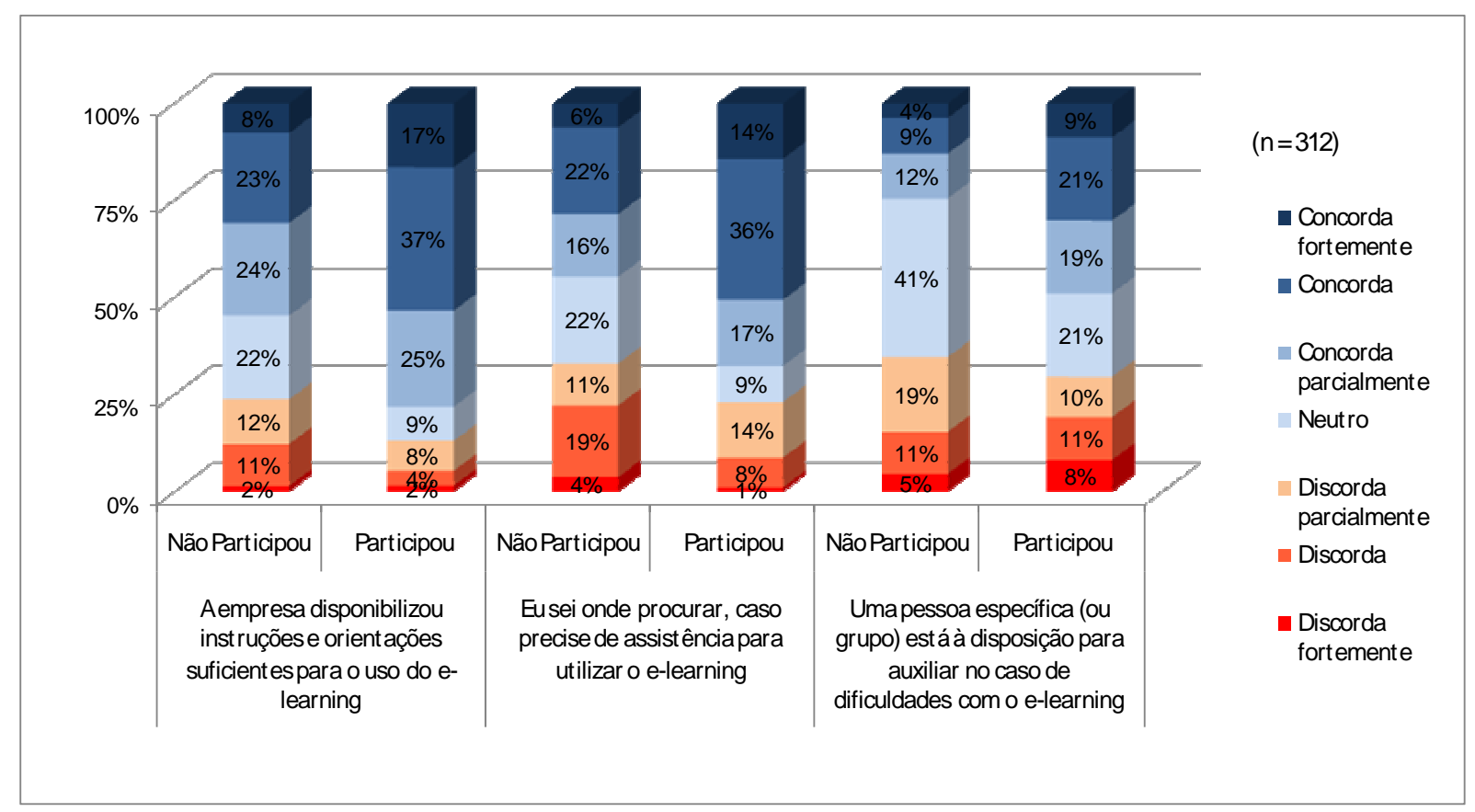

Gráfico 14 - Distribuição das Variáveis Relacionadas ao Suporte no Uso do e-Learning

Essa tendência está coerente com os resultados de Martins e Kellermanns os quais indicam que os "Alunos tinham maior chance de perceber o sistema como fácil de usar se eles acreditassem que havia suporte técnico adequado disponível, quando eles precisassem de ajuda com o sistema [...]"139 $(2004$, p. 19).

Conforme identificado nas entrevistas, além da disponibilização das informações necessárias para acessar os cursos de e-learning na plataforma da empresa e envio do guia de navegação após a inscrição em um curso, os colaboradores contam com uma estrutura de suporte técnico em três níveis:

- $1^{\circ}$ nível - Helpdesk: atende dúvidas simples tais como primeiro acesso, recuperação de senhas, etc.;

- $\quad 2^{\circ}$ nível - Empresa de e-Learning Local: atende questões técnicas mais complexas tais como problemas na inscrição dos cursos, erros no catálogo de cursos, erros no conteúdo dos cursos;

138 "Ease of use significantly affects the students' usefulness directly and course website acceptance indirectly through the mediating construct CWU."

139 "Students were more likely to perceive the system to be easy to use if they believed that there was adequate technical support available when they needed help with the system [...]" 
- $\quad 3^{\circ}$ nível - Empresa de e-Learning da Matriz: problemas graves de funcionamento da plataforma.

Apesar do suporte disponibilizado, alguns respondentes comentaram sobre dificuldades encontradas na plataforma de e-learning da empresa:

- “A plataforma adotada na empresa não é muito intuitiva e pode desmotivar os que possuem menos intimidade com computadores.”

- “O que ouço das pessoas, e também já tive dificuldades, é que é difícil encontrar, por exemplo, onde fazer a inscrição em determinado curso, o caminho não é muito claro.”

- "No segundo [curso] houve problemas com o acesso. Desisti, pois não podemos perder muito tempo tentando.”

A criação de uma rede de facilitadores do e-learning combinada com o apoio da área de Recursos Humanos têm auxiliado na redução destas dificuldades. A rede é formada por funcionários indicados em cada área da empresa, que após realizarem um treinamento, estão aptos a apoiar os colegas no acesso à plataforma de e-learning e fornecer esclarecimentos sobre o programa, cursos e inscrições. O desafio atual desta iniciativa está em lidar com a rotatividade e movimentação das pessoas, uma vez que no caso de saída ou transferência do facilitador para outra área da empresa é preciso capacitar um novo funcionário para assumir este papel. Mais uma vez percebe-se que o papel da Liderança, particularmente da gerência direta, é fundamental para o sucesso do projeto.

Essa ação está alinhada aos fatores de sucesso propostos por Rosenberg (2006) para a gestão da mudança envolvida na implementação do e-learning; entre os quais se destaca a disponibilização do suporte contínuo:

Os melhores esforços de gestão da mudança são estendidos após a disponibilização inicial, com treinamento continuado, linhas de apoio, newletters, Web sites de suporte e outras formas de comunicação (usualmente on-line), testemunhos, estórias de sucesso etc. Até um grupo local de colegas ou comitê que se reúne uma vez por 
semana para discutir como a transformação está progredindo e oferecer sugestões de aprimoramento que podem ser inestimáveis. ${ }^{140}$ (ROSENBERG, 2006, p. 266).

As demais variáveis do fator Facilidade de Uso Percebida estão no Gráfico 15 e apresentam a mesma tendência de maior concordância dos respondentes que participaram de cursos de $e$ learning.

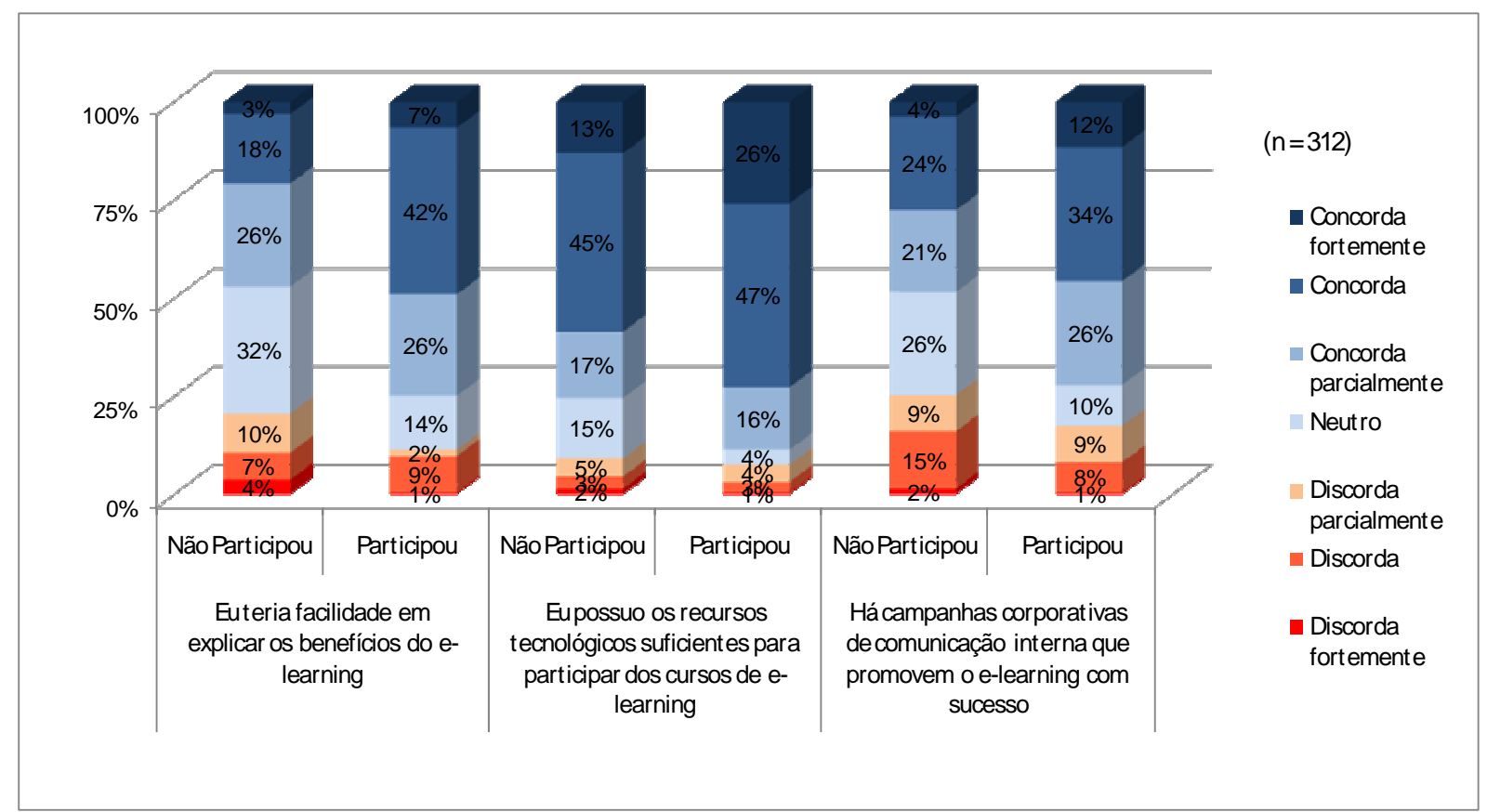

Gráfico 15 - Distribuição das Variáveis Relacionadas à Facilidade em Explicar os Benefícios, à Suficiência dos Recursos Tecnológicos e ao Sucesso da Campanha de Comunicação

A Suficiência dos recursos tecnológicos é a variável do fator Facilidade de Uso Percebida que, de forma geral, apresenta maior concordância dos respondentes (Apêndice 5). Apenas dois respondentes comentaram a falta de disponibilidade de fones de ouvido para realizar cursos com áudio e um respondente comentou sobre limitações na velocidade de acesso à Internet. No caso das operadoras de telecomunicações, esse aspecto estrutural facilita a adoção do e-learning, uma vez que a disponibilidade de infra-estrutura tecnológica faz parte do negócio e do contexto da empresa.

140 "The best change management efforts extend well beyond initial deployment, with continued training, help lines, newsletters, support Web sites and other forms of communication (usually online), testimonials, success stories and case studies, and so forth. Even a local peer group or steering committee that meets once a week to discuss how the transformation is proceeding and offer suggestions for improvement can be invaluable." 
Levando em consideração as dificuldades já discutidas de falta de tempo para realizar o $e$ learning durante a jornada de trabalho, alguns respondentes comentaram que gostariam de participar de cursos a partir de suas residências e que nesse caso, encontraram dificuldades de acesso à plataforma de e-elearning. Um deles inclusive sugeriu a extensão do incentivo da empresa para contratação de Internet rápida e aquisição de microcomputadores para todos os colaboradores, uma vez que esse benefício é parte do pacote oferecido aos executivos da companhia.

Já com relação ao sucesso das campanhas de comunicação do e-learning, há maior espaço para aprimoramento. Oito respondentes enviaram comentários sobre a necessidade de maiores informações em relação aos cursos de e-learning, entre as quais destacam-se:

- “Eu sugiro que a empresa faça uma maior divulgação do e-learning, principalmente entre os gerentes das áreas [...]”.

- “Ainda não tive contato com a plataforma de e-learning, principalmente pela falta de informação."

- "Entendo que os cursos não são bem divulgados, ou seja, não sabemos quais os cursos que estão abertos, os que se encerram e até quando ficam disponíveis. Acredito que se recebêssemos informações pela Newsletter da empresa, a participação na plataforma seria bem maior.”

Apesar dos comentários, as ações de comunicação na empresa pesquisada são realizadas através de diversos veículos de comunicação interna, além do Portal de e-learning na Intranet, tais como: Portal de Recursos Humanos, a Newsletter diária para todos os funcionários da empresa, a Newsletter só para executivos e o jornal impresso com notícias para todas as empresas do grupo. Conforme apontou um dos respondentes: "Acho o projeto inteligente e ousado. O papel da empresa na divulgação está sendo cumprido e é fundamental para os funcionários interessados."

Os novos funcionários parecem ter maior nível de desconhecimento em relação à plataforma de e-learning, considerando que dos 39 respondentes com menos de 6 meses de empresa, apenas 3 realizaram curso de e-learning. A entrada recente na empresa foi o terceiro motivo de não participação em cursos de e-learning, apontado por $18 \%$ dos respondentes (o primeiro foi falta de tempo e o segundo dificuldades ou falta de informação). Este aspecto também foi 
comentado por um dos respondentes: "Acho que deveria ser mais divulgado o método na Empresa e/ou Áreas. Principalmente para os funcionários mais novos, falta esclarecimento e melhor divulgação!".

Desta forma, o aprimoramento das ações de comunicação pode trazer benefícios ao programa da empresa, visto que o "esforço contínuo de marketing e promoção associado aos cursos de e-learning tem se mostrado altamente influente na atração e retenção de aprendizes." DAM, 2004, p. 95).

\subsubsection{Habilidade com Informática \& Pré-disposição para Inovar}

Hipótese 1.4 - $\boldsymbol{H}_{0}$ : Mesmo grau de concordância entre os respondentes que participaram do e-learning e os que não participaram em relação à Habilidade com Informática \& Pré-disposição para Inovar.

$\mathrm{Na}$ presente pesquisa observa-se que das 4 variáveis integrantes do fator Habilidade com Informática \& Pré-disposição para Inovar, 3 delas apresentam diferença entre os respondentes que participaram do e-learning na plataforma da empresa e os que não participaram, com nível de significância de 0,05 ; resultado que rejeita a Hipótese 1.4.

Embora a variável facilidade com informática não apresente diferença significativa entre os respondentes que participaram do e-learning e os que não participaram, é interessante notar que, ao considerar a toda a amostra, essa variável apresenta maior nível de concordância em relação às demais (Apêndice 5). Dos 312 respondentes, 94\% concordam em alguma medida em possuir facilidade com informática ( $73 \%$ concordam ou concordam fortemente). Provavelmente, em função da presença crescente das Tecnologias de Informação e Comunicação no ambiente organizacional (SOUKI et al, 2001) e em função das características do negócio da empresa, a habilidade com informática seja uma necessidade premente para a maioria dos funcionários.

Por outro lado, a habilidade para utilizar um novo software, variável baseada no constructo auto-eficácia com computadores de pesquisas anteriores, apresenta maior concordância dos 
respondentes que participaram de cursos de e-learning na plataforma da empresa, com nível de significância de 0,05 (Gráfico 16).

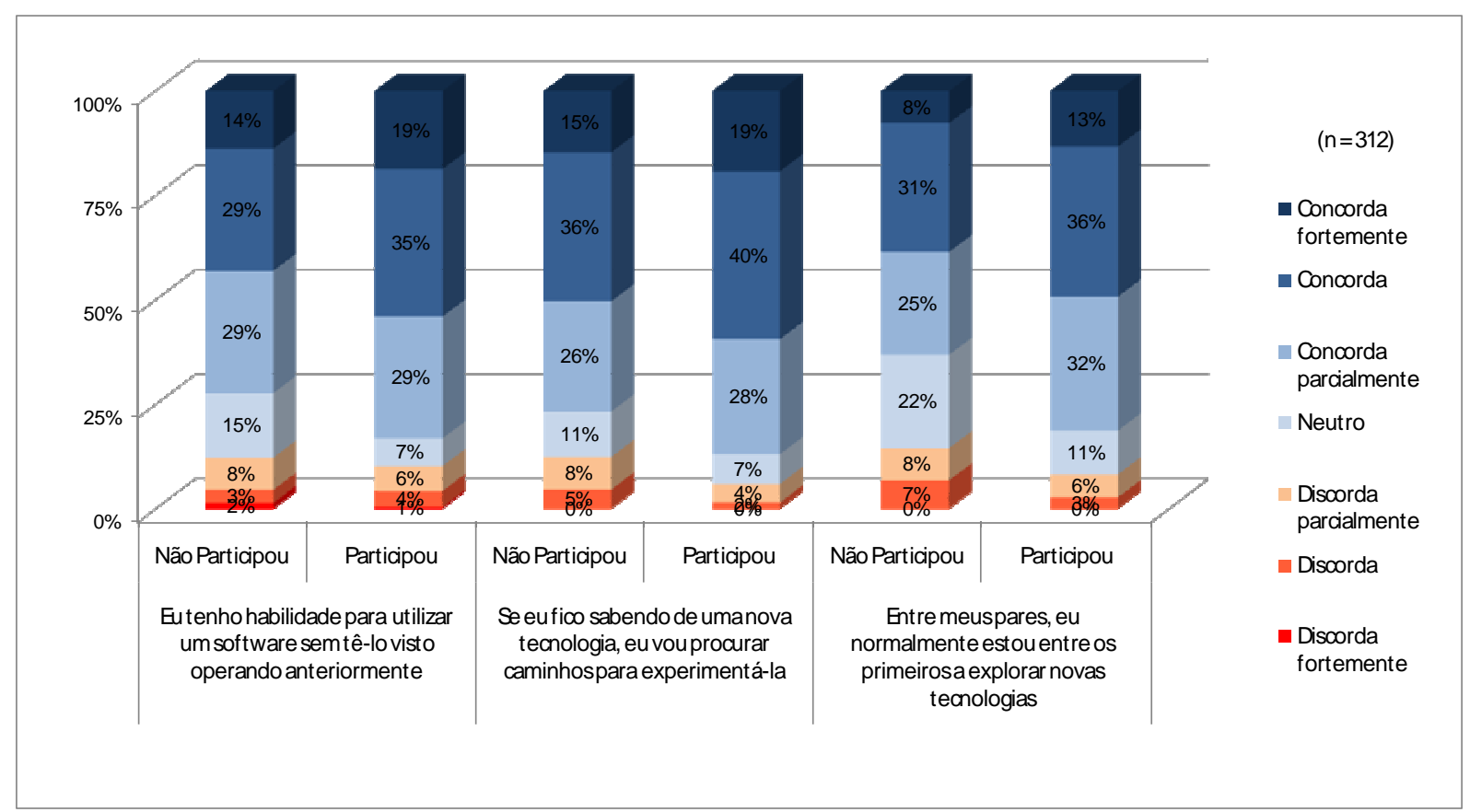

Gráfico 16 - Distribuição das Variáveis Relacionadas à Habilidade para Utilizar Um Novo Software e à Pré-disposição para Inovar

Esse resultado está coerente com pesquisas anteriores, uma vez que a auto-eficácia no uso de computadores $^{142}$ tem sido apontada na literatura como uma variável que influencia positivamente a facilidade de uso percebida do e-learning (GONG et al, 2004; ONG et al, 2004; LEE, 2006) e em alguns casos, influencia também a utilidade percebida (ONG et al, 2004) e a intenção de uso (GONG et al, 2004).

Apesar disso, esse resultado não foi confirmado no estudo conduzido por Martins e Kellermanns (2004); pesquisa em que a freqüência de uso do computador e da Web influenciou de forma significativa a facilidade de uso percebida, porém não foi encontrado efeito significativo da auto-eficácia no uso da web. Os autores explicam que essa diferença pode estar relacionada à idade dos respondentes, que eram mais jovens do que em pesquisas anteriores (idade média de 22 anos), “[...] representando uma geração que havia tido

141 "On-going marketing and promotional efforts associated with e-learning courses have been shown to be highly influential in attracting and retaining learners.” 
significativamente mais acesso e exposição a computadores e à Web que gerações anteriores."143 (MARTINS; KELLERMANNS, 2004, p. 19). Além disso, os itens do questionário aplicado são muito diferentes daqueles utilizados em pesquisas anteriores (SCHILLEWAERT et al, 2000; VENKATESH et al, 2003; GONG et al, 2004; ONG et al, 2004; LEE, 2006).

Em relação às variáveis ligadas à pré-disposição do indivíduo para inovar, a tendência de maior concordância apresentada pelos respondentes que participaram de cursos de e-learning na plataforma da empresa (Gráfico 16) confirma o resultado esperado, com diferença com nível de significância de 0,05 .

Embora esse constructo não tenha sido pesquisado nos estudos sobre $e$-learning analisados, os resultados encontrados estão coerentes com a pesquisa conduzida por Schillewaert et al (2000, p. 30), que “[...] confirmou o relacionamento direto entre pré-disposição para inovar e utilidade. Isso indica que os vendedores inovadores percebem melhor os benefícios de uma tecnologia de vendas.”. Além disso, foi identificado um efeito direto da pré-disposição individual para inovar na aceitação da tecnologia da área de vendas, divergindo da proposta inicial do Modelo TAM, em que as Características Pessoais e Variáveis Externas são mediadas pela Utilidade e Facilidade de Uso Percebidas.

Assim, a Hipótese 1.4 é recusada, uma vez que os respondentes que participaram de cursos de e-learning na plataforma da empresa apresentam maior concordância em 3 de um total de 4 variáveis deste Fator.

\subsubsection{Desconfiança em Relação à Inovação}

Hipótese 1.5 - $\boldsymbol{H}_{0}$ : Mesmo grau de concordância entre os respondentes que participaram do e-learning e os que não participaram sobre a Desconfiança em Relação à Inovação.

142 Refere-se à percepção do indivíduo em relação à sua capacidade em utilizar um computador (GONG et al, 2004, p. 367).

143 "[...] representing a generation that has had significantly more access and exposure to computers and the Web than previous generations." 
Nas variáveis do fator Desconfiança em Relação à Inovação observa-se discordância em alguma medida por pelo menos metade dos respondentes (Gráfico 17 e Apêndice 5), indicando que apenas uma parte dos respondentes (35\% em média) percebe a inovação com desconfiança, apresentando uma atitude cética em relação a novas tecnologias.

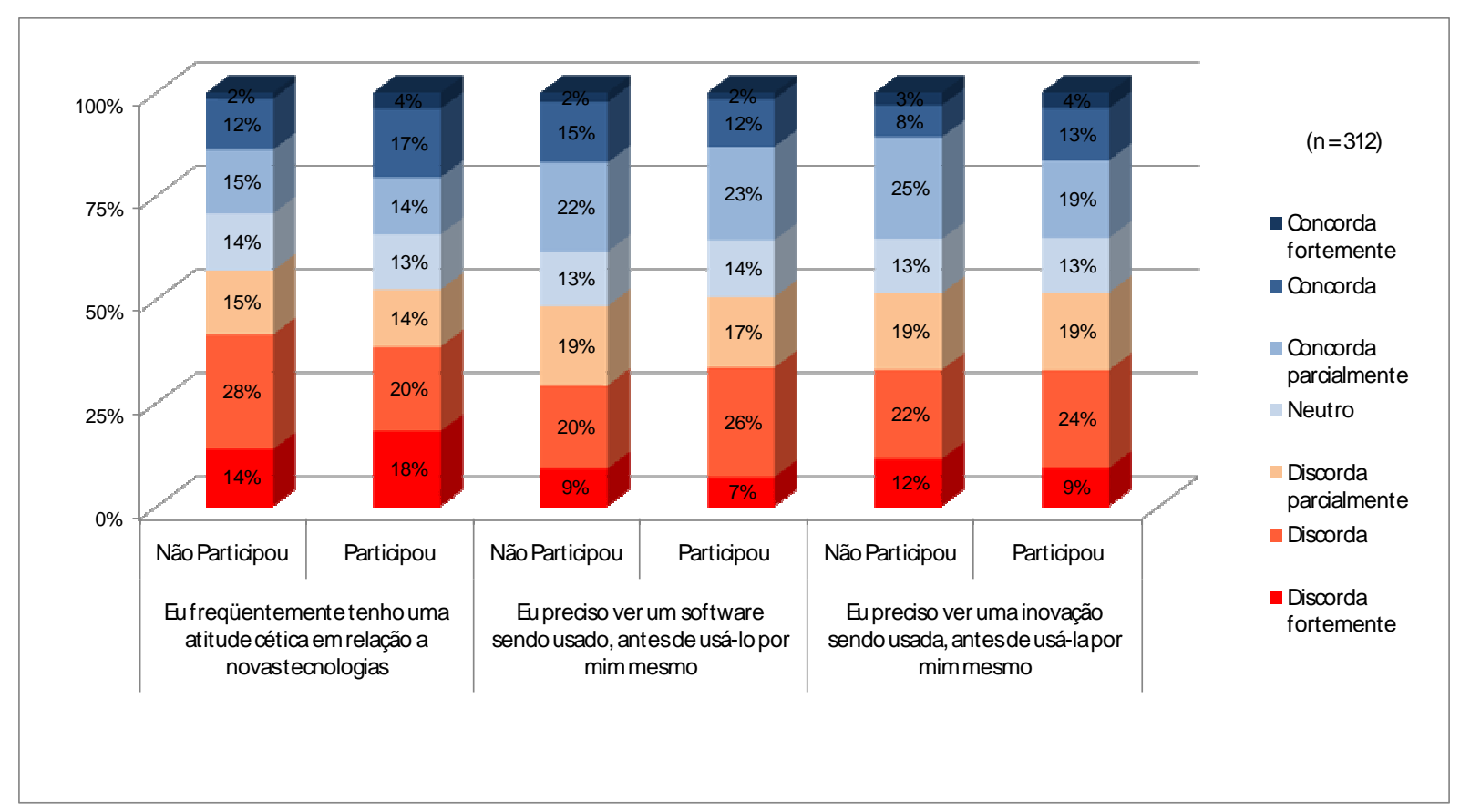

Gráfico 17 - Distribuição das Variáveis Relacionadas à Desconfiança em Relação à Inovação

Kamel e Hassan (2003, p. 19) identificaram uma influência significativa da confiança na aceitação de serviços bancários eletrônicos, incluindo ATMs, cartão de crédito, phone banking e Internet banking; considerando que confiança se referia à percepção de segurança no uso da nova tecnologia.

A pesquisa realizada por Lippert e Forman (2006) com 449 membros de um sistema de suprimentos, então foco de uma inovação recente, identificou que a Confiança na Tecnologia foi influenciada pela satisfação com o sistema existente, pela relação entre as funcionalidades da inovação e as necessidades da tarefa e pelas experiências anteriores similares; e que a Confiança na Tecnologia, por sua vez, influenciou os resultados de longo prazo esperados, fator que leva à adoção.

Dhami (2005, p. 263) verificou a influência positiva da Confiança (crença do usuário de que o sistema funcionará conforme esperado) na intenção de uso de um novo sistema de 
identificação utilizado em barcos, através de uma pesquisa com 118 usuários. Também foi identificada uma influência negativa do risco em usar o sistema, percebido pelo usuário, na intenção de uso. Além disso, os resultados mostraram que a Confiança do usuário no sistema influencia positivamente a utilidade percebida e negativamente a percepção de risco.

Especificamente em relação à adoção do e-learning, Ong et al (2004) analisaram a percepção do usuário de garantia em relação à privacidade e segurança do sistema de e-elearning, constructo denominado Credibilidade Percebida. Os resultados da pesquisa revelaram que "Como esperado, credibilidade percebida foi identificada como outro fator importante influenciando a intenção dos usuários em usar e-learning [...]"144, além da utilidade e facilidade de uso percebidas (ONG et al, 2004, p. 801).

Apesar dos resultados apresentados em pesquisas anteriores, no fator Desconfiança em Relação à Inovação não foi observada uma diferença significativa entre os respondentes que realizaram curso de e-learning na plataforma da empresa e os que não realizaram. Não obstante, na análise sobre a realização de curso de e-learning fora da plataforma da empresa foi identificada uma maior concordância dos respondentes que não realizaram curso de $e$ learning fora da empresa em relação às três variáveis desse fator, com nível de significância de 0,05 . Ou seja, os respondentes que não realizaram curso de e-learning fora da empresa apresentaram maior desconfiança em relação à inovação, aspecto que pode ter influenciado o comportamento de buscar cursos de e-learning por conta própria. Maiores detalhes sobre essa análise são apresentados no terceiro objetivo específico.

Com base nos resultados da pesquisa, a Hipótese 1.5 não pode ser recusada, indicando que não há diferenças entre os respondentes que participaram e não participaram de cursos de $e$ learning na plataforma da empresa no que se refere ao fator Desconfiança em Relação à Inovação.

\footnotetext{
144 “As expected, perceived credibility was found to be another important factor influencing users' intention to use e-learning [...]"
} 


\subsubsection{Intenção de Uso do e-Learning}

Hipótese 1.6 - $\boldsymbol{H}_{0}$ : Mesmo grau de concordância entre os respondentes que participaram do e-learning e os que não participaram em relação à Intenção de Uso do e-learning.

Uma das variáveis da intenção de uso do e-learning consiste na intenção de participar do elearning em 2007, que, por não ter escala Likert, não foi incluída na análise fatorial. Os resultados mostram que a maioria dos respondentes tem intenção de realizar pelo menos um curso na plataforma de e-learning da empresa durante o segundo semestre de 2007 (Gráfico $18)$.

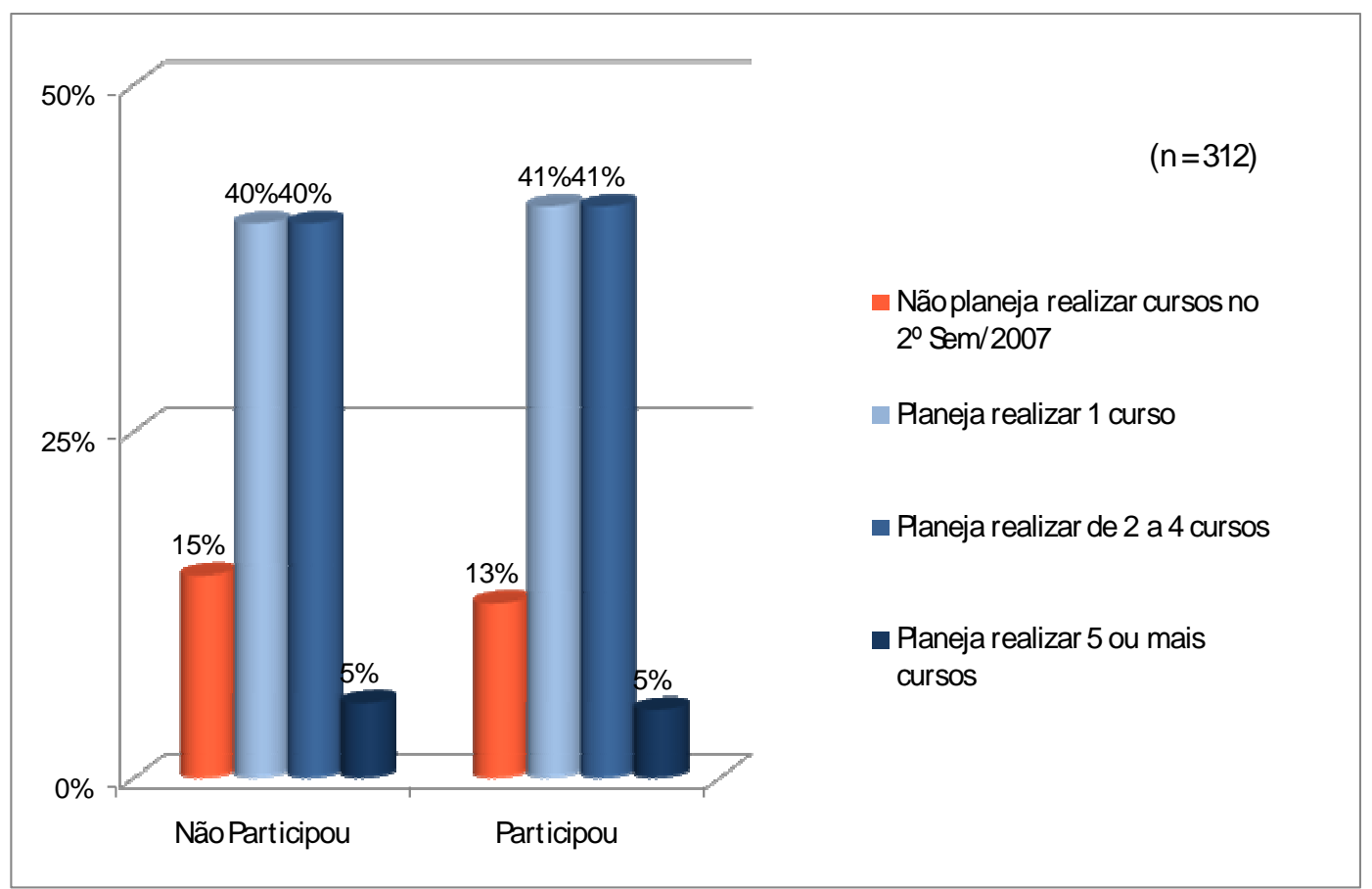

Gráfico 18 - Distribuição das Variáveis Relacionadas à Intenção de participar do e-learning em 2007

Conforme se observa no Gráfico 18, os dados não apresentam diferença significativa entre os respondentes que participaram de cursos de e-learning desde 2006 e os que não participaram, considerando as faixas do número de cursos planejados para serem realizados em 2007. Com base na literatura, seria esperado que os colaboradores que realizaram cursos de e-learning apresentassem maior intenção de participação do e-learning, uma vez que em geral esse subgrupo tenderia a apresentar maior concordância em relação aos fatores que influenciam positivamente a adoção do e-learning. Conforme a pesquisa realizada por Martins e Kellermanns (2004, p. 19), foi identificada uma relação positiva entre a intenção de uso e o uso do sistema da aprendizagem na Web. Por outro lado, a possibilidade de frustração do 
participante com o uso do e-learning poderia influenciar negativamente a intenção de uso, discussão apresentada anteriormente. Além disso, a quantidade de cursos é uma medida relativa, uma vez a duração é variável e os temas são diversos. Essas divergências poderiam explicar a ausência de diferenças significativas entre os respondentes que participaram e não participaram do e-learning em relação a essa variável da intenção de uso.

Os resultados do Gráfico 19 complementam essa discussão, apresentando outras duas variáveis relacionadas à intenção de uso do e-learning. Observa-se que a intenção de utilizar o e-learning é maior no caso da plataforma de e-learning disponibilizar cursos de maior interesse e do respondente dispor de mais tempo, fator que se nota principalmente para os respondentes que utilizaram a plataforma de e-learning da empresa desde 2006, com nível de significância de 0,05. Resultado que rejeita a Hipótese 1.6.

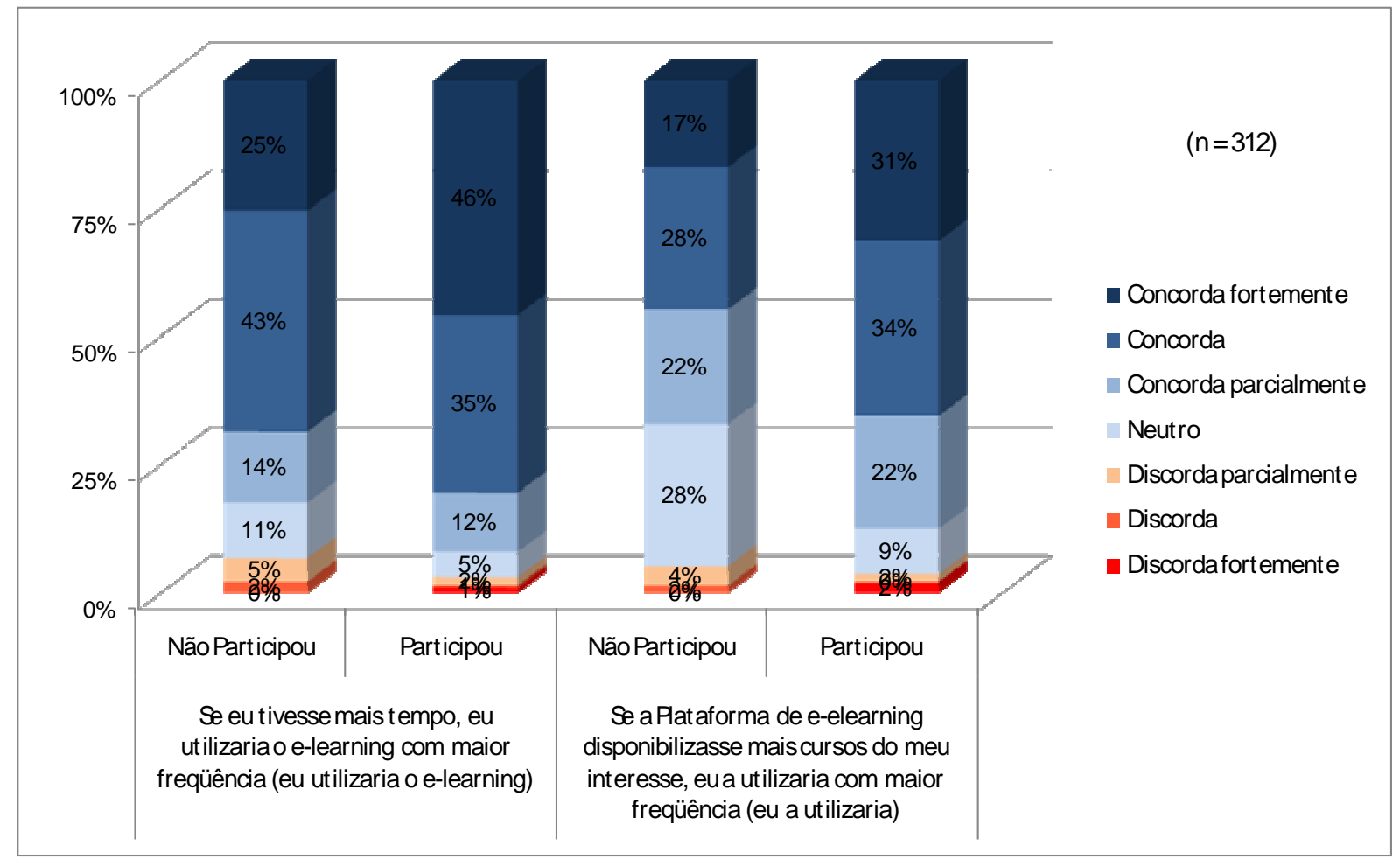

Gráfico 19 - Distribuição das Variáveis Relacionadas à Intenção de Uso do e-Learning

Com relação aos cursos de interesse, observa-se um resultado coerente com a literatura, uma vez que sugere uma relação entre a utilidade percebida, influenciada pelos cursos disponíveis, conforme apontado por Lee (2006), e a intenção de uso, resultado encontrado em pesquisas anteriores sobre adoção do e-learning (SELIM, 2003; GONG et al, 2004; ONG et al, 2004; FUSILIER; DURLABHJI, 2005). 
Além disso, os resultados sugerem a influência do fator tempo na intenção de uso; reforçando as discussões apresentadas anteriormente (item 5.2.2), sobre o apoio da liderança (ROSENBERG, 2000; MACPHERSON et al, 2004; CHANG, 2005) e as dificuldades de falta de tempo para o e-learning (BOROTIS; POULYMENAKOU, 2007; VAN DAM, 2004), apontadas na literatura e nos comentários desta pesquisa.

\subsection{Analisar as diferenças de percepção em função do perfil do respondente}

A análise a seguir foi realizada através do agrupamento dos respondentes em função do perfil, com dados disponibilizados pela área de Recursos Humanos da empresa. A Prova de MannWhitney foi aplicada para todas as variáveis do perfil, exceto no caso da variável área funcional, situação em que foi utilizado o Teste de Kruskal-Wallis.

Foram analisadas as percepções dos respondentes em relação às variáveis da pesquisa, tendo como referência os fatores apresentados anteriormente, incluindo também as duas variáveis não explicadas pela análise fatorial e as duas variáveis respondidas apenas pelos colaboradores que realizaram curso de e-learning. Adicionalmente, foi comparado o comportamento relatado $^{145}$ de uso do e-learning em função de cada variável do perfil do respondente.

Tendo em vista o grande número de variáveis, foram escolhidas duas variáveis para condução da análise em maior detalhe: a experiência com e-learning fora da empresa e o gênero, por se tratarem de discussões mais presentes na literatura. Posteriormente, serão brevemente apresentadas as diferenças em relação aos demais aspectos: idade, tempo de empresa, grau de instrução, localidade de trabalho, nível hierárquico e área funcional.

\footnotetext{
145 Variável baseada na resposta à primeira pergunta do questionário: "Você já participou de algum curso da Plataforma de e-learning da empresa, desde 2006?".
} 


\subsubsection{Experiência com e-Learning Fora da Plataforma da Empresa}

Hipótese 2 - $\boldsymbol{H}_{0}$ : Mesmo grau de concordância entre os respondentes que realizaram e não realizaram curso de e-learning fora da plataforma da empresa em relação às variáveis que influenciam a adoção do e-learning.

Dos 312 respondentes da pesquisa, 26\% apontaram a realização de cursos de e-learning fora da plataforma da empresa. Considerando apenas esse grupo de respondentes, 59\% também realizaram cursos de e-learning na plataforma da empresa; ou seja, $41 \%$ dos que têm experiência anterior com o e-learning fora da empresa não participou de cursos na plataforma empresa desde 2006. Dentre os cursos realizados fora da empresa destacam-se cursos sobre empreendedorismo (Sebrae), gestão, técnicos, idiomas e informática, em alguns casos oferecidos pela empresa em que o respondente trabalhou anteriormente.

Ao dividir a amostra em dois subgrupos com base na experiência com e-learning fora da empresa, os resultados da Prova de Mann-Whitney indicam uma diferença significativa em 17 das 39 variáveis analisadas (Apêndice 6), rejeitando-se a Hipótese 2.

Os respondentes que realizaram curso de e-learning fora da plataforma da empresa apresentaram maior concordância em relação à maior flexibilidade do e-learning para aprender, à facilidade em explicar os benefícios do e-learning e à intenção de uso, caso fossem disponibilizados mais cursos de interesse, reforçando a discussão apresentada sobre o fator Utilidade Percebida, que se refere à relevância do conteúdo do curso disponibilizado (VAN DAM, 2004; LEE, 2006; ONG; LAI, 2006) e ao alinhamento do e-learning com as atividades e objetivos do participante (ANGEHRN et al, 2001).

Esses respondentes que realizaram curso de e-learning fora da plataforma da empresa, também apresentaram maior concordância em 3 variáveis do fator Habilidade com Informática e Pré-disposição para Inovar, com nível de significância de 0,05.

Este resultado está coerente com o que seria esperado, considerando que "Conforme os usuários se tornam mais experientes, eles tendem a descobrir mais finalidades para a tecnologia."146 (FUSILIER; DURLABHJI, 2005, p. 243). De acordo com a pesquisa realizada

\footnotetext{
146 “As users become more experienced, they tend to discover more purposes for the technology."
} 
por Fusilier e Durlabhji, “[...] utilidade percebida parece estar mais fortemente relacionada à intenção de comportamento para aqueles com alto nível de experiência na internet."147 (2005, p. 243), o que influenciaria positivamente a adoção.

Já os respondentes que não realizaram curso de e-learning fora da plataforma da empresa apresentaram maior concordância em relação: à adequação do projeto de e-learning existente na empresa, ao apoio e estímulo do superior imediato, ao compromisso da alta administração, ao apoio da cultura à aprendizagem e ao e-learning e à efetividade da campanha de incentivos e de comunicação - aspectos todos relacionados ao apoio da empresa para o e-learning. É possível que estes respondentes não tenham sentido necessidade de buscar cursos fora da empresa, por perceberem que dispõem do apoio necessário para atingir seus objetivos de aprendizagem. Por outro lado, conforme já comentado, esses respondentes parecem apresentar maior desconfiança em relação à inovação, outra explicação para a não realização de cursos de e-learning fora da plataforma da empresa.

\subsubsection{Gênero}

Hipótese 3 - $\boldsymbol{H}_{0}$ : Mesmo grau de concordância entre os respondentes homens e mulheres em relação às variáveis que influenciam a adoção do e-learning.

Os 312 respondentes foram separados em função do gênero, resultando em um subgrupo do sexo masculino, formado por 208 respondentes (66\%), e outro do sexo feminino, formado por 104 respondentes $(34 \%)$.

Os respondentes de sexo masculino apresentam maior concordância em 6 variáveis do fator Utilidade Percebida, tendo 5 delas nível de significância de 0,10 , e a variável sobre importância do e-learning para o trabalho, com nível de significância de 0,05 (Apêndice 7). Também demonstram maior concordância em 2 variáveis do fator Ambiente Propício à Aprendizagem, relacionadas à influência do e-learning no status do indivíduo (prestígio das pessoas que participam do e-learning e aumento nas chances de promoção), e em 4 variáveis do fator Facilidade de Uso Percebida. 
Enquanto os respondentes do sexo masculino apresentam maior concordância em todas as variáveis do fator Habilidade com Informática e Pré-disposição para Inovar, com nível de significância de 0,05 , as respondentes de sexo feminino apresentam maior concordância em 2 das 3 variáveis do fator Desconfiança em Relação à Inovação, com nível de significância de 0,05 .

Considerando a relação já discutida entre as variáveis analisadas e a intenção de uso do $e$ learning, o resultado esperado, dos respondentes de sexo masculino apresentarem maior intenção em participar do e-learning, pode ser verificado através da maior concordância deste grupo em relação à variável que aponta a intenção de maior participação do e-learning, caso a empresa disponibilize mais cursos de interesse, com nível de significância de 0,05. Além disso, $48 \%$ dos respondentes de sexo masculino planejam realizar dois ou mais cursos de $e$ learning em 2007, comparado com 43\% das mulheres com que indicaram a mesma resposta (Gráfico 20).

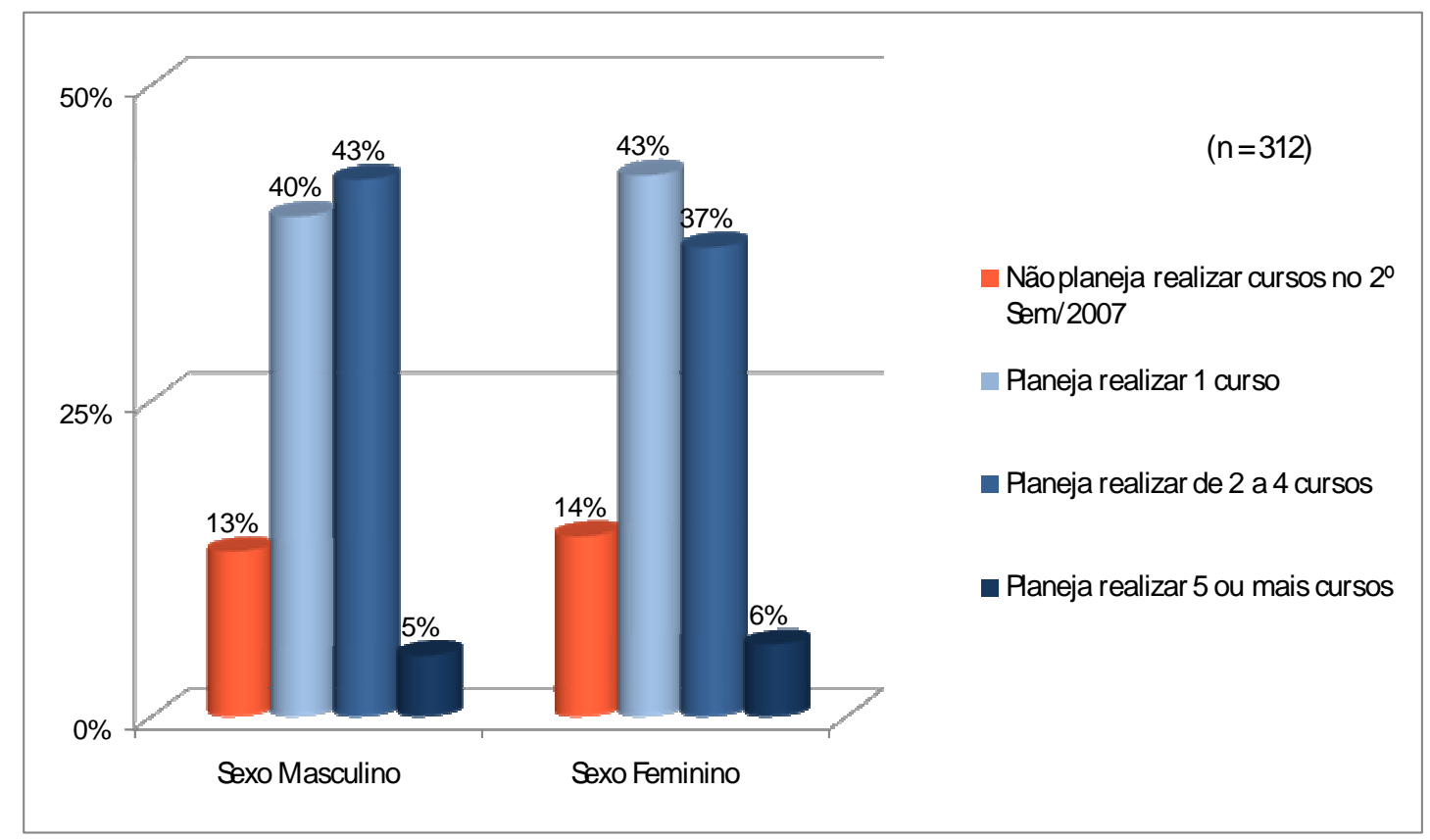

Gráfico 20 - Distribuição da Intenção de Participar do e-Learning em 2007, por Gênero

A atribuição de notas mais altas pelos homens também foi verificada por Ong e Lai (2006), em uma pesquisa sobre a adoção do e-learning em seis empresas internacionais de Taiwan.

147 “[...] perceived usefulness appeared more strongly related to behavioural intention for those with high levels 
Com base nas 156 respostas obtidas, os “[...] resultados mostraram que as notas atribuídas pelos homens para as percepções em relação à auto-eficácia com computadores, utilidade percebida, facilidade de uso percebida e intenção de comportamento para usar o e-learning são todas mais altas que as das mulheres." ${ }^{148}$ (ONG; LAI, 2006, p. 825). Além disso, os autores analisaram as diferenças no processo de decisão sobre a aceitação do e-learning e concluíram que, apenas para os homens, a utilidade percebida apresentou o efeito direto mais significativo na intenção de uso; e, além disso, “[...] para as mulheres, auto-eficácia com computador é um fator relevante afetando utilidade percebida e facilidade de uso percebida, em adição à facilidade de uso percebida ser um fator relevante afetando a intenção do comportamento de uso." ${ }^{149}$ (ONG; LAI, 2006, p. 826).

Corroboram essas evidências os resultados de Venkatesh e Morris (2000), que avaliaram durante cinco meses o uso de novos softwares por 342 trabalhadores de cinco empresas. $\mathrm{O}$ resultado obtido pelos autores confirmam a existência de diferenças em função do gênero (VENKATESH; MORRIS, 2000, p. 128-129):

- "[...] homens consideraram a utilidade percebida como mais importante que as mulheres para tomar decisões sobre o uso de uma nova tecnologia, tanto no curto quanto no longo prazo." 150 ;

- "[... ] facilidade de uso percebida foi mais relevante para as mulheres comparado com os homens tanto após o treinamento inicial quanto durante o tempo com o aumento da experiência no sistema." ${ }^{151}$;

- "Norma subjetiva não influenciou a decisão dos homens em nenhum ponto do tempo. Por outro lado, mulheres consideraram influências normativas no estágio inicial de introdução da tecnologia e após uma mês de experiência."152.

\footnotetext{
of experience."

148 "[...] findings showed that men's ratings of perceptions with respect to computer self-efficacy, perceived usefulness, perceived ease of use, and behavioral intention to use e-learning are all higher than women's."

149 "[...] for women, computer self-efficacy is a salient factor affecting perceived usefulness and perceived ease of use, in addition to perceived ease of use being a salient factor affecting behavioral intention to use."

150 "[...] men consider perceived usefulness to a greater extent than women in making their decisions regarding the use of a new technology, both in the short- and long-term."

151 "[...] perceived ease of use was more salient to women compared with men both after initial training and over time with increasing experience with the system."
} 
Esses autores concluem que "[...] enquanto homens somente consideram fatores relacionados à produtividade, mulheres consideram inputs a partir de várias fontes incluindo avaliação de produtividade quando realizam decisões sobre adoção e uso de tecnologia."153 (VENKATESH; MORRIS, 2000, p. 129).

Por outro lado, Cheung et al (2002) pesquisaram diferenças de gênero na adoção de um ambiente de aprendizagem baseado na Internet por 549 alunos de uma universidade em Hong Kong e encontraram resultados divergentes daqueles obtidos por Venkatesh e Morris (2000): a utilidade percebida tem impacto forte em ambos os grupos classificados por gênero, sem diferença significativa; a norma subjetiva apresentou maior influência na intenção de uso dos homens ao invés das mulheres; a facilidade de uso apresentou maior influência na atitude em relação ao e-learning nos homens do que nas mulheres (CHEUNG et al, 2002, p. 6). Os autores explicam as diferenças em função de efeitos culturais, considerando as diferenças entre a cultura ocidental e oriental.

Já Gefen e Straub (1997) pesquisaram o uso do sistema de e-mail por 392 trabalhadores de três empresas da indústria aérea na América do Norte, Ásia e Europa. Os resultados indicam que as mulheres perceberam o e-mail com maior presença social ${ }^{154}$ e maior utilidade que os homens, e estes, por sua vez, apresentaram maior tendência em relação à facilidade de uso. Por outro lado, apesar das mulheres terem percebido uma maior presença social e utilidade do e-mail, não foi verificado um efeito direto do gênero no uso do e-mail; ou seja, apesar das diferenças de percepção entre homens e mulheres, as diferenças de gênero não afetam o uso do sistema (GEFEN; STRAUB, 1997, p.397).

Da mesma forma que no estudo de Gefen e Straub (1997), na presente pesquisa esperava-se observar uma diferença no Comportamento de Uso do e-learning em função do gênero. Apesar disso, os resultados não indicam uma maior propensão dos respondentes de um gênero em particular para adotar o e-learning. Ao analisar a participação em cursos de e-learning na

\footnotetext{
152 "Subjective norm did not influence men's decision at any point in time. In contrast, women did consider normative influences at the initial stage of technology introduction and after one month experience."

153 " [...] while men only consider productivity-related factors, women consider inputs from a number of sources including productivity assessments when making technology adoption and usage decisions."

${ }^{154}$ Nesta pesquisa, Presença Social se refere ao contato humano combinado com a riqueza de informação de uma mídia (GEFEN; STRAUB, 1997, p.390).
} 
plataforma da empresa essa tendência não é verificada, uma vez que $63 \%$ das respondentes de sexo feminino indicaram participação, comparado a $56 \%$ dos respondentes de sexo masculino com a mesma resposta. Por outro lado, os respondentes de sexo masculino apresentam maior tendência para participar de cursos de e-learning fora da plataforma da empresa, uma vez que 30\% deles fizeram curso fora da empresa, comparado com apenas $17 \%$ das respondentes de sexo feminino que apontaram a participação em cursos desta natureza.

Por outro lado, na pesquisa realizada por Bush (2005), para avaliar a aceitação da comunicação mediada pelo computador no processo de aprendizagem com 160 alunos de uma faculdade de administração, “A análise dos dados não encontrou uma diferença significativa para idade, gênero e estilo de aprendizagem influenciando atitude, intenção de comportamento e uso de CMCs [Comunicações Mediadas por Computador]." "155 (BUSH, 2005, p. 98), e também influenciando facilidade de uso percebida e utilidade percebida. $\mathrm{Na}$ mesma linha, Gao (2005) também não encontrou correlação significativa entre a idade, gênero e tempo conectado à Internet em relação à atitude e à intenção de uso do ambiente on-line do curso, considerando os 56 participantes de sua pesquisa.

Desta forma, observa-se que de modo geral os resultados em relação às diferenças de gênero na adoção de novas tecnologias não são consistentes; provavelmente, há outras questões que influenciam os resultados, como a cultura, conforme apontado por Cheung et al (2002), e a própria tecnologia que está sendo adotada.

Apesar disso, as pesquisas que encontraram diferenças significativas nas percepções de homens e mulheres na adoção de novas tecnologias são mais freqüentes na literatura (ONG; LAI, 2006; VENKATESH; MORRIS, 2000; CHEUNG et al, 2002; GEFEN; STRAUB, 1997) do que as que não verificaram tais diferenças (BUSH, 2005; GAO, 2005); resultado coerente, se consideradas outras áreas do conhecimento que têm pesquisado diferenças de gênero.

De forma geral, os resultados da presente pesquisa confirmam a rejeição à Hipótese 3 , tendo em vista as diferenças significativas encontradas nas percepções em função do gênero, 
corroborando com a literatura. $\mathrm{Na}$ presente pesquisa, os respondentes homens tenderam a apresentar maior concordância com as variáveis que influenciam positivamente a adoção, enquanto que as respondentes mulheres tenderam a concordar mais com as variáveis do fator Desconfiança, que influenciaria negativamente a adoção. Desta forma, ao avaliar no detalhe, essas diferenças não são consistentes com a literatura, que, por sua vez, apresenta resultados diversos.

\subsubsection{Demais Aspectos do Perfil do Respondente}

A seguir, serão brevemente apresentadas as principais diferenças de percepção dos respondentes da pesquisa em função da idade, tempo de empresa, grau de instrução, localidade de trabalho, nível hierárquico e área funcional.

\section{Idade e Tempo de Empresa}

Conforme já apresentado, a média de idade dos respondentes é de 36 anos. A Prova de MannWhitney foi aplicada comparando as percepções dos respondentes mais jovens que 36,43 anos (51\%) e dos respondentes com idade igual ou superior a 36,43 anos $(49 \%)$.

Os resultados indicam que os respondentes com idade igual ou acima de 36 anos apresentaram maior concordância na maioria das variáveis dos fatores Utilidade Percebida, Ambiente Propício à Aprendizagem e Facilidade de Uso Percebida, com nível de significância de 0,05 em 21 variáveis e nível de significância de 0,10 em 2 variáveis (Apêndice 8).

Por outro lado, enquanto os respondentes mais jovens apresentaram maior concordância na maioria das variáveis do fator Habilidade com Informática \& Pré-disposição para Inovar, (com nível de significância de 0,05 ) os respondentes mais velhos apresentaram maior concordância em 2 variáveis do fator Desconfiança em Relação à Inovação, com nível de significância de 0,10 .

\footnotetext{
155 "The data analysis did not find a statistically significant difference for age, gender, and learning style
} influencing attitude, behavioral intention, and use of CMCs." 
A Prova Mann-Whitney foi aplicada comparando os respondentes com tempo de empresa menor que a média de 8,77 anos (65\%) e aqueles com tempo de empresa maior ou igual a $8,77 \operatorname{anos}(35 \%)$.

Da mesma forma que na variável idade, os respondentes com maior tempo de empresa (acima de 8,77 anos) apresentaram maior concordância na maioria das variáveis dos fatores Utilidade Percebida, Ambiente Propício à Aprendizagem e Facilidade de Uso Percebida, com nível de significância de 0,05 em 21 variáveis e nível de significância de 0,10 em 4 variáveis (Apêndice 9).

Os respondentes com menor tempo de empresa também apresentaram maior concordância na maioria das variáveis do fator Habilidade com Informática \& Pré-disposição para Inovar (2 variáveis com nível de significância de 0,05 e 1 a 0,10) e os respondentes com maior tempo de empresa também apresentaram maior concordância em 2 variáveis do fator Desconfiança em Relação à Inovação - 1 variável com nível de significância de 0,05 e outra a 0,10.

Conforme seria esperado em função destes resultados, observa-se que os respondentes com maior idade e maior tempo de empresa apresentam maior participação nos cursos da plataforma de e-learning da empresa: 64\% dos respondentes com idade igual ou maior que 36 anos participaram, comparado a 53\% dos respondentes mais jovens com o mesmo comportamento; e $71 \%$ dos respondentes com mais de 8 anos de empresa participaram, comparado a 51\% dos respondentes com menos anos de empresa com o mesmo comportamento. Além disso, os respondentes com maior tempo de empresa apresentam maior intenção de participar do e-learning, caso tivessem mais tempo, com nível de significância de 0,05 .

\section{Grau de Instrução}

Para análise do grau de instrução, os respondentes foram agrupados a partir do maior grau de instrução (curso superior completo e cursos de pós-graduação completos ou incompletos), representando $62 \%$ dos participantes da pesquisa, e os respondentes com menor grau de instrução (superior incompleto e cursos anteriores completos ou incompletos), representando $38 \%$ dos participantes da pesquisa. 
Os respondentes com menor grau de instrução apresentam maior concordância com 9 das 10 variáveis do fator Utilidade Percebida, em todas as variáveis do fator Ambiente Propício à Aprendizagem, em 5 das 8 variáveis do fator Facilidade de Uso Percebida, em 1 das variáveis do fator Habilidade com Informática \& Pré-disposição para Inovar e nas 3 variáveis do fator Desconfiança em Relação à Inovação. Além disso, demonstram maior intenção de participar do e-learning caso dispusessem de mais tempo ou caso fossem disponibilizados mais cursos de interesse. Das 30 variáveis com diferença significativa, 26 foram com nível de significância de 0,05 e 4 com nível de significância de 0,10 (Apêndice 10). Coerente com a tendência observada em relação à idade e ao tempo de empresa, o grupo de respondentes que apresentou maior concordância com as variáveis, também apresentou maior participação nos cursos da plataforma da empresa; ou seja, apesar da diferença ser pequena, $61 \%$ dos respondentes com menor grau de instrução participaram do e-learning, comparado com 57\% dos respondentes com maior grau de instrução.

Este resultado é divergente do apresentado por Gallaher Jr (2002, p. 89), sugerindo que indivíduos com maior nível educacional têm maior tendência a adotar o e-learning, aspecto também sugerido por Rogers (1995, p. 202), mas no caso se referindo à adoção de inovações. Essa diferença encontrada pode estar relacionada ao conteúdo dos cursos de e-learning disponíveis e à cultura e disponibilidade de infra-estrutura, aspectos já discutido em tópicos anteriores.

\section{Localidade de Trabalho}

Tendo em vista a vantagem do e-learning de facilitar o acesso ao conhecimento em regiões distantes, a análise da localidade de trabalho do respondente seria um aspecto interessante a ser considerado. Sendo assim, foram comparadas as percepções dos respondentes que trabalham na capital, representando $89 \%$ da amostra, com aquelas dos respondentes que trabalham nas cidades do interior do estado (11\% da amostra).

Conforme esperado, os resultados indicam uma tendência de maior concordância por parte dos respondentes que trabalham no interior para as variáveis dos fatores Utilidade Percebida, Ambiente Propício à Aprendizagem e Facilidade de Uso Percebida (Apêndice 11). De um total de 28 variáveis que compõem estes 3 fatores, 24 apresentaram diferença com nível de significância de 0,05, 3 com nível de significância de 0,10 e uma não apresentou diferença 
significativa. Coerente com esta diferença, $82 \%$ dos respondentes do interior realizaram curso de e-learning na plataforma da empresa, comparado com apenas 55\% dos respondentes da capital.

Este resultado diverge da tendência mencionada por Rogers (1995, p. 202) indicando que novos adotantes de uma inovação são caracterizados por serem mais cosmopolitas, entre outros aspectos. Apesar disso, este resultado corrobora com benefícios do e-learning apontados na literatura como redução de custos com viagens, disponibilização de informações mais completas e integração de pessoas distantes geograficamente (VASCONCELLOS; FLEURY, 2004, p.5), aspectos mais críticos no caso dos colaboradores que atuam em cidades do interior.

\section{Nível Hierárquico e Área Funcional}

A análise da posição do respondente na estrutura organizacional da empresa foi realizada em função de duas variáveis: o cargo e a área funcional.

Para condução da Prova Mann-Whitney, os respondentes foram agrupados em função do nível hierárquico, considerado: cargos gerenciais (líderes, gerentes e executivos), representando $32 \%$ dos respondentes, e cargos técnicos (engenheiros, técnicos, analistas e assistentes), representando $68 \%$ dos respondentes.

Os respondentes com cargos gerenciais apresentaram maior concordância em relação à disponibilidade de recursos tecnológicos para o e-learning, à facilidade para explicar os benefícios do e-learning e à 3 variáveis do fator Habilidade com Informática \& Prédisposição para Inovar (Apêndice 12). Curiosamente, estes respondentes apresentaram maior discordância em relação ao apoio e comprometimento percebido da alta administração com o e-learning e com a efetividade das campanhas de comunicação do $e$-learning.

Já os respondentes com cargos operacionais apresentaram maior concordância com as variáveis do fator Desconfiança em Relação à Inovação. Essa pode ser uma das explicações para este grupo ter menos respondentes que participaram de cursos de e-learning na plataforma da empresa (56\%), se comparado aos respondentes de cargo gerencial (62\%). 
Para análise de possíveis diferenças em relação às áreas funcionais, foram criados três grupos: Comercial (áreas de Negócio), representando 28\% dos respondentes; Técnica (áreas de Tecnologia da Informação e Engenharia), representando 57\% dos respondentes; e Apoio (áreas de Finanças, Recursos Humanos, Presidência e Estratégia), representando 15\% dos respondentes. Desta forma, o Teste de Kruskal-Wallis foi realizado para analisar diferenças com nível de significância de 0,05 .

Os resultados indicam uma tendência de maior concordância por parte dos respondentes provenientes das áreas Técnicas em 1 variável do fator Utilidade Percebida, em 6 variáveis do fator Ambiente Propício à Inovação, em 3 variáveis do fator Facilidade de Uso Percebida e em 2 variáveis do fator Desconfiança em Relação à Inovação (Apêndice 13).

\subsection{Identificar as variáveis que melhor explicam a intenção de realizar ou não cursos de e-learning na empresa}

Hipótese 4.1 - $\boldsymbol{H}_{0}$ : O fator Utilidade Percebida não influencia a Intenção de Uso do e-learning.

Hipótese 4.2 - $\boldsymbol{H}_{0}$ : O fator Ambiente Propício à Aprendizagem não influencia a Intenção de Uso do e-learning.

Hipótese 4.3 - $\boldsymbol{H}_{0}$ : O fator Facilidade de Uso Percebida não influencia a Intenção de Uso do e-learning.

Hipótese 4.4 - $\boldsymbol{H}_{0}$ : O fator Habilidade com Informática e Pré-disposição para Inovar não influencia a Intenção de Uso do e-learning.

Hipótese 4.5 - $\boldsymbol{H}_{0}$ : O fator Desconfiança em Relação à Inovação não influencia a Intenção de Uso do elearning.

Para consecução desse objetivo, foi utilizada a Regressão Logística (RL), técnica estatística multivariada utilizada na previsão ou explicação das relações que impactam uma variável dependente não numérica (HAIR et al, 1998, p. 240) e dicotômica, conforme já mencionado no capítulo sobre metodologia da pesquisa.

Diante de uma resposta dicotômica para a questão "Você tem intenção de participar em 2007 de algum curso de e-learning na plataforma da empresa?", buscou-se um modelo que relacione a intenção de participar no curso de e-learning, com um conjunto de variáveis (fatores) explicativas. 
Para condução da análise, os fatores foram estimados segundo a média ponderada das variáveis originais, considerando os pesos como as cargas fatoriais (acima de 0,60). $\mathrm{O}$ resultado é apresentado na Tabela 22.

Tabela 22 - Variáveis do Modelo Intenção de Uso do e-Learning

\begin{tabular}{lrrrrr}
\hline \multicolumn{1}{c}{ Fator } & $\begin{array}{c}\text { Coeficiente } \\
\text { (B) }\end{array}$ & $\begin{array}{c}\text { Erro } \\
\text { Padrão }\end{array}$ & $\begin{array}{c}\text { Estatística } \\
\text { Wald }\end{array}$ & \multicolumn{1}{c}{ p } & Exp(B) \\
\hline FATOR 1 - Utilidade Percebida & 1,418 & 0,256 & 30,576 & 0,000 & 4,129 \\
\hline $\begin{array}{l}\text { FATOR 2- Ambiente Propício à } \\
\text { Aprendizagem }\end{array}$ & 0,383 & 0,188 & 4,150 & 0,042 & 1,467 \\
\hline FATOR 3 - Facilidade de Uso Percebida & 0,336 & 0,208 & 2,602 & 0,107 & 1,400 \\
\hline $\begin{array}{l}\text { FATOR 4 - Habilidade com Informática \& } \\
\text { Pré-disposição para Inovar }\end{array}$ & $-0,200$ & 0,233 & 0,738 & 0,390 & 0,819 \\
\hline $\begin{array}{l}\text { FATOR 5 - Desconfiança em Relação à } \\
\text { Inovação }\end{array}$ & 0,114 & 0,249 & 0,211 & 0,646 & 1,121 \\
\hline Constante & $-7,717$ & 2,061 & 14,017 & 0,000 & 0,000 \\
\hline
\end{tabular}

Ao testar a significância de cada coeficiente, apenas o coeficiente do Fator 1 (Utilidade Percebida) e do Fator 2 (Ambiente Propício à Aprendizagem) são significativamente diferente de zero $(\alpha=0,05)$. Assim, a Tabela 23 apresenta o modelo ajustado, considerando apenas esses dois fatores.

Tabela 23 - Variáveis do Modelo Ajustado Intenção de Uso do e-Learning (*)

\begin{tabular}{lccccc}
\hline \multicolumn{1}{c}{ Fator } & $\begin{array}{c}\text { Coeficiente } \\
\text { (B) }\end{array}$ & $\begin{array}{c}\text { Erro } \\
\text { Padrão }\end{array}$ & $\begin{array}{c}\text { Estatística } \\
\text { Wald }\end{array}$ & p & Exp(B) \\
\hline FATOR 1 - Utilidade Percebida & 1,476 & 0,251 & 34,673 & & \\
\hline FATOR 2 - Ambiente Propício à Aprendizagem & 0,503 & 0,174 & 8,328 & 0,004 & 1,653 \\
\hline Constante & $-7,510$ & 1,297 & 33,530 & 0,000 & 0,001 \\
\hline
\end{tabular}

Com base nos resultados, é apresentado abaixo o modelo ajustado da Intenção de Uso do $e$ Learning:

Probabilidade (Intenção de Uso do e-Learning $)=1 /(1+\exp (-\mathrm{z}))$

Onde $\mathrm{z}=-7,510+1,476$ (Utilidade Percebida) + 0,503 (Ambiente Propício à Aprendizagem)

Observa-se que os fatores Utilidade Percebida e Ambiente Propício à Aprendizagem influenciam positivamente a Intenção (probabilidade) de Uso do e-Learning. Ou seja, quando 
a concordância frente ao aspecto Utilidade Percebida aumenta em 1 ponto (na escala de 7 pontos utilizada), a chance do respondente ter intenção de participar do e-learning praticamente aumenta em 4,4 vezes, o que indica relevância desse fator. Além disso, o aumento de 1 ponto na concordância frente ao fator Ambiente Propício à Aprendizagem, aumenta em 1,7 vezes a probabilidade da intenção em participar do curso.

Este modelo tem nível de acerto de 90,7\% dos casos; $98,5 \%$ de acerto entre os respondentes que têm intenção de participar do e-learning em 2007 e 40,5\% de acerto entre os que não têm esta intenção (Tabela 24).

Tabela 24 - Nível de Acerto do Modelo Ajustado Intenção de Uso do e-Learning

\begin{tabular}{|c|c|c|c|c|}
\hline \multirow[b]{3}{*}{ Observado } & & \multicolumn{3}{|c|}{ Previsto } \\
\hline & & \multicolumn{2}{|c|}{$\begin{array}{l}\text { Você planeja realizar cursos na } \\
\text { Plataforma de e-eLearning da empresa } \\
\text { no } 2^{\circ} \text { Semestre de } 2007 \text { (em 2007)? }\end{array}$} & \multirow[t]{2}{*}{$\begin{array}{c}\text { Percentagem } \\
\text { Correta }\end{array}$} \\
\hline & & Não & Sim & \\
\hline \multirow{2}{*}{$\begin{array}{l}\text { Você planeja realizar cursos na } \\
\text { Plataforma de e-eLearning da empresa } \\
\text { no } 2^{\circ} \text { Semestre de } 2007 \text { (em 2007)? }\end{array}$} & Não & 17 & 25 & 40,5 \\
\hline & Sim & 4 & 266 & 98,5 \\
\hline Percentagem & & & & 90,7 \\
\hline
\end{tabular}

Explicando o resultado da regressão logística, a Tabela 25 apresenta o teste $t$-Student de comparação de médias para duas amostras independentes. Observa-se que apenas as médias dos escores fatoriais referentes ao fator Utilidade Percebida e ao fator Ambiente Propício à Aprendizagem são significativamente diferentes $(p=0,000 \mathrm{em}$ ambos os casos). Em ambos os fatores, as médias de concordância dos respondentes que não têm intenção de realizar cursos de e-learning em 2007 é descritivamente inferior à média dos que têm intenção de realizar; ou seja, conforme observado no modelo, estes dois fatores contribuem positivamente para aumentar a probabilidade de intenção em participar do e-learning. 
Tabela 25 - Teste t-Student para Intenção de Uso do e-Learning

\begin{tabular}{|c|c|c|c|c|c|}
\hline & \multicolumn{4}{|c|}{$\begin{array}{l}\text { Você planeja realizar cursos na Plataforma de e- } \\
\text { eLearning da empresa no } 2^{\circ} \text { Semestre de } 2007 \text { (em 2007)? }\end{array}$} & \multirow{3}{*}{$\mathbf{p}$} \\
\hline & \multicolumn{2}{|c|}{ Média } & \multicolumn{2}{|c|}{ Desvio-Padrão } & \\
\hline & Não & Sim & Não & Sim & \\
\hline Utilidade Percebida & $-1,269$ & 0,196 & 1,310 & 0,776 & 0,000 \\
\hline $\begin{array}{l}\text { Ambiente Propício à } \\
\text { Aprendizagem }\end{array}$ & $-0,500$ & 0,075 & 1,062 & 0,970 & 0,000 \\
\hline Facilidade de Uso Percebida & $-0,390$ & 0,058 & 1,412 & 0,910 & 0,052 \\
\hline $\begin{array}{l}\text { Habilidade com Informática e } \\
\text { Pré-disposição para Inovar }\end{array}$ & 0,158 & $-0,025$ & 0,992 & 1,004 & 0,273 \\
\hline $\begin{array}{l}\text { Desconfiança em Relação à } \\
\text { Inovação }\end{array}$ & $-0,238$ & 0,040 & 0,928 & 1,007 & 0,094 \\
\hline
\end{tabular}

O resultado da análise logística obtido rejetia a Hipótese 4.1 deste estudo, corroborando pesquisas anteriores que constataram a influência da Utilidade Percebida na Intenção de Uso do e-Learning. De acordo com Ong et al, "Baseado no efeito direto na intenção do comportamento de uso, utilidade percebida foi identificada como o fator mais significando afetando a aceitação do e-learning."156 (2004, p. 801); resultado também encontrado por outros autores (LEE, 2006; GONG et al, 2004; SELIM, 2003) e coerente com as premissas do Modelo TAM (DAVIS et al, 1989; VENKATESH; DAVIS, 2000).

A Hipótese 4.2 também é rejeitada, com base na influência positiva observada do fator Ambiente Propício à Aprendizagem na Intenção de Uso do e-Learning. Esse resultado é coerente com a literatura de e-learning, que aponta a importância de aspectos como o apoio do superior imediato, o patrocínio da alta administração, a cultura organizacional na adoção do e-learning (ROSENBERG, 2000; TYAN, 2003; ECONOMIST INTELLIGENCE UNIT; IBM, 2003; BOROTIS; POULYMENAKOU, 2004; VAN DAM, 2004; PSYCHARIS, 2005).

Por outro lado, os resultados não indicam uma influência significativa da Facilidade de Uso Percebida na Intenção de Uso do e-Learning; ou seja, esse fator não foi relevante na explicação da intenção de uso do e-learning apresentada pelos respondentes. Desta forma, os resultados confirmam a Hipótese 4.3, divergindo do observado em pesquisas anteriores sobre

\footnotetext{
156 "Judged by its direct effect on behavioral intention to use, perceived usefulness was found to be the most significant factor affecting users' acceptance of e-learning.”
} 
adoção do e-learning (MARTINS; KELLERMANNS, 2004; GONG et al, 2004; ONG et al, 2004; SELIM, 2003).

Uma possível explicação para este resultado se refere ao negócio da empresa pesquisada, relacionado ao setor das Telecomunicações. Ou seja, é possível que, para os colaboradores dessa empresa na qual o negócio é tecnologia, a percepção em relação à facilidade de uso do e-learning não seja tão relevante na intenção de adotar, quanto observado entre professores e alunos das universidades pesquisadas em estudos anteriores (MARTINS; KELLERMANNS, 2004; GONG et al, 2004; SELIM, 2003).

Por fim, o fator Habilidade com Informática e Pré-disposição para Inovar e o fator Desconfiança em Relação à Inovação também não parecem ter influência relevante na intenção de uso do e-learning pelos colaboradores da empresa pesquisada, confirmando as Hipóteses 4.4 e 4.5. Apesar da importância desses fatores apontada na literatura de e-learning (ROSENBERG, 2006; VAN DAM, 2004; LEE, 2006; GONG et al, 2004; ONG et al, 2004), estes fatores são extensões do Modelo TAM e não são pesquisados com a mesma freqüência que os constructos Utilidade, Facilidade de Uso e Intenção de Uso, como é o caso das pesquisas de Selim (2003), Gabbard (2004) e Ignatius e Ramayah (2005).

Conforme apontado por Fusilier e Durlabhji (2005, p. 243), diferenças nas relações entre as variáveis também podem ser explicadas por particularidades da tecnologia em análise, por questões de infra-estrutura e acesso à tecnologia e por aspectos culturais.

A Figura 27, abaixo, representa graficamente o Modelo Ajustado Intenção de Uso do $e$ Learning, que influencia a intenção de uso do e-learning pelos colaboradores da empresa pesquisada.

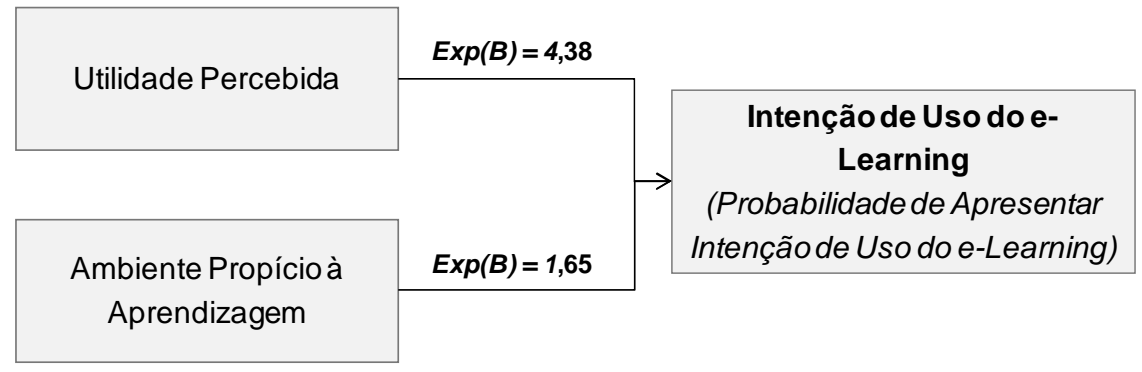

Figura 27 - Representação Gráfica do Modelo Ajustado Intenção de Uso do e-Learning 


\subsection{Identificar as variáveis que melhor explicam a realização ou não de cursos de e-learning na empresa, desde 2006}

Hipótese 5.1 - Ho: $_{0}$ O fator Utilidade Percebida não influencia o Comportamento de Uso do e-learning.

Hipótese 5.2 - $\boldsymbol{H}_{0}$ : O fator Ambiente Propício à Aprendizagem não influencia o Comportamento de Uso do elearning.

Hipótese 5.3 - $\boldsymbol{H}_{0}$ : O fator Facilidade de Uso Percebida não influencia o Comportamento de Uso do e-learning.

Hipótese 5.4 - $\boldsymbol{H}_{0}$ : O fator Habilidade com Informática e Pré-disposição para Inovar não influencia o Comportamento de Uso do e-learning.

Hipótese 5.5 - $\boldsymbol{H}_{0}$ : O fator Desconfiança em Relação à Inovação não influencia o Comportamento de Uso do elearning.

Complementando a análise dos dados, a regressão logística foi conduzida na tentativa de se obter um modelo que relacione o Comportamento de Uso do e-Learning (variável dependente) com um conjunto de variáveis (fatores) explicativas. A variável dependente utilizada se refere à questão: "Você já participou de algum curso da Plataforma de e-learning da empresa, desde 2006?"; ou seja, um comportamento relatado pelo respondente, uma vez que não foi possível obter confirmação de todas as participações através dos relatórios da plataforma de e-learning da empresa. Essa análise complementará os resultados encontrados no segundo objetivo específico, indicando diferenças importantes de percepção entre os respondentes que realizaram e não realizaram cursos de e-learning.

Da mesma forma que na análise do tópico anterior, os fatores foram construídos segundo a média ponderada das variáveis originais, considerando os pesos como as cargas fatoriais (acima de 0,60). A Tabela 26 apresenta os resultados da regressão logística.

Tabela 26 - Variáveis do Modelo Comportamento de Uso do e-Learning

\begin{tabular}{lrrrrr}
\hline \multicolumn{1}{c}{ Fator } & $\begin{array}{c}\text { Coeficiente } \\
\text { (B) }\end{array}$ & $\begin{array}{c}\text { Erro } \\
\text { Padrão }\end{array}$ & $\begin{array}{c}\text { Estatística } \\
\text { Wald }\end{array}$ & \multicolumn{1}{c}{ p } & Exp(B) \\
\hline FATOR 1 - Utilidade Percebida & $-0,890$ & 0,181 & 24,069 & 0,000 & 0,411 \\
\hline FATOR 2- Ambiente Propício à Aprendizagem & 0,291 & 0,120 & 5,863 & 0,015 & 1,337 \\
\hline FATOR 3 - Facilidade de Uso Percebida & 0,795 & 0,166 & 23,020 & 0,000 & 2,214 \\
\hline $\begin{array}{l}\text { FATOR 4 - Habilidade com Informática \& Pré- } \\
\text { disposição para Inovar }\end{array}$ & 0,380 & 0,145 & 6,925 & 0,009 & 1,463 \\
\hline $\begin{array}{l}\text { FATOR 5 - Desconfiança em Relação à } \\
\text { Inovação }\end{array}$ & $-0,074$ & 0,140 & 0,283 & 0,595 & 0,928 \\
\hline Constante & $-1,709$ & 1,101 & 2,409 & 0,121 & 0,181 \\
\hline
\end{tabular}


Ao testar a significância de cada coeficiente, apenas o coeficiente do Fator 5 (Desconfiança em Relação à Inovação) não é significativamente diferente de zero $(\alpha=0,05)$. Ao retirar este fator da análise, obtêm-se o modelo ajustado do Comportamento de Uso do e-Learning (Tabela 27).

Tabela 27 - Variáveis do Modelo Ajustado Comportamento de Uso do e-Learning

\begin{tabular}{lrrrrr}
\hline \multicolumn{1}{c}{ Fator } & $\begin{array}{c}\text { Coeficiente } \\
\text { (B) }\end{array}$ & $\begin{array}{c}\text { Erro } \\
\text { Padrão }\end{array}$ & $\begin{array}{c}\text { Estatística } \\
\text { Wald }\end{array}$ & p & Exp(B) \\
\hline FATOR 1 - Utilidade Percebida & $-0,894$ & 0,181 & 24,296 & 0,000 & 0,409 \\
\hline FATOR 2- Ambiente Propício à Aprendizagem & 0,277 & 0,117 & 5,608 & 0,018 & 1,320 \\
\hline FATOR 3 - Facilidade de Uso Percebida & 0,800 & 0,166 & 23,303 & 0,000 & 2,225 \\
\hline $\begin{array}{l}\text { FATOR 4 - Habilidade com Informática \& Pré- } \\
\text { disposição para Inovar }\end{array}$ & 0,375 & 0,144 & 6,752 & 0,009 & 1,454 \\
\hline Constante & $-1,946$ & 1,012 & 3,693 & 0,055 & 0,143 \\
\hline
\end{tabular}

Com base nos resultados, é apresentado abaixo o modelo ajustado do Comportamento de Uso do e-Learning:

Probabilidade (participação do e-learning $)=1 /(1+\exp (-z))$

Onde $\mathrm{z}=-1,946-0,894$ (Utilidade Percebida) + 0,277 (Ambiente Propício à Aprendizagem $)+0,800$ (Facilidade de Uso Percebida) + 0,375 (Habilidade com Informática \& Pré-disposição para Inovar)

Os resultados da regressão resultaram nos seguintes fatores explicativos da realização de curso de e-learning na plataforma da empresa, por ordem de importância:

1. Facilidade de Uso Percebida (influência positiva)

2. Habilidade com Informática e Pré-disposição para Inovar (influência positiva)

3. Ambiente Propício à Aprendizagem (influência positiva)

4. Utilidade Percebida (influência negativa)

O modelo encontrado indica que, quando a concordância frente ao aspecto Facilidade de Uso Percebida aumenta 1 ponto (na escala de 7 pontos utilizada), a chance do respondente ter participado do e-learning aumenta em 2,2 vezes. Se o respondente aumenta em 1 ponto sua concordância em relação à Habilidade com Informática e Pré-disposição para Inovar, a chance 
de ter participado do e-learning aumenta em 1,5 vezes. Seguindo a mesma tendência, se o respondente aumenta sua concordância com o fator Ambiente Propício à Aprendizagem em 1 ponto, a probabilidade de ter participado do e-learning aumenta 1,3 vezes. Porém, o aumento de 1 ponto na concordância com o fator Utilidade Percebida, reduz a chance do respondente ter participado do e-learning em 0,41 vezes.

De acordo com o modelo estimado, $216(70+146)$ dos 309 casos tiveram sua classificação correta, resultando em $69,9 \%$ de acerto (Tabela 28); sendo que a grande parcela de acerto se refere aos respondentes que participaram do e-learning $(81,1 \%)$ e, no caso dos que não participaram, o acerto é relativamente baixo $(54,3 \%)$.

Tabela 28 - Nível de Acerto do Modelo Ajustado Comportamento de Uso do e-Learning

\begin{tabular}{|c|c|c|c|c|}
\hline \multirow[b]{3}{*}{ Observado } & & \multicolumn{3}{|c|}{ Previsto } \\
\hline & & \multicolumn{2}{|c|}{$\begin{array}{c}\text { Você já participou de algum curso da } \\
\text { Plataforma de e-learning da empresa, } \\
\text { desde 2006? }\end{array}$} & \multirow[t]{2}{*}{$\begin{array}{l}\text { Percentagem } \\
\text { Correta }\end{array}$} \\
\hline & & Não & Sim & \\
\hline \multirow{2}{*}{$\begin{array}{l}\text { Você já participou de algum curso da } \\
\text { Plataforma de e-learning da empresa, desde } \\
2006 ?\end{array}$} & Não & 70 & 59 & 54,3 \\
\hline & Sim & 34 & 146 & 81,1 \\
\hline Percentagem & & & & 69,9 \\
\hline
\end{tabular}

Complementando os resultados da regressão logística, a Tabela 29 apresenta o teste $t$-Student de comparação de médias para duas amostras independentes, considerando o Comportamento de Uso do e-Learning relatado pelo respondente da pesquisa (dados já apresentados na Tabela 21).

Tabela 29 - Teste t-Student para Comportamento de Uso do e-Learning

\begin{tabular}{|c|c|c|c|c|c|}
\hline & \multicolumn{4}{|c|}{$\begin{array}{c}\text { Você já participou de algum curso da Plataforma de } e \text { - } \\
\text { learning da empresa, desde 2006? }\end{array}$} & \multirow{3}{*}{$\mathbf{P}$} \\
\hline & \multicolumn{2}{|c|}{ Média } & \multicolumn{2}{|c|}{ Desvio-Padrão } & \\
\hline & Não & Sim & Não & Sim & \\
\hline Utilidade Percebida & 0,119 & $-0,091$ & 0,950 & 1,031 & 0,072 \\
\hline $\begin{array}{l}\text { Ambiente Propício à } \\
\text { Aprendizagem }\end{array}$ & $-0,223$ & 0,151 & 0,935 & 1,020 & 0,001 \\
\hline Facilidade de Uso Percebida & $-0,405$ & 0,280 & 0,994 & 0,909 & 0 \\
\hline $\begin{array}{l}\text { Habilidade com Informática e } \\
\text { Pré-disposição para Inovar }\end{array}$ & $-0,167$ & 0,118 & 1,074 & 0,934 & 0,017 \\
\hline $\begin{array}{l}\text { Desconfiança em Relação à } \\
\text { Inovação }\end{array}$ & 0,047 & $-0,031$ & 1,019 & 0,987 & 0,501 \\
\hline
\end{tabular}


Diferentemente da análise em relação à intenção de uso, o fator Utilidade Percebida apresentou uma influência negativa no comportamento de uso do e-learning, resultando na rejeição da Hipótese 5.1. Esta tendência está resumida na Tabela 19, já apresentada anteriormente, que confirma a diferença entre as médias $(p=0,072)$, sendo que a média de não participantes é inferior à média dos participantes. Ou seja, Utilidade é considerado um fator que têm efeito negativo no que se refere à participação na plataforma de e-learning da empresa. Esse resultado confirma o maior nível de discordância dos respondentes que realizaram cursos de $e$-learning na plataforma da empresa em relação a esse fator, observado nas análises dos tópicos anteriores; aspecto que pode ser explicado pela frustração do usuário com a tecnologia (DAVIS, 1989; SHIH; VENKATESH, 2004; MUKHERJEE; HOYER, 2001), conforme já discutido.

Já o fator Ambiente Propício à Aprendizagem demonstrou ter impacto relevante tanto na intenção quanto no comportamento de uso, apresentando influência positiva em ambos os casos. Este resultado leva à rejeição da Hipótese 5.2 e reforça a importância do ambiente corporativo na adoção do e-learning, com destaque para o apoio do superior imediato, patrocínio da alta administração, influência dos colegas e cultura organizacional, conforme apontado na literatura de e-learning (ROSENBERG, 2000; TYAN, 2003; ECONOMIST INTELLIGENCE UNIT; IBM, 2003; BOROTIS; POULYMENAKOU, 2004; MACPHERSON et al, 2004; VAN DAM, 2004; PSYCHARIS, 2005; CHANG, 2005) e na literatura sobre adoção de inovações (VENKATESH; DAVIS, 2000; SCHILLEWAERT et al, 2000; MARTINS; KELLERMANNS, 2004; FUSILIER; DURLABHJI, 2005).

A Facilidade de Uso Percebida é o fator com maior influência no Comportamento de Uso do e-Learning dos respondentes, levando à rejeição da Hipótese 5.3; diferentemente da análise anterior, em que esse fator não apresentou influência na intenção de uso. Este resultado reforça os comentários de alguns respondentes sobre as dificuldades encontradas no acesso à plataforma de e-learning e pesquisas anteriores que apontaram para a importância da Facilidade de Uso na adoção do e-learning (MARTINS; KELLERMANNS, 2004; GONG et al, 2004; ONG et al, 2004; SELIM, 2003). 
Da mesma forma que observado no caso da Facilidade de Uso, o fator Habilidade com Informática \& Pré-disposição para Inovar também apresentou um influência positiva no comportamento de uso do e-learning, levando à rejeição da Hipótese 5.4 e corroborando pesquisas anteriores (LEE, 2006; GONG et al, 2004; ONG et al, 2004; SCHILLEWAERT et al, 2000), embora não tenha sido verificada influência na intenção de uso.

Por fim, a Hipótese 5.5 não é rejeitada, uma vez que, de acordo com o modelo, o fator Desconfiança em Relação à Inovação não influencia o comportamento de uso do e-learning. De acordo com a Tabela 29, observa-se que o fator Desconfiança em Relação à Inovação é o único cujas médias não diferem entre os respondentes que participaram e que não participaram do e-learning $(\mathrm{p}=0,501)$. Apesar disso, a média dos respondentes que não participaram do e-learning apresenta um tendência de maior concordância em relação a uma atitude de desconfiança, conforme seria de se esperar (KAMEL; HASSAN, 2003; LIPPERT; FORMAN, 2006; ONG et al, 2004).

A Figura 28, abaixo, representa graficamente o Modelo Ajustado Comportamento de Uso do e-Learning, que explica o comportamento de uso do e-learning pelos colaboradores da empresa pesquisada. Ou seja, o modelo proposto se refere à explicação de um comportamento de uso passado (desde 2006), sendo as percepções coletas em 2007 são influenciadas por esse comportamento.

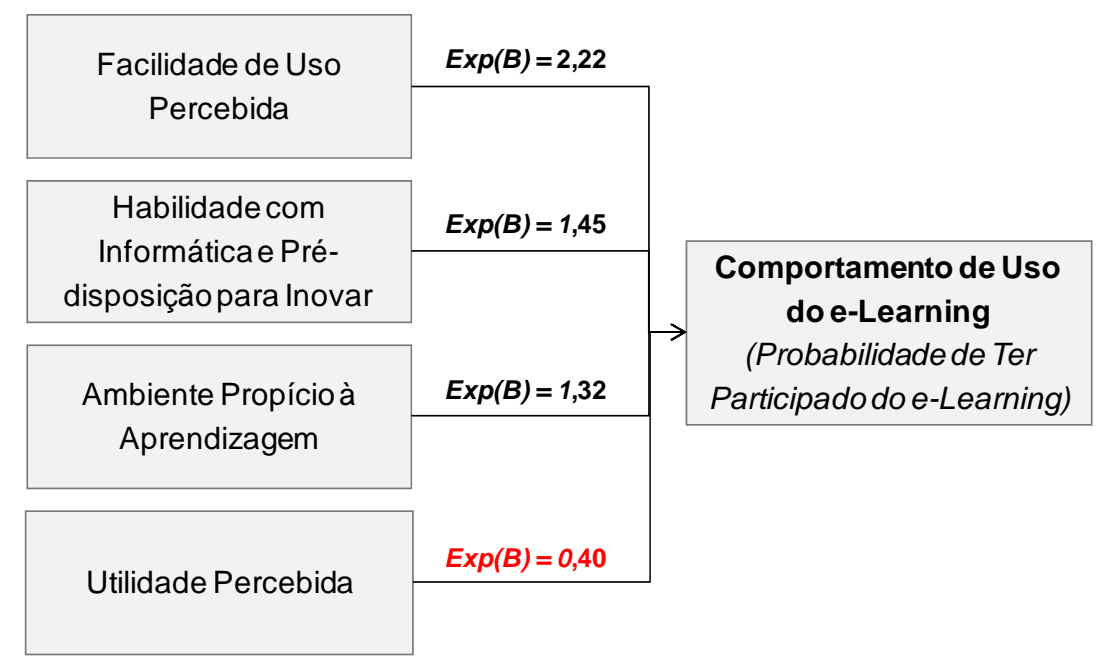

Figura 28 - Representação Gráfica do Modelo Ajustado Comportamento de Uso do e-Learning 
Complementando, os resultados sugerem que ao analisar um modelo preditivo do comportamento de uso do e-learning, uma possível influência negativa da Utilidade Percebida pode ser melhor compreendida como uma conseqüência do comportamento de uso, uma vez que, em termos lógicos, uma diminuição na percepção de utilidade não levaria à adoção.

Desta forma, a presença de usuários com experiência anterior da tecnologia pesquisada deve ser levada em consideração na aplicação do modelo. De acordo com Gabbard, "Conforme mais e mais estudantes ganham experiência com cursos on-line a utilidade do TAM em prever o comportamento de uso deve diminuir." ${ }^{\prime 157}$ (2004, p. 89). Apesar disso, na pesquisa realizada pelo autor (GABBARD, 2004), não foi observada variação da concordância do conjunto das variáveis TAM em função do tempo, considerando que o questionário foi aplicado em três momentos diferentes durante o semestre de realização do curso on-line.

Por outro lado, Gong et al (2004) ao disponibilizarem o sistema de e-learning para uso pelos alunos um mês antes da aplicação dos questionários, concluíram que a "Experiência pode mudar os determinantes do processo de decisão deles"158. (GONG et al, 2004, p. 371). Como resultado, os respondentes tiveram uma percepção mais correta em relação aos benefícios que poderiam ser obtidos com o uso do sistema.

\subsection{Consolidação da Análise de Resultados}

O objetivo geral proposto para este trabalho foi atingido, uma vez que, através da pesquisa bibliográfica e empírica, foi possível analisar em profundidade os fatores que influenciam a adoção individual do e-learning na empresa pesquisada. Os quadros a seguir, apresentam os principais resultados, por objetivo específico da pesquisa.

\footnotetext{
157 "As more and more students gain experience with online courses the usefulness of TAM in predicting user behaviors may decrease."

158 "Experience might change the determinants in their decision making process."
} 
Quadro 17 - Objetivo Específico 1: Comparar os fatores propostos no modelo conceitual com aqueles observados na empresa estudada, identificando aprimoramentos no Modelo de Adoção Individual do $e$ Learning

\begin{tabular}{|c|c|}
\hline Resultado & Explicação \\
\hline $\begin{array}{l}\text { Confirmação das variáveis do constructo } \\
\text { Utilidade Percebida }\end{array}$ & $\begin{array}{l}\text { - Corrobora pesquisas anteriores VENKATESH; DAVIS, } \\
\text { 2000; SCHILLEWAERT et al, 2000; VENKATESH et } \\
\text { al, 2003; SILVA, 2005; OLIVEIRA, 2006 } \\
\text { - Confirma inclusão da variável sobre flexibilidade para } \\
\text { aprender }\end{array}$ \\
\hline $\begin{array}{l}\text { As variáveis aumento nas chances de } \\
\text { promoção e facilidade em explicar os } \\
\text { benefícios integraram outros fatores } \\
\text { (Ambiente Propício à Aprendizagem e } \\
\text { Facilidade de Uso Percebida) }\end{array}$ & $\begin{array}{ll}\text { - } & \text { Diferenças culturais (VEIGA et al, 2001) } \\
\text { - } & \text { Adaptação das variáveis para o e-learning } \\
\text { - } & \text { Tradução do questionário para o português }\end{array}$ \\
\hline $\begin{array}{l}\text { As variáveis da dimensão Atitude em } \\
\text { Relação ao e-Learning foram explicadas } \\
\text { pelo Fator Utilidade Percebida }\end{array}$ & $\begin{array}{l}\text { - Relação positiva entre Utilidade e Atitude identificada em } \\
\text { pesquisas anteriores (DAVIS et al, 1989; GONG et al, } \\
\text { 2004; MARTINS; KELLERMANNS, 2004) } \\
\text { - Constructo Atitude foi excluído em algumas pesquisas } \\
\text { (VENKATESH; DAVIS, 2000; VENKATESH et al, } \\
\text { 2003; ONG et al, 2004). }\end{array}$ \\
\hline
\end{tabular}

As variáveis do Alinhamento com Requisitos do Negócio foram explicadas pelo Fator Utilidade Percebida

A dimensão Influência Social passou a compor o fator Ambiente Propício à Aprendizagem, em conjunto com as variáveis do Apoio da Alta Administração e do Favorecimento da Cultura Organizacional

Confirmação das variáveis do constructo Facilidade de Uso Percebida

A maioria das variáveis da Adequação do Projeto de e-Learning foram incorporadas ao fator Facilidade de Uso Percebida
- Dimensão Requisitos do negócio são aspectos de sucesso do e-learning (ROSENBERG; 2000; TYAN; 2003; BOROTIS; POULYMENAKOU; 2004)

- As variáveis podem ser relacionadas ao ambiente propício à aprendizagem, que considera tempo, espaço e pessoas (FLEURY, 1997)

- Corrobora pesquisas anteriores (VENKATESH; DAVIS, 2000; SCHILLEWAERT et al, 2000; VENKATESH et al, 2003; MARTINS; KELLERMANNS, 2004; SILVA, 2005; OLIVEIRA, 2006; COSTA FILHO et al, 2007)

- Variáveis baseadas nas condições facilitadoras que se observou na literatura de adoção individual de inovações (DAVIS et al, 1989; ROGERS, 1995; SCHILLEWAERT et al, 2000; VENKATESH et al, 2003; MARTINS; KELLERMANNS, 2004) e na literatura de e-learning (ROSENBERG, 2000; VAN DAM, 2004).

Parte das variáveis da Auto-eficácia com Computadores e Pré-disposição para Inovar foram explicadas pelo fator Habilidade com Informática \& Pré-disposição para Inovar
- Habilidade com Informática corrobora pesquisas anteriores de aceitação e implementação do e-learning (GONG et al, 2004; MARTINS; KELLERMANNS, 2004; ONG et al, 2004; LEE, 2006; ROSENBERG, 2000; TYAN, 2003)

- Pré-disposição para inovar corrobora pesquisas anteriores (ROGERS , 1995; SCHILLEWAERT et al, 2000)

Parte das variáveis da Auto-eficácia com Computadores e Pré-disposição para Inovar foram explicadas pelo fator Desconfiança em Relação à Inovação
- Resultado divergente do esperado, referente à autoeficácia com computadores e pré-disposição para inovar (SCHILLEWAERT et al, 2000)

- Baseado em pesquisas sobre desconfiança em relação à novas tecnologias e à inovação (ROGERS, 1995; LIPPERT; FORMAN, 2006)

Observações: Parte das variáveis externas foi incorporadas aos constructos do Modelo TAM. 
Quadro 18 - Objetivo Específico 2: Analisar as diferenças de percepção entre os colaboradores que realizaram e que não realizaram curso de e-learning na empresa, desde 2006.

\begin{tabular}{|c|c|c|}
\hline Hipóteses & Resultado & Explicação \\
\hline \multirow{3}{*}{$\begin{array}{l}1.1 \text { - } H_{0} \text { : Mesmo grau de } \\
\text { concordância entre os } \\
\text { respondentes que } \\
\text { participaram do } e \text { - } \\
\text { learning e os que não } \\
\text { participaram em relação à } \\
\text { Utilidade Percebida do } \\
\text { e-learning }\end{array}$} & $\begin{array}{l}\text { Hipótese rejeitada, há diferença } \\
\text { significativa em } 7 \text { das } 10 \text { variáveis, não } \\
\text { seguindo a mesma tendência: }\end{array}$ & - \\
\hline & $\begin{array}{l}\text { - Em } 5 \text { variáveis os respondentes que } \\
\text { realizaram curso apresentam maior } \\
\text { concordância }\end{array}$ & $\begin{array}{l}\text { Corrobora pesquisas anteriores utilizadas como base conceitual } \\
\text { - Influência da utilidade na adoção }\end{array}$ \\
\hline & $\begin{array}{l}\text { - Em } 2 \text { variáveis respondentes que } \\
\text { realizaram curso apresentam maior } \\
\text { discordância (tendência também } \\
\text { observada em outras } 3 \text { variáveis, mas } \\
\text { sem diferença significativa) }\end{array}$ & $\begin{array}{l}\text { Frustração em relação à tecnologia (DAVIS, 1989; SHIH; VENKATESH, 2004; } \\
\text { MUKHERJEE; HOYER, 2001) } \\
\text { - } \quad \text { Limitações do e-learning (VASCONCELLOS-JACOBSOHN; FLEURY, 2004; TYAN, } \\
\text { 2003; DOWNES, 2003; HARA; KLING, 1999) } \\
\text { - Competências e estilo de aprendizagem dos participantes (VASCONCELLOS- } \\
\text { JACOBSOHN, 2003) } \\
\text { Frustração em relação ao projeto de e-learning da empresa } \\
\text { - Conteúdo dos cursos disponíveis (VAN DAM, 2004; LEE, 2006; ONG; LAI, 2006) e } \\
\text { atendimento às necessidades do colaborador (ANGEHRN et al, 2001) } \\
\text { - Metodologia interativa (TESTA, 2002; ANGEHRN et al, 2001; SELIM, 2003; } \\
\text { GABBARD, 2004) e blended learning (ECONOMIST INTELLIGENCE UNIT; IBM, } \\
\text { 2003; VAN DAM, 2004) } \\
\text { Desafio de concretizar o potencial do e-learning e gerar contribuições para o negócio } \\
\text { (ANGEHRN et al, 2001), foco do projeto da empresa }\end{array}$ \\
\hline
\end{tabular}


Quadro 18 - Objetivo Específico 2: Analisar as diferenças de percepção entre os colaboradores que realizaram e que não realizaram curso de e-learning na empresa, desde 2006.

\begin{tabular}{|c|c|c|}
\hline Hipóteses & Resultado & Explicação \\
\hline $\begin{array}{l}1.2 \text { - } \boldsymbol{H}_{0} \text { : Mesmo grau de } \\
\text { concordância entre os } \\
\text { respondentes que } \\
\text { participaram do } e^{-} \\
\text {learning e os que não } \\
\text { participaram em relação à } \\
\text { percepção do Ambiente } \\
\text { Propício à } \\
\text { Aprendizagem }\end{array}$ & $\begin{array}{l}\text { Hipótese rejeitada, há diferença } \\
\text { significativa em } 8 \text { das } 10 \text { variáveis: } \\
\text { tendência dos respondentes que } \\
\text { realizaram curso apresentarem maior } \\
\text { concordância }\end{array}$ & $\begin{array}{l}\text { Corrobora pesquisas anteriores utilizadas como base conceitual } \\
\text { - } \quad \text { Importância do apoio da Liderança (ROSENBERG, 2000; MACPHERSON et al, 2004; } \\
\text { CHANG, 2005) } \\
\text { - Cultura Organizacional (ROSENBERG, 2000; TYAN, 2003; ECONOMIST } \\
\text { INTELLIGENCE UNIT; IBM, 2003; BOROTIS; POULYMENAKOU, 2004; VAN } \\
\text { DAM, 2004; PSYCHARIS, 2005) } \\
\text { - } \quad \text { Falta de tempo (motivo de não participação): } \\
\text { Participação durante o horário de trabalho (BOROTIS; POULYMENAKOU, 2007; VAN } \\
\text { DAM, 2004) => Rede de Facilitadores, Conteúdo alinhado ao negócio, conteúdo em blocos, } \\
\text { laboratórios de } e \text {-learning } \\
\text { Diferenças entre áreas e níveis hierárquicos - subculturas (SCHEIN, 1996) } \\
\text { - } \quad \text { Relação entre incentivo e intenção de uso (MARTINS; KELLERMANNS, 2004) } \\
\text { - Influência social: colegas, imagem (MARTINS; KELLERMANNS, 2004) }\end{array}$ \\
\hline $\begin{array}{l}1.3 \text { - } H_{0} \text { : Mesmo grau de } \\
\text { concordância entre os } \\
\text { respondentes que } \\
\text { participaram do } e \text { - } \\
\text { learning e os que não } \\
\text { participaram em relação à } \\
\text { Facilidade de Uso } \\
\text { Percebida do } e \text {-learning }\end{array}$ & $\begin{array}{l}\text { Hipótese rejeitada, há diferença } \\
\text { significativa em todas as variáveis: } \\
\text { tendência dos respondentes que } \\
\text { realizaram curso apresentarem maior } \\
\text { concordância }\end{array}$ & $\begin{array}{l}\text { Corrobora pesquisas anteriores utilizadas como base conceitual } \\
\text { - } \quad \text { Dificuldade ou falta de informação no acesso à plataforma de e-elearning (motivos de não } \\
\text { participação) } \\
\text { - } \quad \text { Facilidade de uso do ambiente (SELIM, 2003) } \\
\text { - } \quad \text { Disponibilidade de suporte técnico (MARTINS; KELLERMANNS, 2004; } \\
\text { ROSENBERG, 2006) - Rede de facilitadores } \\
\text { - } \quad \begin{array}{l}\text { Disponibilidade de recursos (setor de telecomunicações) / realização do curso da } \\
\text { residência }\end{array} \\
\text { - }\end{array}$ \\
\hline $\begin{array}{l}1.4 \text { - } \boldsymbol{H}_{0} \text { : Mesmo grau de } \\
\text { concordância entre os } \\
\text { respondentes que } \\
\text { participaram do } e \text { - } \\
\text { learning e os que não } \\
\text { participaram em relação à } \\
\text { Habilidade com } \\
\text { Informática \& Pré- } \\
\text { disposição para Inovar }\end{array}$ & $\begin{array}{l}\text { Hipótese rejeitada, há diferença } \\
\text { significativa em } 3 \text { das } 4 \text { variáveis: } \\
\text { tendência dos respondentes que } \\
\text { realizaram curso apresentarem maior } \\
\text { concordância }\end{array}$ & $\begin{array}{l}\text { Corrobora pesquisas anteriores utilizadas como base conceitual } \\
\text { - Auto-eficácia com computadores (GONG et al, 2004; ONG et al, 2004; LEE, 2006) } \\
\text { - Pré-disposição para inovar (SCHILLEWAERT et al, 2000) }\end{array}$ \\
\hline
\end{tabular}


Quadro 18 - Objetivo Específico 2: Analisar as diferenças de percepção entre os colaboradores que realizaram e que não realizaram curso de e-learning na empresa, desde 2006.

\begin{tabular}{|c|c|c|}
\hline Hipóteses & Resultado & Explicação \\
\hline $\begin{array}{l}1.5 \text { - } H_{0} \text { : Mesmo grau de } \\
\text { concordância entre os } \\
\text { respondentes que } \\
\text { participaram do } e \text { - } \\
\text { learning e os que não } \\
\text { participaram sobre a } \\
\text { Desconfiança em } \\
\text { Relação à Inovação }\end{array}$ & $\begin{array}{l}\text { Hipótese não rejeitada, não há diferença } \\
\text { significativa em nenhuma das variáveis }\end{array}$ & $\begin{array}{l}\text { Divergente da literatura que identificou: } \\
\text { - Influência positiva da confiança na adoção de tecnologia (KAMEL; HASSAN, 2003; } \\
\text { LIPPERT; FORMAN, 2006, DHAMI, } 2005 \\
\text { - Influência da credibilidade percebida na adoção do e-learning (ONG et al, 2004) } \\
\text { Nota: Há maior concordância a este fator entre aqueles que não fizeram curso de e-learning } \\
\text { fora da empresa }\end{array}$ \\
\hline $\begin{array}{l}\text { 1.6 - } \boldsymbol{H}_{0} \text { : Mesmo grau de } \\
\text { concordância entre os } \\
\text { respondentes que } \\
\text { participaram do } e \text { - } \\
\text { learning e os que não } \\
\text { participaram em relação à } \\
\text { Intenção de Uso do } e \text { - } \\
\text { learning }\end{array}$ & $\begin{array}{l}\text { Hipótese rejeitada, há diferença } \\
\text { significativa em } 2 \text { das } 3 \text { variáveis, } \\
\text { tendência dos respondentes que } \\
\text { realizaram curso apresentarem maior } \\
\text { concordância }\end{array}$ & $\begin{array}{l}\text { Resultado não verificado para o número de cursos planejados para participar em } 2007 \\
\text { - Possibilidade de frustração do participante } \\
\text { - Quantidade de cursos é uma medida relativa } \\
\text { Há diferença em relação à intenção de uso, se considerado o interesse nos cursos e o tempo } \\
\text { disponível } \\
\text { Corrobora com pesquisas anteriores } \\
\text { - Relação entre utilidade e intenção de uso (LEE, 2006; SELIM, 2003; GONG et al, 2004; } \\
\text { ONG et al, 2004; FUSILIER; DURLABHJ, 2005 } \\
\text { - Influência da falta de Tempo (BOROTIS; POULYMENAKOU, 2007; VAN DAM, 2004) }\end{array}$ \\
\hline
\end{tabular}


Quadro 19 - Objetivo Específico 3: Analisar as diferenças de percepção em função do perfil do respondente

\begin{tabular}{|c|c|c|}
\hline Hipóteses & Resultado & Explicação \\
\hline $\begin{array}{l}2 \text { - } \boldsymbol{H}_{0} \text { : Mesmo grau de concordância entre os } \\
\text { respondentes que realizaram e não realizaram curso de } \\
\text { e-learning fora da plataforma da empresa em relação } \\
\text { às variáveis que influenciam a adoção do e-learning }\end{array}$ & $\begin{array}{l}\text { Hipótese rejeitada, há diferença } \\
\text { significativa em } 17 \text { das } 39 \\
\text { variáveis, tendência dos } \\
\text { respondentes que realizaram } \\
\text { curso fora da empresa } \\
\text { apresentarem maior } \\
\text { concordância }\end{array}$ & $\begin{array}{l}\text { Corrobora pesquisas anteriores utilizadas como base conceitual } \\
\text { - } \\
\text { Relevância do conteúdo (VAN DAM, 2004; LEE, 2006; ONG; LAI, } \\
\text { - } \\
\text { Alinhamento às atividades e objetivos do participante (ANGEHRN } \\
\text { et al, 2001) } \\
\text { - Experiência influencia positivamente a percepção de utilidade } \\
\text { (FUSILIER; DURLABHJ, 2005) }\end{array}$ \\
\hline $\begin{array}{l}3 \text { - } \boldsymbol{H}_{0} \text { : Mesmo grau de concordância entre os } \\
\text { respondentes homens e mulheres em relação às } \\
\text { variáveis que influenciam a adoção do e-learning }\end{array}$ & $\begin{array}{l}\text { Hipótese rejeitada, há diferença } \\
\text { significativa em } 20 \text { das } 39 \\
\text { variáveis, respondentes homens } \\
\text { tendem a apresentar maior } \\
\text { concordância }\end{array}$ & $\begin{array}{l}\text { Corrobora pesquisas anteriores utilizadas como base conceitual } \\
\text { - } \\
\text { influencens apresentam maior concordância com os fatores que } \\
\text { - } \quad \text { Homens consideram mais importante a utilidade e mulheres a } \\
\text { facilidade de uso e norma subjetiva (VENKATESH; MORRIS, } \\
\text { 2000) } \\
\text { - Mulheres perceberam maior utilidade e presença social e homens } \\
\text { maior facilidade de uso (GEFEN; STRAUB, 1997) } \\
\text { - Não é observada influência do gênero no comportamento de uso } \\
\text { (GEFEN; STRAUB, 1997) }\end{array}$ \\
\hline
\end{tabular}


Quadro 20 - Objetivo Específico 4: Identificar as variáveis que melhor explicam a intenção de realizar ou não cursos de e-learning na empresa

\begin{tabular}{|c|c|c|}
\hline Hipóteses & Resultado & Explicação \\
\hline $\begin{array}{l}4.1 \text { - } \boldsymbol{H}_{0}: \text { O fator Utilidade Percebida não influencia a } \\
\text { Intenção de Uso do e-learning }\end{array}$ & $\begin{array}{l}\text { Hipótese rejeitada, influência } \\
\text { positiva }\end{array}$ & $\begin{array}{l}\text { Corrobora pesquisas anteriores utilizadas como base conceitual } \\
\text { - Influência da utilidade na intenção de uso do e-learning (ONG et al, } \\
\text { 2006; LEE, 2006; GONG et al, 2004; SELIM, 2003) } \\
\text { - Premissas do Modelo TAM (DAVIS et al, 1989; VENKATESH; } \\
\text { DAVIS, 2000) }\end{array}$ \\
\hline $\begin{array}{l}4.2-H_{0}: O \text { fator Ambiente Propício à Aprendizagem } \\
\text { não influencia a Intenção de Uso do e-learning }\end{array}$ & $\begin{array}{l}\text { Hipótese rejeitada, influência } \\
\text { positiva }\end{array}$ & $\begin{array}{l}\text { Corrobora pesquisas anteriores utilizadas como base conceitual } \\
\text { - Literatura de e-learning - influência do superior, alta administração } \\
\text { e cultura (ROSENBERG, 2000; TYAN, 2003; ECONOMIST } \\
\text { INTELLIGENCE UNIT; IBM, 2003; BOROTIS; } \\
\text { POULYMENAKOU, 2004; VAN DAM, 2004; PSYCHARIS, 2005) }\end{array}$ \\
\hline $\begin{array}{l}4.3 \text { - } \boldsymbol{H}_{0} \text { : O fator Facilidade de Uso Percebida não } \\
\text { influencia a Intenção de Uso do e-learning }\end{array}$ & $\begin{array}{l}\text { Hipótese não rejeitada, não é } \\
\text { observada influência }\end{array}$ & $\begin{array}{l}\text { Divergente da literatura sobre adoção do e-learning } \\
\text { - Influência positiva da facilidade de uso na adoção do e-learning } \\
\text { (MARTINS; KELLERMANNS, 2004; GONG et al, 2004; ONG et } \\
\text { al, 2004; SELIM, 2003) } \\
\text { Resultado que pode estar relacionado ao setor de Telecomunicações }\end{array}$ \\
\hline $\begin{array}{l}4.4 \text { - } H_{0}: \text { O fator Habilidade com Informática \& Pré- } \\
\text { disposição para Inovar não influencia a Intenção de } \\
\text { Uso do e-learning }\end{array}$ & $\begin{array}{l}\text { Hipótese não rejeitada, não é } \\
\text { observada influência }\end{array}$ & $\begin{array}{l}\text { Divergente da literatura sobre e-learning } \\
\text { - Aponta para a importância dos fatores (ROSENBERG, 2006; VAN } \\
\text { DAM, 2004; LEE, 2006; GONG et al, 2004; ONG et al, 2004) } \\
\text { Resultado que pode ser explicado pelas particularidades da tecnologia em } \\
\text { análise (FUSILIER; DURLABHJI, 2005) }\end{array}$ \\
\hline $\begin{array}{l}4.5 \text { - } H_{0} \text { : O fator Desconfiança em Relação à Inovação } \\
\text { não influencia a Intenção de Uso do e-learning }\end{array}$ & $\begin{array}{l}\text { Hipótese não rejeitada, não é } \\
\text { observada influência }\end{array}$ & $\begin{array}{l}\text { Divergente da literatura sobre adoção de tecnologias (KAMEL; } \\
\text { HASSAN, 2003; LIPPERT; FORMAN, 2006; VENKATESH et al, 2003) } \\
\text { e pesquisas sobre adoção do e-learning (ONG et al, 2004) }\end{array}$ \\
\hline
\end{tabular}


Quadro 21 - Objetivo Específico 5: Identificar as variáveis que melhor explicam a realização ou não de cursos de e-learning na empresa

\begin{tabular}{|c|c|c|}
\hline Hipóteses & Resultado & Explicação \\
\hline $\begin{array}{l}5.1 \text { - } H_{0}: \text { O fator Utilidade Percebida não influencia o } \\
\text { Comportamento de Uso do e-learning }\end{array}$ & $\begin{array}{l}\text { Hipótese rejeitada, influência } \\
\text { negativa }\end{array}$ & $\begin{array}{l}\text { Corrobora pesquisas anteriores } \\
\text { - Frustração do usuários com a tecnologia (DAVIS, 1989; SHIH; } \\
\text { VENKATESH, 2004; MUKHERJEE; HOYER, 2001) }\end{array}$ \\
\hline $\begin{array}{l}5.3 \text { - } \boldsymbol{H}_{0} \text { : O fator Facilidade de Uso Percebida não } \\
\text { influencia o Comportamento de Uso do } e \text {-learning }\end{array}$ & $\begin{array}{l}\text { Hipótese rejeitada, influência } \\
\text { positiva }\end{array}$ & $\begin{array}{l}\text { Corrobora pesquisas anteriores utilizadas como base conceitual } \\
\text { - Importância da facilidade de uso na adoção do e-learning } \\
\text { (MARTINS; KELLERMANNS, 2004; GONG et al, 2004; ONG et } \\
\text { al, 2004; SELIM, 2003) }\end{array}$ \\
\hline $\begin{array}{l}5.4 \text { - } H_{0}: \text { O fator Habilidade com Informática e Pré- } \\
\text { disposição para Inovar não influencia o } \\
\text { Comportamento de Uso do e-learning }\end{array}$ & $\begin{array}{l}\text { Hipótese rejeitada, influência } \\
\text { positiva }\end{array}$ & $\begin{array}{l}\text { Corrobora pesquisas anteriores utilizadas como base conceitual } \\
\text { - Adoção do e-learning (LEE, 2006; GONG et al, 2004; ONG et al, } \\
\text { 2004) e de inovações (SCHILLEWAERT et al, 2000) }\end{array}$ \\
\hline
\end{tabular}




\section{CONSIDERAÇÕES FINAIS}

\subsection{Conclusões e Contribuições da Pesquisa}

O desafio da criação e manutenção de vantagem competitiva em um ambiente de globalização, alta concorrência e constante transformação exige a adoção de estratégias e práticas diferenciadas por parte das empresas; dentre as quais está o desenvolvimento contínuo dos colaboradores. Nesse contexto, o e-learning desponta como alternativa para capacitação de uma força de trabalho cada vez mais dispersa geograficamente e com necessidade de rápida atualização.

Não obstante essa necessidade, a efetivação dos benefícios esperados do e-learning, dependem de maneira essencial do grau de adoção desta inovação pelos colaboradores. Assim, a mera disponibilização de cursos on-line não é suficiente para o sucesso e "[...] levar as pessoas a usar e aceitar o e-learning, especialmente a longo prazo, exige muito trabalho em gestão da mudança, comunicação e liderança - e tempo."159 (ROSENBERG, 2006, p. 22).

Este trabalho analisou sob considerável conjunto de fatores que influenciam a adoção individual do e-learning no contexto organizacional de uma grande empresa multinacional de telecomunicações. Os resultados encontrados são a base para as reflexões apresentadas a seguir.

\subsubsection{O Modelo de Adoção Individual do e-Learning}

O Modelo TAM, usado como base na presente pesquisa, mostrou-se adequado tendo em vista o objetivo proposto. A confirmação dos constructos Utilidade Percebida e Facilidade de Uso Percebida na análise fatorial reforça a contribuição do Modelo TAM para a compreensão da adoção do e-learning, corroborando pesquisas anteriores (MARTINS; KELLERMANNS, 
2004; LEE, 2006; GONG et al, 2004; SELIM, 2003; ONG et al, 2004; BUSH, 2005; GABBARD, 2004), que confirmaram a validade do modelo nesse contexto.

Conforme orientado na literatura sobre adoção de inovações (DAVIS et al, 1989, p.; FRAMBACH; SCHILLEWAERT, 1999; TORNATZKY; FLEISCHER, 1990), o modelo utilizado foi adaptado para a tecnologia em análise e para o contexto de adoção. Taylor e Todd apontam para a "[...] necessidade de uma exploração mais ampla de outros fatores além daqueles sugeridos pelos tradicionais modelos de intenção e de inovação."160 (1995, p. 171), caracterizados por serem altamente específicos em relação ao contexto. Dessa forma, o Modelo TAM foi estendido para incluir variáveis particulares relacionadas ao e-learning e ao ambiente organizacional. A inclusão do fator Ambiente Propício à Aprendizagem destaca-se como uma contribuição importante dessa pesquisa, além da aplicação do Modelo TAM para analisar a adoção do e-learning em uma empresa brasileira.

\subsubsection{A Influência do Uso da Inovação na Percepção dos Fatores de Adoção}

Os resultados da pesquisa confirmaram as diferenças de percepção entre os respondentes que participaram de cursos de e-learning na plataforma da empresa e os que não participaram. Ao colocar luz sobre estas diferenças, torna-se mais fácil a compreensão dos fatores da não adoção e, por conseqüência, a elaboração de ações mais adequadas para lidar com resistências. Conforme apontado por Fusilier e Durlabhji, “Análises das percepções e atitudes dos não-usuários devem ser exploradas. [...] Aprendendo sobre as razões de não utilização deste grupo pode ajudar educadores a quebrar as barreiras para a participação dos alunos nos aspectos tecnológicos da aprendizagem." ${ }^{\prime 161}$ (2005, p. 244). Também é necessário estabelecer ações para lidar com potenciais frustrações dos colaboradores que participaram do e-learning, de forma a estimular a continuidade do uso.

\footnotetext{
159 “[...] getting people to use and accept e-learning, especially over the long haul, will take work - change management, communications, and leadership - and time."

160 “[...] need for a broader exploration of factors beyond those suggested by the traditional intention and innovations models."

161 "Analysis of non-user perceptions and attitudes should be explored. [...] Learning the reasons for this group's non-usage may help educators to break down barriers to students' participation in the technological aspects of learning."
} 
Este trabalho contribui no sentido de confirmar a importância da identificação dos respondentes que já são usuários e os que ainda não são usuários da inovação em estudo, considerando que a experiência com a inovação pode alterar os fatores explicativos da adoção (GABBARD, 2004; GONG et al, 2004). De acordo com Karahanna et al, “[...] poucos estudos empíricos fizeram uma distinção entre as crenças e atitudes dos indivíduos pré-adoção e pós-adoção (continuidade do uso). Essa distinção é crucial no entendimento e gerenciamento desse processo no tempo." ${ }^{\text {"162 }}$ (1999, p. 183).

\subsubsection{As Diferenças em Função do Perfil do Respondente}

$\mathrm{Na}$ análise do perfil do respondente, observaram-se diferenças importantes em função das variáveis analisadas: experiência com e-learning fora da empresa, gênero, idade, tempo de empresa, grau de instrução, localidade de trabalho, nível hierárquico e área funcional. Da mesma forma que no caso do uso da inovação, o perfil também influenciou as percepções dos respondentes em relação ao e-learning. Assim, é preciso elaborar estratégias diferenciadas e corretamente segmentadas para estimular a adoção do e-learning entre os vários grupos de usuários potenciais.

\subsubsection{Explicando a Intenção e o Comportamento de Uso do e-Learning}

O fator Ambiente Propício à Aprendizagem destaca-se dos demais, uma vez que influencia positivamente tanto a intenção quanto o comportamento de uso do e-learning, reforçando a importância do ambiente organizacional na adoção, conforme apontado na literatura (MACPHERSON et al, 2004; ROSENBERG, 2000; TYAN, 2003; BOROTIS; POULYMENAKOU, 2004; VAN DAM, 2004; PSYCHARIS, 2005) e, ainda, a importância das variáveis adicionadas ao Modelo TAM.

É interessante notar que a Facilidade de Uso Percebida, apesar de não influenciar a intenção de uso, é o fator de influência mais importante no comportamento de uso do e-learning,

162 "[...] few empirical studies have made a distinction between individuals' pre-adoption and post-adoption (continued use) beliefs and attitudes. This distinction is crucial in understanding and managing this process over time." 
incluindo não só a facilidade em relação ao sistema, mas também as instruções, os recursos tecnológicos e a estrutura de suporte técnico disponibilizados.

Por outro lado, a Utilidade Percebida apresenta a influência mais importante na intenção de uso e uma influência negativa em relação ao comportamento de uso. Conforme já discutido, esse resultado pode ser explicado por uma possível frustração apresentada por colaboradores que participaram de cursos de e-learning, eventualmente relacionada à existência de uma distância entre os cursos oferecidos e a expectativa e/ou necessidade dos colaboradores. Essa questão está em linha com o desafio apontado por Rosenberg (2006) de migração de um projeto de e-learning baseado na quantidade ou no custo-benefício para um projeto que ofereça soluções de aprendizagem com ênfase no desempenho do negócio (Quadro 4).

A Figura 29, a seguir, consolida as influências identificadas dos fatores analisados na intenção e no comportamento de uso do e-learning. $\mathrm{O}$ exponencial de $\mathrm{B}[\operatorname{Exp}(\mathrm{B})]$ indica a influência do Fator sobre a variável dependente.

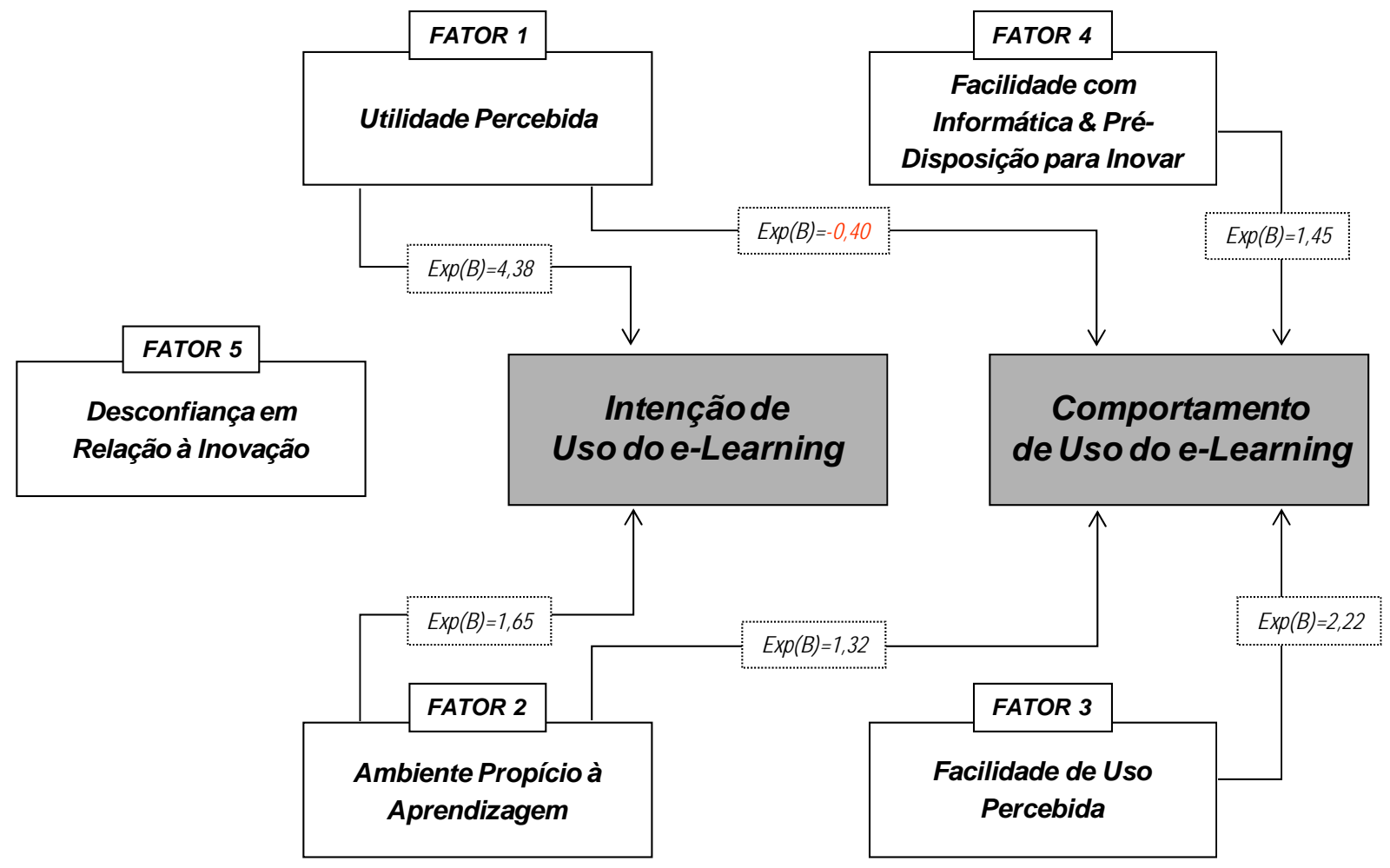

Figura 29 - Modelo de Adoção Individual do e-Learning na Empresa Estudada 


\subsubsection{Sugestões para Ampliação da Adoção do e-Learning na Empresa Pesquisada}

Através desta pesquisa, foi possível identificar possíveis ações com potencial de ampliar a adoção do e-learning pelos colaboradores da empresa pesquisada, algumas delas já em andamento. Tratam-se de sugestões, levantadas a partir dos resultados, e que exigem uma análise à luz da estratégia geral de educação corporativa, tendo em vista que o e-learning é um dos métodos disponíveis, que deve ser utilizado em função do objetivo, público-alvo, conteúdo e contexto da capacitação.

- $\quad$ Alinhamento dos conteúdos oferecidos em função das necessidades do participante e do negócio: disponibilizar mais cursos alinhados ao negócio da empresa e relacionados diretamente às áreas de trabalho; utilizar formas de verificar a adequação do nível do curso em função da necessidade do participante, como a aplicação de um pré-teste, por exemplo;

- Inovação na metodologia de e-learning: oferecer cursos com metodologia híbrida (blended learning) e com maior interatividade, estimulando, por exemplo, a troca de idéias entre participantes de diferentes áreas da empresa;

- Aumento do envolvimento da liderança: desenvolver ações de comunicação e participação dos gestores do projeto de e-learning, com foco nas contribuições para o negócio;

- Apoio para participação no e-learning durante a jornada de trabalho: oferecer conteúdos em módulos curtos e disponibilizar laboratórios de e-learning para participação nos cursos;

- Identificação de grupos por afinidade: percebeu-se que há significativas diferenças na pré-disposição a participar de cursos de e-learning de funcionários em função do tempo de empresa, nível hierárquico e outros fatores. Estabelecer políticas de desenvolvimento de conteúdos e comunicação apropriadas para cada grupo identificado pode contribuir sensivelmente para o aumento do uso da plataforma de e-learning da empresa;

- Apoio para participação no e-learning de fora da empresa: facilitar o acesso à plataforma de e-learning da residência do colaborador, estender incentivo para contratação de Internet rápida e aquisição de microcomputadores para todos os colaboradores;

- Ampliação da divulgação do e-learning: ampliar as ações de divulgação do e-learning para todos os colaboradores, com destaque para os funcionários recém contratados; 
- Aprimoramento da navegação na Plataforma de e-Learning: facilitar a navegação e acesso aos cursos na plataforma de e-learning;

- Ampliação da divulgação do suporte técnico disponível: divulgar contato dos facilitadores e demais canais disponíveis para suporte no uso do e-learning.

Assim, para ampliar a adoção do e-learning na empresa pesquisada, é necessária a combinação de esforços no alinhamento do e-learning às necessidades do negócio (Utilidade), na gestão da mudança (Ambiente), no acesso à plataforma de $e$-learning e suporte oferecido (Facilidade de Uso).

\subsection{Limitações da Pesquisa}

Se, por um lado, a realização da pesquisa em uma única empresa possibilita maior aprofundamento na compreensão das variáveis em análise, por outro, impossibilita a generalização dos resultados para outras empresas e contextos.

Outra limitação se refere ao recorte do estudo, uma vez que a percepção dos respondentes foi levantada em apenas um momento no tempo. Apesar desta ser uma limitação apresentada também em estudos anteriores (MARTINS; KELLERMANNS, 2004; LEE, 2006), "Evidências longitudinais devem aprimorar nosso entendimento sobre a causalidade e interrelações entre as variáveis, fatores que podem ser importantes na aceitação do e-learning pelo usuário."163 (ONG; LAI, 2006, p. 826).

Para realização deste trabalho, foi utilizado um modelo de adoção de novas tecnologias amplamente reconhecido (LEE et al, 2003) e com pesquisas anteriores sobre adoção do elearning (GONG et al , 2004; SELIM, 2003; MARTINS; KELLERMANNS, 2004; ONG et al, 2004; FUSILIER; DURLABHJ, 2005; GONG et al, 2004, SELIM, 2003). Tendo em vista que adaptações foram propostas, de forma a atender os objetivos da pesquisa, estudos adicionais são necessários para avaliar a validade do modelo proposto e dos resultados

\footnotetext{
163 "Longitudinal evidences might enhance our understanding of the causality and interrelationships between variables, factors which could be important to user acceptance of e-learning."
} 
observados, considerando as novas variáveis que foram adicionadas ao Modelo TAM, a aplicação para a adoção do e-learning no ambiente organizacional e a tradução do instrumento original para o português.

Além disso, evitou-se a construção de um questionário muito extenso, de forma a facilitar a participação no estudo. Nesse sentido, foi necessário selecionar as variáveis mais importantes para o objetivo da pesquisa, considerando também sua fundamentação teórica e as particularidades do e-learning e da empresa pesquisada.

$\mathrm{O}$ uso de um questionário auto-preenchido envolve um viés do respondente quanto às informações relatadas. Outro viés presente no auto-preenchimento refere-se à compreensão dos itens do questionário, sendo natural que os respondentes apresentem entendimento diverso em relação a determinados termos do questionário. Além disso, a aplicação do questionário on-line com identificação do respondente, que possibilitou a consolidação das informações do perfil e dos relatórios da plataforma de e-learning da empresa, também pode ter influenciado a sinceridade no preenchimento das respostas, conforme apontado por Gabbard (2004, p.87).

No caso de estudos sobre adoção do e-learning, a análise do comportamento de uso relatado pelo respondente ao invés do comportamento verificado através de relatórios do sistema pode ser fonte de viés, apesar do uso freqüente me pesquisas anteriores (GONG et al, 2004; MARTINS; KELLERMANNS, 2004; LEE, 2006). Na presente pesquisa, foi possível confirmar o comportamento de uso de $53 \%$ dos respondentes que afirmaram ter participado do e-learning na plataforma da empresa; mas, como os relatórios disponíveis não eram completos, não foi possível utilizá-los como base para as análises. E, apesar de não ser tão preciso quanto o uso real, esse método tem sido considerado apropriado como uma medida relativa (DAVIS et al, 1989, p. 991).

Está também presente o viés pró-tecnologia, observado em estudos sobre adoção de inovações e de novas tecnologias (ROGERS, 1995; DAVIS et al, 1989). É preciso considerar que "A possibilidade de impactos disfuncionais gerados pela tecnologia de informação enfatiza que a aceitação do usuário não é um objetivo universal e, na verdade, é indesejado em casos em que 
o sistema falha em proporcionar ganhos reais de desempenho." ${ }^{\prime 164}$ (DAVIS, 1989, p. 335).

A resposta à pesquisa foi voluntária, potencial fonte de viés; uma vez que aqueles mais interessados em e-learning poderiam apresentar maior tendência para responder, conforme apontado por Ong et al (2004). De qualquer forma, tal viés foi mitigado, fato evidenciado pela representatividade estatística da amostra em relação à população.

Desta forma, a presente pesquisa cumpriu os objetivos inicialmente propostos, sendo que os resultados encontrados devem ser considerados à luz de suas limitações.

\subsection{Sugestões para Estudos Futuros}

Este estudo também cumpre seu papel no que se refere à formulação de sugestões para pesquisas futuras. Primeiramente, novos estudos validando as variáveis adicionadas ao Modelo TAM se fazem necessários, principalmente em relação às particularidades do $e$ learning e do ambiente organizacional. Além disso, a ampliação da presente pesquisa para outras empresas de telecomunicações e para outros setores também são possibilidades para estudos futuros.

Outra sugestão se refere ao aprofundamento do entendimento sobre a frustração do participante em relação ao e-learning e sua influência na percepção de utilidade, no contexto da adoção de inovações. Esse tema pode ser estendido para o estudo das mudanças nos fatores que influenciam a adoção do e-learning em decorrência da experiência de uso da inovação. Em uma abordagem diferente dessa questão, sugere-se o estudo de relações entre as percepções e os estágios de adoção da tecnologia, como o modelo de "Estágios do Processo de Decisão sobre Inovação”, proposto por Rogers (1995, p. 163).

\footnotetext{
164 "The possibility of dysfunctional impacts generated by information technology emphasizes that user acceptance is not a universal goal and is actually undesirable in cases where systems fail to provide true performance gains."
} 
A comparação efetiva do comportamento de uso relatado pelo respondente com os relatórios do sistema de e-learning, assim como a comparação do uso do e-learning em contextos obrigatórios e voluntários, também podem trazer novas perspectivas no aprofundamento da compreensão dos fatores que influenciam a adoção desta metodologia de ensino.

Outra questão que os resultados da pesquisa indicaram relevância se refere às variáveis do perfil do participante do e-learning, que demandariam ainda algum detalhamento: experiência anterior com e-learning, gênero, idade, tempo de empresa, grau de instrução, localidade de trabalho, nível hierárquico e área funcional. Além disso, a relação entre o estilo de aprendizagem do aluno e sua tendência na adoção do e-learning também é um foco para pesquisas futuras.

Por fim, a partir de um enfoque pedagógico, sugere-se um estudo detalhado sobre o impacto das estratégias didáticas, mídias e nível de interatividade que são característicos dos cursos de e-learning, na adoção dessa inovação. 


\section{REFERÊNCIAS}

AAKER, David A.; DAY, George S. Marketing Research. 4. ed. New York: Wiley, 1990. $739 \mathrm{p}$.

ANATEL - Agência Nacional de Telecomunicações. Disponível em: $<$ http://www.anatel.gov.br> Acesso em: 26 Jan. 2008.

ANGEHRN, Albert et al. Towards personalised, socially aware and active e-learning systems: Illustrated with the agent-based system K-InCA. Centre for Advanced Learning Technologies (CALT) - INSEAD, 2001. Disponível em: http:/www.calt.insead.fr/K-InCAwhitepaper.pdf Acesso em: 18 Dez. 2007.

BARDIN, Laurence. Análise de Conteúdo. $3^{\mathrm{a}}$ Ed. Trad. Luís Antero Reto e Augusto Pinheiro. Liboa: Edição 70, 2004.

BATAGLIA, Walter. As Competências Organizacionais de Resolução de Conflitos e o Consenso no Processo Decisório Estratégico em Ambientes Organizacionais Instáveis, Complexos e Não Munificientes: Um Estudo no Setor de Telefonia Fixa. São Paulo, 2006. Tese (Doutorado em Administração) - Faculdade de Economia, Administração e Contabilidade da Universidade de São Paulo.

BOROTIS, Spiros A.; POULYMENAKOU, Angeliki K. Examining employees' acceptance of e-learning: an application of the theory of planned behavior. Proceedings of the Sixth IASTED International Conference Web-Based Education, Chamonix, France, 2007, p. 216221.

BRANNEN, Julia (Ed.). Mixing Methods: qualitative and quantitative research. Aldershot: Avebury, 1992.

BRASIL. Decreto ${ }^{0}$ 5.622, de 19 de dezembro de 2005. Regulamenta o Art. 80 da LDB (Lei $\mathrm{n}^{\circ}$ 9.394/96). Diário Oficial da União, Brasília, DF, 20 dez. 2005. Disponível em: $<$ http://portal.mec.gov.br/seed/arquivos/pdf/dec_5622.pdf>. Acesso em: 5 dez. 2006.

BROWN, Shona L.; EISENHARDT, Kathleen M. Competing on the edge: strategy as structured chaos. Harvard Business School Press, 1998.

BUSH, Richard G. Student Perceptions and Institution Decisions of Technology: The Technology Acceptance Model. 2005. Dissertation (Doctor of Philosophy Applied Management and Decision Sciences), School of Management, Walden University.

CAMPOS, Stela. Depois de tantos erros, a hora é de refletir sobre o melhor uso do ensino a distância. Valor Econômico, São Paulo, 20 nov. 2002.

CHANG, Ying-Ying. A Study of Leadership Perceptions of Managers in Select Companies in Taiwan that Utilize e-Learning. Dissertation (Doctor of Philosophy) - School of Graduate Studies of the University of the Incarnate Word, 2005.

CHAPNICK, Samantha. Are Your Ready for E-Learning? Learning Circuits - ASTD, 
November 2000. Disponível em: <http://www.learningcircuits.org/2000/nov2000/ Chapnick.htm> Acesso em: 4 jan. 2007.

CHEUNG, Christy M.K. et al. Using the Internet as a Learning Medium: An Exploration of Gender Difference in the Adoption of FaBWeb. Proceedings of the $35^{\text {th }}$ Hawaii International Conference on System Sciences, 2002.

COELHO Jr., Francisco Antonio; BORGES-ANDRADE, Jairo Eduardo. Percepção de cultura organizacional: uma análise empírica da produção científica brasileira. Psico-USF, v. 9, n. 2, Jul./Dez. 2004, p. 191-199.

COSTA FILHO, Bento A. da et al. Modelo Technology Acceptance Model - TAM Aplicado aos Automated Teller Machines - ATM's. RAI - Revista de Administração e Inovação, v. 4, n. 1, São Paulo, 2007, p. 40-56.

COUPER, Mick P. Web surveys: A review of issues and approaches. Public Opinion Quarterly, v. 64, n. 4, Chicago, Winter 2000 p. 464-494.

CRESWELL, John W. Research Design: Qualitative, Quantitative, and Mixed Methods Approaches. $2^{\text {nd }}$ Ed. Thousand Oaks: Sage Publications, 2003.

CROTTY, M. The Foundations of Social Research: Meaning and Perspective in the Research Process. London: Sage, 1998.

DHAMI, Hemil S. The Role of Trust and Perceived Risk in User Acceptance of Technology Innovation in Safety-Critical Systems. Thesis (Doctor of Philosophy), Department of Decision Scienes and Engineering Systems, Rensselaer Polytechnic Institute, Troy, July, 2005.

DAVIS, Fred D. Perceived Usefulness, Perceived Ease Of Use, And User Acceptance of Information Technology. MIS Quarterly, 13, 3, Sep 1989, p. 319-340.

DAVIS, Fred D et al. User Acceptance of Computer Technology: A Comparison Of Two Theoretical Models. Management Science, 35, 8, Aug 1989, p. 982-1003.

DEVARAJ, Sarv; KOHLI, Rajiv. Information Technology Payoff in the Health-care Industry: a Longitudinal Study. Journal of Management Information Systems, v. 16, n. 4, Spring 2000, p. 41-68.

DOWNES, Stephen. Where the Market Is: IDC on E-Learning. March 18, 2003. Disponível em: <http://www.downes.ca/files/IDC.doc>. Acesso em: 24 abr. 2006.

DUNCAN, W. Jack. Organizational Culture: “Getting A Fix” On An Elusive Concept. The Academy of Management Executive, v. 3, n. 3, Aug. 1989, p. 229-236.

DUNCAN, W.J. A proposal for a multimethod approach to organizational culture research. Graduate School of Management, University of Alabama, Birmingham, 1986 apud FLEURY et al. Entre a antropologia e a psicanálise: dilemas metodológicos dos estudos sobre cultura organizacional. RAUSP - Revista de Administração, São Paulo, v. 32, n. 1, jan./mar. 1997, p. 35 . 
EBOLI, Marisa. Educação Corporativa no Brasil: mitos e verdades. São Paulo: Editora Gente, 2004.

ECONOMIST INTELLIGENCE UNIT; IBM. The 2003 e-learning readiness rankings, 2003. Disponível em: <http://www-304.ibm.com/jct03001c/services/learning/solutions/ pdfs/eiu_e-learning_readiness_rankings.pdf $>$ Acesso em: 4 jan. 2007.

EISENHARDT, Kathleen M. Building Theories from Case Study Research. Academy of Management Review, v. 14, n. 4, 1989, p. 532-550.

EVANS, J. R.; MATHUR, A. The Value of Online Surveys. Internet Research, v. 15, n. 2, 2005, p. 195-219.

FELSON, Leonard. Netting limitations. Marketing News, Chicago, 26 de Fevereiro de 2001, Volume 35, No. 5, p. 43.

FISCHER, André L.; ALBUQUERQUE, Lindolfo G. de. Delphi - RH 2010: Tendências em Gestão de Pessoas nas Empresas Brasileiras. 2 ${ }^{\mathrm{a}}$ Ed. São Paulo: PROGEP/FIA, 2004.

FLEURY et al. Entre a antropologia e a psicanálise: dilemas metodológicos dos estudos sobre cultura organizacional. RAUSP - Revista de Administração, São Paulo, v. 32, n. 1, jan./mar. 1997, p. 23-37.

FLEURY, A.; FLEURY, M. T. L. Aprendizagem e Inovação Organizacional: As Experiências de Japão, Coréia e Brasil. São Paulo: Editora Atlas, 1997.

FLEURY, Maria Tereza Leme, O Desvendar a Cultura de uma Organização: uma Discussão Metodológica. In: FLEURY, Maria Tereza Leme; FISCHER, Rosa Maria (orgs.).Cultura e poder nas organizações. São Paulo: Editora Atlas, 1992, p.15-27.

FLEURY, Maria Tereza Leme. O Ambiente para Aprendizagem Organizacional. In: CASALI, Alípio et al (Org.). Empregabilidade e Educação: Novos Caminhos no Mundo do Trabalho. São Paulo: EDUC, 1997, p. 151-166.

FONTANA, Andrea; FREY, James H. Interviewing: The Art of Science. In: DENZIN, Norman K.; LINCOLN, Yvonna S. Handbook of Qualitative Research, London: Sage Publications, 1994. p.361-376.

FRAMBACH, Ruud T.; SCHILLEWAERT, Niels. Organizational Innovation Adoption: A Multi-Level Framework of Determinants and Opportunities for Future Research. ISBM Report. Institute for the Study of Business Markets - The Pennsylvania State University, University Park, 1999.

FRANSMAN, M. Mapping the Evolving Telecoms Industry: The uses and shortcomings of the layer model. Telecommunications Policy, v. 26, n. 9,10, p. 473. Disponível em: $<$ http://www.telecomvisions.com/> Acesso em: 7 jan. 2007.

FRICKER et al. An Experimental Comparison of Web and Telephone Surveys. Public Opinion Quarterly, v. 69, n. 3, Fall 2005, p. 370-392.

FUSILIER, Marcelline; DURLABJHI, Subhash. An Exploration of Student Internet Use in 
India: The Technology Acceptance Model and The Theory of Planned Behavior. CampusWide Information Systems, v. 22, n. 4, 2005, p. 233-246.

GABBARD, Ralph B. Applying the Technology Acceptance Model to Online Education. 2004. Dissertation (Doctor of Philosophy). School of Library and Information Science, Indiana University.

GALLAHER JR, James W. The Adoption of e-Learning Across Professional Groups in a Fortune 500 Company. Thesis (Doctor of Philosophy in Education). University of Illinois at Urbana-Champaign, Urbana, 2002.

GAO, Yuan. Applying the Technology Acceptance Model (TAM) to Educational Hypermedia: A Field Study. Journal of Educational Multimedia and Hypermedia, v. 14, n. 3, 2005, p. 237-247.

GEFEN, David; STRAUB, Detmar W. Gender Differences in Perception and Use of E-Mail: An Extension to the Technology Acceptance Model. MIS Quarterly, v. 21, n. 4, Dec. 1997, p. $389-400$

GONG, Min et al. An Enhanced Technology Acceptance Model of Web-Based Learning. Journal of Information Systems Education, v. 15, n. 4, Winter 2004, p. 365-374.

GORDON, Wendy; LANGMAID, Roy. Qualitative Market Research: A Practitioner's and Buyer's Guide, England: Gower, 1988.

GORMAN, J. W. An Opposing View of Online Surveying. Marketing News. April 24, 2000, p. 48.

GUILHODO, Lúcia F.M.; RUBAL, Jacques, M. Estratégia de Lançamento de Novos Produtos e de Serviços Inovadores em Operadoras do Sistema de Telefonia Fixa Comutável (STFC). In: SBRAGIA, Roberto; GALINA, Simone V. R. (ed.). Gestão da Inovação no Setor de Telecomunicações. São Paulo: PGT/USP, 2006, 336 p.

GUIMARÃES, Tomás de Aquino; CARTAXO, Mac Amaral. Aprendizagem e Cultura nas Organizações: Um Estudo em uma Organização Militar. In: Encontro de Estudos Organizacionais, 2, 2002, Recife. Anais... Recife: Observatório da Realidade Organizacional: PROPAD/UFPE: ANPAD, 2002. 1 CD.

HAIR, Joseph F. et al. Multivariate Data Analysis. $5^{\text {th }}$ Ed., Upper Saddle River, NJ: Prentice Hall, 1998.

HALL, G.E.; HORD, S.M. Change in schools facilitating the process. Albany, NY: State University of New York Press, 1987 apud CHANG, Ying-Ying. A Study of Leadership Perceptions of Managers in Select Companies in Taiwan that Utilize e-Learning. Dissertation (Doctor of Philosophy) - School of Graduate Studies of the University of the Incarnate Word, 2005, p. 23.

HARA, Noriko; KLING, Rob. Students' frustrations with a web-based distance education course. First Monday, v.4, n. 12, Dec. 1999.

HENRICH, Joseph. Cultural Transmission and the Diffusion of Innovations: Adoption 
Dynamics Indicate That Biased Cultural Transmission Is the Predominate Force in Behavioral Change. American Anthropologist, v. 103, n. 4, 2001, p. 992-1013.

HOFSTEDE, Geert et al. Measuring organizational cultures: a qualitative and quantitative study across twenty cases. Administrative Science Quarterly, v. 35, n. 2, 1990, p. 286-316.

HORNIK, Steven; TUPCHIY, Anna. Culture's Impact on Technology Mediated Learning: The Role of Horizontal and Vertical Individualism and Collectivism. Journal of Global Information Management, v. 14, n. 4, October-December 2006, p. 31-56.

HUTCHINS, Holly M. Enhancing the business communication course through WebCT. Business Communication Quarterly, New York, v.64, n.3, p.87-94, set. 2001.

IGNATIUS, Joshua; RAMAYAH, T. An Empirical Investigation of the Course Website Acceptance Model (CWAM). International Journal of Business and Society, v. 6, n. 2, Jul. 2005, p. 69-82.

JAMROG, Jay et al. Building and Sustaining a Culture that Supports Innovation. HR. Human Resource Planning, v. 29, n. 3, 2006, p. 9-19.

JICK, T.D. Mixing qualitative and quantitative methods: triangulation in action. Administrative Science Quaterly, v. 24, dez. 1979, p. 602-611 apud FLEURY et al. Entre a antropologia e a psicanálise: dilemas metodológicos dos estudos sobre cultura organizacional. RAUSP - Revista de Administração, São Paulo, v. 32, n. 1, jan./mar. 1997, p. 35.

KAMEL, Sherif; HASSAN, Ahmed. Assessing the Introduction of Electronic Banking in Egypt Using the Technology Acceptance Model. Annals of Cases on Information Technology, v. 5, 2003, p. 1-25.

KARAHANNA, Elena et al. Information Technology Adoption Across Time: A CrossSectional Comparison of Pre-Adoption and Post-Adoption Beliefs. MIS Quarterly, v. 23, n. 2, Jun. 1999, p. 183-213.

KAUFMAN, Julie. Surviving the Shakedown: Understanding the New Reality for eLearning. IDC Canada, Nov. 2002. Disponível em: $<$ http://www.technocompetences.qc.ca/pdf/IDC-Presentation.pdf $>$. Acesso em: 2 jan. 2007.

KIM, Dong-Yool. A Study of Distance Learning Students' Interaction with Available Resources. 2004. Dissertation (Doctor of Philosophy). Department of Industrial Engineering, The State University of New York at Buffalo.

KLINE, S.J.; ROSENBERG, W. An overview of innovation. In: LANDAU, R.; ROSENBERG, N. (Eds.). The positive sum of strategy, Washington, DC: National Academy Press, p. 275-305 apud TORNATZKY, Louis G.; FLEISCHER, Mitchell. The Processes of Technological Innovation. Lexington.: Lexington Books, 1990.

KRUGLiAnSKAS, Isak. Tornando a Pequena e Média Empresa Competitiva. São Paulo: Instituto de Estudos Gerenciais e Editora, 1996, 152 p.

LANDRY, Brett Jéan-Louis. Student Reactions to Web Enhanced Instructional Elements. 
Dissertation (Doctor of Philosophy in Technology Education) - Department of Instructional Systems, Leadership, and Workforce Development, Mississippi State University, Mississippi, 2003.

LEE, Jae-Shin. Testing Social Information Processing and Technology Acceptance Models in a Distance Learning Environment with a Social Network Approach. 2003. Dissertation (Doctor of Philosophy). Cornell University.

LEE, Y. et al. The Technology Acceptance Model: Past, Present, and Future. Communications of the Association of Information Systems, Volume 12, Article 50, December 2003.

LEE, Ya-Ching. An empirical investigation into factors influencing the adoption of an elearning system. Online Information Review, v. 30, n.5, 2006, p. 517-541.

LEE, Yao-kuei. Factors Affecting Learner Behavioral Intentions to Adopt Web-Based Learning Technology in Adult and Higher Education. 2001. Dissertation (Doctor of Education). Division of Educational Administration Adult and Higher Education Program in the Graduate School, The University of South Dakota.

LEONARD-BARTON, Dorothy; DESCHAMPS, Isabelle. Managerial Influence in The Implementation Of New Technology. Management Science, v. 34, n. 10, Oct. 1988, p. 12521265.

LIPPERT, Susan K.; FORMAN, Howard. A Supply Chain Study of Technology Trust and Antecedents to Technology Internalization Consequences. International Journal of Physical Distribution \& Logistics Management, v. 36, n. 4, 2006, p. 271-288.

LITVIN, Stephen W.; KAR, Goh Hwai. E-surveying for tourism research: Legitimate tool or a researcher's fantasy? Journal of Travel Research, v. 39, n. 3, Boulder, Fevereiro de 2001, p. 308-314.

MACPHERSON, Allan et al. E-learning: reflections and evaluation of corporate programmes. Human Resource Development International, v. 7, n.3, 2004, p. 295-313.

MACPHERSON, Allan et al. The implementation and use of e-learning in the corporate university. Journal of Workplace Learning, v. 17, n. 1/2, 2005, p. 33-48.

MAHMOOD, Mo Adam; MANN, Gary J. Special issue: Impacts of Information Technology Investment on Organizational Performance. Journal of Management Information Systems, v. 16, n. 4, Spring 2000, p. 3-10.

MARCHETTI, Renato Z.; PRADO, Paulo H.M. Setor de Telecomunicações e Energia Elétrica: Em ritmo de mudança. In: Lucratividade pela Inovação: Como eliminar ineficiências nos seus negócios e na cadeia de valor. Rio de Janeiro: Elsevier / Editora Campus / Mircrosoft, 2006.

MARCONI, Marina de A.; LAKATOS, Eva M. Fundamentos de Metodologia Científica. $6^{\text {a }}$ Ed., São Paulo: Editora Atlas, 2005.

MARTINS, Gilberto de A. Estatística Geral e Aplicada. São Paulo: Atlas, 2001. 
MARTINS, Luis L.; KELLERMANNS, Franz W. A Model of Business School Students' Acceptance of a Web-Based Course Management System. Academy of Management Learning and Education, v. 3, n. 1, 2004, p. 7-26.

MATHIESON, Kieran. Predicting User Intentions: Comparing the Technology Acceptance Model with the Theory of Planned Behavior. Information Systems Research, v. 2, n. 3, September 1991, p. 173-191.

MATTAR, Fauze Najib. Pesquisa de Marketing: metodologia e planejamento. v. 1. 5. ed. São Paulo: Editora Atlas, 1999. 337 p.

MEYER, Alan D.; GOES, James B. Organizational Assimilations of Innovations: A Multilevel Contextual Analysis. Academy of Management Journal, v. 31, n. 4, Dec 1988, p. 897-923.

MUKHERJEE, Ashesh; HOYER, Wayne D. The Effect of Novel Attributes on Product Evaluation. Journal of Consumer Research, v. 28, December 2001, p. 462-472.

NEVES, Mauricio dos Santos. O Setor de Telecomunicações. In: BNDES 50 Anos Histórias Setoriais, BNDES, 2002. Disponível em: <http://www.bndes.gov.br/conhecimento/ publicacoes/catalogo/livsetorial.asp > Acesso em: 7 jan. 2007.

O ENSINO a distância ainda não pegou. Carta Capital, São Paulo: Editora Confiança, ano IX, n. 232, p.43, 19 mar. 2003.

OLIVEIRA Jr., Raul S. de. Utilização do Modelo TAM na Avaliação da Aceitação de Sistemas ERP. Dissertação (Mestrado em Administração), Faculdades IBMEC, Rio de Janeiro, 2006.

ONG, Chorng-Shyong et al. Factors Affecting Engineers' Acceptance of Asynchronous eLearnng Systems in High-Tech Companies. Information \& Management, v. 41, 2004, p. 795-804.

ONG; Chorng-Shyong; LAI, Jung-Yu. Gender Differences in Perceptions and Relationships Among Dominants of e-Learning Acceptance. Computers in Human Behavior, v. 22, 2006, p. 816-829.

ORLIKOWSKI, Wanda. The Duality of Technology: Rethinking the Concept of Technology in Organizations. Organization Science, v. 3, n.3, August 1992, p. 390-427.

ORLIKOWSKI, Wanda; BAROUDI, J. Studying Information Technology in Organizations: research approaches and assumptions. Information Systems Research, v. 2, n. 1, March 1991, p. 1-28.

PALMER, Calvin. E-research in focus. Adweek, v. 22, n. 29, Dallas, 17 de Julho de 2000, p. 8.

PAN, Cheng-Chang. System Use of WebCT in the Light of the Technology Acceptance Model: A Student Perspective. 2003. Dissertation (Doctor of Philosophy). Department of Educational Research, Technology and Leadership in the College of Education at the University of Central Florida, Orlando. 
PETTIGREW, Andrew M. A Cultura das Organizações é Administrável? In: FLEURY, Maria Tereza Leme; FISCHER, Rosa Maria (orgs.).Cultura e poder nas organizações. São Paulo: Editora Atlas, 1992, p.145-153.

PRICEWATERHOUSECOOPERS. e-Learning: O Potencial da América Latina. Relatório Técnico, 2001.

PRUSAK, L. Learning Decisions. Newsletter, v. 1, n. 1, The Masie Center, Saratoga Springs, NY, Jan. 2000 apud ROSENBERG, Marc J. e-Learning: Estratégias para a Transmissão do Conhecimento na Era Digital. São Paulo: MAKRON Books, 2002, p. 9.

PSYCHARIS, Sarantos. Presumptions and actions affecting an e-learning adoption by the educational system Implementation using virtual private networks. European Journal of Open, Distance and E-Learning. Issue 2005/II, 2005. Available at: http://www.eurodl.org/materials/ contrib/2005/Sarantos_Psycharis.htm Accessed Nov. 23rd 2006.

ROGERS, Everett M. Diffusion of Innovations. $4^{\text {th }}$ ed., New York: The Free Press, 1995.

ROSENBERG, Marc J. Beyond E-Learning: Approaches and Technologies to Enhance Organizational Knowledge, Learning, and Performance. San Francisco: Pfeifeer, 2006.

ROSENBERG, Marc J. E-Learning: Estratégias para a Transmissão do Conhecimento na Era Digital. São Paulo: MAKRON Books, 2002. 320 p.

ROSENBERG, Marc J. The E-Learning Readiness Survey, e-Learning Downloads, McGraw-Hill, 2000. Disponível em: $\quad<\mathrm{http} / /$ books.mcgrawhill.com/training/elearning/elearning_survey.pdf> Acesso em: 4 jan. 2007.

SACCOL, Amarolinda I. C. Z. A Teoria da Hospitalidade e o Processo de Adoção de Tecnologias da Informação Móveis e Sem Fio. São Paulo. 2005. Tese (Doutorado em Administração), Faculdade de Economia, Administração e Contabilidade da Universidade de São Paulo.

SBRAGIA, Roberto et al. Panorama Setorial em Telecomunicações. In: SBRAGIA, Roberto; GALINA, Simone V. R. (ed.). Gestão da Inovação no Setor de Telecomunicações. São Paulo: PGT/USP, 2006, 336 p.

SCHANK, Roger C. Designing World-class e-Learning: How IBM, GE, Harvard Business School, \& Columbia University are Succeeding at e-Learning. New York: McGraw-Hill, 2002.

SCHEIN, E. Organizational culture and leadership. $2^{\text {nd }}$ Ed. San Francisco: Jossey Bass, 1992.

SCHEIN, Edgar H. Three Cultures of Management: The Key to Organizational Learning. Sloan Management Review, v. 38, n. 1, Fall 1996, p. 9-20.

SCHILLEWAERT, Niels et al. The Acceptance of Information Technology in the Sales Force. ISBM Report 15-2000. Institute for the Study of Business Markets - The Pennsylvania State University, 2000. 
SELIM, Hassan M. An Empirical Investigation of Student Acceptance of Course Websites.

Computers \& Education, v. 40, 2003, p. 343-360.

SHIH, Chuan-Fong; VENKATESH, Alladi. Beyond Adoption: Development and Application of a Use-Diffusion Model. Journal of Marketing, v. 68, n. 1, Jan. 2004, p. 59-72.

SILVA et al. O Uso do Questionário Eletrônico na Pesquisa Acadêmica: Um Caso de Uso na Escola Politécnica da Universidade de São Paulo, II Semead - Seminários em Administração do Programa de Pós-Graduação em Administração da FEA/USP, 1997. p.408-421.

SILVA, André L. M. R. da. A Influência do Treinamento de Usuários na Aceitação de Sistemas ERP em Empresas no Brasil. Instituto COPPEAD de Administração. Dissertação (Mestrado em Administração), Universidade Federal do Rio de Janeiro, Rio de Janeiro, 2005.

SINGH, Harvey. Building Effective Blended Learning Programs. Educational Technology, v. 43, n. 6, December 2003, p. 51-54.

SLOMAN, M.; Van BUREN, M. E-Learning's learning curve: Will they come, will they learn? In: ASTD Conference, San Diego, Mai. 2003 apud ROSENBERG, Marc J. Beyond ELearning: Approaches and Technologies to Enhance Organizational Knowledge, Learning, and Performance. San Francisco: Pfeifeer, 2006, p. 15.

SNYDER, Warren E. Perceptions on the Diffusion and Adoption of SkillSoft ${ }^{\circledR}$, an elearning program: A Case Study of a Military Organization. $\mathrm{PhD}, 2003$. Disponível em: http://scholar.lib.vt.edu/theses/available/etd-04072003-193511/ Acesso em: 18 Dez. 2007.

SOUKI, Gustavo Q. et al. Interdisciplinaridade na era da informação: um estudo sobre a mudança na metodologia de ensino de informática para administradores. In: ENCONTRO ANUAL DA ANPAD, 25., 2001, Campinas, Anais... 2001. 1 CD-Rom.

STACEY, Paul. E-Learning Value Chain \& Market Map. New Media BC E-Learning, Dec. 2001 Disponível em http://www.bctechnology.com/statics/BCelearning.swf Acesso em: 16 set. 2006.

STOEL, Leslie; LEE, Kyu Hye. Modeling the effect of experience on student acceptance of Web-based courseware. Internet Research: Electronic Networking Applications and Policy, v. 13, n. 5, 2003, p. 364-374.

TABACHNICK, Barbara G; FIDELL, Linda S. Using Multivariate Statistics. $4^{\text {th }}$ Ed., Boston, MA: Allyn and Bacon, 2001.

TAYLOR, Shirley; TODD, Peter A. Understanding Information Technology Usage: A Test of Competing Models. Information Systems Research, v. 6, n. 2, June 1995, p. 144-176.

TELECO - Informações em Telecomunicações. Telefonia Fixa: Operadoras de Serviço Local, Nov. 2006. Disponível em: <http://www.teleco.com.br/opfixa.asp> Acesso em: 7 jan. 2007.

TESTA, Maurício Gregianin. Fatores Críticos de Sucesso de Programas de Educação a Distância Via Internet. 2002. 127 f. Dissertação (Mestrado) - Escola de Administração, Universidade Federal do Rio Grande do Sul, Porto Alegre, 2002. Disponível em: http://www.dominiopublico.gov.br/download/texto/me001425.pdf 
TORNATZKY, Louis G.; FLEISCHER, Mitchell. The Processes of Technological Innovation. Lexington.: Lexington Books, 1990.

TROTTER, Dan Lewis. The Acceptance and Effectiveness of Hypertext Systems in Legal Education: An Experimental Evaluation. 1993. Dissertation (Doctor of Philosophy). College of Business Administration, University of South Carolina.

TULL, D.S.; HAWKINS, D.I. Meaning, Measurement and Method. London: Macmillan Publishing Co., 1976 apud SILVA et al. O Uso do Questionário Eletrônico na Pesquisa Acadêmica: Um Caso de Uso na Escola Politécnica da Universidade de São Paulo, II Semead - Seminários em Administração do Programa de Pós-Graduação em Administração da FEA/USP, 1997. p.408-421.

TWATI, J.M.; GAMMACK, J.G. The impact of organisational culture innovation on the adoption of IS/IT: the case of Lybia. Journal of Enterprise Information Management, v. 19, n. 1/2, 2006, p. 175.

TYAN, Kwan-Jun. Diffusion Barriers to E-learning in Corporate Taiwan: A Factor Analysis of Practitioners' Perspectives. Ph.D Dissertation. Department of Instructional Systems Technology - School of Education - Indiana University. 2003.

Van DAM, Nick. The e-Learning Fieldbook: Implementation lessons and case studies from companies that are making e-learning work. New York: McGraw-Hill, 2004.

VASCONCELLOS-JACOBSOHN, L.; FLEURY, M.T.L. The e-Learning Contribution to Manager's Education: Considering the Undergraduate Student's Learning Style. In: BALAS - The Business Association of Latin American Studies Annual Conference, May 19 to 22, Wellesley, USA, 2004

VASCONCELLOS-JACOBSOHN, Liliana. A contribuição do e-learning no desenvolvimento de competências do administrador: considerando o estilo de aprendizagem do aluno de graduação. Dissertação (Mestrado em Administração), FEA/USP, São Paulo, 2003.

VEIGA, John F. et al. Towards modelling the effects of national culture on IT implementation and acceptance. Journal of Information Technology, v. 16, 2001, p. 145-158.

VENKATESH, Viswanath et al. User Acceptance of Information Technology: Toward a Unified View. MIS Quarterly, 27, 3, Sep 2003, p. 425-478.

VENKATESH, Viswanath; DAVIS, Fred D. A Theoretical Extension of the Technology Acceptance Model: Four Longitudinal Field Studies. Management Science, 46, 2, Feb 2000, p. 186-204.

VENKATESH, Viswanath; MORRIS, Michael G. Why Don't Men Ever Stop to Ask for Directions? Gender, Social Influence, and Their Role in Technology. MIS Quarterly, v. 24, n. 1, Mar. 2000, p. 115-139

WANG, Tzong-Song. Adult Cyber Learning Receptivity Factors. 2003. Dissertation (Doctor of Education). Division of Educational Administration Adult and Higher Education Program in the Graduate School, The University of South Dakota. 
WEIBLE, Rick; WALLACE, John. Cyber research: The impact of the internet on data collection, Marketing Research, Chicago, Fall 1998, Vol. 10, No. 3, página 19-24. 
214 


\section{APÊNDICE 1 - Itens Originais do Instrumento - Modelo TAM}

\begin{tabular}{|c|c|c|c|c|}
\hline Variáveis & Itens & $\begin{array}{l}\text { Venkatesh e Davis } \\
\text { (2000) }\end{array}$ & $\begin{array}{l}\text { Schillewaert et } \\
\text { al (2000) }\end{array}$ & $\begin{array}{l}\text { Venkatesh et } \\
\text { al (2003) }\end{array}$ \\
\hline \multirow{8}{*}{$\begin{array}{l}\text { Perceived } \\
\text { Usefulness }\end{array}$} & Using the system improves my job performance & $\mathrm{X}$ & $\mathrm{X}$ & \\
\hline & Using the system in my job increases my productivity & $\mathrm{X}$ & $\mathrm{X}$ & $\mathrm{X}$ \\
\hline & Using the system enhances my effectiveness on my job & $\mathrm{X}$ & $\mathrm{X}$ & $\mathrm{X}$ \\
\hline & I find the system useful in my job & $\mathrm{X}$ & $\mathrm{X}$ & $\mathrm{X}$ \\
\hline & If I use the system, I will increase my chances of getting a raise & & & $\mathrm{X}$ \\
\hline & The quality of the output I get from the system is high & $\begin{array}{l}\text { X output quality } \\
\text { construct }\end{array}$ & & \\
\hline & I would have difficulty explaining why using the system may or may not be beneficial & $\begin{array}{l}\text { X result } \\
\text { demonstrability } \\
\text { construct }\end{array}$ & & \\
\hline & In my job, usage of the system is important & $\begin{array}{c}\mathrm{X} \text { job relevance } \\
\text { construct }\end{array}$ & & \\
\hline \multirow{4}{*}{$\begin{array}{l}\text { Perceived Ease } \\
\text { of Use }\end{array}$} & I find the system ease to use & $\mathrm{X}$ & $\mathrm{X}$ & $\mathrm{X}$ \\
\hline & I find it ease to get the system to do what I want it to do & $\mathrm{X}$ & $\mathrm{X}$ & $\mathrm{X}$ \\
\hline & My interaction with the system is clear and understandable & $\mathrm{X}$ & $\mathrm{X}$ & $\mathrm{X}$ \\
\hline & I find the system to be flexible to interact with & & & $\mathrm{X}$ \\
\hline \multirow{5}{*}{$\begin{array}{l}\text { Social } \\
\text { Influences }\end{array}$} & The majority of my colleagues in my department use the system & & $\mathrm{X}$ & \\
\hline & I am continuously encouraged by my immediate supervisor to use the system & & $\mathrm{X}$ & \\
\hline & My immediate supervisor repeatedly refers to the importance of using the system during my job & & $\mathrm{X}$ & \\
\hline & People in my organization who use the system have more prestige than those who do not & $\begin{array}{c}\mathrm{X} \\
\text { image construct } \\
\end{array}$ & & \\
\hline & Our competitors use the system extensively & & $\mathrm{X}$ & \\
\hline \multirow[t]{4}{*}{$\begin{array}{l}\text { Facilitating } \\
\text { Conditions }\end{array}$} & $\begin{array}{l}\text { Training } \\
\text { - My company provided me complete instructions and practice in using the system } \\
\text { - I am getting the training I need to be able to use the system effectively }\end{array}$ & & $\mathrm{X}$ & \\
\hline & $\begin{array}{l}\text { Technical User Support } \\
\text { - I know where to turn to when I need any assistance with the system } \\
\text { - In my company we get good technical support for our system } \\
\text { - A specific person (group) is available for assistance with system difficulties }\end{array}$ & & $\begin{array}{l}X \\
X \\
X\end{array}$ & $\mathrm{X}$ \\
\hline & $\begin{array}{l}\text { Organizational Implementation Effort } \\
\quad \text { - From a top management level there is strong interest in the system }\end{array}$ & & $\mathrm{X}$ & \\
\hline & - The usage of the system is strongly championed and advocated by our organization & & $\mathrm{X}$ & \\
\hline
\end{tabular}




\begin{tabular}{|c|c|c|c|c|}
\hline Variáveis & Itens & $\begin{array}{l}\text { Venkatesh e Davis } \\
\quad(2000)\end{array}$ & $\begin{array}{l}\text { Schillewaert et } \\
\text { al (2000) }\end{array}$ & $\begin{array}{l}\text { Venkatesh et } \\
\text { al (2003) }\end{array}$ \\
\hline & $\begin{array}{l}\text { - Extensive internal communication campaigns have promoted the system } \\
\text { - To management shows clear and visible commitment towards the system }\end{array}$ & & $\begin{array}{l}\mathrm{X} \\
\mathrm{X}\end{array}$ & \\
\hline & I have the resources necessary to use the system & & & $\mathrm{X}$ \\
\hline \multirow{3}{*}{$\begin{array}{l}\text { Attitude } \\
\text { Towards the } \\
\text { Innovation }\end{array}$} & Using the system is a good idea & & & $\mathrm{X}$ \\
\hline & Working with the system is fun & & & $\mathrm{X}$ \\
\hline & I like working with the system & & & $\mathrm{X}$ \\
\hline \multirow{2}{*}{$\begin{array}{l}\text { Intention to } \\
\text { Use }\end{array}$} & Assuming I have access to the system, I intend to use it & $\mathrm{X}$ & & $\mathrm{X}$ \\
\hline & Given that I have access to the system, I predict that I would use it & $\mathrm{X}$ & & $\mathrm{X}$ \\
\hline \multirow[t]{2}{*}{ Use Behavior } & Compared to others, I consider myself a frequent user of my company's system & & $\mathrm{X}$ & \\
\hline & Compared to others, I fully use the capabilities of the system & & $\mathrm{X}$ & \\
\hline \multirow[t]{3}{*}{$\begin{array}{l}\text { Personal } \\
\text { Characteristics }\end{array}$} & $\begin{array}{l}\text { Self-efficacy }\left(^{*}\right) \text { (The following questions ask you to indicate whether you could use unfamiliar } \\
\text { system under a variety of conditions. Please rate the extent to which you are confident that you } \\
\text { would be able to complete the job using the new system.) } \\
\text { I could complete a job or task using the system... } \\
\text { - If there was no one around to tell me what to do as I go } \\
\text { - If I had seen someone else using it before trying it myself } \\
\text { - If I could call someone for help if I got stuck } \\
\text { - If I had just the built-in facility for assistance } \\
\text { - If I had used similar systems before this one to do the same job }\end{array}$ & & $\begin{array}{l}X \\
X \\
X \\
X\end{array}$ & $\mathrm{X}$ \\
\hline & $\begin{array}{l}\text { Anxiety } \\
\text { - I feel apprehensive about using the system } \\
\text { - I hesitate to use the system for fear of making mistakes I cannot correct } \\
\text { - The system is somewhat intimidating to me }\end{array}$ & & & $\begin{array}{l}X \\
X \\
X\end{array}$ \\
\hline & $\begin{array}{l}\text { Personal Innovativeness (The following set of statements refers to your attitudes towards all new } \\
\text { technologies and computer applications you may possibly encounter in and outside your job.) } \\
\text { - If I heard about a new technology, I would look for ways to experiment with it } \\
\text { - I must see other people using technology innovations before I will use them } \\
\text { - Among my peers, I am usually among the first to explore new technologies } \\
\text { - I often find myself skeptical of new technologies }\end{array}$ & & $\begin{array}{l}X \\
X \\
X \\
X \\
X\end{array}$ & \\
\hline \multirow{3}{*}{$\begin{array}{l}\text { Voluntariness } \\
\text { of Use }\end{array}$} & My use of the system is voluntary & $\mathrm{X}$ & & \\
\hline & My supervisor does not require me to use the system & $\mathrm{X}$ & & \\
\hline & Although it might be helpful, using the system is certainly not compulsory in my job & $\mathrm{X}$ & & \\
\hline
\end{tabular}

(*) Different scale: "not at all confident / extremely confident" 


\section{APÊNDICE 2 - Questionário da Pesquisa}

\section{Pesquisa USP: Adoção do e-Learning na Empresa}

$\mathrm{Pg} 1$ de 5

\section{Apresentação}

Primeiramente, agradecemos sua disposição e boa vontade em colaborar com a presente pesquisa, conduzida no âmbito do Programa de Pós-Graduação da FEA/USP, com o objetivo de compreender os fatores que influenciam a adoção do e-learning pelos colaboradores em empresas de Telecomunicações e fornecer insights para a prática organizacional.

Este questionário é confidencial, suas respostas individuais não serão reveladas e o resultado da pesquisa somente apresentará dados consolidados.

Nas seções seguintes serão apresentadas questões relacionadas ao projeto de e-learning da sua empresa. É muito importante que você responda da forma mais precisa e sincera possível. As questões indicadas com asterisco $\left(^{*}\right)$ não podem ser deixadas em branco - você não levará mais do que alguns minutos para respondê-las.

Desde já, agradecemos sua colaboração.

\section{Pesquisa USP: Adoção do e-Learning na Empresa}

\section{Introdução}

1. Você já participou de algum curso da Plataforma de e-learning da empresa, desde 2006?*

SIM, eu participei de PELO MENOS UM curso da Plataforma de e-learning, desde 2006.

NÃO, eu não participei de NENHUM curso da Plataforma de e-learning, desde 2006. 
Pesquisa USP: Adoção do e-Learning na Empresa

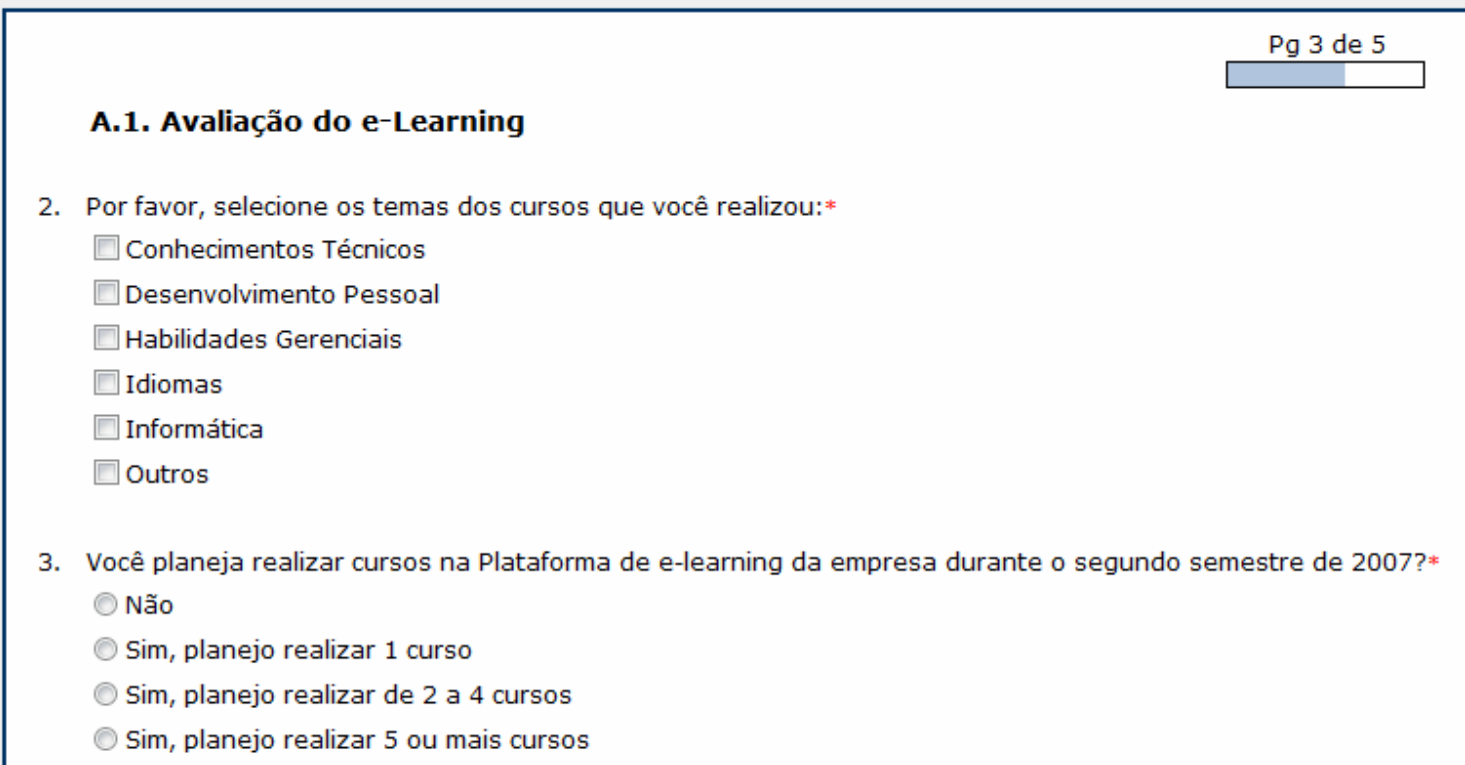

4. Você já realizou cursos de e-learning fora da Plataforma da empresa?

Não

Sim, por exemplo: 
5. Considere os cursos da Plataforma de e-learning da empresa dos quais participou, desde 2006, para avaliar o grau de concordância com as afirmações a seguir:*

Legenda: Concordo Fortemente / Concordo / Concordo Parcialmente / Neutro / Discordo Parcialmente / Discordo / Discordo Fortemente

$\begin{aligned} \text { Conc. Conc. Conc. Neut. Disc. Darc. Disc. Parc. Dort. } & \text { Fort. Parc. }\end{aligned}$

A participação em cursos de e-learning é importante para a realização do meu trabalho

A maioria dos colegas da minha área participa de cursos de e-learning

Achei o e-learning fácil de usar

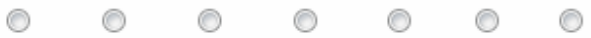

○ 00000

Comparado com outras pessoas, eu considero que participo dos cursos de e-learning com maior frequencia que a média

A participação em cursos de e-learning melhorou meu desempenho no trabalho

Comparado com outras pessoas, eu tiro melhor proveito dos cursos de e-learning disponíveis na empresa

Eu gosto de participar de cursos de e-learning

O

C

○ $\bigcirc 0$

Eu obtive ótimos resultados de aprendizagem com o elearning

00000

Eu sou continuamente encorajado pelo meu superior imediato a participar dos cursos de e-learning

Eu teria facilidade em explicar os benefícios do elearning

Meu superior imediato freqüentemente aponta a importância do e-learning

Minha interação com o ambiente do e-learning foi clara e compreensível

O e-learning é útil em meu trabalho

Participar de cursos de e-learning é uma boa idéia

Quando participo de cursos de e-learning, estou aumentando minhas chances de ser promovido(a)

Se a Plataforma de e-learning disponibilizasse mais cursos do meu interesse, eu a utilizaria com maior freqüência

○ 00000

○ 00000

○ 00000

○ 00000

○ 00000

○ 00000

$\circ \quad 0 \quad 0 \quad 0 \quad 0$

○ 00000

○ 00000

○ 00000

O e-learning permite maior flexibilidade para aprender Se eu tivesse mais tempo, eu utilizaria o e-learning com maior freqüência

Sinto-me satisfeito(a) em utilizar o e-learning

As pessoas da minha empresa que participam de cursos

de e-learning têm mais prestígio do que aquelas que não participam

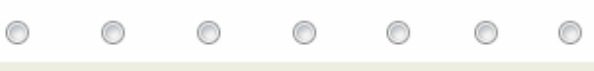

00000

○ $\bigcirc 000$

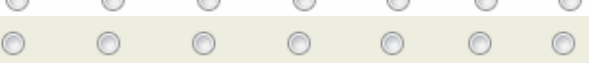

○ 00000

$0 \quad 0 \quad 0 \quad 00000$ 
Pesquisa USP: Adoção do e-Learning na Empresa

$\mathrm{Pg} 4$ de 5

\section{A.2. Avaliação do e-Learning}

2. Quais itens a seguir explicam os motivos de não participação em nenhum curso da Plataforma de e-learning da empresa, desde 2006?*
$\square$ Falta de tempo
$\square$ Dificuldade no acesso à Plataforma de e-learning
$\square$ Recursos tecnológicos insuficientes (ex.: acesso à internet)
$\square$ e-Learning não funciona
$\square$ Não sei acessar a Plataforma de e-learning
$\square$ outro. Por favor, especifique:

3. Você planeja realizar cursos na Plataforma de e-learning da empresa em 2007 ?*
Não
Sim, planejo realizar 1 curso
Sim, planejo realizar de 2 a 4 cursos
Sim, planejo realizar 5 ou mais cursos

4. No caso de realizar cursos na Plataforma de e-learning da empresa, por favor, selecione os temas de interesse.*

$\square$ Conhecimentos Técnicos

$\square$ Desenvolvimento Pessoal

$\square$ Habilidades Gerenciais

$\square$ Idiomas

$\square$ Informática

$\square$ Outros temas

$\square$ Não planejo realizar cursos de e-learning em 2007

5. Você já realizou cursos de e-learning fora da Plataforma da empresa?
Não
Sim, por exemplo:

6. Considere os cursos disponíveis na Plataforma de e-elearning da sua empresa para avaliar o grau de concordância com as afirmações a seguir:*

Legenda: Concordo Fortemente / Concordo / Concordo Parcialmente / Neutro / Discordo Parcialmente / Discordo / Discordo Fortemente

\begin{tabular}{|c|c|c|c|c|c|c|c|}
\hline & $\begin{array}{l}\text { Conc. } \\
\text { Fort. }\end{array}$ & Conc. & $\begin{array}{l}\text { Conc. } \\
\text { Parc. }\end{array}$ & Neut. & $\begin{array}{l}\text { Disc. } \\
\text { Parc. }\end{array}$ & Disc. & $\begin{array}{l}\text { Disc. } \\
\text { Fort. }\end{array}$ \\
\hline $\begin{array}{l}\text { A participação em cursos de e-learning é importante } \\
\text { para a realização do meu trabalho }\end{array}$ & 0 & $\bigcirc$ & ○ & ○ & 0 & O & ○ \\
\hline $\begin{array}{l}\text { A maioria dos colegas da minha área participa de cursos } \\
\text { de e-learning }\end{array}$ & ○ & ○ & ○ & O & ○ & ○ & ○ \\
\hline O e-learning parece fácil de usar & ○ & ○ & O & 0 & 0 & O & $\bigcirc$ \\
\hline $\begin{array}{l}\text { A participação em cursos de e-learning pode melhorar } \\
\text { meu desempenho no trabalho }\end{array}$ & 0 & $\bigcirc$ & O & $\bigcirc$ & 0 & ○ & ○ \\
\hline Eu gostaria de participar de cursos de e-learning & O & ○ & 0 & 0 & 0 & 0 & 0 \\
\hline $\begin{array}{l}\text { Eu poderia obter ótimos resultados de aprendizagem } \\
\text { com o e-learning }\end{array}$ & 0 & 0 & 0 & 0 & 0 & 0 & (1) \\
\hline $\begin{array}{l}\text { Eu sou continuamente encorajado pelo meu superior } \\
\text { imediato a participar dos cursos de e-learning }\end{array}$ & 0 & 0 & $\odot$ & 0 & (1) & 0 & 0 \\
\hline
\end{tabular}


Eu teria facilidade em explicar os benefícios do elearning

Meu superior imediato freqüentemente aponta a importância do e-learning

A interação com o ambiente do e-learning parece clara e compreensível

O e-learning pode ser útil em meu trabalho

Participar de cursos de e-learning é uma boa idéia

Se eu participasse de cursos de e-learning, estaria aumentando minhas chances de ser promovido(a)

Se a Plataforma de e-learning da empresa

disponibilizasse mais cursos do meu interesse, eu utilizaria o e-learning

O e-learning permite maior flexibilidade para aprender

Se eu tivesse mais tempo, eu utilizaria o e-learning

Eu ficaria satisfeito(a) em utilizar o e-learning

As pessoas da minha empresa que participam de cursos

de e-learning têm mais prestígio do que aquelas que não participam

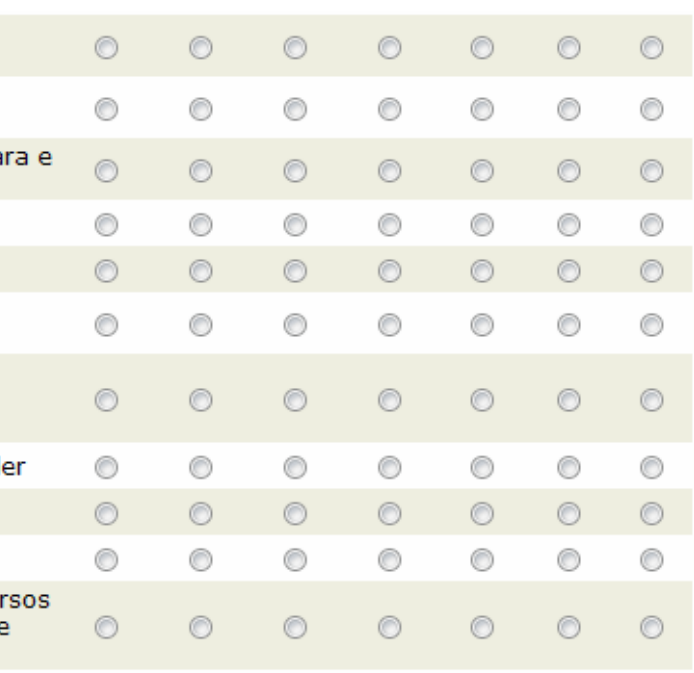

Pesquisa USP: Adoção do e-Learning na Empresa

\begin{tabular}{|c|c|c|c|c|c|c|c|c|}
\hline & & & & & & \multicolumn{3}{|c|}{$\mathrm{Pg} 5$ de 5} \\
\hline & \multicolumn{8}{|l|}{ B. Projeto de e-Learning \& Novas Tecnologias } \\
\hline 6. & \multicolumn{8}{|c|}{$\begin{array}{l}\text { Considere o projeto de e-learning da sua empresa para avaliar o grau de concordância com as afirmações a } \\
\text { seguir:* } \\
\text { Legenda: Concordo Fortemente / Concordo / Concordo Parcialmente / Neutro / Discordo Parcialmente / Discordo / Discordo } \\
\text { Fortemente }\end{array}$} \\
\hline & & $\begin{array}{l}\text { Conc. } \\
\text { Fort. }\end{array}$ & Conc. & $\begin{array}{l}\text { Conc. } \\
\text { Parc. }\end{array}$ & Neut. & $\begin{array}{l}\text { Disc. } \\
\text { Parc. }\end{array}$ & Disc. & $\begin{array}{l}\text { Disc. } \\
\text { Fort. }\end{array}$ \\
\hline & $\begin{array}{l}\text { A campanha de incentivo realizada estimulou o uso do e- } \\
\text { learning na empresa }\end{array}$ & O & 0 & 0 & 0 & ○ & O & ○ \\
\hline & $\begin{array}{l}\text { A alta administração da empresa demonstra claramente } \\
\text { estar comprometida com o uso do e-learning }\end{array}$ & O & ○ & 0 & O & O & O & ○ \\
\hline & $\begin{array}{l}\text { A cultura da organização favorece a adoção do e- } \\
\text { learning pelos colaboradores }\end{array}$ & ○ & ○ & O & ○ & O & O & ○ \\
\hline & $\begin{array}{l}\text { A participação em cursos de e-learning é fortemente } \\
\text { patrocinada e defendida pela minha empresa }\end{array}$ & 0 & O & O & ○ & ○ & ○ & ○ \\
\hline & $\begin{array}{l}\text { A empresa disponibilizou instruções e orientações } \\
\text { suficientes para o uso do e-learning }\end{array}$ & 0 & 0 & 0 & 0 & 0 & 0 & ○ \\
\hline & $\begin{array}{l}\text { Eu possuo os recursos tecnológicos suficientes para } \\
\text { participar dos cursos de e-learning }\end{array}$ & 0 & 0 & 0 & (1) & 0 & 0 & ○ \\
\hline & $\begin{array}{l}\text { Eu sei onde procurar, caso precise de assistência para } \\
\text { utilizar o e-learning }\end{array}$ & 0 & 0 & 0 & 0 & 0 & 0 & ○ \\
\hline & $\begin{array}{l}\text { Há campanhas corporativas de comunicação interna que } \\
\text { promovem o e-learning com sucesso }\end{array}$ & 0 & 0 & 0 & 0 & 0 & 0 & 0 \\
\hline & $\begin{array}{l}\text { O e-learning tem grande potencial para atender às } \\
\text { necessidades de treinamento da minha área de negócio }\end{array}$ & 0 & 0 & 0 & 0 & 0 & 0 & ○ \\
\hline & $\begin{array}{l}\text { A empresa possui uma cultura que valoriza a } \\
\text { aprendizagem }\end{array}$ & 0 & 0 & 0 & 0 & 0 & 0 & 0 \\
\hline & $\begin{array}{l}\text { O projeto de e-learning existente na empresa atende } \\
\text { adequadamente às necessidades do negócio }\end{array}$ & 0 & 0 & 0 & 0 & 0 & 0 & ○ \\
\hline & $\begin{array}{l}\text { Uma pessoa específica (ou grupo) está à disposição } \\
\text { para auxiliar no caso de dificuldades com o e-learning }\end{array}$ & 0 & 0 & 0 & 0 & 0 & ○ & ○ \\
\hline
\end{tabular}


7. As afirmações a seguir se referem à sua atitude em relação a novas tecnologias e sistemas de informática que você possa encontrar dentro ou fora do seu ambiente de trabalho:

Legenda: Concordo Fortemente / Concordo / Concordo Parcialmente / Neutro / Discordo Parcialmente / Discordo / Discordo Fortemente

Conc. Conc. Conc. Neut. Disc. Disc. Disc.

Entre meus pares, eu normalmente estou entre os primeiros a explorar novas tecnologias

$\begin{array}{lll}\text { Conc. Conc. Conc. Neut. Disc. Disc. } & \text { Disc. } \\ \text { Fort. } & \text { Parc. }\end{array}$

Eu tenho habilidade para utilizar um software sem tê-lo

visto operando anteriormente

Eu freqüentemente tenho uma atitude cética em relação

a novas tecnologias

Eu preciso ver um software sendo usado, antes de usá-

lo por mim mesmo

Eu tenho facilidade no uso de informática

Eu preciso ver uma inovação sendo usada, antes de

usá-la por mim mesmo

- 10

Se eu fico sabendo de uma nova tecnologia, eu vou

procurar caminhos para experimentá-la

$\begin{array}{ccccccc}0 & 0 & 0 & 0 & 0 & 0 & 0 \\ 0 & 0 & 0 & 0 & 0 & 0 & 0 \\ 0 & 0 & 0 & 0 & 0 & 0 & 0 \\ 0 & 0 & 0 & 0 & 0 & 0 & 0 \\ 0 & 0 & 0 & 0 & 0 & 0 & 0 \\ 0 & 0 & 0 & 0 & 0 & 0 & 0 \\ 0 & 0 & 0 & 0 & 0 & 0 & 0\end{array}$

8. Comentários / Sugestões:

\section{Pesquisa USP: Adoção do e-Learning na Empresa}

Pesquisa Finalizada

Muito obrigado por completar este questionário! Sua colaboração foi de grande valor para a pesquisa. Os resultados serão divulgados em breve. 


\section{APÊNDICE 3 - Roteiros de Entrevista}

\section{Roteiro de Entrevista com Especialistas de e-Learning}

- Em sua opinião, quais os fatores mais importantes que influenciam a adoção individual do e-learning nas organizações?

- Considerando o Modelo de Adoção Individual do e-Learning proposto, que ajustes você sugere?

\section{Roteiro da Entrevista com Responsável pelo e-Learning na Empresa}

- Qual a solução de e-learning adotada atualmente pela empresa (conteúdos, serviços e tecnologias)?

- A participação nos cursos de e-learning na empresa é voluntária?

- A empresa oferece incentivos aos funcionários para participarem nos cursos de $e$ learning? Em caso positivo, que tipo de incentivos?

- Como são alocados os custos do e-learning? Os cursos são gratuitos para o funcionário? E para o departamento?

- Até que ponto a estratégia de e-learning está integrada com os processos de gestão de pessoas da empresa? Que processos estão relacionados (por exemplo, controle do treinamento, avaliação de desempenho, gestão por competências)? Há integração entre os softwares e soluções utilizadas?

- Qual a relação entre as iniciativas de e-learning conduzidas no Brasil e as de outros países de atuação da empresa?

- Você considera que os processos praticados atualmente na condução das iniciativas de $e$ learning são adequados? Que melhorias poderiam ser implementadas?

- Qual a estrutura atual da equipe envolvida nas iniciativas de e-learning? A equipe possui as competências adequadas para realizar o trabalho?

- Qual a importância das parcerias para os projetos de e-learning? Há dificuldades na seleção e gestão dessas parcerias?

- Você considera que a infra-estrutura disponível atualmente na empresa é adequada para a realização dos projetos de e-learning (hardware dos participantes, servidores, equipe técnica de suporte e software de gestão de e-learning)? 
- Em sua opinião, os recursos financeiros disponíveis para investimento em e-learning são suficientes? Estão adequados com a realidade atual e necessidades da empresa?

- Os projetos de e-learning realizados até o momento apresentaram retorno sobre o investimento aceitável?

- Como o funcionário aprende a utilizar o sistema de e-learning?

- Como funciona o suporte técnico disponibilizado aos usuários do sistema de e-learning?

- Em sua opinião, a alta administração apóia publicamente e através de ações o uso do $e$ learning na empresa? E quanto aos líderes?

- Que tipo de comunicação é realizada para divulgar o e-learning internamente?

- Você acha que a cultura organizacional ajuda ou atrapalha a adoção do e-learning (valor para a aprendizagem, apoio à inovação, compatibilidade com práticas existentes)?

- E quanto à estrutura organizacional (níveis de centralização e de formalização) e ambiente externo da empresa (características do setor e regulamentações)?

- Qual o potencial do e-learning para atender necessidades de treinamento da empresa?

- Você considera que as iniciativas de e-learning em andamento têm atendido às necessidades do negócio? 


\section{APÊNDICE 4 - Tabela de Comunalidades}

\begin{tabular}{|c|c|c|}
\hline Fator & Variável & $\begin{array}{l}\text { Comuna- } \\
\text { lidade }\end{array}$ \\
\hline \multirow{10}{*}{$\begin{array}{l}\text { Utilidade } \\
\text { Percebida }\end{array}$} & Eu obtive (poderia obter) ótimos resultados de aprendizagem com o $e$-learning & 0,727 \\
\hline & O e-learning é (pode ser) útil em meu trabalho & 0,721 \\
\hline & Eu gosto (gostaria) de participar de cursos de e-learning & 0,661 \\
\hline & $\begin{array}{l}\text { A participação em cursos de e-learning melhorou (pode melhorar) meu desempenho no } \\
\text { trabalho }\end{array}$ & 0,680 \\
\hline & Participar de cursos de e-learning é uma boa idéia & 0,627 \\
\hline & Sinto-me (eu ficaria) satisfeito(a) em utilizar o e-learning & 0,625 \\
\hline & O e-learning permite maior flexibilidade para aprender & 0,494 \\
\hline & $\begin{array}{l}\text { O e-learning tem grande potencial para atender às necessidades de treinamento da } \\
\text { minha área de negócio }\end{array}$ & 0,579 \\
\hline & A participação em cursos de e-learning é importante para a realização do meu trabalho & 0,494 \\
\hline & $\begin{array}{l}\text { O projeto de e-learning existente na empresa atende adequadamente às necessidades do } \\
\text { negócio }\end{array}$ & 0,661 \\
\hline \multirow{10}{*}{$\begin{array}{l}\text { Ambiente } \\
\text { Propício à } \\
\text { Aprendiza- } \\
\text { gem }\end{array}$} & Meu superior imediato freqüentemente aponta a importância do e-learning & 0,798 \\
\hline & $\begin{array}{l}\text { Eu sou continuamente encorajado pelo meu superior imediato a participar dos cursos de } \\
\text { e-learning }\end{array}$ & 0,782 \\
\hline & $\begin{array}{l}\text { A participação em cursos de e-learning é fortemente patrocinada e defendida pela } \\
\text { minha empresa }\end{array}$ & 0,705 \\
\hline & $\begin{array}{l}\text { A alta administração da empresa demonstra claramente estar comprometida com o uso } \\
\text { do } e \text {-learning }\end{array}$ & 0,727 \\
\hline & A maioria dos colegas da minha área participa de cursos de e-learning & 0,543 \\
\hline & A cultura da organização favorece a adoção do e-learning pelos colaboradores & 0,684 \\
\hline & $\begin{array}{l}\text { As pessoas da minha empresa que participam de cursos de e-learning têm mais prestígio } \\
\text { do que aquelas que não participam }\end{array}$ & 0,611 \\
\hline & A empresa possui uma cultura que valoriza a aprendizagem & 0,529 \\
\hline & A campanha de incentivo realizada em 2006 estimulou o uso do e-learning na empresa & 0,540 \\
\hline & $\begin{array}{l}\text { Quando participo (se eu participasse) de cursos de e-learning, estou (estaria) } \\
\text { aumentando minhas chances de ser promovido(a) }\end{array}$ & 0,619 \\
\hline \multirow{8}{*}{$\begin{array}{l}\text { Facilidade } \\
\text { de Uso } \\
\text { Percebida }\end{array}$} & Achei o $(\mathrm{O})$ e-learning (parece) fácil de usar & 0,637 \\
\hline & A empresa disponibilizou instruções e orientações suficientes para o uso do e-learning & 0,663 \\
\hline & Eu sei onde procurar, caso precise de assistência para utilizar o $e$-learning & 0,588 \\
\hline & Minha (A) interação com o ambiente do e-learning foi (parece) clara e compreensível & 0,647 \\
\hline & Eu possuo os recursos tecnológicos suficientes para participar dos cursos de $e$-learning & 0,515 \\
\hline & $\begin{array}{l}\text { Há campanhas corporativas de comunicação interna que promovem o e-learning com } \\
\text { sucesso }\end{array}$ & 0,627 \\
\hline & $\begin{array}{l}\text { Uma pessoa específica (ou grupo) está à disposição para auxiliar no caso de } \\
\text { dificuldades com o e-learning }\end{array}$ & 0,526 \\
\hline & Eu teria facilidade em explicar os benefícios do e-learning & 0,560 \\
\hline \multirow{4}{*}{$\begin{array}{l}\text { Habilidade } \\
\text { com } \\
\text { Informática } \\
\text { e Pré- } \\
\text { disposição } \\
\text { para } \\
\text { Inovador }\end{array}$} & Eu tenho habilidade para utilizar um software sem tê-lo visto operando anteriormente & 0,678 \\
\hline & Eu tenho facilidade no uso de informática & 0,618 \\
\hline & $\begin{array}{l}\text { Se eu fico sabendo de uma nova tecnologia, eu vou procurar caminhos para } \\
\text { experimentá-la }\end{array}$ & 0,621 \\
\hline & eus pares, eu normalmente estou entre os primeiros a explorar novas tecnologias & 0,611 \\
\hline \multirow{3}{*}{$\begin{array}{l}\text { Descon- } \\
\text { fiança em } \\
\text { Relação à } \\
\text { Inovação }\end{array}$} & Eu preciso ver uma inovação sendo usada, antes de usá-la por mim mesmo & 0,780 \\
\hline & Eu freqüentemente tenho uma atitude cética em relação a novas tecnologias & 0,673 \\
\hline & Eu preciso ver um software sendo usado, antes de usá-lo por mim mesmo & 0,770 \\
\hline
\end{tabular}




\section{APÊNDICE 5 - Distribuição da Concordância Total em Relação às Variáveis da Pesquisa}

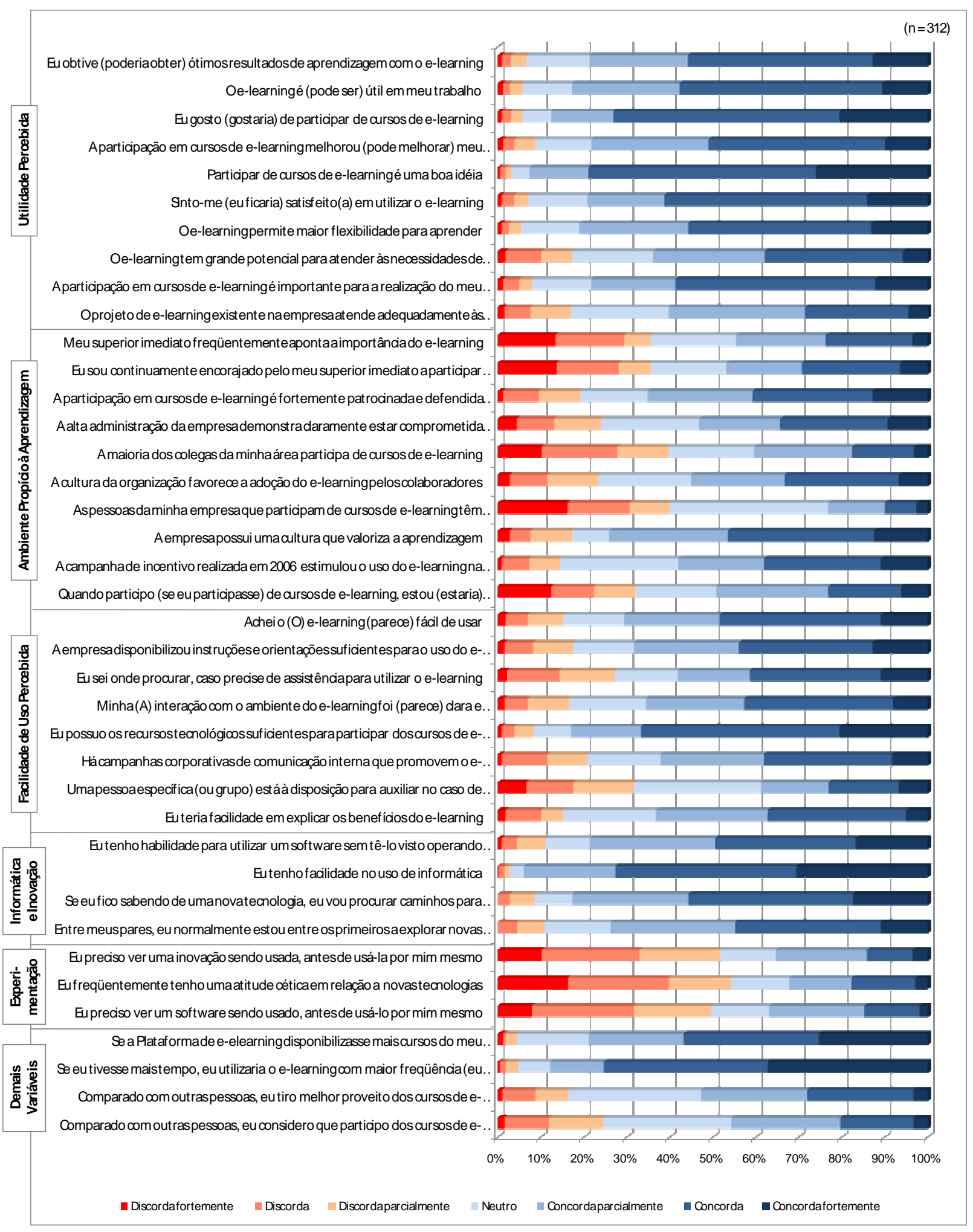




\section{APÊNDICE 6 - Prova de Mann-Whitney para a Variável Realização de Cursos de $e$ - Learning Fora da Plataforma da Empresa}

\begin{tabular}{|c|c|c|c|c|c|}
\hline Fator & Variável & $\begin{array}{c}\text { Mann- } \\
\text { Whitney U }\end{array}$ & $\mathbf{Z}$ & $\mathbf{p}$ & \\
\hline \multirow[t]{10}{*}{$\begin{array}{l}\text { Utilidade } \\
\text { Percebida }\end{array}$} & $\begin{array}{l}\text { Eu obtive (poderia obter) ótimos resultados de aprendizagem } \\
\text { com o e-learning }\end{array}$ & 8837 & $-0,494$ & 0,621 & \\
\hline & O e-learning é (pode ser) útil em meu trabalho & 9152,5 & $-0,012$ & 0,991 & \\
\hline & Eu gosto (gostaria) de participar de cursos de e-learning & 8702,5 & $-0,724$ & 0,469 & \\
\hline & $\begin{array}{l}\text { A participação em cursos de } e \text {-learning melhorou (pode } \\
\text { melhorar) meu desempenho no trabalho }\end{array}$ & 8473,5 & $-1,047$ & 0,295 & \\
\hline & Participar de cursos de e-learning é uma boa idéia & 8754,5 & $-0,647$ & 0,518 & \\
\hline & Sinto-me (eu ficaria) satisfeito(a) em utilizar o e-learning & 9070,5 & $-0,138$ & 0,89 & \\
\hline & $\mathrm{O} e$-learning permite maior flexibilidade para aprender & 7338,5 & $-2,787$ & 0,005 & $* *_{\mathrm{S}}$ \\
\hline & $\begin{array}{l}\text { O e-learning tem grande potencial para atender às } \\
\text { necessidades de treinamento da minha área de negócio }\end{array}$ & 8623 & $-0,804$ & 0,421 & \\
\hline & $\begin{array}{l}\text { A participação em cursos de e-learning é importante para a } \\
\text { realização do meu trabalho }\end{array}$ & 8579,5 & $-0,894$ & 0,371 & \\
\hline & $\begin{array}{l}\text { O projeto de e-learning existente na empresa atende } \\
\text { adequadamente às necessidades do negócio }\end{array}$ & 7882 & $-1,914$ & 0,056 & $* \mathrm{n}$ \\
\hline \multirow{10}{*}{$\begin{array}{l}\text { Ambiente } \\
\text { Propício à } \\
\text { Aprendiza- } \\
\text { gem }\end{array}$} & $\begin{array}{l}\text { Meu superior imediato freqüentemente aponta a importância } \\
\text { do e-learning }\end{array}$ & 8179,5 & $-1,449$ & 0,147 & \\
\hline & $\begin{array}{l}\text { Eu sou continuamente encorajado pelo meu superior } \\
\text { imediato a participar dos cursos de e-learning }\end{array}$ & 7931 & $-1,813$ & 0,07 & $*_{\mathrm{n}}$ \\
\hline & $\begin{array}{l}\text { A participação em cursos de e-learning é fortemente } \\
\text { patrocinada e defendida pela minha empresa }\end{array}$ & 7412 & $-2,598$ & 0,009 & $* * \mathrm{n}$ \\
\hline & $\begin{array}{l}\text { A alta administração da empresa demonstra claramente estar } \\
\text { comprometida com o uso do e-learning }\end{array}$ & 7759,5 & $-2,074$ & 0,038 & $* * \mathrm{n}$ \\
\hline & $\begin{array}{l}\text { A maioria dos colegas da minha área participa de cursos de } \\
\text { e-learning }\end{array}$ & 8046,5 & $-1,644$ & 0,1 & \\
\hline & $\begin{array}{l}\text { A cultura da organização favorece a adoção do e-learning } \\
\text { pelos colaboradores }\end{array}$ & 8042 & $-1,66$ & 0,097 & $*_{\mathrm{n}}$ \\
\hline & $\begin{array}{l}\text { As pessoas da minha empresa que participam de cursos de } e \text { - } \\
\text { learning têm mais prestígio do que aquelas que não } \\
\text { participam }\end{array}$ & 8152,5 & $-1,51$ & 0,131 & \\
\hline & A empresa possui uma cultura que valoriza a aprendizagem & 8001 & $-1,741$ & 0,082 & $*_{n}$ \\
\hline & $\begin{array}{l}\text { A campanha de incentivo realizada em } 2006 \text { estimulou o uso } \\
\text { do e-learning na empresa }\end{array}$ & 8030,5 & $-1,685$ & 0,092 & $*_{\mathrm{n}}$ \\
\hline & $\begin{array}{l}\text { Quando participo (se eu participasse) de cursos de } e \text { - } \\
\text { learning, estou (estaria) aumentando minhas chances de ser } \\
\text { promovido(a) }\end{array}$ & 8913 & $-0,365$ & 0,715 & \\
\hline
\end{tabular}

Legenda:

** prova significativa a um nível de significância de 0,05: foi possível apontar diferença entre as amostras * $\quad$ prova significativa a um nível de significância de 0,10 : foi possível apontar diferença entre as amostras Expressão sem qualquer indicador, prova estatística não significativa: não foi possível concluir pela diferença entre as duas amostras

$\mathrm{S} \quad$ maior concordância dos respondentes que realizaram curso de e-learning fora da plataforma da empresa

$\mathrm{n}$ maior concordância dos respondentes que não realizaram curso de e-learning fora da plataforma da empresa 
(Continuação)

\begin{tabular}{|c|c|c|c|c|c|}
\hline Fator & Variável & $\begin{array}{c}\text { Mann- } \\
\text { Whitney U }\end{array}$ & $\mathbf{Z}$ & $\mathbf{p}$ & \\
\hline \multirow{8}{*}{$\begin{array}{l}\text { Facilidade de } \\
\text { Uso } \\
\text { Percebida }\end{array}$} & Achei o (O) e-learning (parece) fácil de usar & 8777,5 & $-0,576$ & 0,565 & \\
\hline & $\begin{array}{l}\text { A empresa disponibilizou instruções e orientações } \\
\text { suficientes para o uso do e-learning }\end{array}$ & 8512 & $-0,967$ & 0,334 & \\
\hline & $\begin{array}{l}\text { Eu sei onde procurar, caso precise de assistência para } \\
\text { utilizar o e-learning }\end{array}$ & 8646 & $-0,763$ & 0,446 & \\
\hline & $\begin{array}{l}\text { Minha (A) interação com o ambiente do e-learning foi } \\
\text { (parece) clara e compreensível }\end{array}$ & 9093,5 & $-0,1$ & 0,921 & \\
\hline & $\begin{array}{l}\text { Eu possuo os recursos tecnológicos suficientes para } \\
\text { participar dos cursos de e-learning }\end{array}$ & 8314,5 & $-1,304$ & 0,192 & \\
\hline & $\begin{array}{l}\text { Há campanhas corporativas de comunicação interna que } \\
\text { promovem o e-learning com sucesso }\end{array}$ & 7753,5 & $-2,095$ & 0,036 & $* * \mathrm{n}$ \\
\hline & $\begin{array}{l}\text { Uma pessoa específica (ou grupo) está à disposição para } \\
\text { auxiliar no caso de dificuldades com o e-learning }\end{array}$ & 8499 & $-0,98$ & 0,327 & \\
\hline & Eu teria facilidade em explicar os benefícios do e-learning & 7634,5 & $-2,288$ & 0,022 & $* * \mathrm{~s}$ \\
\hline \multirow{4}{*}{$\begin{array}{l}\text { Habilidade } \\
\text { com } \\
\text { Informática e } \\
\text { Pré- } \\
\text { disposição } \\
\text { para } \\
\text { Inovador }\end{array}$} & $\begin{array}{l}\text { Eu tenho habilidade para utilizar um software sem tê-lo visto } \\
\text { operando anteriormente }\end{array}$ & 7071 & $-3,143$ & 0,002 & $* *_{\mathrm{s}}$ \\
\hline & Eu tenho facilidade no uso de informática & 6781,5 & $-3,622$ & 0 & $* * \mathrm{~s}$ \\
\hline & $\begin{array}{l}\text { Se eu fico sabendo de uma nova tecnologia, eu vou procurar } \\
\text { caminhos para experimentá-la }\end{array}$ & 7745,5 & $-2,093$ & 0,036 & $* * \mathrm{~s}$ \\
\hline & $\begin{array}{l}\text { Entre meus pares, eu normalmente estou entre os primeiros a } \\
\text { explorar novas tecnologias }\end{array}$ & 8196,5 & $-1,395$ & 0,163 & \\
\hline \multirow{3}{*}{$\begin{array}{l}\text { Desconfiança } \\
\text { em Relação à } \\
\text { Inovação }\end{array}$} & $\begin{array}{l}\text { Eu preciso ver uma inovação sendo usada, antes de usá-la } \\
\text { por mim mesmo }\end{array}$ & 6907 & $-3,329$ & 0,001 & $* * \mathrm{n}$ \\
\hline & $\begin{array}{l}\text { Eu freqüentemente tenho uma atitude cética em relação a } \\
\text { novas tecnologias }\end{array}$ & 7576,5 & $-2,286$ & 0,022 & $* * \mathrm{n}$ \\
\hline & $\begin{array}{l}\text { Eu preciso ver um software sendo usado, antes de usá-lo por } \\
\text { mim mesmo }\end{array}$ & 6922 & $-3,311$ & 0,001 & $* * \mathrm{n}$ \\
\hline \multirow[t]{2}{*}{$\begin{array}{l}\text { Intenção de } \\
\text { Uso }\end{array}$} & $\begin{array}{l}\text { Se a Plataforma da Empresa disponibilizasse mais cursos do } \\
\text { meu interesse, eu a utilizaria o e-learning }\end{array}$ & 8039,5 & $-1,682$ & 0,093 & $*_{\mathrm{s}}$ \\
\hline & Se eu tivesse mais tempo, eu utilizaria o e-learning & 8769 & $-0,602$ & 0,547 & \\
\hline \multirow{2}{*}{$\begin{array}{l}\text { Comporta- } \\
\text { mento de } \\
\text { Uso }\end{array}$} & $\begin{array}{l}\text { Comparado com outras pessoas, eu considero que participo } \\
\text { dos cursos de } e \text {-learning com maior freqüência que a média }\end{array}$ & 3029 & $-0,398$ & 0,69 & \\
\hline & $\begin{array}{l}\text { Comparado com outras pessoas, eu tiro melhor proveito dos } \\
\text { cursos de e-learning disponíveis na Plataforma da Empresa }\end{array}$ & 2822,5 & $-1,089$ & 0,276 & \\
\hline
\end{tabular}

Legenda:

** prova significativa a um nível de significância de 0,05 : foi possível apontar diferença entre as amostras

* prova significativa a um nível de significância de 0,10 : foi possível apontar diferença entre as amostras Expressão sem qualquer indicador, prova estatística não significativa: não foi possível concluir pela diferença entre as duas amostras

$\mathrm{s}$ maior concordância dos respondentes que realizaram curso de $e$-learning fora da plataforma da empresa

$\mathrm{n}$ maior concordância dos respondentes que não realizaram curso de e-learning fora da plataforma da empresa 


\section{APÊNDICE 7 - Prova de Mann-Whitney para a Variável Gênero}

\begin{tabular}{|c|c|c|c|c|c|}
\hline Fator & Variável & $\begin{array}{c}\text { Mann- } \\
\text { Whitney U }\end{array}$ & $\mathbf{Z}$ & $\mathbf{p}$ & \\
\hline \multirow[t]{10}{*}{$\begin{array}{l}\text { Utilidade } \\
\text { Percebida }\end{array}$} & $\begin{array}{l}\text { Eu obtive (poderia obter) ótimos resultados de aprendizagem } \\
\text { com o e-learning }\end{array}$ & 10005,5 & $-0,927$ & 0,354 & \\
\hline & O e-learning é (pode ser) útil em meu trabalho & 9345 & $-1,888$ & 0,059 & $* \mathrm{~m}$ \\
\hline & Eu gosto (gostaria) de participar de cursos de e-learning & 10046,5 & $-0,899$ & 0,369 & \\
\hline & $\begin{array}{l}\text { A participação em cursos de e-learning melhorou (pode } \\
\text { melhorar) meu desempenho no trabalho }\end{array}$ & 9629,5 & $-1,455$ & 0,146 & \\
\hline & Participar de cursos de e-learning é uma boa idéia & 9380 & $-1,889$ & 0,059 & $*_{\mathrm{m}}$ \\
\hline & Sinto-me (eu ficaria) satisfeito(a) em utilizar o e-learning & 9404,5 & $-1,795$ & 0,073 & $*_{\mathrm{m}}$ \\
\hline & O e-learning permite maior flexibilidade para aprender & 9311,5 & $-1,91$ & 0,056 & $*_{\mathrm{m}}^{\mathrm{m}}$ \\
\hline & $\begin{array}{l}\text { O e-learning tem grande potencial para atender às } \\
\text { necessidades de treinamento da minha área de negócio }\end{array}$ & 9374,5 & $-1,782$ & 0,075 & $*_{\mathrm{m}}$ \\
\hline & $\begin{array}{l}\text { A participação em cursos de e-learning é importante para a } \\
\text { realização do meu trabalho }\end{array}$ & 9159 & $-2,142$ & 0,032 & $* * \mathrm{~m}$ \\
\hline & $\begin{array}{l}\text { O projeto de } e \text {-learning existente na empresa atende } \\
\text { adequadamente às necessidades do negócio }\end{array}$ & 10231 & $-0,595$ & 0,552 & \\
\hline \multirow{10}{*}{$\begin{array}{l}\text { Ambiente } \\
\text { Propício à } \\
\text { Aprendiza- } \\
\text { gem }\end{array}$} & $\begin{array}{l}\text { Meu superior imediato freqüentemente aponta a importância } \\
\text { do e-learning }\end{array}$ & 10465 & $-0,267$ & 0,789 & \\
\hline & $\begin{array}{l}\text { Eu sou continuamente encorajado pelo meu superior } \\
\text { imediato a participar dos cursos de e-learning }\end{array}$ & 10453,5 & $-0,283$ & 0,778 & \\
\hline & $\begin{array}{l}\text { A participação em cursos de e-learning é fortemente } \\
\text { patrocinada e defendida pela minha empresa }\end{array}$ & 10646,5 & $-0,019$ & 0,985 & \\
\hline & $\begin{array}{l}\text { A alta administração da empresa demonstra claramente estar } \\
\text { comprometida com o uso do e-learning }\end{array}$ & 10340 & $-0,439$ & 0,66 & \\
\hline & $\begin{array}{l}\text { A maioria dos colegas da minha área participa de cursos de } \\
\text { e-learning }\end{array}$ & 10036 & $-0,853$ & 0,394 & \\
\hline & $\begin{array}{l}\text { A cultura da organização favorece a adoção do e-learning } \\
\text { pelos colaboradores }\end{array}$ & 9990 & $-0,921$ & 0,357 & \\
\hline & $\begin{array}{l}\text { As pessoas da minha empresa que participam de cursos de } e \text { - } \\
\text { learning têm mais prestígio do que aquelas que não } \\
\text { participam }\end{array}$ & 8710,5 & $-2,705$ & 0,007 & $* * \mathrm{~m}$ \\
\hline & A empresa possui uma cultura que valoriza a aprendizagem & 10178 & $-0,671$ & 0,502 & \\
\hline & $\begin{array}{l}\text { A campanha de incentivo realizada em } 2006 \text { estimulou o uso } \\
\text { do e-learning na empresa }\end{array}$ & 9905,5 & $-1,042$ & 0,297 & \\
\hline & $\begin{array}{l}\text { Quando participo (se eu participasse) de cursos de } e \text { - } \\
\text { learning, estou (estaria) aumentando minhas chances de ser } \\
\text { promovido(a) }\end{array}$ & 9329,5 & $-1,821$ & 0,069 & $*_{\mathrm{m}}$ \\
\hline
\end{tabular}

Legenda:

** prova significativa a um nível de significância de 0,05: foi possível apontar diferença entre as amostras

* $\quad$ prova significativa a um nível de significância de 0,10 : foi possível apontar diferença entre as amostras Expressão sem qualquer indicador, prova estatística não significativa: não foi possível concluir pela diferença entre as duas amostras

m maior concordância dos respondentes de sexo masculino

f maior concordância dos respondentes de sexo feminino 
(Continuação)

\begin{tabular}{|c|c|c|c|c|c|}
\hline Fator & Variável & $\begin{array}{c}\text { Mann- } \\
\text { Whitney U }\end{array}$ & $\mathbf{Z}$ & $\mathbf{p}$ & \\
\hline \multirow{8}{*}{$\begin{array}{l}\text { Facilidade de } \\
\text { Uso } \\
\text { Percebida }\end{array}$} & Achei o $(\mathrm{O})$ e-learning (parece) fácil de usar & 9227 & $-1,996$ & 0,046 & $* * \mathrm{~m}$ \\
\hline & $\begin{array}{l}\text { A empresa disponibilizou instruções e orientações } \\
\text { suficientes para o uso do e-learning }\end{array}$ & 9523 & $-1,57$ & 0,116 & \\
\hline & $\begin{array}{l}\text { Eu sei onde procurar, caso precise de assistência para } \\
\text { utilizar o e-learning }\end{array}$ & 9804 & $-1,176$ & 0,24 & \\
\hline & $\begin{array}{l}\text { Minha (A) interação com o ambiente do e-learning foi } \\
\text { (parece) clara e compreensível }\end{array}$ & 8986,5 & $-2,322$ & 0,02 & $* * \mathrm{~m}$ \\
\hline & $\begin{array}{l}\text { Eu possuo os recursos tecnológicos suficientes para } \\
\text { participar dos cursos de } e \text {-learning }\end{array}$ & 9388,5 & $-1,814$ & 0,07 & *m \\
\hline & $\begin{array}{l}\text { Há campanhas corporativas de comunicação interna que } \\
\text { promovem o e-learning com sucesso }\end{array}$ & 10616,5 & $-0,061$ & 0,952 & \\
\hline & $\begin{array}{l}\text { Uma pessoa específica (ou grupo) está à disposição para } \\
\text { auxiliar no caso de dificuldades com o e-learning }\end{array}$ & 9994 & $-0,915$ & 0,36 & \\
\hline & Eu teria facilidade em explicar os benefícios do e-learning & 9001,5 & $-2,302$ & 0,021 & $* * \mathrm{~m}$ \\
\hline \multirow{4}{*}{$\begin{array}{l}\text { Habilidade } \\
\text { com } \\
\text { Informática e } \\
\text { Pré- } \\
\text { disposição } \\
\text { para } \\
\text { Inovador }\end{array}$} & $\begin{array}{l}\text { Eu tenho habilidade para utilizar um software sem tê-lo visto } \\
\text { operando anteriormente }\end{array}$ & 7574 & $-4,296$ & 0 & $* * \mathrm{~m}$ \\
\hline & Eu tenho facilidade no uso de informática & 7896,5 & $-3,89$ & 0 & $* * \mathrm{~m}$ \\
\hline & $\begin{array}{l}\text { Se eu fico sabendo de uma nova tecnologia, eu vou procurar } \\
\text { caminhos para experimentá-la }\end{array}$ & 8165,5 & $-3,443$ & 0,001 & $* *_{\mathrm{m}}$ \\
\hline & $\begin{array}{l}\text { Entre meus pares, eu normalmente estou entre os primeiros a } \\
\text { explorar novas tecnologias }\end{array}$ & 8487 & $-2,968$ & 0,003 & $* * \mathrm{~m}$ \\
\hline \multirow{3}{*}{$\begin{array}{l}\text { Desconfiança } \\
\text { em Relação à } \\
\text { Inovação }\end{array}$} & $\begin{array}{l}\text { Eu preciso ver uma inovação sendo usada, antes de usá-la } \\
\text { por mim mesmo }\end{array}$ & 8960,5 & $-2,325$ & 0,02 & $* * f$ \\
\hline & $\begin{array}{l}\text { Eu freqüentemente tenho uma atitude cética em relação a } \\
\text { novas tecnologias }\end{array}$ & 10245,5 & $-0,498$ & 0,618 & \\
\hline & $\begin{array}{l}\text { Eu preciso ver um software sendo usado, antes de usá-lo por } \\
\text { mim mesmo }\end{array}$ & 8859 & $-2,467$ & 0,014 & $* * f$ \\
\hline \multirow[t]{2}{*}{$\begin{array}{l}\text { Intenção de } \\
\text { Uso }\end{array}$} & $\begin{array}{l}\text { Se a Plataforma da Empresa disponibilizasse mais cursos do } \\
\text { meu interesse, eu a utilizaria o e-learning }\end{array}$ & 8535 & $-2,952$ & 0,003 & $* * \mathrm{~m}$ \\
\hline & Se eu tivesse mais tempo, eu utilizaria o e-learning & 10629 & $-0,045$ & 0,964 & \\
\hline \multirow{2}{*}{$\begin{array}{l}\text { Comporta- } \\
\text { mento de } \\
\text { Uso }\end{array}$} & $\begin{array}{l}\text { Comparado com outras pessoas, eu considero que participo } \\
\text { dos cursos de } e \text {-learning com maior freqüência que a média }\end{array}$ & 3296 & $-1,526$ & 0,127 & \\
\hline & $\begin{array}{l}\text { Comparado com outras pessoas, eu tiro melhor proveito dos } \\
\text { cursos de e-learning disponíveis na Plataforma da Empresa }\end{array}$ & 3003,5 & $-2,42$ & 0,016 & $* * \mathrm{~m}$ \\
\hline
\end{tabular}

Legenda:

** prova significativa a um nível de significância de 0,05: foi possível apontar diferença entre as amostras * $\quad$ prova significativa a um nível de significância de 0,10: foi possível apontar diferença entre as amostras Expressão sem qualquer indicador, prova estatística não significativa: não foi possível concluir pela diferença entre as duas amostras

m maior concordância dos respondentes de sexo masculino

f maior concordância dos respondentes de sexo feminino 


\section{APÊNDICE 8 - Prova de Mann-Whitney para a Variável Idade}

\begin{tabular}{|c|c|c|c|c|c|}
\hline Fator & Variável & $\begin{array}{c}\text { Mann- } \\
\text { Whitney U }\end{array}$ & $\mathbf{Z}$ & $\mathbf{p}$ & \\
\hline \multirow[t]{10}{*}{$\begin{array}{l}\text { Utilidade } \\
\text { Percebida }\end{array}$} & $\begin{array}{l}\text { Eu obtive (poderia obter) ótimos resultados de aprendizagem } \\
\text { com o e-learning }\end{array}$ & 10729 & $-1,587$ & 0,113 & \\
\hline & O e-learning é (pode ser) útil em meu trabalho & 10606 & $-1,776$ & 0,076 & $*_{\mathrm{V}}$ \\
\hline & Eu gosto (gostaria) de participar de cursos de e-learning & 11401 & $-0,711$ & 0,477 & \\
\hline & $\begin{array}{l}\text { A participação em cursos de } e \text {-learning melhorou (pode } \\
\text { melhorar) meu desempenho no trabalho }\end{array}$ & 10339,5 & $-2,102$ & 0,036 & $* *_{\mathrm{V}}$ \\
\hline & Participar de cursos de $e$-learning é uma boa idéia & 10906,5 & $-1,406$ & 0,16 & \\
\hline & Sinto-me (eu ficaria) satisfeito(a) em utilizar o e-learning & 10311,5 & $-2,167$ & 0,03 & $* * *_{\mathrm{V}}$ \\
\hline & O e-learning permite maior flexibilidade para aprender & 10612,5 & $-1,743$ & 0,081 & $*_{\mathrm{V}}$ \\
\hline & $\begin{array}{l}\text { O e-learning tem grande potencial para atender às } \\
\text { necessidades de treinamento da minha área de negócio }\end{array}$ & 9365 & $-3,342$ & 0,001 & $* * \mathrm{v}$ \\
\hline & $\begin{array}{l}\text { A participação em cursos de e-learning é importante para a } \\
\text { realização do meu trabalho }\end{array}$ & 9416 & $-3,371$ & 0,001 & $* * \mathrm{~V}$ \\
\hline & $\begin{array}{l}\mathrm{O} \text { projeto de e-learning existente na empresa atende } \\
\text { adequadamente às necessidades do negócio }\end{array}$ & 9667,5 & $-2,947$ & 0,003 & $* * \mathrm{v}$ \\
\hline \multirow{10}{*}{$\begin{array}{l}\text { Ambiente } \\
\text { Propício à } \\
\text { Aprendiza- } \\
\text { gem }\end{array}$} & $\begin{array}{l}\text { Meu superior imediato freqüentemente aponta a importância } \\
\text { do e-learning }\end{array}$ & 9492,5 & $-3,132$ & 0,002 & $* * \mathrm{v}$ \\
\hline & $\begin{array}{l}\text { Eu sou continuamente encorajado pelo meu superior } \\
\text { imediato a participar dos cursos de e-learning }\end{array}$ & 9956,5 & $-2,528$ & 0,011 & $* * \mathrm{~V}$ \\
\hline & $\begin{array}{l}\text { A participação em cursos de e-learning é fortemente } \\
\text { patrocinada e defendida pela minha empresa }\end{array}$ & 9527,5 & $-3,106$ & 0,002 & $* * \mathrm{v}$ \\
\hline & $\begin{array}{l}\text { A alta administração da empresa demonstra claramente estar } \\
\text { comprometida com o uso do e-learning }\end{array}$ & 9196,5 & $-3,524$ & 0 & $* * \mathrm{~V}$ \\
\hline & $\begin{array}{l}\text { A maioria dos colegas da minha área participa de cursos de } \\
\text { e-learning }\end{array}$ & 7769,5 & $-5,357$ & 0 & $* * \mathrm{~V}$ \\
\hline & $\begin{array}{l}\text { A cultura da organização favorece a adoção do e-learning } \\
\text { pelos colaboradores }\end{array}$ & 9913,5 & $-2,601$ & 0,009 & $* *_{\mathrm{V}}$ \\
\hline & $\begin{array}{l}\text { As pessoas da minha empresa que participam de cursos de } e \text { - } \\
\text { learning têm mais prestígio do que aquelas que não } \\
\text { participam }\end{array}$ & 10268 & $-2,16$ & 0,031 & $* * \mathrm{~V}$ \\
\hline & A empresa possui uma cultura que valoriza a aprendizagem & 9721 & $-2,885$ & 0,004 & $* *_{\mathrm{V}}$ \\
\hline & $\begin{array}{l}\text { A campanha de incentivo realizada em } 2006 \text { estimulou o uso } \\
\text { do e-learning na empresa }\end{array}$ & 9004 & $-3,801$ & 0 & $* *_{\mathrm{V}}$ \\
\hline & $\begin{array}{l}\text { Quando participo (se eu participasse) de cursos de } e \text { - } \\
\text { learning, estou (estaria) aumentando minhas chances de ser } \\
\text { promovido(a) }\end{array}$ & 10997,5 & $-1,187$ & 0,235 & \\
\hline
\end{tabular}

Legenda:

** prova significativa a um nível de significância de 0,05: foi possível apontar diferença entre as amostras

* $\quad$ prova significativa a um nível de significância de 0,10: foi possível apontar diferença entre as amostras

Expressão sem qualquer indicador, prova estatística não significativa: não foi possível concluir pela diferença entre as duas amostras

j maior concordância dos respondentes com idade inferior à média de 36 anos (mais jovens)

v maior concordância dos respondentes com idade igual ou superior à média de 36 anos (mais velhos) 
(Continuação)

\begin{tabular}{|c|c|c|c|c|c|}
\hline Fator & Variável & $\begin{array}{c}\text { Mann- } \\
\text { Whitney U }\end{array}$ & $\mathbf{Z}$ & $\mathbf{p}$ & \\
\hline \multirow{8}{*}{$\begin{array}{l}\text { Facilidade de } \\
\text { Uso } \\
\text { Percebida }\end{array}$} & Achei o $(\mathrm{O})$ e-learning (parece) fácil de usar & 9827 & $-2,75$ & 0,006 & $* * \mathrm{v}$ \\
\hline & $\begin{array}{l}\text { A empresa disponibilizou instruções e orientações } \\
\text { suficientes para o uso do e-learning }\end{array}$ & 9466,5 & $-3,196$ & 0,001 & $* * \mathrm{v}$ \\
\hline & $\begin{array}{l}\text { Eu sei onde procurar, caso precise de assistência para } \\
\text { utilizar o e-learning }\end{array}$ & 9258 & $-3,451$ & 0,001 & $* * \mathrm{v}$ \\
\hline & $\begin{array}{l}\text { Minha (A) interação com o ambiente do e-learning foi } \\
\text { (parece) clara e compreensível }\end{array}$ & 9630 & $-2,998$ & 0,003 & $* * \mathrm{v}$ \\
\hline & $\begin{array}{l}\text { Eu possuo os recursos tecnológicos suficientes para } \\
\text { participar dos cursos de e-learning }\end{array}$ & 9822,5 & $-2,822$ & 0,005 & $* * \mathrm{v}$ \\
\hline & $\begin{array}{l}\text { Há campanhas corporativas de comunicação interna que } \\
\text { promovem o } e \text {-learning com sucesso }\end{array}$ & 9133,5 & $-3,625$ & 0 & $* *_{\mathrm{V}}$ \\
\hline & $\begin{array}{l}\text { Uma pessoa específica (ou grupo) está à disposição para } \\
\text { auxiliar no caso de dificuldades com o e-learning }\end{array}$ & 10302,5 & $-2,092$ & 0,036 & $* * \mathrm{v}$ \\
\hline & Eu teria facilidade em explicar os benefícios do e-learning & 10729,5 & $-1,556$ & 0,12 & \\
\hline \multirow{4}{*}{$\begin{array}{l}\text { Habilidade } \\
\text { com } \\
\text { Informática e } \\
\text { Pré- } \\
\text { disposição } \\
\text { para } \\
\text { Inovador }\end{array}$} & $\begin{array}{l}\text { Eu tenho habilidade para utilizar um software sem tê-lo visto } \\
\text { operando anteriormente }\end{array}$ & 10087,5 & $-2,406$ & 0,016 & $* * \mathrm{j}$ \\
\hline & Eu tenho facilidade no uso de informática & 8888 & $-4,012$ & 0 & $* *_{\mathrm{j}}$ \\
\hline & $\begin{array}{l}\text { Se eu fico sabendo de uma nova tecnologia, eu vou procurar } \\
\text { caminhos para experimentá-la }\end{array}$ & 10708 & $-1,515$ & 0,13 & \\
\hline & $\begin{array}{l}\text { Entre meus pares, eu normalmente estou entre os primeiros a } \\
\text { explorar novas tecnologias }\end{array}$ & 10029,5 & $-2,384$ & 0,017 & $* *_{\mathrm{j}}$ \\
\hline \multirow{3}{*}{$\begin{array}{l}\text { Desconfiança } \\
\text { em Relação à } \\
\text { Inovação }\end{array}$} & $\begin{array}{l}\text { Eu preciso ver uma inovação sendo usada, antes de usá-la } \\
\text { por mim mesmo }\end{array}$ & 10583,5 & $-1,722$ & 0,085 & $*_{\mathrm{v}}$ \\
\hline & $\begin{array}{l}\text { Eu freqüentemente tenho uma atitude cética em relação a } \\
\text { novas tecnologias }\end{array}$ & 10674,5 & $-1,517$ & 0,129 & \\
\hline & $\begin{array}{l}\text { Eu preciso ver um software sendo usado, antes de usá-lo por } \\
\text { mim mesmo }\end{array}$ & 10463,5 & $-1,879$ & 0,06 & $*_{\mathrm{V}}$ \\
\hline \multirow[t]{2}{*}{$\begin{array}{l}\text { Intenção de } \\
\text { Uso }\end{array}$} & $\begin{array}{l}\text { Se a Plataforma da Empresa disponibilizasse mais cursos do } \\
\text { meu interesse, eu a utilizaria o e-learning }\end{array}$ & 11826,5 & $-0,116$ & 0,908 & \\
\hline & Se eu tivesse mais tempo, eu utilizaria o e-learning & 11392,5 & $-0,704$ & 0,482 & \\
\hline \multirow{2}{*}{$\begin{array}{l}\text { Comporta- } \\
\text { mento de } \\
\text { Uso }\end{array}$} & $\begin{array}{l}\text { Comparado com outras pessoas, eu considero que participo } \\
\text { dos cursos de e-learning com maior freqüência que a média }\end{array}$ & 4068,5 & $-0,208$ & 0,835 & \\
\hline & $\begin{array}{l}\text { Comparado com outras pessoas, eu tiro melhor proveito dos } \\
\text { cursos de e-learning disponíveis na Plataforma da Empresa }\end{array}$ & 3942,5 & $-0,575$ & 0,565 & \\
\hline
\end{tabular}

Legenda:

** prova significativa a um nível de significância de 0,05 : foi possível apontar diferença entre as amostras

* prova significativa a um nível de significância de 0,10 : foi possível apontar diferença entre as amostras Expressão sem qualquer indicador, prova estatística não significativa: não foi possível concluir pela diferença entre as duas amostras

j maior concordância dos respondentes com idade inferior a 36 anos (mais jovens)

v maior concordância dos respondentes com idade igual ou superior a 36 anos (mais velhos) 


\section{APÊNDICE 9 - Prova de Mann-Whitney para a Variável Tempo de Empresa}

\begin{tabular}{|c|c|c|c|c|c|}
\hline Fator & Variável & $\begin{array}{c}\text { Mann- } \\
\text { Whitney U }\end{array}$ & $\mathbf{Z}$ & $\mathbf{p}$ & \\
\hline \multirow[t]{10}{*}{$\begin{array}{l}\text { Utilidade } \\
\text { Percebida }\end{array}$} & $\begin{array}{l}\text { Eu obtive (poderia obter) ótimos resultados de aprendizagem } \\
\text { com o e-learning }\end{array}$ & 9106 & $-2,46$ & 0,014 & $* * \mathrm{~V}$ \\
\hline & O e-learning é (pode ser) útil em meu trabalho & 9297,5 & $-2,222$ & 0,026 & $* * \mathrm{v}$ \\
\hline & Eu gosto (gostaria) de participar de cursos de e-learning & 10298 & $-0,816$ & 0,415 & \\
\hline & $\begin{array}{l}\text { A participação em cursos de e-learning melhorou (pode } \\
\text { melhorar) meu desempenho no trabalho }\end{array}$ & 9829 & $-1,442$ & 0,149 & \\
\hline & Participar de cursos de $e$-learning é uma boa idéia & 9717 & $-1,671$ & 0,095 & $*_{\mathrm{V}}$ \\
\hline & Sinto-me (eu ficaria) satisfeito(a) em utilizar o e-learning & 8625,5 & $-3,164$ & 0,002 & $* *_{\mathrm{V}}$ \\
\hline & O e-learning permite maior flexibilidade para aprender & 10192,5 & $-0,937$ & 0,349 & \\
\hline & $\begin{array}{l}\text { O e-learning tem grande potencial para atender às } \\
\text { necessidades de treinamento da minha área de negócio }\end{array}$ & 8743,5 & $-2,906$ & 0,004 & $* * \mathrm{v}$ \\
\hline & $\begin{array}{l}\text { A participação em cursos de e-learning é importante para a } \\
\text { realização do meu trabalho }\end{array}$ & 8770,5 & $-2,953$ & 0,003 & $* * \mathrm{~V}$ \\
\hline & $\begin{array}{l}\mathrm{O} \text { projeto de e-learning existente na empresa atende } \\
\text { adequadamente às necessidades do negócio }\end{array}$ & 7734,5 & $-4,294$ & 0 & $* *$ \\
\hline \multirow{10}{*}{$\begin{array}{l}\text { Ambiente } \\
\text { Propício à } \\
\text { Aprendiza- } \\
\text { gem }\end{array}$} & $\begin{array}{l}\text { Meu superior imediato freqüentemente aponta a importância } \\
\text { do e-learning }\end{array}$ & 7637 & $-4,366$ & 0 & $* * \mathrm{v}$ \\
\hline & $\begin{array}{l}\text { Eu sou continuamente encorajado pelo meu superior } \\
\text { imediato a participar dos cursos de e-learning }\end{array}$ & 8156 & $-3,658$ & 0 & $* * \mathrm{~V}$ \\
\hline & $\begin{array}{l}\text { A participação em cursos de e-learning é fortemente } \\
\text { patrocinada e defendida pela minha empresa }\end{array}$ & 7873,5 & $-4,071$ & 0 & $* * \mathrm{v}$ \\
\hline & $\begin{array}{l}\text { A alta administração da empresa demonstra claramente estar } \\
\text { comprometida com o uso do e-learning }\end{array}$ & 7942,5 & $-3,963$ & 0 & $* * \mathrm{~V}$ \\
\hline & $\begin{array}{l}\text { A maioria dos colegas da minha área participa de cursos de } \\
\text { e-learning }\end{array}$ & 7145,5 & $-5,029$ & 0 & $* * \mathrm{~V}$ \\
\hline & $\begin{array}{l}\text { A cultura da organização favorece a adoção do e-learning } \\
\text { pelos colaboradores }\end{array}$ & 9107 & $-2,387$ & 0,017 & $* *_{\mathrm{V}}$ \\
\hline & $\begin{array}{l}\text { As pessoas da minha empresa que participam de cursos de } e \text { - } \\
\text { learning têm mais prestígio do que aquelas que não } \\
\text { participam }\end{array}$ & 9529,5 & $-1,829$ & 0,067 & $*_{\mathrm{V}}$ \\
\hline & A empresa possui uma cultura que valoriza a aprendizagem & 9428 & $-1,974$ & 0,048 & $* * \mathrm{~V}$ \\
\hline & $\begin{array}{l}\text { A campanha de incentivo realizada em } 2006 \text { estimulou o uso } \\
\text { do e-learning na empresa }\end{array}$ & 7461,5 & $-4,649$ & 0 & $* * \mathrm{~V}$ \\
\hline & $\begin{array}{l}\text { Quando participo (se eu participasse) de cursos de } e \text { - } \\
\text { learning, estou (estaria) aumentando minhas chances de ser } \\
\text { promovido(a) }\end{array}$ & 9515,5 & $-1,823$ & 0,068 & $*_{\mathrm{V}}$ \\
\hline
\end{tabular}

Legenda:

** prova significativa a um nível de significância de 0,05: foi possível apontar diferença entre as amostras

* $\quad$ prova significativa a um nível de significância de 0,10: foi possível apontar diferença entre as amostras

Expressão sem qualquer indicador, prova estatística não significativa: não foi possível concluir pela diferença entre as duas amostras

j maior concordância dos respondentes com tempo de empresa inferior a 8,7 anos (mais jovens na empresa)

v maior concordância dos respondentes com tempo de empresa igual ou superior a 8,7 anos (mais velhos na empresa) 
(Continuação)

\begin{tabular}{|c|c|c|c|c|c|}
\hline Fator & Variável & $\begin{array}{c}\text { Mann- } \\
\text { Whitney U }\end{array}$ & $\mathbf{Z}$ & $\mathbf{p}$ & \\
\hline \multirow{8}{*}{$\begin{array}{l}\text { Facilidade de } \\
\text { Uso } \\
\text { Percebida }\end{array}$} & Achei o $(\mathrm{O})$ e-learning (parece) fácil de usar & 8878,5 & $-2,735$ & 0,006 & $* * \mathrm{v}$ \\
\hline & $\begin{array}{l}\text { A empresa disponibilizou instruções e orientações } \\
\text { suficientes para o uso do e-learning }\end{array}$ & 8525 & $-3,194$ & 0,001 & $* * \mathrm{v}$ \\
\hline & $\begin{array}{l}\text { Eu sei onde procurar, caso precise de assistência para } \\
\text { utilizar o e-learning }\end{array}$ & 7956 & $-3,952$ & 0 & $* * \mathrm{~V}$ \\
\hline & $\begin{array}{l}\text { Minha (A) interação com o ambiente do e-learning foi } \\
\text { (parece) clara e compreensível }\end{array}$ & 8488,5 & $-3,26$ & 0,001 & $* * \mathrm{~V}$ \\
\hline & $\begin{array}{l}\text { Eu possuo os recursos tecnológicos suficientes para } \\
\text { participar dos cursos de e-learning }\end{array}$ & 9046,5 & $-2,563$ & 0,01 & $* * \mathrm{v}$ \\
\hline & $\begin{array}{l}\text { Há campanhas corporativas de comunicação interna que } \\
\text { promovem o e-learning com sucesso }\end{array}$ & 6989,5 & $-5,285$ & 0 & $* * \mathrm{~V}$ \\
\hline & $\begin{array}{l}\text { Uma pessoa específica (ou grupo) está à disposição para } \\
\text { auxiliar no caso de dificuldades com o e-learning }\end{array}$ & 9433,5 & $-1,94$ & 0,052 & $*_{\mathrm{v}}$ \\
\hline & Eu teria facilidade em explicar os benefícios do e-learning & 9128,5 & $-2,381$ & 0,017 & $* * *_{\mathrm{V}}$ \\
\hline \multirow{4}{*}{$\begin{array}{l}\text { Habilidade } \\
\text { com } \\
\text { Informática e } \\
\text { Pré- } \\
\text { disposição } \\
\text { para } \\
\text { Inovador }\end{array}$} & $\begin{array}{l}\text { Eu tenho habilidade para utilizar um software sem tê-lo visto } \\
\text { operando anteriormente }\end{array}$ & 9370,5 & $-2,055$ & 0,04 & $* * \mathrm{j}$ \\
\hline & Eu tenho facilidade no uso de informática & 8517,5 & $-3,253$ & 0,001 & $* * \mathrm{j}$ \\
\hline & $\begin{array}{l}\text { Se eu fico sabendo de uma nova tecnologia, eu vou procurar } \\
\text { caminhos para experimentá-la }\end{array}$ & 10624,5 & $-0,255$ & 0,799 & \\
\hline & $\begin{array}{l}\text { Entre meus pares, eu normalmente estou entre os primeiros a } \\
\text { explorar novas tecnologias }\end{array}$ & 9496 & $-1,754$ & 0,079 & $* \mathrm{j}$ \\
\hline \multirow{3}{*}{$\begin{array}{l}\text { Desconfiança } \\
\text { em Relação à } \\
\text { Inovação }\end{array}$} & $\begin{array}{l}\text { Eu preciso ver uma inovação sendo usada, antes de usá-la } \\
\text { por mim mesmo }\end{array}$ & 9639,5 & $-1,654$ & 0,098 & $*_{\mathrm{V}}$ \\
\hline & $\begin{array}{l}\text { Eu freqüentemente tenho uma atitude cética em relação a } \\
\text { novas tecnologias }\end{array}$ & 10341,5 & $-0,632$ & 0,527 & \\
\hline & $\begin{array}{l}\text { Eu preciso ver um software sendo usado, antes de usá-lo por } \\
\text { mim mesmo }\end{array}$ & 9119 & $-2,362$ & 0,018 & $* * \mathrm{v}$ \\
\hline \multirow[t]{2}{*}{$\begin{array}{l}\text { Intenção de } \\
\text { Uso }\end{array}$} & $\begin{array}{l}\text { Se a Plataforma da Empresa disponibilizasse mais cursos do } \\
\text { meu interesse, eu a utilizaria o e-learning }\end{array}$ & 10586,5 & $-0,377$ & 0,706 & \\
\hline & Se eu tivesse mais tempo, eu utilizaria o e-learning & 9345,5 & $-2,139$ & 0,032 & $* * \mathrm{v}$ \\
\hline \multirow{2}{*}{$\begin{array}{l}\text { Comporta- } \\
\text { mento de } \\
\text { Uso }\end{array}$} & $\begin{array}{l}\text { Comparado com outras pessoas, eu considero que participo } \\
\text { dos cursos de } e \text {-learning com maior freqüência que a média }\end{array}$ & 3922,5 & $-0,351$ & 0,726 & \\
\hline & $\begin{array}{l}\text { Comparado com outras pessoas, eu tiro melhor proveito dos } \\
\text { cursos de e-learning disponíveis na Plataforma da Empresa }\end{array}$ & 3696,5 & $-1,016$ & 0,309 & \\
\hline
\end{tabular}

Legenda:

** prova significativa a um nível de significância de 0,05: foi possível apontar diferença entre as amostras * $\quad$ prova significativa a um nível de significância de 0,10: foi possível apontar diferença entre as amostras Expressão sem qualquer indicador, prova estatística não significativa: não foi possível concluir pela diferença entre as duas amostras

j maior concordância dos respondentes com tempo de empresa inferior à média (mais jovens na empresa) v maior concordância dos respondentes com tempo de empresa igual ou superior à média (mais velhos na empresa) 


\section{APÊNDICE 10 - Prova de Mann-Whitney para a Variável Grau de Instrução}

\begin{tabular}{|c|c|c|c|c|c|}
\hline Fator & Variável & $\begin{array}{c}\text { Mann- } \\
\text { Whitney U }\end{array}$ & $\mathbf{Z}$ & $\mathbf{p}$ & \\
\hline \multirow[t]{10}{*}{$\begin{array}{l}\text { Utilidade } \\
\text { Percebida }\end{array}$} & $\begin{array}{l}\text { Eu obtive (poderia obter) ótimos resultados de aprendizagem } \\
\text { com o e-learning }\end{array}$ & 9185,5 & $-2,987$ & 0,003 & $* *$ si \\
\hline & O e-learning é (pode ser) útil em meu trabalho & 9628 & $-2,413$ & 0,016 & $* *$ si \\
\hline & Eu gosto (gostaria) de participar de cursos de e-learning & 9249,5 & $-2,998$ & 0,003 & $* *_{\mathrm{si}}$ \\
\hline & $\begin{array}{l}\text { A participação em cursos de e-learning melhorou (pode } \\
\text { melhorar) meu desempenho no trabalho }\end{array}$ & 9903 & $-1,997$ & 0,046 & $* *$ si \\
\hline & Participar de cursos de $e$-learning é uma boa idéia & 10156 & $-1,726$ & 0,084 & $*_{\mathrm{si}}$ \\
\hline & Sinto-me (eu ficaria) satisfeito(a) em utilizar o e-learning & 10007 & $-1,879$ & 0,06 & $*_{\text {si }}$ \\
\hline & O e-learning permite maior flexibilidade para aprender & 10297,5 & $-1,463$ & 0,144 & \\
\hline & $\begin{array}{l}\text { O e-learning tem grande potencial para atender às } \\
\text { necessidades de treinamento da minha área de negócio }\end{array}$ & 9455,5 & $-2,562$ & 0,01 & $* *$ si \\
\hline & $\begin{array}{l}\text { A participação em cursos de e-learning é importante para a } \\
\text { realização do meu trabalho }\end{array}$ & 9432 & $-2,67$ & 0,008 & $* *$ si \\
\hline & $\begin{array}{l}\text { O projeto de e-learning existente na empresa atende } \\
\text { adequadamente às necessidades do negócio }\end{array}$ & 8296,5 & $-4,119$ & 0 & $* *$ si \\
\hline \multirow{10}{*}{$\begin{array}{l}\text { Ambiente } \\
\text { Propício à } \\
\text { Aprendiza- } \\
\text { gem }\end{array}$} & $\begin{array}{l}\text { Meu superior imediato freqüentemente aponta a importância } \\
\text { do e-learning }\end{array}$ & 9532,5 & $-2,426$ & 0,015 & $* *$ si \\
\hline & $\begin{array}{l}\text { Eu sou continuamente encorajado pelo meu superior } \\
\text { imediato a participar dos cursos de } e \text {-learning }\end{array}$ & 9510 & $-2,452$ & 0,014 & $* *$ si \\
\hline & $\begin{array}{l}\text { A participação em cursos de e-learning é fortemente } \\
\text { patrocinada e defendida pela minha empresa }\end{array}$ & 8345 & $-4,023$ & 0 & $* *$ si \\
\hline & $\begin{array}{l}\text { A alta administração da empresa demonstra claramente estar } \\
\text { comprometida com o uso do e-learning }\end{array}$ & 9245,5 & $-2,813$ & 0,005 & $* *_{\text {si }}$ \\
\hline & $\begin{array}{l}\text { A maioria dos colegas da minha área participa de cursos de } \\
\text { e-learning }\end{array}$ & 9543,5 & $-2,41$ & 0,016 & $* *$ si \\
\hline & $\begin{array}{l}\text { A cultura da organização favorece a adoção do e-learning } \\
\text { pelos colaboradores }\end{array}$ & 8914 & $-3,261$ & 0,001 & $* *_{\text {si }}$ \\
\hline & $\begin{array}{l}\text { As pessoas da minha empresa que participam de cursos de } e \text { - } \\
\text { learning têm mais prestígio do que aquelas que não } \\
\text { participam }\end{array}$ & 9975,5 & $-1,866$ & 0,062 & $*_{\text {si }}$ \\
\hline & A empresa possui uma cultura que valoriza a aprendizagem & 9214 & $-2,896$ & 0,004 & $* *_{\text {si }}$ \\
\hline & $\begin{array}{l}\text { A campanha de incentivo realizada em } 2006 \text { estimulou o uso } \\
\text { do e-learning na empresa }\end{array}$ & 8969 & $-3,203$ & 0,001 & $* *$ si \\
\hline & $\begin{array}{l}\text { Quando participo (se eu participasse) de cursos de } e \text { - } \\
\text { learning, estou (estaria) aumentando minhas chances de ser } \\
\text { promovido(a) }\end{array}$ & 8331 & $-4,02$ & 0 & $* *$ si \\
\hline
\end{tabular}

Legenda:

** prova significativa a um nível de significância de 0,05: foi possível apontar diferença entre as amostras

* $\quad$ prova significativa a um nível de significância de 0,10: foi possível apontar diferença entre as amostras

Expressão sem qualquer indicador, prova estatística não significativa: não foi possível concluir pela diferença entre as duas amostras

si maior concordância dos respondentes com grau de instrução até superior incompleto 
(Continuação)

\begin{tabular}{|c|c|c|c|c|c|}
\hline Fator & Variável & $\begin{array}{c}\text { Mann- } \\
\text { Whitney U }\end{array}$ & $\mathbf{Z}$ & $\mathbf{p}$ & \\
\hline \multirow{8}{*}{$\begin{array}{l}\text { Facilidade de } \\
\text { Uso } \\
\text { Percebida }\end{array}$} & Achei o $(\mathrm{O})$ e-learning (parece) fácil de usar & 10955 & $-0,552$ & 0,581 & \\
\hline & $\begin{array}{l}\text { A empresa disponibilizou instruções e orientações } \\
\text { suficientes para o uso do e-learning }\end{array}$ & 9214 & $-2,875$ & 0,004 & $* *$ si \\
\hline & $\begin{array}{l}\text { Eu sei onde procurar, caso precise de assistência para } \\
\text { utilizar o e-learning }\end{array}$ & 8975,5 & $-3,177$ & 0,001 & $* *$ si \\
\hline & $\begin{array}{l}\text { Minha (A) interação com o ambiente do e-learning foi } \\
\text { (parece) clara e compreensível }\end{array}$ & 9859 & $-2,023$ & 0,043 & $* *$ si \\
\hline & $\begin{array}{l}\text { Eu possuo os recursos tecnológicos suficientes para } \\
\text { participar dos cursos de e-learning }\end{array}$ & 10884,5 & $-0,663$ & 0,507 & \\
\hline & $\begin{array}{l}\text { Há campanhas corporativas de comunicação interna que } \\
\text { promovem o } e \text {-learning com sucesso }\end{array}$ & 9434,5 & $-2,576$ & 0,01 & $* *$ si \\
\hline & $\begin{array}{l}\text { Uma pessoa específica (ou grupo) está à disposição para } \\
\text { auxiliar no caso de dificuldades com o e-learning }\end{array}$ & 9910,5 & $-1,932$ & 0,053 & *si \\
\hline & Eu teria facilidade em explicar os benefícios do e-learning & 10935,5 & $-0,577$ & 0,564 & \\
\hline \multirow{4}{*}{$\begin{array}{l}\text { Habilidade } \\
\text { com } \\
\text { Informática e } \\
\text { Pré- } \\
\text { disposição } \\
\text { para } \\
\text { Inovador }\end{array}$} & $\begin{array}{l}\text { Eu tenho habilidade para utilizar um software sem tê-lo visto } \\
\text { operando anteriormente }\end{array}$ & 9969 & $-1,881$ & 0,06 & \\
\hline & Eu tenho facilidade no uso de informática & 10288 & $-1,365$ & 0,172 & \\
\hline & $\begin{array}{l}\text { Se eu fico sabendo de uma nova tecnologia, eu vou procurar } \\
\text { caminhos para experimentá-la }\end{array}$ & 10511 & $-1,084$ & 0,278 & \\
\hline & $\begin{array}{l}\text { Entre meus pares, eu normalmente estou entre os primeiros a } \\
\text { explorar novas tecnologias }\end{array}$ & 9820 & $-2,012$ & 0,044 & $* *$ si \\
\hline \multirow{3}{*}{$\begin{array}{l}\text { Desconfiança } \\
\text { em Relação à } \\
\text { Inovação }\end{array}$} & $\begin{array}{l}\text { Eu preciso ver uma inovação sendo usada, antes de usá-la } \\
\text { por mim mesmo }\end{array}$ & 7755,5 & $-4,78$ & 0 & $* *$ si \\
\hline & $\begin{array}{l}\text { Eu freqüentemente tenho uma atitude cética em relação a } \\
\text { novas tecnologias }\end{array}$ & 8410 & $-3,802$ & 0 & $* *$ si \\
\hline & $\begin{array}{l}\text { Eu preciso ver um software sendo usado, antes de usá-lo por } \\
\text { mim mesmo }\end{array}$ & 7788 & $-4,743$ & 0 & $* *$ si \\
\hline \multirow[t]{2}{*}{$\begin{array}{l}\text { Intenção de } \\
\text { Uso }\end{array}$} & $\begin{array}{l}\text { Se a Plataforma da Empresa disponibilizasse mais cursos do } \\
\text { meu interesse, eu a utilizaria o e-learning }\end{array}$ & 9704 & $-2,234$ & 0,025 & $* *$ si \\
\hline & Se eu tivesse mais tempo, eu utilizaria o e-learning & 8929,5 & $-3,36$ & 0,001 & $* * \mathrm{si}$ \\
\hline \multirow{2}{*}{$\begin{array}{l}\text { Comporta- } \\
\text { mento de } \\
\text { Uso }\end{array}$} & $\begin{array}{l}\text { Comparado com outras pessoas, eu considero que participo } \\
\text { dos cursos de e-learning com maior freqüência que a média }\end{array}$ & 3890 & $-0,261$ & 0,794 & \\
\hline & $\begin{array}{l}\text { Comparado com outras pessoas, eu tiro melhor proveito dos } \\
\text { cursos de e-learning disponíveis na Plataforma da Empresa }\end{array}$ & 3533 & $-1,319$ & 0,187 & \\
\hline
\end{tabular}

Legenda:

** prova significativa a um nível de significância de 0,05 : foi possível apontar diferença entre as amostras

* prova significativa a um nível de significância de 0,10 : foi possível apontar diferença entre as amostras Expressão sem qualquer indicador, prova estatística não significativa: não foi possível concluir pela diferença entre as duas amostras

si maior concordância dos respondentes com grau de instrução até superior incompleto 


\section{APÊNDICE 11 - Prova de Mann-Whitney para a Variável Localidade de Trabalho}

\begin{tabular}{|c|c|c|c|c|c|}
\hline Fator & Variável & $\begin{array}{c}\text { Mann- } \\
\text { Whitney U }\end{array}$ & $\mathbf{Z}$ & $\mathbf{p}$ & \\
\hline \multirow[t]{10}{*}{$\begin{array}{l}\text { Utilidade } \\
\text { Percebida }\end{array}$} & $\begin{array}{l}\text { Eu obtive (poderia obter) ótimos resultados de aprendizagem } \\
\text { com o e-learning }\end{array}$ & 3463,5 & $-2,841$ & 0,004 & $* * \mathrm{i}$ \\
\hline & O e-learning é (pode ser) útil em meu trabalho & 3806,5 & $-2,148$ & 0,032 & $* *_{\mathrm{i}}$ \\
\hline & Eu gosto (gostaria) de participar de cursos de e-learning & 4021,5 & $-1,723$ & 0,085 & $*_{\mathrm{i}}$ \\
\hline & $\begin{array}{l}\text { A participação em cursos de e-learning melhorou (pode } \\
\text { melhorar) meu desempenho no trabalho }\end{array}$ & 3677 & $-2,385$ & 0,017 & $* * \mathrm{i}$ \\
\hline & Participar de cursos de e-learning é uma boa idéia & 3857 & $-2,097$ & 0,036 & $* * \mathrm{i}$ \\
\hline & Sinto-me (eu ficaria) satisfeito(a) em utilizar o e-learning & 3438 & $-2,923$ & 0,003 & $* * \mathrm{i}$ \\
\hline & O e-learning permite maior flexibilidade para aprender & 4230 & $-1,227$ & 0,22 & \\
\hline & $\begin{array}{l}\mathrm{O} \text { e-learning tem grande potencial para atender às } \\
\text { necessidades de treinamento da minha área de negócio }\end{array}$ & 3422 & $-2,868$ & 0,004 & $* * \mathrm{i}$ \\
\hline & $\begin{array}{l}\text { A participação em cursos de e-learning é importante para a } \\
\text { realização do meu trabalho }\end{array}$ & 3402,5 & $-2,993$ & 0,003 & $* * \mathrm{i}$ \\
\hline & $\begin{array}{l}\mathrm{O} \text { projeto de e-learning existente na empresa atende } \\
\text { adequadamente às necessidades do negócio }\end{array}$ & 3219 & $-3,288$ & 0,001 & $* * \mathrm{i}$ \\
\hline \multirow{10}{*}{$\begin{array}{l}\text { Ambiente } \\
\text { Propício à } \\
\text { Aprendiza- } \\
\text { gem }\end{array}$} & $\begin{array}{l}\text { Meu superior imediato freqüentemente aponta a importância } \\
\text { do e-learning }\end{array}$ & 2654,5 & $-4,391$ & 0 & $* * \mathrm{i}$ \\
\hline & $\begin{array}{l}\text { Eu sou continuamente encorajado pelo meu superior } \\
\text { imediato a participar dos cursos de e-learning }\end{array}$ & 3138 & $-3,402$ & 0,001 & $* * \mathrm{i}$ \\
\hline & $\begin{array}{l}\text { A participação em cursos de e-learning é fortemente } \\
\text { patrocinada e defendida pela minha empresa }\end{array}$ & 3196 & $-3,31$ & 0,001 & $* * \mathrm{i}$ \\
\hline & $\begin{array}{l}\text { A alta administração da empresa demonstra claramente estar } \\
\text { comprometida com o uso do e-learning }\end{array}$ & 2951 & $-3,798$ & 0 & $* * \mathrm{i}$ \\
\hline & $\begin{array}{l}\text { A maioria dos colegas da minha área participa de cursos de } \\
\text { e-learning }\end{array}$ & 3379 & $-2,915$ & 0,004 & $* * \mathrm{i}$ \\
\hline & $\begin{array}{l}\text { A cultura da organização favorece a adoção do e-learning } \\
\text { pelos colaboradores }\end{array}$ & 3243 & $-3,21$ & 0,001 & $* * \mathrm{i}$ \\
\hline & $\begin{array}{l}\text { As pessoas da minha empresa que participam de cursos de } e \text { - } \\
\text { learning têm mais prestígio do que aquelas que não } \\
\text { participam }\end{array}$ & 3260 & $-3,205$ & 0,001 & $* * \mathrm{i}$ \\
\hline & A empresa possui uma cultura que valoriza a aprendizagem & 3823 & $-2,048$ & 0,041 & $* * \mathrm{i}$ \\
\hline & $\begin{array}{l}\text { A campanha de incentivo realizada em } 2006 \text { estimulou o uso } \\
\text { do e-learning na empresa }\end{array}$ & 2993 & $-3,739$ & 0 & $* * \mathrm{i}$ \\
\hline & $\begin{array}{l}\text { Quando participo (se eu participasse) de cursos de } e \text { - } \\
\text { learning, estou (estaria) aumentando minhas chances de ser } \\
\text { promovido(a) }\end{array}$ & 3230,5 & $-3,222$ & 0,001 & $* * \mathrm{i}$ \\
\hline
\end{tabular}

Legenda:

** prova significativa a um nível de significância de 0,05: foi possível apontar diferença entre as amostras * $\quad$ prova significativa a um nível de significância de 0,10: foi possível apontar diferença entre as amostras Expressão sem qualquer indicador, prova estatística não significativa: não foi possível concluir pela diferença entre as duas amostras

i maior concordância dos respondentes que trabalham no interior 
(Continuação)

\begin{tabular}{|c|c|c|c|c|c|}
\hline Fator & Variável & $\begin{array}{c}\text { Mann- } \\
\text { Whitney U }\end{array}$ & $\mathbf{Z}$ & $\mathbf{p}$ & \\
\hline \multirow{8}{*}{$\begin{array}{l}\text { Facilidade de } \\
\text { Uso } \\
\text { Percebida }\end{array}$} & Achei o (O) e-learning (parece) fácil de usar & 3281 & $-3,175$ & 0,002 & $* * \mathrm{i}$ \\
\hline & $\begin{array}{l}\text { A empresa disponibilizou instruções e orientações } \\
\text { suficientes para o uso do e-learning }\end{array}$ & 3410,5 & $-2,88$ & 0,004 & $* * \mathrm{i}$ \\
\hline & $\begin{array}{l}\text { Eu sei onde procurar, caso precise de assistência para } \\
\text { utilizar o e-learning }\end{array}$ & 3654 & $-2,368$ & 0,018 & $* *_{\mathrm{i}}$ \\
\hline & $\begin{array}{l}\text { Minha (A) interação com o ambiente do e-learning foi } \\
\text { (parece) clara e compreensível }\end{array}$ & 3293 & $-3,137$ & 0,002 & $* *_{\mathrm{i}}$ \\
\hline & $\begin{array}{l}\text { Eu possuo os recursos tecnológicos suficientes para } \\
\text { participar dos cursos de e-learning }\end{array}$ & 3747 & $-2,262$ & 0,024 & $* *_{\mathrm{i}}$ \\
\hline & $\begin{array}{l}\text { Há campanhas corporativas de comunicação interna que } \\
\text { promovem o e-learning com sucesso }\end{array}$ & 3953,5 & $-1,762$ & 0,078 & $*_{\mathrm{i}}$ \\
\hline & $\begin{array}{l}\text { Uma pessoa específica (ou grupo) está à disposição para } \\
\text { auxiliar no caso de dificuldades com o e-learning }\end{array}$ & 3889 & $-1,886$ & 0,059 & $*_{\mathrm{i}}$ \\
\hline & Eu teria facilidade em explicar os benefícios do e-learning & 3190,5 & $-3,35$ & 0,001 & $* * \mathrm{i}$ \\
\hline \multirow{4}{*}{$\begin{array}{l}\text { Habilidade } \\
\text { com } \\
\text { Informática e } \\
\text { Pré- } \\
\text { disposição } \\
\text { para } \\
\text { Inovador }\end{array}$} & $\begin{array}{l}\text { Eu tenho habilidade para utilizar um software sem tê-lo visto } \\
\text { operando anteriormente }\end{array}$ & 4770 & $-0,088$ & 0,93 & \\
\hline & Eu tenho facilidade no uso de informática & 4610,5 & $-0,394$ & 0,694 & \\
\hline & $\begin{array}{l}\text { Se eu fico sabendo de uma nova tecnologia, eu vou procurar } \\
\text { caminhos para experimentá-la }\end{array}$ & 4128,5 & $-1,397$ & 0,162 & \\
\hline & $\begin{array}{l}\text { Entre meus pares, eu normalmente estou entre os primeiros a } \\
\text { explorar novas tecnologias }\end{array}$ & 3853,5 & $-1,731$ & 0,084 & $*_{\mathrm{i}}$ \\
\hline \multirow{3}{*}{$\begin{array}{l}\text { Desconfiança } \\
\text { em Relação à } \\
\text { Inovação }\end{array}$} & $\begin{array}{l}\text { Eu preciso ver uma inovação sendo usada, antes de usá-la } \\
\text { por mim mesmo }\end{array}$ & 4723 & $-0,182$ & 0,855 & \\
\hline & $\begin{array}{l}\text { Eu freqüentemente tenho uma atitude cética em relação a } \\
\text { novas tecnologias }\end{array}$ & 4598 & $-0,402$ & 0,688 & \\
\hline & $\begin{array}{l}\text { Eu preciso ver um software sendo usado, antes de usá-lo por } \\
\text { mim mesmo }\end{array}$ & 4718 & $-0,193$ & 0,847 & \\
\hline \multirow[t]{2}{*}{$\begin{array}{l}\text { Intenção de } \\
\text { Uso }\end{array}$} & $\begin{array}{l}\text { Se a Plataforma da Empresa disponibilizasse mais cursos do } \\
\text { meu interesse, eu a utilizaria o e-learning }\end{array}$ & 4499,5 & $-0,647$ & 0,518 & \\
\hline & Se eu tivesse mais tempo, eu utilizaria o e-learning & 4699 & $-0,241$ & 0,81 & \\
\hline \multirow{2}{*}{$\begin{array}{l}\text { Comporta- } \\
\text { mento de } \\
\text { Uso }\end{array}$} & $\begin{array}{l}\text { Comparado com outras pessoas, eu considero que participo } \\
\text { dos cursos de e-learning com maior freqüência que a média }\end{array}$ & 1898,5 & $-1,262$ & 0,207 & \\
\hline & $\begin{array}{l}\text { Comparado com outras pessoas, eu tiro melhor proveito dos } \\
\text { cursos de e-learning disponíveis na Plataforma da Empresa }\end{array}$ & 1945,5 & $-1,083$ & 0,279 & \\
\hline
\end{tabular}

Legenda:

** prova significativa a um nível de significância de 0,05 : foi possível apontar diferença entre as amostras

* prova significativa a um nível de significância de 0,10 : foi possível apontar diferença entre as amostras Expressão sem qualquer indicador, prova estatística não significativa: não foi possível concluir pela diferença entre as duas amostras

i maior concordância dos respondentes que trabalham no interior 


\section{APÊNDICE 12 - Prova de Mann-Whitney para a Variável Nível Hierárquico}

\begin{tabular}{|c|c|c|c|c|c|}
\hline Fator & Variável & $\begin{array}{c}\text { Mann- } \\
\text { Whitney U }\end{array}$ & $\mathbf{Z}$ & $\mathbf{p}$ & \\
\hline \multirow[t]{10}{*}{$\begin{array}{l}\text { Utilidade } \\
\text { Percebida }\end{array}$} & $\begin{array}{l}\text { Eu obtive (poderia obter) ótimos resultados de aprendizagem } \\
\text { com o e-learning }\end{array}$ & 9446 & $-1,577$ & 0,115 & \\
\hline & O e-learning é (pode ser) útil em meu trabalho & 10413,5 & $-0,203$ & 0,839 & \\
\hline & Eu gosto (gostaria) de participar de cursos de e-learning & 9448 & $-1,627$ & 0,104 & \\
\hline & $\begin{array}{l}\text { A participação em cursos de e-learning melhorou (pode } \\
\text { melhorar) meu desempenho no trabalho }\end{array}$ & 10264,5 & $-0,411$ & 0,681 & \\
\hline & Participar de cursos de e-learning é uma boa idéia & 10433 & $-0,18$ & 0,857 & \\
\hline & Sinto-me (eu ficaria) satisfeito(a) em utilizar o e-learning & 10366 & $-0,271$ & 0,787 & \\
\hline & $\mathrm{O}$ e-learning permite maior flexibilidade para aprender & 9480 & $-1,529$ & 0,126 & \\
\hline & $\begin{array}{l}\text { O e-learning tem grande potencial para atender às } \\
\text { necessidades de treinamento da minha área de negócio }\end{array}$ & 10322,5 & $-0,323$ & 0,747 & \\
\hline & $\begin{array}{l}\text { A participação em cursos de e-learning é importante para a } \\
\text { realização do meu trabalho }\end{array}$ & 10079,5 & $-0,681$ & 0,496 & \\
\hline & $\begin{array}{l}\text { O projeto de } e \text {-learning existente na empresa atende } \\
\text { adequadamente às necessidades do negócio }\end{array}$ & 9548 & $-1,402$ & 0,161 & \\
\hline \multirow{10}{*}{$\begin{array}{l}\text { Ambiente } \\
\text { Propício à } \\
\text { Aprendiza- } \\
\text { gem }\end{array}$} & $\begin{array}{l}\text { Meu superior imediato freqüentemente aponta a importância } \\
\text { do e-learning }\end{array}$ & 9867 & $-0,945$ & 0,345 & \\
\hline & $\begin{array}{l}\text { Eu sou continuamente encorajado pelo meu superior } \\
\text { imediato a participar dos cursos de e-learning }\end{array}$ & 9801,5 & $-1,033$ & 0,302 & \\
\hline & $\begin{array}{l}\text { A participação em cursos de e-learning é fortemente } \\
\text { patrocinada e defendida pela minha empresa }\end{array}$ & 8998,5 & $-2,151$ & 0,031 & $* * \mathrm{t}$ \\
\hline & $\begin{array}{l}\text { A alta administração da empresa demonstra claramente estar } \\
\text { comprometida com o uso do e-learning }\end{array}$ & 8921,5 & $-2,25$ & 0,024 & $* * \mathrm{t}$ \\
\hline & $\begin{array}{l}\text { A maioria dos colegas da minha área participa de cursos de } \\
\text { e-learning }\end{array}$ & 10515 & $-0,054$ & 0,957 & \\
\hline & $\begin{array}{l}\text { A cultura da organização favorece a adoção do e-learning } \\
\text { pelos colaboradores }\end{array}$ & 9792 & $-1,053$ & 0,292 & \\
\hline & $\begin{array}{l}\text { As pessoas da minha empresa que participam de cursos de } e \text { - } \\
\text { learning têm mais prestígio do que aquelas que não } \\
\text { participam }\end{array}$ & 9597,5 & $-1,334$ & 0,182 & \\
\hline & A empresa possui uma cultura que valoriza a aprendizagem & 9503,5 & $-1,469$ & 0,142 & \\
\hline & $\begin{array}{l}\text { A campanha de incentivo realizada em } 2006 \text { estimulou o uso } \\
\text { do e-learning na empresa }\end{array}$ & 9662,5 & $-1,238$ & 0,216 & \\
\hline & $\begin{array}{l}\text { Quando participo (se eu participasse) de cursos de } e \text { - } \\
\text { learning, estou (estaria) aumentando minhas chances de ser } \\
\text { promovido(a) }\end{array}$ & 9725,5 & $-1,14$ & 0,254 & \\
\hline
\end{tabular}

Legenda:

** prova significativa a um nível de significância de 0,05: foi possível apontar diferença entre as amostras

* $\quad$ prova significativa a um nível de significância de 0,10: foi possível apontar diferença entre as amostras

Expressão sem qualquer indicador, prova estatística não significativa: não foi possível concluir pela diferença entre as duas amostras

g maior concordância dos respondentes de nível gerencial (Diretor, Gerente e Consultor)

$\mathrm{t}$ maior concordância dos respondentes de nível técnico (Engenheiro, Técnico, Analista, Assistente e Secretária) 
(Continuação)

\begin{tabular}{|c|c|c|c|c|c|}
\hline Fator & Variável & $\begin{array}{c}\text { Mann- } \\
\text { Whitney U }\end{array}$ & $\mathbf{Z}$ & $\mathbf{p}$ & \\
\hline \multirow{8}{*}{$\begin{array}{l}\text { Facilidade de } \\
\text { Uso } \\
\text { Percebida }\end{array}$} & Achei o (O) e-learning (parece) fácil de usar & 10147,5 & $-0,57$ & 0,569 & \\
\hline & $\begin{array}{l}\text { A empresa disponibilizou instruções e orientações } \\
\text { suficientes para o uso do e-learning }\end{array}$ & 9497 & $-1,467$ & 0,142 & \\
\hline & $\begin{array}{l}\text { Eu sei onde procurar, caso precise de assistência para } \\
\text { utilizar o e-learning }\end{array}$ & 9936 & $-0,854$ & 0,393 & \\
\hline & $\begin{array}{l}\text { Minha (A) interação com o ambiente do e-learning foi } \\
\text { (parece) clara e compreensível }\end{array}$ & 10524,5 & $-0,042$ & 0,967 & \\
\hline & $\begin{array}{l}\text { Eu possuo os recursos tecnológicos suficientes para } \\
\text { participar dos cursos de e-learning }\end{array}$ & 8889,5 & $-2,386$ & 0,017 & $* * \mathrm{~g}$ \\
\hline & $\begin{array}{l}\text { Há campanhas corporativas de comunicação interna que } \\
\text { promovem o e-learning com sucesso }\end{array}$ & 8898,5 & $-2,294$ & 0,022 & $* * \mathrm{t}$ \\
\hline & $\begin{array}{l}\text { Uma pessoa específica (ou grupo) está à disposição para } \\
\text { auxiliar no caso de dificuldades com o e-learning }\end{array}$ & 9793 & $-1,05$ & 0,294 & \\
\hline & Eu teria facilidade em explicar os benefícios do e-learning & 9370,5 & $-1,651$ & 0,099 & $* g$ \\
\hline \multirow{4}{*}{$\begin{array}{l}\text { Habilidade } \\
\text { com } \\
\text { Informática e } \\
\text { Pré- } \\
\text { disposição } \\
\text { para } \\
\text { Inovador }\end{array}$} & $\begin{array}{l}\text { Eu tenho habilidade para utilizar um software sem tê-lo visto } \\
\text { operando anteriormente }\end{array}$ & 8070,5 & $-3,475$ & 0,001 & $* * \mathrm{~g}$ \\
\hline & Eu tenho facilidade no uso de informática & 8702,5 & $-2,596$ & 0,009 & $* * \mathrm{~g}$ \\
\hline & $\begin{array}{l}\text { Se eu fico sabendo de uma nova tecnologia, eu vou procurar } \\
\text { caminhos para experimentá-la }\end{array}$ & 10167,5 & $-0,477$ & 0,634 & \\
\hline & $\begin{array}{l}\text { Entre meus pares, eu normalmente estou entre os primeiros a } \\
\text { explorar novas tecnologias }\end{array}$ & 8674,5 & $-2,502$ & 0,012 & $* * \mathrm{~g}$ \\
\hline \multirow{3}{*}{$\begin{array}{l}\text { Desconfiança } \\
\text { em Relação à } \\
\text { Inovação }\end{array}$} & $\begin{array}{l}\text { Eu preciso ver uma inovação sendo usada, antes de usá-la } \\
\text { por mim mesmo }\end{array}$ & 7660 & $-3,978$ & 0 & $* * \mathrm{t}$ \\
\hline & $\begin{array}{l}\text { Eu freqüentemente tenho uma atitude cética em relação a } \\
\text { novas tecnologias }\end{array}$ & 8748 & $-2,419$ & 0,016 & $* * *_{\mathrm{t}}$ \\
\hline & $\begin{array}{l}\text { Eu preciso ver um software sendo usado, antes de usá-lo por } \\
\text { mim mesmo }\end{array}$ & 7580,5 & $-4,092$ & 0 & $* * *_{\mathrm{t}}$ \\
\hline \multirow[t]{2}{*}{$\begin{array}{l}\text { Intenção de } \\
\text { Uso }\end{array}$} & $\begin{array}{l}\text { Se a Plataforma da Empresa disponibilizasse mais cursos do } \\
\text { meu interesse, eu a utilizaria o e-learning }\end{array}$ & 9461 & $-1,526$ & 0,127 & \\
\hline & Se eu tivesse mais tempo, eu utilizaria o e-learning & 9986 & $-0,814$ & 0,416 & \\
\hline \multirow{2}{*}{$\begin{array}{l}\text { Comporta- } \\
\text { mento de } \\
\text { Uso }\end{array}$} & $\begin{array}{l}\text { Comparado com outras pessoas, eu considero que participo } \\
\text { dos cursos de e-learning com maior freqüência que a média }\end{array}$ & 3689,5 & $-0,262$ & 0,794 & \\
\hline & $\begin{array}{l}\text { Comparado com outras pessoas, eu tiro melhor proveito dos } \\
\text { cursos de e-learning disponíveis na Plataforma da Empresa }\end{array}$ & 3609 & $-0,508$ & 0,612 & \\
\hline
\end{tabular}

Legenda:

** prova significativa a um nível de significância de 0,05 : foi possível apontar diferença entre as amostras

* $\quad$ prova significativa a um nível de significância de 0,10 : foi possível apontar diferença entre as amostras Expressão sem qualquer indicador, prova estatística não significativa: não foi possível concluir pela diferença entre as duas amostras

g maior concordância dos respondentes de nível gerencial (Diretor, Gerente e Consultor)

$\mathrm{t}$ maior concordância dos respondentes de nível técnico (Engenheiro, Técnico, Analista, Assistente e Secretária) 


\section{APÊNDICE 13 - Teste de Kruskal Wallis para a Variável Área Funcional}

\begin{tabular}{|c|c|c|c|c|}
\hline Fator & Variável & $\begin{array}{c}\text { Qui- } \\
\text { quadrado }\end{array}$ & $\mathbf{p}$ & \\
\hline \multirow[t]{10}{*}{$\begin{array}{l}\text { Utilidade } \\
\text { Percebida }\end{array}$} & $\begin{array}{l}\text { Eu obtive (poderia obter) ótimos resultados de aprendizagem } \\
\text { com o e-learning }\end{array}$ & 1,442 & 0,486 & \\
\hline & O e-learning é (pode ser) útil em meu trabalho & 1,939 & 0,379 & \\
\hline & Eu gosto (gostaria) de participar de cursos de e-learning & 2,535 & 0,281 & \\
\hline & $\begin{array}{l}\text { A participação em cursos de e-learning melhorou (pode } \\
\text { melhorar) meu desempenho no trabalho }\end{array}$ & 0,571 & 0,752 & \\
\hline & Participar de cursos de e-learning é uma boa idéia & 1,974 & 0,373 & \\
\hline & Sinto-me (eu ficaria) satisfeito(a) em utilizar o e-learning & 2,991 & 0,224 & \\
\hline & O e-learning permite maior flexibilidade para aprender & 1,837 & 0,399 & \\
\hline & $\begin{array}{l}\mathrm{O} \text { e-learning tem grande potencial para atender às } \\
\text { necessidades de treinamento da minha área de negócio }\end{array}$ & 1,499 & 0,473 & \\
\hline & $\begin{array}{l}\text { A participação em cursos de e-learning é importante para a } \\
\text { realização do meu trabalho }\end{array}$ & 2,654 & 0,265 & \\
\hline & $\begin{array}{l}\text { O projeto de e-learning existente na empresa atende } \\
\text { adequadamente às necessidades do negócio }\end{array}$ & 7,463 & 0,024 & $* * \mathrm{t}-\mathrm{c} / \mathrm{s}$ \\
\hline \multirow{10}{*}{$\begin{array}{l}\text { Ambiente } \\
\text { Propício à } \\
\text { Aprendiza- } \\
\text { gem }\end{array}$} & $\begin{array}{l}\text { Meu superior imediato freqüentemente aponta a importância } \\
\text { do e-learning }\end{array}$ & 15,867 & 0 & $* * \mathrm{t}-\mathrm{c} / \mathrm{s}$ \\
\hline & $\begin{array}{l}\text { Eu sou continuamente encorajado pelo meu superior } \\
\text { imediato a participar dos cursos de e-learning }\end{array}$ & 11,711 & 0,003 & $* * \mathrm{t}-\mathrm{c} / \mathrm{s}$ \\
\hline & $\begin{array}{l}\text { A participação em cursos de } e \text {-learning é fortemente } \\
\text { patrocinada e defendida pela minha empresa }\end{array}$ & 10,629 & 0,005 & $* * \mathrm{t}-\mathrm{c} / \mathrm{s}$ \\
\hline & $\begin{array}{l}\text { A alta administração da empresa demonstra claramente estar } \\
\text { comprometida com o uso do e-learning }\end{array}$ & 5,515 & 0,063 & \\
\hline & $\begin{array}{l}\text { A maioria dos colegas da minha área participa de cursos de } \\
\text { e-learning }\end{array}$ & 19,979 & 0 & $* * \mathrm{t}-\mathrm{c} / \mathrm{s}$ \\
\hline & $\begin{array}{l}\text { A cultura da organização favorece a adoção do e-learning } \\
\text { pelos colaboradores }\end{array}$ & 2,539 & 0,281 & \\
\hline & $\begin{array}{l}\text { As pessoas da minha empresa que participam de cursos de } e \text { - } \\
\text { learning têm mais prestígio do que aquelas que não } \\
\text { participam }\end{array}$ & 5,067 & 0,079 & \\
\hline & A empresa possui uma cultura que valoriza a aprendizagem & 1,833 & 0,4 & \\
\hline & $\begin{array}{l}\text { A campanha de incentivo realizada em } 2006 \text { estimulou o uso } \\
\text { do e-learning na empresa }\end{array}$ & 10,063 & 0,007 & $* * \mathrm{t}-\mathrm{c} / \mathrm{s}$ \\
\hline & $\begin{array}{l}\text { Quando participo (se eu participasse) de cursos de } e \text { - } \\
\text { learning, estou (estaria) aumentando minhas chances de ser } \\
\text { promovido(a) }\end{array}$ & 7,456 & 0,024 & $* * \mathrm{t}-\mathrm{s}$ \\
\hline
\end{tabular}

Legenda:

** prova significativa a um nível de significância de 0,05: foi possível apontar diferença entre as amostras * $\quad$ prova significativa a um nível de significância de 0,10: foi possível apontar diferença entre as amostras Expressão sem qualquer indicador, prova estatística não significativa: não foi possível concluir pela diferença entre as duas amostras

t - c maior concordância dos respondentes da área Técnica em relação aos respondentes da área Comercial $\mathrm{t}$ - $\mathrm{s}$ maior concordância dos respondentes da área Técnica em relação aos respondentes da área de Suporte $\mathrm{t}$ - c/s maior concordância dos respondentes da área Técnica em relação aos respondentes das áreas Comercial e de Suporte

c-s maior concordância dos respondentes da área Comercial em relação aos respondentes da área de Suporte 
(Continuação)

\begin{tabular}{|c|c|c|c|c|}
\hline Fator & Variável & $\begin{array}{c}\text { Qui- } \\
\text { quadrado }\end{array}$ & $\mathbf{p}$ & \\
\hline \multirow{8}{*}{$\begin{array}{l}\text { Facilidade de } \\
\text { Uso } \\
\text { Percebida }\end{array}$} & Achei o $(\mathrm{O})$ e-learning (parece) fácil de usar & 4,25 & 0,119 & \\
\hline & $\begin{array}{l}\text { A empresa disponibilizou instruções e orientações } \\
\text { suficientes para o uso do e-learning }\end{array}$ & 11,356 & 0,003 & $* * \mathrm{t}-\mathrm{c} / \mathrm{s}$ \\
\hline & $\begin{array}{l}\text { Eu sei onde procurar, caso precise de assistência para } \\
\text { utilizar o e-learning }\end{array}$ & 6,573 & 0,037 & $* * \mathrm{t}-\mathrm{c} / \mathrm{s}$ \\
\hline & $\begin{array}{l}\text { Minha (A) interação com o ambiente do e-learning foi } \\
\text { (parece) clara e compreensível }\end{array}$ & 3,218 & 0,2 & \\
\hline & $\begin{array}{l}\text { Eu possuo os recursos tecnológicos suficientes para } \\
\text { participar dos cursos de e-learning }\end{array}$ & 2,344 & 0,31 & \\
\hline & $\begin{array}{l}\text { Há campanhas corporativas de comunicação interna que } \\
\text { promovem o e-learning com sucesso }\end{array}$ & 16,635 & 0 & $* * \mathrm{t}-\mathrm{c} / \mathrm{s}$ \\
\hline & $\begin{array}{l}\text { Uma pessoa específica (ou grupo) está à disposição para } \\
\text { auxiliar no caso de dificuldades com o e-learning }\end{array}$ & 2,947 & 0,229 & \\
\hline & Eu teria facilidade em explicar os benefícios do e-learning & 6,77 & 0,034 & $* * \mathrm{c}-\mathrm{S}$ \\
\hline \multirow{4}{*}{$\begin{array}{l}\text { Habilidade } \\
\text { com } \\
\text { Informática e } \\
\text { Pré- } \\
\text { disposição } \\
\text { para } \\
\text { Inovador }\end{array}$} & $\begin{array}{l}\text { Eu tenho habilidade para utilizar um software sem tê-lo visto } \\
\text { operando anteriormente }\end{array}$ & 4,778 & 0,092 & \\
\hline & Eu tenho facilidade no uso de informática & 1,788 & 0,409 & \\
\hline & $\begin{array}{l}\text { Se eu fico sabendo de uma nova tecnologia, eu vou procurar } \\
\text { caminhos para experimentá-la }\end{array}$ & 0,33 & 0,848 & \\
\hline & $\begin{array}{l}\text { Entre meus pares, eu normalmente estou entre os primeiros a } \\
\text { explorar novas tecnologias }\end{array}$ & 0,178 & 0,915 & \\
\hline \multirow{3}{*}{$\begin{array}{l}\text { Desconfiança } \\
\text { em Relação à } \\
\text { Inovação }\end{array}$} & $\begin{array}{l}\text { Eu preciso ver uma inovação sendo usada, antes de usá-la } \\
\text { por mim mesmo }\end{array}$ & 5,432 & 0,066 & \\
\hline & $\begin{array}{l}\text { Eu freqüentemente tenho uma atitude cética em relação a } \\
\text { novas tecnologias }\end{array}$ & 7,668 & 0,022 & $* * \mathrm{t}-\mathrm{c} / \mathrm{s}$ \\
\hline & $\begin{array}{l}\text { Eu preciso ver um software sendo usado, antes de usá-lo por } \\
\text { mim mesmo }\end{array}$ & 11,516 & 0,003 & $* * \mathrm{t}-\mathrm{c}$ \\
\hline \multirow[t]{2}{*}{$\begin{array}{l}\text { Intenção de } \\
\text { Uso }\end{array}$} & $\begin{array}{l}\text { Se a Plataforma da Empresa disponibilizasse mais cursos do } \\
\text { meu interesse, eu a utilizaria o e-learning }\end{array}$ & 3,39 & 0,184 & \\
\hline & Se eu tivesse mais tempo, eu utilizaria o e-learning & 0,237 & 0,888 & \\
\hline \multirow{2}{*}{$\begin{array}{l}\text { Comporta- } \\
\text { mento de } \\
\text { Uso }\end{array}$} & $\begin{array}{l}\text { Comparado com outras pessoas, eu considero que participo } \\
\text { dos cursos de } e \text {-learning com maior freqüência que a média }\end{array}$ & 0,609 & 0,738 & \\
\hline & $\begin{array}{l}\text { Comparado com outras pessoas, eu tiro melhor proveito dos } \\
\text { cursos de e-learning disponíveis na Plataforma da Empresa }\end{array}$ & 0,27 & 0,874 & \\
\hline
\end{tabular}

\section{Legenda:}

** prova significativa a um nível de significância de 0,05 : foi possível apontar diferença entre as amostras * $\quad$ prova significativa a um nível de significância de 0,10 : foi possível apontar diferença entre as amostras Expressão sem qualquer indicador, prova estatística não significativa: não foi possível concluir pela diferença entre as duas amostras

t - c maior concordância dos respondentes da área Técnica em relação aos respondentes da área Comercial $\mathrm{t}$ - s maior concordância dos respondentes da área Técnica em relação aos respondentes da área de Suporte $\mathrm{t}$ - c/s maior concordância dos respondentes da área Técnica em relação aos respondentes das áreas Comercial e de Suporte

c - s maior concordância dos respondentes da área Comercial em relação aos respondentes da área de Suporte 


\section{ANEXO A - Barreiras para Difusão do e-Learning (TYAN, 2003)}

Os 132 respondentes do questionário aplicado por Tyan atribuíram uma nota a cada uma das barreiras para difusão do e-learning, conforme a seguinte escala ${ }^{165}$ (2003, p. 68): $0=$ Extremamente insignificante; 1 = Muito insignificante; 2 = Insignificante; 3 = Importante; $4=$ Muito importante; 5 = Extremamente importante.

Tabela - Média e Desvio Padrão das Notas atribuídas às 30 barreiras

\begin{tabular}{|c|c|c|}
\hline Barreira & Média & $\begin{array}{c}\text { Desvio } \\
\text { padrão }\end{array}$ \\
\hline Falta de conhecimento para gerenciar os sistemas de e-learning & 3,95 & 1,090 \\
\hline Falta de designer educacional para os sistemas de $e$-learning & 3,93 & 0,967 \\
\hline Produtos e serviços não satisfatórios oferecidos pelos fornecedores & 3,93 & 0,982 \\
\hline Pequena escala para adotar o e-learning com eficiência de custos & 3,89 & 1,176 \\
\hline $\begin{array}{l}\text { Corte significativo no orçamento de treinamento por conta de situações } \\
\text { econômicas adversas }\end{array}$ & 3,89 & 1,150 \\
\hline Incerteza sobre o custo/benefício do e-learning & 3,83 & 0,966 \\
\hline Pouca oferta de cursos via e-learning & 3,78 & 1,036 \\
\hline Treinamento não é normalmente bem aceito nas empresas & 3,70 & 1,228 \\
\hline Baixa compatibilidade entre o sistema de $e$-learning e os sistemas de TI & 3,69 & 1,099 \\
\hline O processo de implementação do e-learning consome muito tempo & 3,67 & 1,039 \\
\hline Falta de certificações dos produtos de e-learning & 3,62 & 1,074 \\
\hline Custa muito adotar o e-learning & 3,61 & 0,913 \\
\hline Processo complexo de adoção e revisão do e-learning & 3,61 & 1,032 \\
\hline Baixo ROI dos sistemas de e-learning & 3,58 & 1,092 \\
\hline Resultado ineficaz do aprendizado via e-learning & 3,53 & 1,129 \\
\hline Falta de provedores únicos de serviços & 3,49 & 1,122 \\
\hline Preferência por treinamento presencial & 3,45 & 1,262 \\
\hline E-learning não atende demandas de treinamento da empresa & 3,44 & 1,141 \\
\hline Falta de iniciativas governamentais & 3,42 & 1,242 \\
\hline Sistemas de $e$-learning têm conflito com os recursos existentes & 3,38 & 1,239 \\
\hline Preocupações sobre a fragilidade de controle dos direitos autorais & 3,36 & 1,332 \\
\hline Alto custo da conexão em banda larga & 3,30 & 1,228 \\
\hline Falta de incentivos via redução de impostos & 3,29 & 1,438 \\
\hline Falta de mecanismos para avaliar o aprendizado & 3,27 & 1,365 \\
\hline Empregados não aprovam o e-learning & 3,20 & 1,190 \\
\hline Empregados com competências limitadas em informática & 3,11 & 1,357 \\
\hline Ceticismo sobre outras experiências de sucesso do e-learning & 3,05 & 1,138 \\
\hline Equipamentos insuficientes para adotar o e-learning & 3,03 & 1,381 \\
\hline Ceticismo sobre o apoio governamental ao e-learning & 3,03 & 1,348 \\
\hline Restrições regulamentares ao $e$-learning & 2,89 & 1,221 \\
\hline
\end{tabular}

FONTE: TYAN, 2003, p.69-70

165 "Extremely Unimportant"; "Very Unimportant"; "Unimportant”; "Important”; "Very Important"; "Extremely Important" 